\title{
Modeling of Barrier Failure and Fire Spread in CUrisk
}

$$
\text { by }
$$

Xiao Li

A thesis submitted to the Faculty of Graduate and Postdoctoral Affairs in partial fulfillment of the requirements for the degree of

Doctor of Philosophy

in

Civil Engineering

Carleton University

Ottawa, Ontario

(C) 2015, Xiao Li 


\begin{abstract}
CUrisk, a computer fire risk analysis model, has been under development at Carleton University for over a decade. To better evaluate failure of building elements and spread of fire beyond the room of fire origin, this thesis developed and integrated into CUrisk a barrier failure model and a fire spread model.

A probabilistic fire spread model developed at Carleton University was incorporated into CUrisk system model. The role and position of the Fire Spread submodel were analyzed and changes to the system model and some other submodels were undertaken. With these modifications, CUrisk can employ the Fire Spread submodel to predict the fire hazard conditions in a building fire, and to use the results to predict the life risk and fire damages. Through a comprehensive case study of fire risk assessment of a six-storey residential building using the improved CUrisk, the Fire Spread submodel demonstrated the impacts of fire spread level on building occupant safety and fire losses.

To assist the development of a barrier failure model for CUrisk, six full-scale room fire tests were conducted and analyzed. The tests considered the following construction types: Cross Laminated Timber, Light Timber Frame and Light Steel Frame. The fire evolution and contribution of the timber assembly components to the room fire were investigated. The response of assembly components in the fire were studied as well. Findings suggest that the barrier failure characteristics of a building assembly in an arbitrary real fire might be very different than its performance in a fire resistance test. The test findings were extensively used to improve the CUrisk submodels and particularly to develop the barrier failure model.
\end{abstract}

A barrier failure model was developed based on the concept of component subtractive 
method. The temperature profile of a building assembly is calculated by a one-dimensional finite difference heat transfer approach. In conjunction with the assembly component response and failure criterion, the deterministic heat transfer and component response model was developed that can calculate the temperature profile and response of assembly components as well as the charring depth in timber component. A probabilistic barrier failure model was also developed by taking into account the uncertainties of some factors that affect the assembly failure. With this model, the probability of failure as a function of fire exposure time can be generated. The model performance was verified by comparing with the fire test measurements, which demonstrated good agreements. Comparable results are also predicted regarding the fall-off behaviour of the fire-exposed gypsum board as well as the charring behaviour. In addition, an example calculation was made using the probabilistic barrier failure model. Finally, a fire risk analysis case study was conducted on a six-storey apartment building with the purpose of showing the effect of wall barriers on fire risk. Results indicated that CUrisk can evaluate the impact of fire barriers on the fire risk with the new Barrie Failure submodel. 


\section{Acknowledgements}

Firstly and mostly, I would like to express my sincere gratitude to my research supervisor Professor George Hadjisophocleous. I appreciate the freedom that he gave me to explore my research and I am grateful of the encouragements from him at times when I felt frustrated with my work.

I would like to thank Dr. Xia Zhang whom I regarded as my co-supervisor. Dr. Zhang was always ready to help when I had questions with my research. He is my role model and one of the greatest scholars I have ever met. His positive attitude toward life and deep loves to his family are something I should also learn.

I feel extremely lucky to participate in the NEWBuildS research project which provided financial supports on my research and extensive travel opportunities to present our work and network with other researchers and engineers in Canada and other counties. Thanks are also given to Professor Y.H. Chui and Mr. Kenneth Koo from NEWBuildS research network, and Mr. Christian Dagenais from FPInnovations. I also want to thank Professor Jim Mehaffey for his interests in my research.

I will miss the great times with $\mathrm{PhD}$ and Master students in the Fire Safety Engineering programme at Carleton University including Amir Rafinazari, Aaron Akotuah Ohene, Alejandro Medina Hevia, Ba Lamthien, Cameron McGregor, Marc Aguanno, Naki Ocran, Samuel Amankwah Boadiand, Sabah Ali, Lindsay Osborne and so many others.

Lastly, I would like to thank for the continuous love and care from my parents and family, and that is the meaning of life and the motive of hard work. 


\section{Table of Contents}

Abstract $\quad$ ii

Acknowledgements $\quad$ iv

Table of Contents $\quad \mathrm{V}$

List of Symbols and Abbreviations vii

List of Tables $\quad$ xiii

List of Figures $\quad$ XV

Chapter 1 Introduction and Research Objectives 1

1.1 Introduction to CUrisk 1

1.2 Problem Statement and Research Objectives 12

Chapter 2 Literature Review 14

2.1 A review of comprehensive fire risk analysis models 14

2.2 Fire resistance tests of building assemblies 19

2.3 Methods to determine fire resistance of building assemblies 27

Chapter 3 Modelling of Fire Spread in CUrisk 45

3.1 Brief introduction of the existing Fire Spread model 45

3.2 Implementation of the Fire Spread submodel in CUrisk 49

3.3 Case study of a six-storey building using the improved CUrisk 58

$\begin{array}{lll}3.4 & \text { Summary } & 79\end{array}$

Chapter 4 Full-Scale Fire Tests on Combustible and Non-Combustible

$\begin{array}{lr}\text { Constructions } & 80\end{array}$

$\begin{array}{llr}4.1 & \text { Introduction } & 80\end{array}$

$\begin{array}{lll}4.2 & \text { Test descriptions } & 82\end{array}$

$\begin{array}{lll}4.3 & \text { Test results and discussion } & 99\end{array}$

$\begin{array}{lll}4.4 & \text { Summary } & 125\end{array}$ 
Chapter 5 Development of the Barrier Failure Submodel for CUrisk

5.1 Objective and scope of the proposed Barrier Failure submodel

5.2 The framework of the barrier failure model

5.3 The deterministic heat transfer and component response model

5.4 The probabilistic barrier failure model

5.5 Validation of the Barrier Failure Model and An example calculation

5.6 An example calculation of the probability of barrier failure

5.7 Summary

Chapter 6 Modelling of Barrier Failure in CUrisk and a Case Study

6.1 Integration of the Barrier Failure Model into CUrisk

6.2 A case study using CUrisk with the Barrier Failure submodel

6.3 Results and discussion of the case study

6.4 Summary

Chapter 7 Conclusions and Recommendations for Future Work

7.1 Summary and Conclusions

7.2 Recommendation for future work 


\section{List of Symbols and Abbreviations}

\begin{tabular}{|c|c|c|}
\hline$\Delta H_{c, o x}$ & $\begin{array}{l}\text { heat of combustion of fuel per unit mass of } \\
\text { oxygen consumed (13.1) }\end{array}$ & $\mathrm{kJ} / \mathrm{g}$ \\
\hline$\Delta x$ & width of a control volume & \\
\hline$A_{C L T}$ & total area of exposed CLT panels & $\mathrm{m}^{2}$ \\
\hline$A_{T}$ & $\begin{array}{l}\text { total area of inner boundary surfaces } \\
\text { (opening area included) }\end{array}$ & $a^{2}$ \\
\hline$A_{v}$ & area of window opening & $\mathrm{m}^{2}$ \\
\hline$b$ & width of the compartment doorway & \\
\hline$C$ & flow coefficient & \\
\hline$c_{i}$ & $\begin{array}{l}\text { specific heat of the boundary material } i \text { or the } \\
\text { control volume } i\end{array}$ & $\mathrm{~J} / \mathrm{kg} \cdot \mathrm{K}$ \\
\hline$c_{J, l e f t}$ & $\begin{array}{l}\text { specific heat of the left half of a control } \\
\text { volume }\end{array}$ & $\mathrm{J} / \mathrm{kg} \cdot \mathrm{K}$ \\
\hline$c_{J, \text { right }}$ & $\begin{array}{l}\text { specific heat of the right half of a control } \\
\text { volume }\end{array}$ & $\mathrm{J} / \mathrm{kg} \cdot \mathrm{K}$ \\
\hline DamageFS(j) & $\begin{array}{l}\text { estimate of damage or the amount of } \\
\text { downtime from a fire in compartment } j \text { due } \\
\text { to fire spread }\end{array}$ & $\$$ \\
\hline $\operatorname{DamageSS}(j)$ & $\begin{array}{l}\text { estimate of damage or the amount of } \\
\text { downtime for compartment } j \text { due to smoke } \\
\text { spread }\end{array}$ & \\
\hline$f_{F O}(t)$ & $\begin{array}{l}\text { probability density function of flashover in } \\
\text { a compartment at time } t\end{array}$ & \\
\hline$f_{F S}(t)$ & $\begin{array}{l}\text { probability density function of fire spread to } \\
\text { a compartment at time } t\end{array}$ & \\
\hline$F I D_{H G}(t)$ & $\begin{array}{l}\text { probability of death due to hot gases at time } \\
t\end{array}$ & \\
\hline$F I D_{T G}(t)$ & probability of death due to intaking of all & \\
\hline
\end{tabular}


asphyxiant gases at time $t$

$h_{\infty}$

$h_{b}$

$H_{c}$

$h_{c}$

$H_{c, \text { eff }}$

$h_{f}$

$h_{n}$

$h_{t}$,

$H_{v}$

$k_{i}$

$k_{i, l}$

$k_{i, r}$

$k_{r}$

$L$

$L_{\text {existing }}$

$\dot{m}_{\text {air }}$

$\dot{m}_{\text {air }, \text { add }}$

$\dot{m}_{b}$

$\dot{m}_{\text {out }}$ convective heat transfer coefficient at the $\mathrm{W} / \mathrm{m}^{2} \cdot \mathrm{K}$ ambient surface

height of sill of the opening

$\mathrm{m}$

heat of combustion of wood

$\mathrm{MJ} / \mathrm{kg}$

convective heat transfer coefficient in the $\mathrm{W} / \mathrm{m}^{2} \cdot \mathrm{K}$ void cavity

effective heat of combustion

$\mathrm{kJ} / \mathrm{g}$

convective heat transfer coefficient on the $\mathrm{W} / \mathrm{m}^{2} \cdot \mathrm{K}$

fire side

heights of the neutral plane in the doorway

$\mathrm{m}$

the soffit of the opening

$\mathrm{m}$

height of the window opening

$\mathrm{m}^{2}$

thermal conductivity of boundary material $i \quad \mathrm{~W} / \mathrm{m} \cdot \mathrm{K}$

interface conductivity at the left face of the $\mathrm{W} / \mathrm{m} \cdot \mathrm{K}$

control volume $i$

interface conductivity at the right face of the $\quad \mathrm{W} / \mathrm{m} \cdot \mathrm{K}$

control volume $i$

interface conductivity at the right face of a $\mathrm{W} / \mathrm{m} \cdot \mathrm{K}$ control volume

fire load

MJ

existing fire load

MJ

air entrainment rate into the room through the compartment doorway

$\mathrm{kg}$

additional air used for the external $\mathrm{kg} / \mathrm{s}$ combustion

fuel burning rate

$\mathrm{kg} / \mathrm{s}$

smoke outflow rate through the compartment doorway $\mathrm{kg} / \mathrm{s}$ 
probability of fire growth from ignition to a fully-developed fire in compartment A

probability of fire spread from compartment B to compartment A

probability of barrier failure indicating the probability that heat is transferred from the fire compartment $\mathrm{B}$ to the adjacent compartment A

probability that a fully-developed fire occur in compartment $\mathrm{B}$

probability of death due to flashover in the given compartment at time $t$

cumulative probability of fire spread in compartment $j$ at the end time of simulation

cumulative probability of fire spread in compartment $j$ at time $t$

$P_{i g}\left(a^{\prime} \mid b\right)$

probability of fire ignition in compartment A due to heat transfer from fire compartment B

overall probability of the death of an occupant $m$ at a time $t$

overall probability of death in a given compartment at time $t$

POP

number of occupants in the building

probability of death due to thermal radiation 


$\bar{Q}_{\text {fd }}$
$\dot{Q}_{\text {max,air }}$
$\dot{q}_{\text {rad }}^{\prime \prime}$
$R$
$t$
$t_{1}$
$t_{2}$
$T_{\text {door }}$
$T_{\text {fail,assemly }}$
$T_{\text {fail,gyp,fire }}$
$T_{\text {fail,steelstud }}$
$T_{i}^{m}$
$t_{F D a c t i o n}$
$t_{f o}$
$T_{\text {ig }}$
$T_{\text {in }}$
$T_{\text {out }}$
rs

mean of total heat release rate during the MW fully developed fire period

MW

maximum possible heat release rate in the room

radiative heat flux through the void cavity from one solid surface to the other

$\mathrm{W} / \mathrm{m}^{2}$ universal gas constant

time

Second or Minute starting time of the fully developed fire Second end time of the fully developed fire Second temperatures at the doorway K failure temperature criterion of the unexposed component

${ }^{\circ} \mathrm{C}$

${ }^{\circ} \mathrm{C}$

failure temperature criterion of fire-exposed gypsum board

deflection temperature criterion of steel stud in Light Steel Frame assembly

${ }^{\circ} \mathrm{C}$

temperature in node $i$ at time step $m$

K

Fire Department action time

Minute

time of flashover in the fire compartment

Minute

total cost of damage for compartment $j$ $\$$ taking into account both smoke spread and fire spread

ignition time in a compartment

Minute

temperature inside the room

K

temperature on the left surface of void cavity

K

ambient temperature

K

temperature on the right surface of void

K 
cavity

$Y_{o x}$

$\beta_{c h}$

$\varepsilon$

$\varepsilon_{c}$

$\varepsilon l s$

$\varepsilon_{r s}$

$\mu$

$\mu_{b f}$

$\mu_{b f, i}$

$\mu_{f o}$

$\mu_{F R R, i}$

$\mu_{\alpha}$

$\rho_{i}$

$\rho_{J, l e f t}$

$\rho_{J, \text { right }}$

$\rho_{w}$

$\sigma$

$\sigma_{b f}$

$\sigma_{b f, i}$ mass fraction of oxygen in air (0.23)

wood charring rate

$\mathrm{mm} / \mathrm{min}$

emissivity

emissivity in the cavity

emissivity on the left surface of the void cavity

emissivity on the right surface of the void cavity

yield rate of volatiles from the CLT panel

mean time of failure of a barrier linking the

Minute

fire compartment to an adjacent compartment

mean of the time to failure in a fully Minute developed compartment fire for assembly $i$

mean time for a fire to develop from ignition Minute to flashover in a compartment fire

mean of the duration of fire resistance to the Minute standard ISO 834 fire for assembly $i$

mean of the fire growth coefficient for a $\mathrm{t}^{2} \mathrm{~kW} / \mathrm{s}^{2}$ fire

density of the boundary material $i$ or the $\mathrm{kg} / \mathrm{m}^{3}$ control volume $i$

densities of the left half of a control volume $\mathrm{kg} / \mathrm{m}^{3}$

densities of the right half of a control volume $\mathrm{kg} / \mathrm{m}^{3}$

density of wood $\mathrm{kg} / \mathrm{m}^{3}$

Stefan-Boltzmann constant

standard deviation of time of failure Minute

standard deviation of the time to failure in a Minute

fully developed compartment fire for 
assembly $i$

$\sigma_{f o}$

$\sigma_{F R R, i}$

$\sigma_{\alpha}$

$\tau_{f d}$

$\tau_{g r}$

$\tau_{g r}^{\max }$

$\varphi$

$\Phi$ standard deviation of duration for a fire to develop from ignition to flashover

standard deviation of the duration of fire resistance to the standard ISO 834 fire for assembly $i$

standard deviation of the fire growth $\mathrm{kW} / \mathrm{s}^{2}$ coefficient for $\mathrm{at}^{2}$ fire

duration of the fully-developed fire period Minute

duration of fire growth phase in the Minute compartment

maximum duration of fire growth phase

global fuel combustion efficiency

global equivalence ratio representing the fuel-to-air mass ratio in the fire compartment normalized by the stoichiometric fuel-to-air ratio
Minute

Minute

Minute

Minute 


\section{List of Tables}

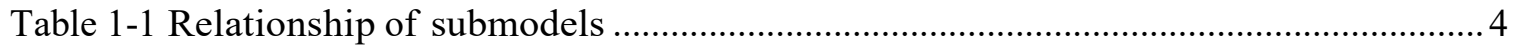

Table 2-1 A comparison of comprehensive fire risk analysis models ..................................... 19

Table 2-2 A comparison of failure times of two types of fire doors in the ISO fire and natural

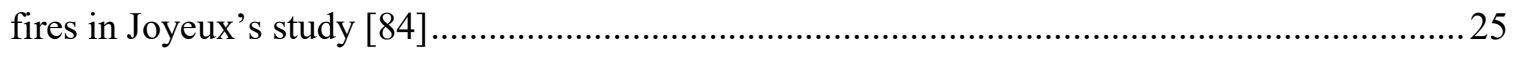

Table 2-3 Design charring rates of timber, LVL, wood panelling and wood-based panels in

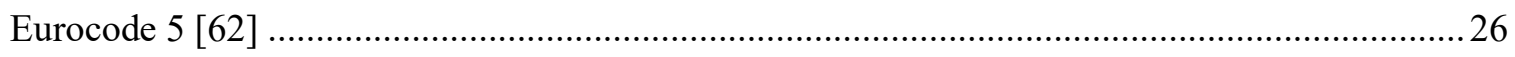

Table 3-1 Fire growth speed and maximum heat release of different compartments ................... 62

Table 3-2 Five different Fire Resistance Rating (in minutes) options of building elements ......... 63

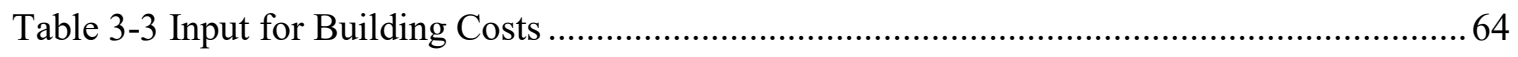

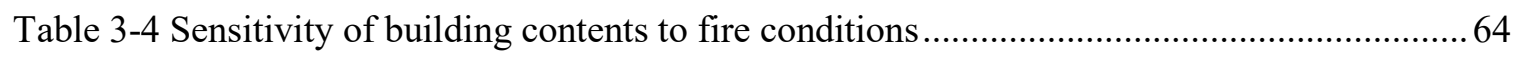

Table 3-5 CUrisk results for three different fire scenario design options ...................................... 78

Table 3-6 Ontario, Canada fire statistics in recent five years .................................................. 79

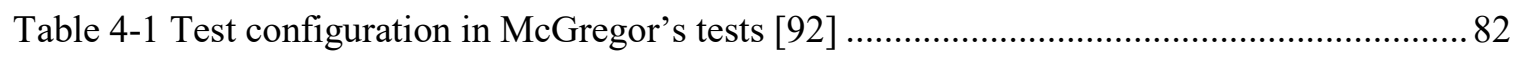

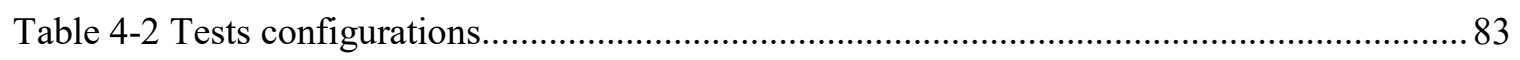

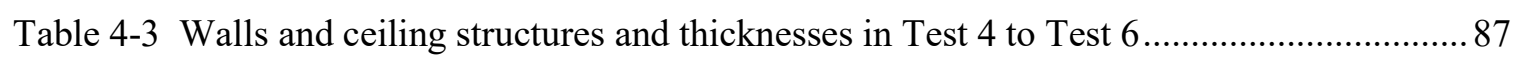

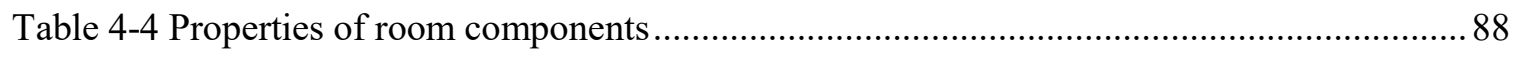

Table 4-5 Interior room sizes, doorway sizes and estimated maximum heat release rates............ 89

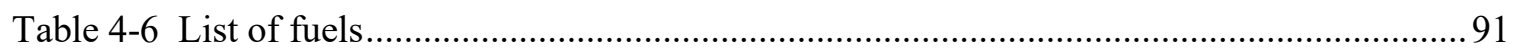

Table 4-7 ETC positions from fire exposed side to outside, number denotes mm into wood

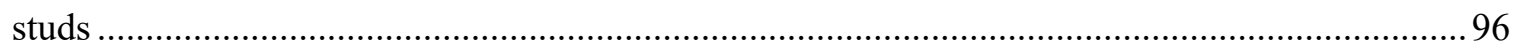

Table 4-8 Summary of fuel loads and maximum THRRs and average THRRs in the fully

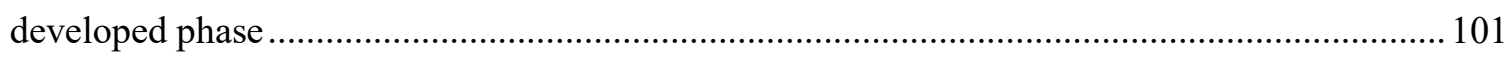

Table 4-9 Events related to the fall-off of the exposed layer of gypsum board, time in minutes

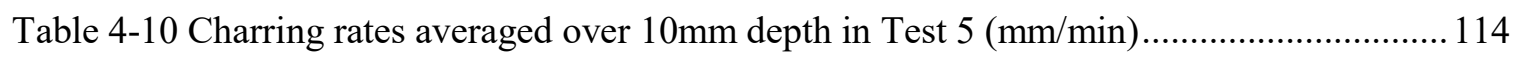

Table 4-11 Total energy release and global combustion efficiency ........................................ 117 
Table 4-12 Average temperature profiles during the fully developed phase

Table 4-13 Summary of combustion conditions during fully developed phase in selected tests

Table 5-1 Type X Gypsum board fall-off or failure temperature criteria (taken from [124]) ..... 147

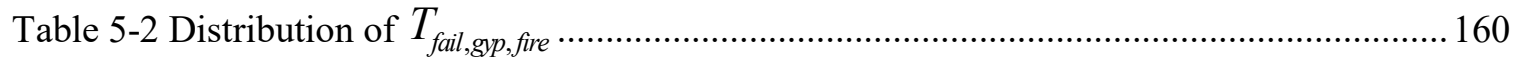

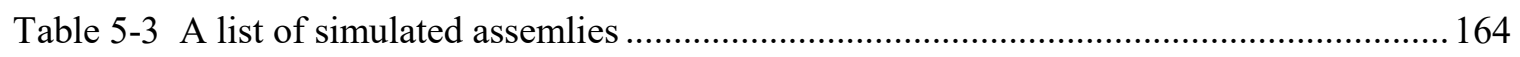

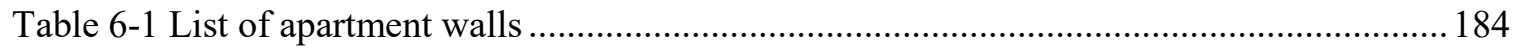




\section{List of Figures}

Figure 1-1 A schematic of the fire risk assessment system model........................................ 3

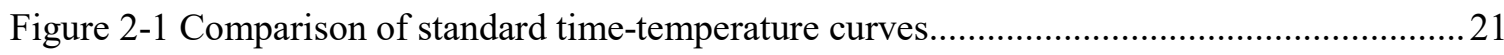

Figure 3-1 Flowchart of CUrisk system model and Position of Fire Spread submodel.................51

Figure 3-2 An example of the cumulative probability of fire spread and the related cumulative

probability of flashover due to fire spread .54

Figure 3-3 Simplified flow chart of computer module of Life Hazard submodel related to Fire Spread submodel .55

Figure 3-4 Conceptual sketch of the building and floor layout .59

Figure 3-5 Plan of the first floor

Figure 3-6 Layout of the Fire Apartment (first apartment) on the first floor.....

Figure 3-7 Design Option 1, sprinklers, detectors and alarms are installed in the building, and fire department is available.

Figure 3-8 (a) Design Option 2, detectors and alarms are installed and Fire Department is available, and (b) Design Option 3, only Fire Department is available

Figure 3-9 CO concentration and smoke layer heights $v s$. time in the apartment of fire origin, when the room of fire origin is $\mathrm{R} 11$

Figure 3-10 HRR and radiation $v s$. time in the room of fire origin $\mathrm{R} 11$ .70

Figure 3-11 Smoke layer temperature $v s$. time Fire conditions in the apartment of fire origin, when the room of fire origin is $\mathrm{R} 11$

Figure 3-12 Occupant evacuation time vs. occupant ID, when the room of fire origin is R21......71

Figure 3-13 Probability of fire spread at the end of simulation time 1800 seconds with 5 different fire resistance rating options. Fire origin room, living room on the first floor (R1) .......73

Figure 3-14 Life hazards with five different fire resistance rating options; Fire origin room: living room (R21) on third floor

Figure 3-15 Fire losses to building contents with five different fire resistance rating options; Fire origin room: living room (R21) on third floor. 
Figure 3-16 The effect of different fire protection measures on smoke temperature in fire origin room

Figure 3-17 The effect of different fire protection measures on $\mathrm{CO}$ concentration in the room of fire origin.

Figure 3-18 Total damages to the buiding due to 8 different fire protection options when the room of fire origin is $\mathrm{R} 31$

Figure 3-19 Total deaths and injuries due to 8 different fire protection options. Fire origin room: R31

Figure 4-1 An illustration of CLT panel configuration (taken from [78]) .81

Figure 4-2 CLT room outlook. 84

Figure 4-3 Front View of the test room 84

Figure 4-4 Top View of the test room .85

Figure 4-5 Photos of furniture set inside the test room. 90

Figure 4-6 Fuel layout in the room 90

Figure 4-7 Image of segment of thermocouple trees (left: steel tube after protection; right: steel tube with drilled holes) 92

Figure 4-8 Locations of TCTs, PTCs and ceiling ETCs in all the tests. 93

Figure 4-9 Wall thermocouple groups locations in Test 1 to 3 . 94

Figure 4-10 Thermocouple depths in each ETC group in Test 4 to Test 6, an illustration 95

Figure 4-11 An illustration of one group of ETC on the external wall surface 95

Figure 4-12 Mechanism of HRR measurement system (taken from [95]) .97

Figure 4-13 Temperature data acquisition system .98

Figure 4-14 LabVIEW data acquisition program interface 1 .98

Figure 4-15 LabVIEW data acquisition program interface 2. 99

Figure 4-16 Total heat release rates of all the tests........ 100

Figure 4-17 Room temperature measured by PTCs as well as standard curves 102

Figure 4-18 Room temperature in Hakkarainen's tests (reproduced from [77]) ; (a) unprotected 
CLT room, same as Test 3; (b) protected by 2 layers of gypsum boards, same as Test 1 and Test 2 in this study. Curves were average of thermocouple trees located at front corner, center and rear corner.

Figure 4-19 Wall temperatures behind the $2^{\text {nd }}$ layer of gypsum board in Test 2 ...................... 105

Figure 4-20 Wall temperatures behind the $2^{\text {nd }}$ layer of gypsum board in Test 4 ....................... 106

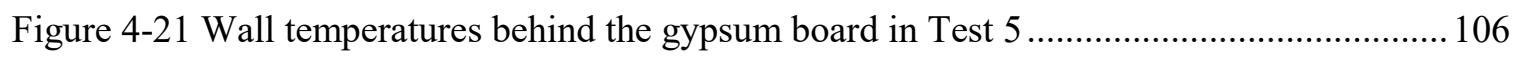

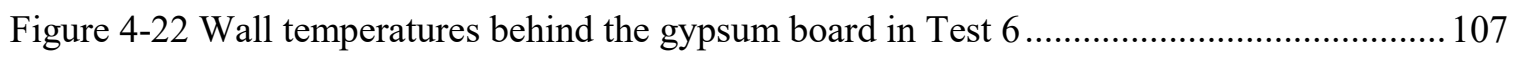

Figure 4-23 Illustration of heat penetration and soot accumulation in Test 4.......................... 108

Figure 4-24 (a): An illustration of internal burning of wood studs under gypsum boards in Test

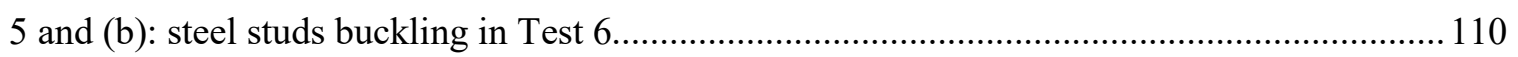

Figure 4-25 Times onset times at different ETC depth in Test 3 (adapted from [92]) ............... 111

Figure 4-26 Times onset times at different ETC depth in Test 5 .......................................... 113

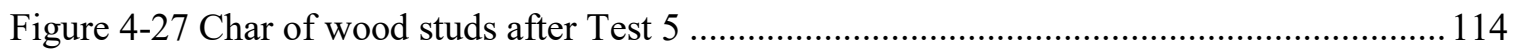

Figure 4-28 Rough estimation of CLT panels contribution in Test 3 [92] .............................. 124

Figure 5-1 Illustration of the Component Subtractive Method .............................................. 128

Figure 5-2 Heat transfer across components and grid spacing ............................................. 132

Figure 5-3 Boundary condition at the fire-exposed surface .................................................... 135

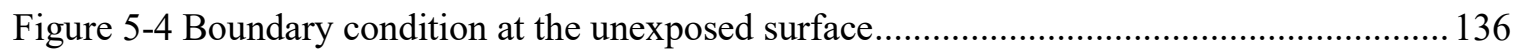

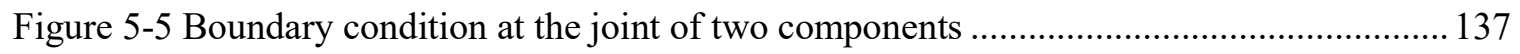

Figure 5-6 An demonstration of heat transfer at the interface of void cavity and right solid

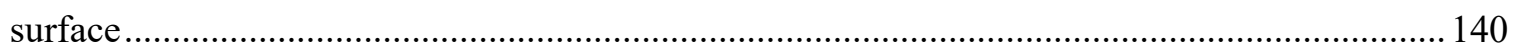

Figure 5-7 Thermal conductivity of Type X gypsum board with temperature (reproduced from

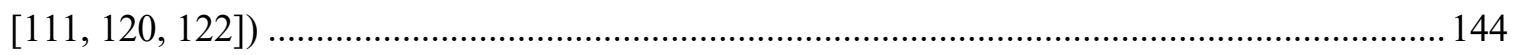

Figure 5-8 Specific heat of Type X gypsum board with temperature (reproduced from [72]) .... 145

Figure 5-9 Density reduction rate of Type X gypsum board with temperature (reproduced from [120]) 145

Figure 5-10 Density of air as a function of temperature (reproduced from [125]) ..................... 148 
Figure 5-11 Specific Heat of air as a function of temperature (reproduced from [125])

Figure 5-12 Thermal conductivity of rock and glass fiber as a function of temperature (reproduced from [120])

Figure 5-13 Specific heat of rock and glass fiber as a function of temperature (reproduced from [120]) 150

Figure 5-14 Density reduction factor of rock and glass fiber as a function of temperature (reproduced from [120])

Figure 5-15 Thermal conductivity of wood with temperature (reproduced from [62])

Figure 5-16 Specific heat of wood with temperature (reproduced from [62])

Figure 5-17 Density reduction factor of wood with temperature (reproduced from [62]).

Figure 5-18 Flow chart illustrating the sampling process

Figure 5-19 Temperature behind the 2nd layer of fire-exposed gypsum board in Test 2, a comparison of the test results and model prediction. 165

Figure 5-20 Temperature behind the $2^{\text {nd }}$ layer of fire-exposed gypsum board in Test 4 , a comparison of the test results and model prediction. 165

Figure 5-21 Temperature behind the $1^{\text {st }}$ layer of fire-exposed gypsum board in Test 5, a comparison of the test results and model prediction. 167

Figure 5-22 Temperature behind the $1^{\text {st }}$ layer of fire-exposed gypsum board in Test 6, a comparison of the test results and model prediction. 168

Figure 5-23 Temperature profile behind the $1^{\text {st }}$ unexposed gypsum board in Test 5, a comparison of the test results and model prediction. 168

Figure 5-24 Temperature profile behind the $1^{\text {st }}$ unexposed gypsum board in Test 6, a comparison of the test results and model prediction (input with room temperature in Test 6).... 169

Figure 5-25 Modelling results of accumulative charring depth in Test 3 170

Figure 5-26 Two fire curves used in the calculation. 173

Figure 5-27 Cumulative probability of barrier failure for six light-frame walls in the ISO 834 fire. 174

Figure 5-28 Probability of barrier failure for six light-frame walls under the fire curve of the room fire test curve .174 
Figure 6-1 Floor plan of the first storey

Figure 6-2 Dimensions of apartment and other spaces

Figure 6-3 Event tree demonstrating the cluster of fire scenarios

Figure 6-4 Smoke layer temperature in the apartment of fire origin Apt.1

Figure 6-5 Probability of barrier failure of the 16 types of walls located in the apartment of fire origin under unsuppressed fires in Scenario 4

Figure 6-6 Probability of barrier failure of the 16 types of walls located in the apartment of fire origin under Fire Department intervened fires in Scenario 3

Figure 6-7 Probability of fire spread in Apartment 2 from Apartment 1, results are taken from Scenario 4 comparing 18 types of wall barriers. 189

Figure 6-8 Probability of fire spread on the $1^{\text {st }}$ and $2^{\text {nd }}$ floor at 60 minutes in Scenario 4 , comparing 18 types of wall barriers. Fire originated in Apartment 1 without fire suppression. . 190 Figure 6-9 Probability of fire spread on the $3^{\text {rd }}$ to $5^{\text {th }}$ floor at 60 minutes in Scenario 4 comparing 18 types of wall barriers. Fire originated in Apartment 1 without fire suppression. . 191 Figure 6-10 Probability of fire spread on the $1^{\text {st }}$ and $2^{\text {nd }}$ floor at 60 minutes in Scenario 8 comparing 18 types of wall barriers. Fire originated in Apartment 3 without fire suppression. . 192 Figure 6-11 Probability of fire spread on the $3^{\text {rd }}$ to $5^{\text {th }}$ floor at 60 minutes in Scenario 8 comparing 18 types of wall barriers. Fire originated in Apartment 3 without fire suppression. . 193

Figure 6-12 The effect of active fire protection systems on the fire losses in the building constructed with wall Barrier 1. (SPK: sprinkler, FD: Fire Department). 196

Figure 6-13 Annual Fire Loss of the 18 building wall barrier designs. (LTF: Light Timber Frame; LSF: Light Steel Frame)

Figure 6-14 Mean evacuation time of each occupant in Scenario 4 and in the building designed with Wall Barrier 1

Figure 6-15 Total probability of death due to fire spread in Scenario 16, comparing 10 different types of wall barriers. . .200 


\section{Chapter 1 Introduction and Research Objectives}

All the work in this thesis is related to the fire risk analysis model CUrisk. In this chapter, an introduction to CUrisk is presented, including the system model and all the submodels, and the objectives of the current research are presented.

\subsection{Introduction to CUrisk}

CUrisk is a comprehensive fire risk analysis model being developed at Carleton University in Canada. It can evaluate the overall fire risk of a building using selected fire scenarios based on the building characteristics and the available active and passive fire protection systems. It includes a system model and more than ten submodels, see Figure 1-1 for system structure. The system model deals with the system methodology and the basic structure of the model, the basic functions of each submodel, the relationship of all the submodels, as well as the data input and output of the whole model. CUrisk comprises a number of submodels, including Fire Growth, Smoke Movement, Boundary Failure and Fire Spread, Smoke and Fire Detection, Occupant Response and Evacuation, Fire Department Response and Action, as well as Economic Loss submodel.

The system model sets up a predetermined set of procedures to coordinate all the submodels. When performing a fire risk analysis, fire scenarios are generated by the Fire Scenario submodel. For each fire scenario, building fire tenability conditions are predicted by the submodels of Fire Growth, Smoke Movement, Barrier Failure and Fire Spread, considering the intervention of active fire protection systems such as sprinklers, detectors, alarms or the fire department. Furthermore, occupant response and evacuation processes are simulated incorporating the effects of building tenability conditions on human movement and behaviour, and the resulting life risks are predicted. Economic losses due 
to fires are also calculated using the Economic Loss submodel. After addressing all the fire scenarios for a specific design, the two final output parameters, Fire Cost Expectation and Expected Risk to Life, are determined. Significant improvements [1-3] of the Smoke Movement submodel, Occupant Response submodel and Occupant Evacuation submodel have been made in recent years. A more detailed description can be found in the CUrisk Technical Report [4].

In the following sections, the basic methodology of the system model will be introduced, including the basic structure of the system model, a brief description of each submodel, and the input and output data of the system model and each submodel.

\subsubsection{System Structure of the Risk Assessment Model}

This risk assessment model begins with the production of all the fire scenarios. For each scenario, a design fire is selected. Then, the Fire Growth submodel is run to predict the fire conditions in the compartment of fire origin. The Smoke Movement submodel is used to predict hazardous conditions in non-fire compartments. The Fire Spread submodel is used to calculate the probability of fire spread to other compartments. The information about the building hazardous conditions is then sent to the submodels of Smoke and Fire Detection, Occupant Response, Occupant Evacuation, Fire Department Response and Action, and Life Hazard to calculate the life risk of this scenario. Economic losses for this scenario are also calculated using the hazardous conditions. After finishing all the scenarios, the final two decision-making parameters, Expected Risk to Life and Fire Cost Expectation are obtained. Figure 1-1 gives a schematic diagram of the system model, and Table 1-1 lists a description of the relationship of submodels. The following paragraphs provide a brief description of each submodel. 


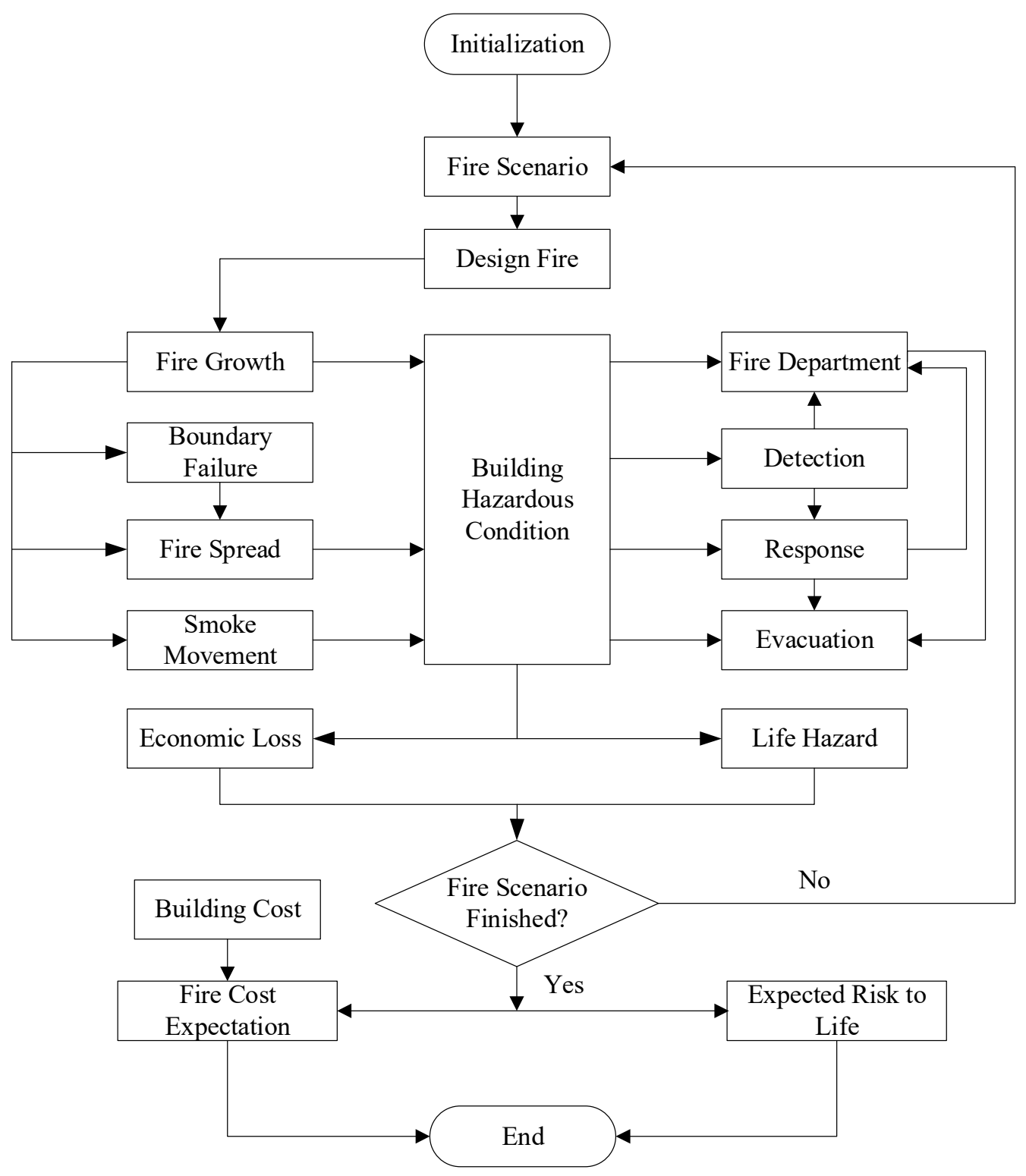

Figure 1-1 A schematic of the fire risk assessment system model 
Table 1-1 Relationship of submodels

\begin{tabular}{|c|c|c|}
\hline Submodels & Input Submodels & Output Submodels \\
\hline Fire Scenarios & User Input & $\begin{array}{l}\text { Expected Risk to Life } \\
\text { Fire Cost Expectation }\end{array}$ \\
\hline Design Fire & User Input & $\begin{array}{l}\text { Fire Growth } \\
\text { Smoke Movement }\end{array}$ \\
\hline Fire Growth & $\begin{array}{l}\text { User Input } \\
\text { Design Fire }\end{array}$ & $\begin{array}{l}\text { Smoke Movement } \\
\text { Barrier Failure } \\
\text { Hazardous Conditions }\end{array}$ \\
\hline Smoke Movement & $\begin{array}{l}\text { User Input } \\
\text { Design Fire }\end{array}$ & Hazardous Conditions \\
\hline $\begin{array}{l}\text { Barrier Failure and } \\
\text { Fire Spread }\end{array}$ & User Input & Hazardous Conditions \\
\hline Smoke and Fire Detection & $\begin{array}{l}\text { User Input } \\
\text { Hazardous Conditions }\end{array}$ & $\begin{array}{l}\text { Fire Department Response } \\
\text { and Action } \\
\text { Occupant Response }\end{array}$ \\
\hline Occupant Response & $\begin{array}{l}\text { User Input } \\
\text { Smoke and Fire Detection } \\
\text { Hazardous Conditions }\end{array}$ & $\begin{array}{l}\text { Occupant Evacuation } \\
\text { Fire Department Response } \\
\text { and Action }\end{array}$ \\
\hline Occupant Evacuation & $\begin{array}{l}\text { User Input } \\
\text { Hazardous Conditions } \\
\text { Occupant Response }\end{array}$ & Life Hazard \\
\hline Life Hazard & $\begin{array}{l}\text { Occupant Evacuation } \\
\text { Fire Department Response and Action } \\
\text { Hazardous Conditions }\end{array}$ & Expected Risk to Life \\
\hline $\begin{array}{l}\text { Fire Department Response } \\
\text { and Action }\end{array}$ & $\begin{array}{l}\text { User Input } \\
\text { Occupant Response } \\
\text { Smoke and Fire Detection } \\
\text { Hazardous Conditions }\end{array}$ & Life Hazard \\
\hline Hazardous Conditions & $\begin{array}{l}\text { Fire Growth } \\
\text { Smoke Movement } \\
\text { Fire Spread }\end{array}$ & $\begin{array}{l}\text { Smoke and Fire Detection } \\
\text { Occupant Response } \\
\text { Occupant Evacuation } \\
\text { Fire Department Response } \\
\text { and Action } \\
\text { Economic Loss } \\
\text { Life Hazard }\end{array}$ \\
\hline Building Cost & User Input & Fire Cost Expectation \\
\hline Economic Hazard & $\begin{array}{l}\text { User Input } \\
\text { Fire Scenarios } \\
\text { Hazardous Conditions }\end{array}$ & Fire Cost Expectation \\
\hline Expected Risk to Life & $\begin{array}{l}\text { Fire Scenarios } \\
\text { Life Hazard }\end{array}$ & Final Output \\
\hline Fire Cost Expectation & $\begin{array}{l}\text { Fire Scenarios } \\
\text { Building Cost } \\
\text { Economic Loss }\end{array}$ & Final Output \\
\hline
\end{tabular}




\subsubsection{Fire Scenarios Submodel}

A scenario is composed of a number of clearly defined events. In this model, the event tree is composed of the following events: fire initiation in the room of fire origin, selection of design fire, sprinkler suppression, detectors and alarms, and firefighting. The first event is fire ignition or fire start at a specific location. According to the contents and characteristics of the fire compartment, the relevant design fire will then be selected for each compartment. Whether the door of the room of fire origin is open or closed is the next event since it has a significant impact on fire development and smoke movement. In addition, weather conditions also affect the fire development and smoke movement. The possibility and reliability of sprinklers and firefighting suppression are also considered as they can change the heat release rate of the fire.

The Fire Scenario submodel produces the number of fire scenarios, and the probability of each scenario. The results of this submodel are used by the Risk to Life submodel and the Fire Cost Expectation submodel.

\subsubsection{Design Fire Submodel}

This submodel is used to produce the design fire, defined as a typical fire reflecting the combustion characteristics of the fuel in the compartment. This submodel provides the Fire Growth submodel with the composition of the fuel, ratios of species production and consumption, and the nominal heat release rate. For this, the properties, arrangement, and amount of the fuel, and the geometry and dimension of the compartment are taken into account to obtain the required results. Details of the fire will be further computed with the Fire Growth submodel. The Design Fire submodel is only run once for each case study. 


\subsubsection{Fire Growth Submodel}

The Fire Growth submodel predicts the fire conditions in all compartments to which the fire may spread from the room of fire origin. This submodel takes inputs from the Design Fire submodel. The required input parameters are the nominal heat release rate, the amount, arrangement, and composition of the fuels, ratios of species production, compartment geometry and dimensions, and ventilation. The results of the submodel are used by the Hazardous Conditions submodels, and then by the Economic Loss submodel to calculate the fire damages resulting from fire spread.

This submodel adjusts the nominal heat release rate from the design fire and provides species production rates based on the ventilation conditions in the compartment. This submodel outputs the temperature of the gas layers and mass flow rates, by running the same two-zone fire model as used in the Smoke Movement submodel in each room rather than in the whole building. This model will be run only once for each compartment at the beginning of CUrisk simulation.

\subsubsection{Smoke Movement Submodel}

The Smoke Movement submodel based on a two-layer zone model detailed in [5]. It is used to predict the fire hazardous conditions in each non-fire compartment in the building, including smoke temperature, species concentrations, depth of the smoke layer, radiative heat flux to the boundaries, and smoke obscuration in each compartment based on the conditions of fire growth, building geometry and dimension, properties of boundary materials, ventilation system, and the environmental conditions. The Smoke Movement submodel is run once for each scenario. The results of the submodel are used by the submodel of Hazardous Conditions. A recent improvement has been made [1] to describe 
heat and mass transfer across the interface between the upper and lower layers as a result of the temperature difference between the two layers.

\subsubsection{Boundary Failure Submodel and Fire Spread submodel}

Originally there was a very simple Boundary Failure submodel that was based on the fire curve and temperature criteria. Alternatively, the calculation of the submodel can be based on the results of an external model called WALL2D [6], a computer model developed by FPInnovations to calculate the fire resistance of light-frame walls. However, WALL2D is a two dimensional heat transfer model and only suitable to wood frame building elements. Later a Monte Carlo process was employed to generate barrier failure probabilities [7]. This model considered the uncertainties in the thermo-physical properties of timber-frame assembly components and could generate time-dependent probability of barrier failure. However, it only considered standard fire exposure and running the model requires long computer times that make it not suitable for risk analysis applications.

A Fire Spread model [8] developed at Carleton University is integrated into CUrisk as the Fire Spread submodel, and related work can be found in Chapter 3 of this thesis. The Fire Spread submodel provides a time-dependent probability of fire spread to any other compartment in the building from the compartment of fire origin in a fire scenario. A Barrier Failure submodel is also developed for the use in CUrisk, and related work can be found in Chapter 5 of this thesis.

Together with other hazardous information provided by the Fire Growth and Smoke Movement submodels, the fire spread results are used to calculate the number of deaths in the building. 


\subsubsection{Smoke and Fire Detection Submodel}

This submodel is used to calculate the detection time of fire or smoke. It takes input from the submodel of Hazardous Conditions, and provides data to the submodels of Occupant Response and Evacuation, and Fire Department Response and Action. A fire alarm can be activated by the smoke temperature or smoke concentration at the location of the fire alarm. The Fire and Smoke Detection submodel checks temperatures and smoke concentration in each compartment to see whether the activation conditions are satisfied so that the activation time can be predicted.

\subsubsection{Fire Department Response and Action}

This submodel is used to estimate the arrival time of the fire department at the fire building and the fire room as well as to estimate their efforts to fight the fire and rescue occupants. This submodel takes input from the submodels for Smoke and Fire Detection, and Hazardous Conditions, and outputs data to the submodels of Occupant Response and Evacuation, and Economic Loss. Intervention time is a very important parameter, which is defined as the period of time from ignition to the first application of firefighting agent over the fire. This time is composed of the following intervals: detection, notification, dispatch, preparation, travel and set-up. This submodel calculates these times based on the properties of the fire building, characteristics of the fire department, the travelling distance of the fire department to reach the fire scene, and the environmental conditions. It is assumed that when a fire firefighter enters a compartment, the fire will be under control, and the occupants who are alive will be saved.

\subsubsection{Hazardous Conditions Submodel}

The Hazardous Conditions submodel is used to collect all the information on hazardous 
conditions in each compartment in the building. This submodel collects data from the submodels of Fire Growth, Smoke Movement, and Fire Spread, and outputs data on the temperature and species concentrations of gas layers, interface height, radiation flux, and temperature to the submodels of Smoke and Fire Detection, Occupant Response and Evacuation, Fire Department Response and Action, and Economic Loss.

\subsubsection{Occupant Response Submodel}

The Occupant Response submodel is used to predict the response of occupants in fire emergencies [3]. It is a probabilistic model based on the PIA process, i.e., Perception, Interpretation and Action. The occupant response model predicts the probabilities of occupants perceiving fire signals due to direct perception, receiving fire alarms signals after the activation of local alarms, central alarm and voice alarm. Occupants can be warned by other occupants or the fire department, and take actions including pulling the fire alarm, warning other occupants, calling the fire department, and commencing evacuation. The Occupant response begins from the time of receiving cues of fire or smoke. Some occupants will immediately begin to evacuate and other occupants will further check the conditions and then decide whether they should leave the compartment. This submodel takes input data from the submodels of Hazardous Conditions, Smoke and Fire Detection, and provides data to the Occupant Evacuation submodel.

\subsubsection{Occupant Evacuation Submodel}

The Occupant Evacuation submodel is used to calculate the evacuation of occupants. The evacuation model uses a coarse network approach to describe a building and an individual perspective to represent occupants [9]. The Monte Carlo method samples random variables including the occupants' gender, age, speed, exit selection, pre- 
evacuation time, and distance to be traveled to exit the initial compartment with uniform distributions [2]. This submodel takes input data from the submodels of Hazardous Conditions, and then provides the data on the evacuation route and time of each occupant to the Life Hazard submodel. The Occupant evacuation submodel begins from the time when an occupant decides to evacuate. There will be different routes for them to select and different speeds for them to move based on their mobility and judgment ability as well as their familiarity with the building.

\subsubsection{Life Hazard Submodel}

The Life Hazard submodel is used to calculate the expected number of casualties in each fire scenario. This submodel takes input data from the submodels of Hazardous Conditions, Occupant Response and Evacuation, and Fire Department Response and Action, and then provides the number of deaths and injuries to the submodel of Expected Risk to Life.

This submodel calculates the fractional effective dose for each occupant based on the hazardous conditions for each occupant as well as the information of occupant movement provided by the Occupant Response and Evacuation. In addition, once a fire in a compartment reaches flashover, the occupants in that compartment are assumed to be immediately killed.

\subsubsection{Building Cost Submodel}

The objective of this submodel is to calculate the capital cost of the passive and active fire protection systems and the maintenance cost of the active fire protection systems. These parameters will later be used by the Fire Cost Expectation submodel. It takes input data directly from users. 


\subsubsection{Economic Loss Submodel}

The objective of this submodel is to calculate the economic loss incurred for each fire scenario. This parameter will later be used by the Fire Cost Expectation submodel. It takes the input data of fire conditions from the Hazardous Conditions submodel, the data of economic values of contents, and damage criteria of contents from users to estimate the economic loss. A detailed description of this submodel can be found in Reference [10].

\subsubsection{Expected Risk to Life Submodel}

The primary focus of building and fire codes is life safety, thus in a quantitative fire risk assessment model, it is essential to determine a parameter to measure risk to life. In this model, the Expected Risk to Life is one of the two final decision-making parameters, defined as the expected death frequency per year per individual of a building.

$$
E R L=\frac{F \sum_{i=1}^{K} P_{i} N_{i}}{P O P}
$$

where $F$ is the annual fire frequency of the building; $P_{i}$ is the probability of scenario $i$; $N_{i}$ is the number of deaths in the scenario $i$; $K$ is the number of scenarios; POP is the population of the building.

$E R L$ can be directly used as a decision-making parameter if there is available reference data or can be compared with that of another similar deemed-to-satisfy building.

\subsubsection{Fire Cost Expectation Submodel}

Fire Cost Expectation (FCE) is the other final decision-making parameter of CUrisk. It is assumed that the fire costs are composed of three parts, fixed capital investment of active and passive fire protection systems, maintenance and inspection cost of the active fire protection systems, and the expected losses due to fire and smoke spread. The $F C E$ does not include other costs such as the costs related to the impact on the environment of 
fire, and costs of fire department services. This model does not calculate the present worth of expected losses but directly calculate them based on the current data.

FCE is defined as a vector with four components: $C O S T_{\text {Fixed }}$, the capital cost of the passive and active fire protection systems; $C O S T_{\text {Maintain, }}$, the annual maintaince cost of the active fire protection systems; $\operatorname{COST}_{\text {Loss }}$, the expected annual loss as a result of all probable fire incidents in the building; $\operatorname{COST}_{\text {Total }}$, as well as the total cost of the building damages in the time span of the design life.

$$
A F L=\operatorname{COST}_{\text {Loss }}=F \cdot \sum_{i=1}^{k} P_{i} C_{D}
$$

The $\operatorname{COST}_{\text {Loss }}$ is the Annual Fire Loss $(A F L)$ which is calculated by Equ.(1.2); $P_{i}$ is the probability of scenario $i$ occurring; $C_{D}$ is the total cost of damage to the entire building in scenario $i(\$) ; k$ is the number of scenarios.

\subsection{Problem Statement and Research Objectives}

CUrisk is a comprehensive fire risk assessment model, which contains a number of submodels each addressing different aspects of the fire safety system. The aim of CUrisk is to evaluate the fire risk in buildings of various sizes or construction types. One of the current shortcomings of CUrisk is that it does not have appropriate Barrier Failure submodel and Fire Spread submodel. The prediction of barrier failure in CUrisk relies on external barrier failure models, such as WALL2D [6]. This process is not automatic and hence it is time-consuming. Though external specialized Barrier Failure submodels can be used, it is very difficult to handle the compatibility issue and to create accurate data flow between the external models and CUrisk. Besides, most numerical barrier failure models are deterministic and time-consuming, and usually cannot effectively serve the purpose.

As CUrisk will be used to perform evaluation of performance-based design in wood 
buildings, the Barrier Failure submodel should be able to predict barrier failure of combustible building assemblies as well as non-combustible ones for comparison. The current version of CUrisk does not have this capability.

The main objective of this research is to develop a Barrier Failure submodel and incorporate an existing Fire Spread model into CUrisk. The existing fire spread model has been developed at Carleton University and can be used in CUrisk as a submodel to predict probability of fire spread in a building. The proposed Barrier Failure submodel should be capable of predicting the barrier failure characteristics of various types of building elements, including (but possibly not limited to) light steel/timber-frame, concrete and cross-laminated timber. The proposed model should be such that it can be incorporated in the CUrisk system model and function with the other submodels, especially the Fire Spread submodel. Available test results will be adopted for comparison with the barrier failure model. Full-scale fire tests will also be conducted to evaluate the performance of assemblies of different construction types, and the contribution of the fire development process. The results of these tests will be used to develop and validate the barrier failure model. 


\section{Chapter 2 Literature Review}

In this chapter, a review of existing comprehensive fire risk analysis models is presented, followed by a review of some simple fire resistance or barrier failure models. Finally a literature survey of the fire resistance tests on building elements in natural fires is given. The review of fire resistance models and fire resistance tests would provide references and insights upon the development of a barrier failure model in this work.

\subsection{A review of comprehensive fire risk analysis models}

Some of the existing comprehensive fire risk assessment models are reviewed, including FiRECAM and FIERAsystem in Canada, CESARE-Risk in Australia, CRISP in the UK and B-RISK in New Zealand. The system structure of these models are reviewed, with special attention given to modules or submodels that are used to simulate barrier failure and fire spread.

\subsubsection{FiRECAM}

To support the introduction of performance-based building regulations in Canada, the National Research Council of Canada (NRC) developed a computer model FiRECAM (Fire Risk Evaluation and Cost Assessment Model) that can be used to assess both the life risk to the occupants and the fire damages to fire protection systems and property in apartment and office buildings [11]. FiRECAM is one of the earliest comprehensive fire risk assessment models and it greatly influenced the development of other similar models such as CUrisk.

FiRECAM is composed of a series of submodels that simulate fire growth, fire spread, smoke movement, occupant behaviour, and the capital and maintenance costs of fire protection systems. These submodels run in sequence and repeatedly based on predefined 
fire scenarios to evaluate the life risk and fire damage in apartment or office buildings. The fire growth submodel [12] is a simplified one-zone compartment fire growth model that can predict the fire development in the compartment of fire origin. Fire growth in the compartment of fire origin is modelled using a one-zone model and two zones are considered in the corridor on the floor of fire origin in the Smoke Movement submodel [13]. The submodel that predicts fire spread in FiRECAM provides a non-time-dependent probability of fire spread in all locations in the building at the time of fire burnout in the compartment of fire origin.

\subsubsection{FIERAsystem}

FIERAsystem [14,15] (Fire Evaluation and Risk Assessment system) is another risk assessment tool developed by the National Research Council Canada. This tool uses a similar risk assessment concept as FiRECAM, but extended the application to industrial buildings such as warehouses and aircraft hangars. FIERAsystem can perform calculations using standard engineering correlations [16], or it can perform partial or complete fire risk analysis. The individual submodels can simulate the different aspects of fire incidents similar to the submodels of FiRECAM.

The Fire Spread submodel of FIERAsystem [17] considers only fire spread from the compartment of fire origin to the adjacent compartments by shifting the fire curve that is obtained from the Smoke Movement submodel by a delay time. The time of fire spread in the destination room is the lesser of the failure time predicted by the Boundary Element Failure submodel and the time when room temperature reaches $1000^{\circ} \mathrm{C}$. Thus the fire spread process is only dependent on the fire conditions in the compartment of fire origin and never spreads beyond the adjacent rooms. Documentation on the Boundary Element 
Failure submodel was not found in the literature.

\subsubsection{CESARE-Risk}

CESARE-Risk [18] is a fire risk assessment tool developed by the Centre for Environmental Safety and Risk Engineering (CESARE) in Australia. Similar to FiRECAM, the computer model aims to quantify the performance of a building fire safety design in terms of life risk and economic cost, and identify alternative cost-effective design solutions. CESARE-Risk has a similar system structure as FiRECAM. Firstly it defines multiple scenarios using an event tree, and then for each scenario, fire growth and smoke spread are predicted through the Fire Growth and Smoke Spread submodels. After that the submodels of Human Behaviour, Fire Brigade and Staff Rescue are run. The fire cost can be obtained by the Economic Model. Among the above submodels, the Fire Growth submodel is based on the Fire Growth submodel of FiRECAM with some modifications, and the Smoke Spread model [19] uses the zone concept and network approach. Given the occurrence of a particular scenario, a so-called three-point realisation method [20] was used to calculate the expected risk to life values. The Barrier Response Model [21] can predict the time and probability of barrier failure, and when the fire is not controlled a non-time dependent and stochastic Fire Spread Model (detailed information was not found in the literature) is invoked to calculate fire spread through the building.

\subsubsection{CRISP}

CRISP (Computation of Risk Indices by Simulation Procedures) [22-25] is a fire risk assessment model developed by the Building Research Establishment (BRE) in the United Kingdom. To some extent this model resembles FiRECAM and CESARE-Risk, but does not contain economic loss assessment and produces results in a quite different way. 
CRISP2 is basically a two layer multi-room zone model with a closely integrated occupant egress model, with further consideration of smoke detection and fire brigade, which are very simple and based on a single threshold. A Monte Carlo simulation is adopted which can account for all possible fire scenarios.

In general, CRISP could be considered as an evacuation model rather than a comprehensive fire risk assessment model. CRISP does not include a barrier failure model and all barriers are assumed to retain their integrity during the simulation. Furthermore, analysis is limited to flaming fires on single items and smouldering fires are ignored [22].

\subsubsection{B-RISK}

B-RISK [26] is a fire simulation and risk analysis model developed by BRANZ Ltd and the University of Canterbury in New Zealand. This model samples from the distribution of input parameter to create Monte Carlo input files [27] and then adopts a deterministic model to estimate the fire and smoke spread in a building, and eventually generates probability distributions for relevant model outputs [28]. Besides, B-RISK can be used in a single deterministic run for a specific scenario. The core of B-RISK is a deterministic multi-room two-zone model known as BRANZFIRE [29]. For fire growth and flame spread in the fire origin room, an item-to-item design fire or the popular power law design fire can be selected. For smoke spread beyond the fire origin room, the two zone model is used to estimate smoke spread in up to 10 compartments. In addition, the deterministic fire and smoke spread model has modules to account for the impact of sprinkler systems, smoke detectors, passive features, and smoke management systems. Based on data produced by these calculations, life hazard is predicted based on visibility and Fractional Effective Dose (Asphyxiant Gases and Thermal Effects). However, these parameters are calculated based 
on a fixed position in a specific room. Although the life hazard of an individual occupant can be calculated based on egress routes, egress path segments have to be input manually. An optional barrier failure calculation is also specified in B-RISK, which is based on the time-equivalent method developed by Nyman [30]. This method has significant limitations and can only be treated as indicative. Most importantly, the effect of barrier failure and the resulting fire spread beyond the fire origin room is not considered in B-RISK. Furthermore, economic loss prediction is not included in the model, either.

\subsubsection{Summary}

\section{The comprehensive fire risk assessment models reviewed earlier are listed in}

Table 2-1. It can be found that all the comprehensive fire risk analysis models have submodels to predict the fire development in the compartment of fire origin and smoke conditions in the building, using one or two zone models. All of them have evacuation models to evaluate occupant safety under a fire. Most of them have an Economic loss submodel to calculate fire damages.

For the calculation of the barrier failure and fire spread, none of the models have satisfactory solutions. They either use extremely simple approaches or engineering judgement, or they rely on results of external models that do not quite fit in their system structure. Likewise, CUrisk has similar weaknesses and it needs integrated barrier failure and fire spread submodels. 
Table 2-1 A comparison of comprehensive fire risk analysis models

\begin{tabular}{|l|l|l|l|l|l|l|}
\hline \multicolumn{1}{|c|}{ Name } & CUrisk & B-RISK & FiRECAM & FIERAsystem & CESARE-Risk & CRISP \\
\hline Fire and smoke & Yes & Yes & Yes & Yes & Yes & Yes \\
\hline $\begin{array}{l}\text { Occupant } \\
\text { evacuation }\end{array}$ & Yes & Yes & Yes & Yes & Yes & Yes \\
\hline Life risk & Yes & Yes & Yes & Yes & Yes & No \\
\hline Economic loss & Yes & No & Yes & Yes & Yes & No \\
\hline Farrier Failure & & $\begin{array}{l}\text { Time } \\
\text { equivalent }\end{array}$ & $\begin{array}{l}\text { Time } \\
\text { equivalent, } \\
\text { probabilistic }\end{array}$ & $\begin{array}{l}\text { Engineering } \\
\text { correlations, } \\
\text { or simple } \\
\text { numerical } \\
\text { techniques }\end{array}$ & $\begin{array}{l}\text { Barrier-failure } \\
\text { Matrix or } \\
\text { external models }\end{array}$ & No \\
& & N/A & $\begin{array}{l}\text { Non-time } \\
\text { dependent, at } \\
\text { the time of fire } \\
\text { burnout }\end{array}$ & $\begin{array}{l}\text { Fire origin to } \\
\text { adjacent } \\
\text { compartments } \\
\text { only }\end{array}$ & $\begin{array}{l}\text { Network } \\
\text { analysis } \\
\text { combined with } \\
\text { probability } \\
\text { theory and } \\
\text { engineering } \\
\text { judgement }\end{array}$ & No \\
\hline
\end{tabular}

\subsection{Fire resistance tests of building assemblies}

Traditionally the fire resistance of a building component is determined using a standard furnace test that subjects the component to the effects of a standard fire. However, it is well-acknowledged that the fire resistance of a building element obtained from a standard test might not represent its fire performance in real fires. Hence, a competent barrier failure model should be able to predict the failure of building assemblies not only in the standard fire but also in an arbitrary fire exposure. In the following section is a review of the widely adopted standard fire tests and, more importantly, some real fire resistance tests of building assemblies. 


\subsubsection{Fire resistance testing and standard curves}

As early as in the late $19^{\text {th }}$ century, engineers and researchers became aware of the importance of fire resistance testing. To test the fire resistance of building components, time-temperature curves and failure criteria were developed. In 1917, a new standard, ASTM C19, later renumbered as E119, was published, and failure criteria of building assemblies including floors and partitions were also provided in this standard [31]. This fire testing time-temperature regime has not been significantly modified since that time. Later on other countries created similar time-temperature curves in a similar fashion. ASTM E119 [32] as well as the Canadian standard CAN/ULC-S101-M89 [33] curves are defined by a number of discrete points and can be approximated using the following expression,

$$
T_{g}=T_{0}+750(1-\exp (-0.49 \sqrt{t}))+22 \sqrt{t}
$$

The standard time-temperature relationship for the fire used in such tests has been standardized internationally by ISO 834 [34],

$$
T-T_{0}=345 \log _{10}(8 t+1)
$$

In the UK, BS 476: Part 20-24 [35] specifies the equation below to represent a hydrocarbon time-temperature curve,

$$
T_{g}=1100\left(1-0.325 e^{-0.1667 t}-0.204 e^{-1.417 t}-0.471 e^{-15.833 t}\right) \quad \text { Equ.(2.3) }
$$

In the above equations, $T_{g}$ is the average furnace temperature in ${ }^{\circ} \mathrm{C}, T_{0}$ is the ambient temperature in ${ }^{\circ} \mathrm{C}$, and $t$ is the time in minutes.

Figure 2-1 compares the ASTM E119 and CAN/ULC-S101-M89 standard curves with the standard curve of ISO 834. These time-temperature relationships can be generally 
considered the same when comparing fire resistance test methods.

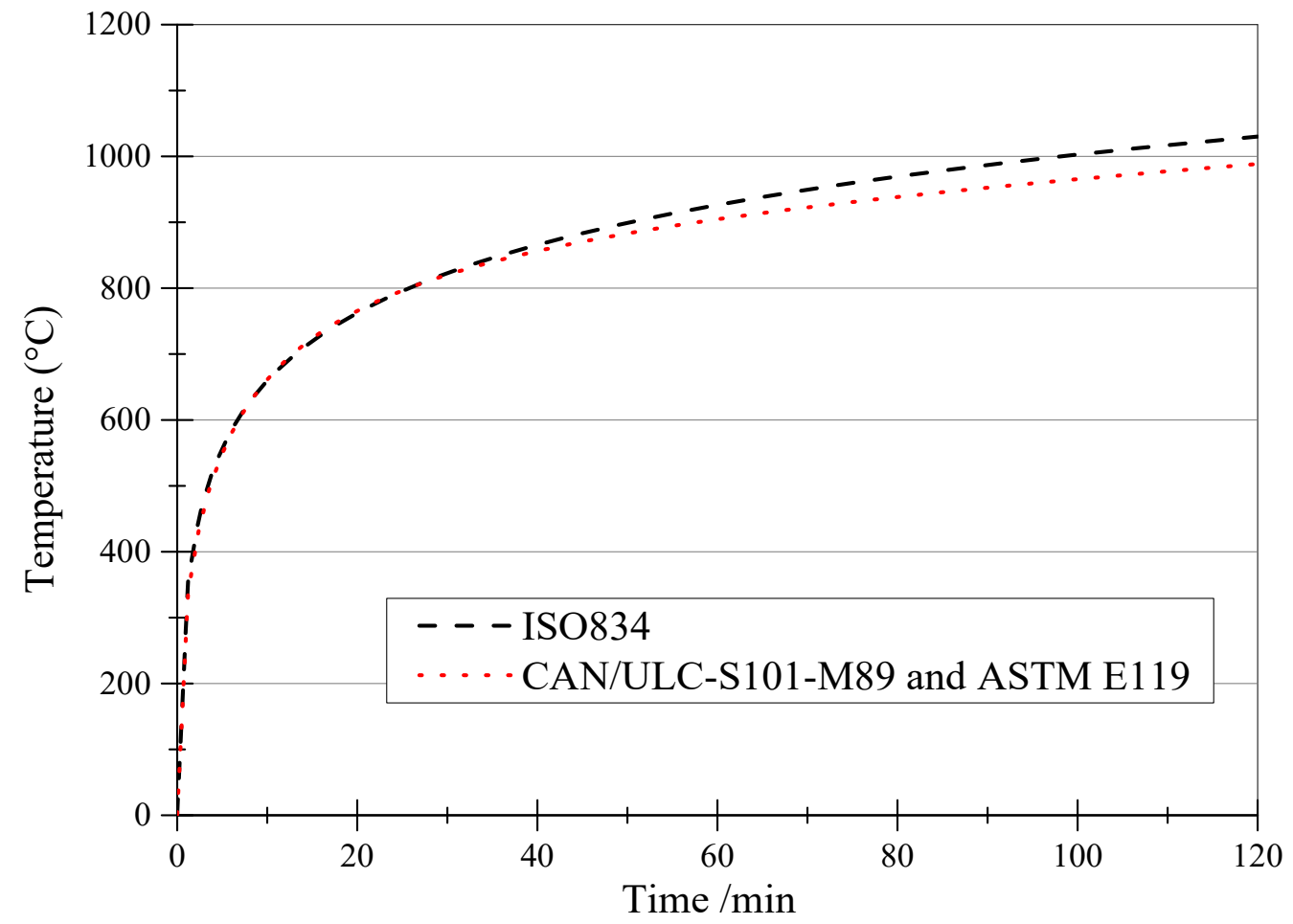

Figure 2-1 Comparison of standard time-temperature curves

To determine the failure time of a test specimen in the standard fire resistance tests, both ISO 834 and CAN/ULC-S101-M89 use the same failure criteria including insulation, integrity and structural failure. In CAN/ULC-S101-M89, the time to failure is judged based on the following conditions [33],

a) Insulation failure $-140^{\circ} \mathrm{C}$ average temperature rise or $180^{\circ} \mathrm{C}$ maximum above ambient temperature on the unexposed face, or

b) Integrity failure - penetration of flame and gases hot enough to ignite cotton waste, or

c) Structural failure - loss of load-bearing capacity or excessive deflection of load-bearing walls.

\subsubsection{Fire performance of building assemblies in natural fires}

The concept of the standard fire test has been broadly used to determine the Fire Resistance 
Ratings of building assemblies, which are often prescribed by building codes to regulate building construction. Although the invention of the standard fire and standard tests facilitated fire protection practices, the standard fire curve has shortcomings. The most obvious weakness is that it bears little relationship to what happens in most real fires. The severity of real fires is directly related to several parameters such as enclosure dimensions, ventilation conditions, fire load and enclosure lining materials, and those parameters in reality vary significantly. Furthermore, unlike the uniform heating of building assembly sample in a standard test, local or travelling fires in reality may cause a different failure mechanism in the structure. Wall linings in real fires also have a significant impact on severity, for instance, walls with higher thermal inertia are likely to absorb more energy than walls with low thermal inertia, and this will reduce fire severity.

There are growing concerns that the fire resistance of a building element obtained from a standard test might not represent its fire performance in real fires. Park [36] argued that in performance-based fire resistance design, natural fire curves should be used instead of the standard fire curve. One of the substitutes of the standard curve is the most frequently quoted parametric temperature-time curve documented in Eurocode 1, Part 1-2 [37]. A number of experimental studies suggested that standard tests may underestimate the fire severity of real fires. Manzello et.al [38-40] studied real fire performance of simplified light steel frame wall assemblies and found that combustibles generated peak heat release rates over $10 \mathrm{MW}$ in a compartment with $10.7 \mathrm{~m}$ length, $7 \mathrm{~m}$ width and $3.4 \mathrm{~m}$ height. The rate of increase of the heat flux at the surface of building elements was higher than that obtained in standard tests conducted by Sultan [41]. Lennon et.al [42] conducted eight large 
scale fire tests in a room with a plan of $12 \mathrm{~m}$ by $12 \mathrm{~m}$ and a height of $3.4 \mathrm{~m}$ and constructed with load bearing concrete blocks. Comparing the obtained temperature curve with the standard curve (ISO834 [34] and BS476 Part 20 [35]), he suggested that the use of standard exposure would severely underestimate the severity of the fire in terms of maximum temperature and duration of high temperature exposure of structural elements. BRE Global in the UK conducted some full scale natural fire tests on protected engineered timber floor systems [43] as well as typical Structural Insulated Panel (SIP) wall assemblies [44]. The purpose was to evaluate the performance of these systems in a realistic fire and the mode of failure of three different load-bearing floor systems (with a nominal 60 minutes fire resistance). It was concluded that engineered floors (engineered I-section and truss joints floors, see explanation in [43]) may be able to offer the same fire resistance as that of solid timber joists floors provided they are properly protected, but some engineered joists may fail in a more rapid manner than solid timber joists. SIP system generally meet the performance requirements and SIP wall panels showed no collapse or deflection of wall members.

Some other studies using various fire curves demonstrated that assemblies could fail at significantly different times compared with that from the standard tests. Jones [45] conducted five pilot-scale furnace tests and investigated the fire resistance of light steel frame wall assemblies subjected to five different furnace time-temperature curves, including the standard ISO834 fire curve and four non-standard fire curves. He found that the fire resistance of the wall was reduced by almost $50 \%$, when subjected to the most severe fire that simulates a natural fire curve. In another study, Nyman [30,46,47] performed three full scale fire tests that allowed simultaneous testing of various non-load- 
bearing lightweight timber and steel framed walls and ceiling/floor systems. He reported that the failure times of the typical light timber/steel framed assemblies, when exposed to more severe realistic fires, were significantly less than the fire resistance ratings derived from the standard tests. Light steel framed plasterboard wall assemblies subjected to realistic fires failed on the integrity criterion rather than the insulation criterion that caused failure in the standard test.

There are a limited number of studies that investigated the fire contribution of combustible room structures in real fires. A study by Frangi et.al [48] presented results of full-scale tests on wooden modular hotels performed under natural fire conditions, and showed that when rooms were lined with combustible linings, a significant amount of the in-room pyrolysis gases burnt outside the window area. This effect was well illustrated by the failure times of the standard double glass windows installed above the window of the fire room. Glass windows failed at about 7 minutes after ignition in this case, but they failed at about 40 minutes when the fire room was protected by gypsum boards. Hakkarainen [49] conducted 4 full-scale fire tests, three of which were constructed with heavy laminated timber and one of which was light timber frame construction. Using energy balance analysis she discovered that the fire contribution of the wood structure was significant and greatly enhanced external combustion.

Since the early 2000's interest to use Cross Laminated Timber (CLT) in construction has increased dramatically through a number of drivers including the green building movement, changes in code and improved business initiatives. The use of CLT in North America is gaining interest in both the construction and wood industries [50]. CLT panels have the potential to provide good fire resistance, often comparable to typical massive assemblies 
of non-combustible construction. CLT is a preferable engineered product to be used in midand high-rise buildings [51]. Experimental studies on the fire performance of CLT panels have been mainly conducted in furnaces and under standard fires. Such studies include the small-scale furnace tests on the charring behaviour of CLT panels conducted by Frangi et.al $[52,53]$, and the small-scale and full-scale furnace fire resistance tests conducted in Canada [54]. A natural full-scale fire test on a three storey CLT building reported by Frangi [55] concluded that with the protection of gypsum boards the damage of CLT panels was relatively small and the fire spread could be contained within the room of fire origin.

Besides the fire tests of wall or floor assemblies, there are also investigations of fire resistance of door in natural fires. Joyeux [56] argued that building components assessed according to standard fire lack the knowledge of their performance under real fires. Two natural fire tests were performed to study the behaviour of fire doors, a steel door and a wooden door, respectively. The results of these tests and comparisons with the ISO-fire results were discussed. A comparison of the failure times in the ISO fire and the natural fires are listed in Table 2-3.

Table 2-2 A comparison of failure times of two types of fire doors in the ISO fire and natural fires in Joyeux's study [56]

\begin{tabular}{|c|l|l|l|}
\hline \multirow{3}{*}{ Steel door } & Failure type & $\begin{array}{l}\text { Failure time in ISO } \\
\text { fire (mins) }\end{array}$ & $\begin{array}{l}\text { Failure time in } \\
\text { natural fire* (mins) }\end{array}$ \\
\hline \multirow{2}{*}{ Wooden door } & Integrity & 70 & $<10$ \\
\cline { 2 - 4 } & Insulation & $\begin{array}{l}52 \text { on the Frame } \\
64 \text { on the Leaf }\end{array}$ & $\begin{array}{l}10 \\
\text { NOT REACHED }\end{array}$ \\
\cline { 2 - 4 } & Integrity & 37 & $<16$ \\
\cline { 2 - 4 } & Insulation & 37 & $<16$ \\
\hline
\end{tabular}

*The smouldering time of fire source was deducted, considering only the fully developed part of the fire. 


\subsubsection{Wood charring in natural fire}

For building assemblies that contain timber components, it is important to know their charring behaviour in fires. Charring of timber components may affect the ability of a building assembly to contain a fire, and sometimes timber members might get involved in the fire and contribute to room fire severity. For the standard fire exposure, Eurocode 5 [57] specified design charring rates for surfaces of timber and wood-based materials, unprotected throughout the time of fire exposure. Design charring rates $\beta_{0}$ and $\beta_{n}$ are given in Table 2-3.

Table 2-3 Design charring rates of timber, LVL, wood panelling and wood-based panels in Eurocode $5[57]$

\begin{tabular}{|c|c|c|}
\hline & $\beta_{0}(\mathrm{~mm} / \mathrm{min})$ & $\beta_{n}(\mathrm{~mm} / \mathrm{min})$ \\
\hline $\begin{array}{l}\text { a) Softwood and beech } \\
\text { Glued laminated timber with a characteristic density of } \\
290 \mathrm{~kg} / \mathrm{m}^{3}\end{array}$ & 0.65 & 0.7 \\
\hline Solid timber with a characteristic density of $290 \mathrm{~kg} / \mathrm{m}^{3}$ & 0.65 & 0.8 \\
\hline $\begin{array}{l}\text { b) Hardwood } \\
\text { Solid or glued laminated hardwood with a characteristic } \\
\text { density of } 290 \mathrm{~kg} / \mathrm{m}^{3}\end{array}$ & 0.65 & 0.7 \\
\hline $\begin{array}{l}\text { Solid or glued laminated hardwood with a characteristic } \\
\text { density of } \geq 450 \mathrm{~kg} / \mathrm{m}^{3}\end{array}$ & 0.50 & 0.55 \\
\hline $\begin{array}{l}\text { c) } \mathbf{L V L} \\
\text { with a characteristic density of } 480 \mathrm{~kg} / \mathrm{m}^{3}\end{array}$ & 0.65 & 0.7 \\
\hline $\begin{array}{l}\text { d) Panels } \\
\text { Wood panelling } \\
\text { Plywood } \\
\text { Wood-based panels other than plywood } \\
\text { (The above values apply to a characteristic density of } \\
450 \mathrm{~kg} / \mathrm{m}^{3} \text { and a panel thickness of } 20 \mathrm{~mm} \text { ) }\end{array}$ & $\begin{array}{l}0.9 \\
1.0 \\
0.9\end{array}$ & $\begin{array}{l}- \\
-\end{array}$ \\
\hline
\end{tabular}

Nyman [30] performed three full-scale fire tests and found that for fires more severe than the standard furnace test fire exposure, charring rates can be significantly higher than the design charring rates applied. Charring rates of wood studs in two of the tests reached 1.07 $\mathrm{mm} / \mathrm{min}$, showing that the standard rate of charring $(0.65 \mathrm{~mm} / \mathrm{min})$ used in design would 
be insufficient for fires of severity greater than the standard fire test severity. However, it should be noted that the wood stud was exposed to the fire on three sides during these tests. Frangi et.at $[52,53]$ tested the charring behavior of CLT panels subjected to the ISO 834 fire and found that the fire behaviour of multilayer timber panels was strongly influenced by the thickness and the number of layers of CLT panels. The falling off of the charred layers observed during the fire tests led to an increase of the charring rate of the crosslaminated timber panels compared to homogenous timber panels. Cross-laminated timber panels with thick layers showed better fire behaviour compared to cross-laminated timber panels with thin layers. Moreover, when the specimens were manufactured with a less temperature-sensitive adhesive, the charred layers almost remained in place until the end of the fire tests.

\subsection{Methods to determine fire resistance of building assemblies}

In order to avoid the high cost of the fire resistance tests, many fire resistance models have been developed to predict the fire behavior of building assemblies. Some of them are numerical models employing two- or three-dimensional heat or mass transfer processes, sometimes considering thermal and mechanical properties of materials at elevated temperatures. After reviewing the existing numerical models, Benichou et.al [58] suggested that most models have some limitations in modeling both the thermal and structural behavior, although good correlation between their model prediction and test results were reported. Besides, Jones [45] pointed out that modeling of the fire resistance of (gypsum board) assemblies subjected to realistic fires needs further work although significant research and model development have been done in this field.

Despite the fact that numerical fire resistance or barrier failure models are becoming more 
and more useful, especially with high performance computers, in some cases designers might prefer easy-to-use mathematical models rather than time-consuming numerical solutions. On one hand, simple mathematical models can be used in a large model that requires quick access of the results such as the fire risk analysis model CUrisk; on the other hand, comprehensive mathematical models can be used to deal with multi-types of building components at the same time, easily switching among several construction types, for instance, light timber/steel-frame, heavy timber, concrete and steel construction.

Some simple fire resistance or barrier failure models are reviewed in this section, including time equivalence methods, probabilistic approaches, Component Additive Method and Eurocode method and others.

\subsubsection{Equivalent time of fire exposure}

For almost a century the fire resistance rating of building construction elements was obtained through standard fire tests that subject the elements to a standard fire curve. However, it is always a concern that a standard fire cannot represent real fire severity which could be much more severe and elements could fail earlier than what the fire resistance ratings suggest. One approach to evaluate the fire resistance in real fires is called the equivalent time of fire exposure or simply time equivalence. It is defined as the equivalent exposure time of a building element in a standard fire when the element is subjected to a real fire.

After reviewing all the time equivalence methods, it is found that those methods can be divided into three different categories: equal area, equal temperature and equal energy.

\subsubsection{Equivalent area concept}

The pioneering work to relate fire resistance to fire severity was done by Ingberg [59]. He 
proposed that fire severity can be related to fire resistance requirements by the so-called "equal area hypothesis". It was assumed that if at certain times the areas under different time-temperature curves above a baseline of $300^{\circ} \mathrm{C}$ are equal then the fire severities are equal. By comparing with the areas under the standard fire curve, time equivalence can be obtained. This approach is deemed to have no theoretical or technical basis. One well known shortcoming is that the dominant heat transfer to building elements during a compartment fire is radiation [60]; the other reason is that a short hot fire might bring about structural damage while a long cool fire could possibly cause no damage. Nevertheless, he identified fire load as an important factor of fire severity and it has become an important parameter in fire modelling and design.

\subsubsection{Equivalent temperature concept}

More realistic approaches were proposed later. They were not based on an equal area concept, but to define the equivalent fire severity as the time of exposure to the standard fire that would cause the same temperature in a protected steel member during a complete burnout of a compartment fire. Law [61,62] developed an empirical model to predict the time equivalence of protected steel members in a real compartment fire, by considering the fire load and opening conditions of the fire room. Pettersson [63] developed a model for steel structures that took properties of compartment boundaries into consideration besides fire load and ventilation conditions.

The two main time equivalent formulae for structural fire resistance, commonly used for fire engineering design are the CIB formula [64] and the Eurocode formula [37]. The CIB formula is an empirical expression for equivalent fire severity, based on experiments on insulated steel members exposed to fires in concrete lined compartments. For the CIB 
formula, the time equivalent to an ISO834 fire is written as follows [64],

$$
t_{e}=k_{c} w_{f} q_{f}
$$

where $k_{c}$ is a parameter to account for different compartment linings, $\min \cdot \mathrm{m}^{2.25} / \mathrm{MJ}$; $q_{f}$ is the fuel load density $\left(\mathrm{MJ} / \mathrm{m}^{2}\right)$ based on floor area; $w_{f}$ is the ventilation factor, defined as [64],

$$
w_{f}=\frac{A_{f}}{\left(A_{w} A_{t} H_{v}^{0.5}\right)^{0.5}}
$$

where $A_{f}$ is the floor area of the compartment, $\mathrm{m}^{2} ; A_{w}$ is the total opening area, $\mathrm{m}^{2} ; A_{t}$ is the total area of compartment interior surface, $\mathrm{m}^{2} ; H_{v}$ is the opening height, $\mathrm{m}$.

It should be noted that the CIB formula is only valid for compartments with vertical wall openings.

The Eurocode formula is an improvement on the CIB formula, where the equivalent time of the ISO fire is expressed as follows [37],

$$
t_{e, d}=\left(q_{f, d} \cdot k_{b} \cdot w_{f}\right) k_{c}
$$

Where $t_{e, d}$ is time equivalence in minutes; $q_{f, d}$ is the design fire load density based on floor area, $\mathrm{MJ} / \mathrm{m}^{2} ; k_{b}$ is a conversion factor which is related to the thermal properties of the enclosure lining materials, and appropriate values of the factor can be chosen based on the so-called b value (thermal inertia). $k_{c}$ is a correction factor corresponding to reinforced concrete, protected steel and unprotected steel. $w_{f}$ is a ventilation factor that can be calculated as below [37],

$$
w_{f}=\left(\frac{6.0}{H}\right)^{0.3}\left[0.62+\frac{90\left(0.4-\alpha_{v}\right)^{4}}{1+b_{v} \alpha_{h}}\right] \geq 0.5
$$


With [37],

$$
a_{v}=A_{v} / A_{f}, a_{h}=A_{h} / A_{f}, b_{v}=12.5\left(1+10 \alpha_{v}-\alpha_{v}^{2}\right) \geq 10.0
$$

where, $A_{v}$ is the area of vertical openings in the façade; $A_{f}$ is the compartment floor area; $A_{h}$ is the area of horizontal opening in the roof; $\mathrm{H}$ is the height of the compartment, $\mathrm{m}$.

For small fire compartments of floor area less than $100 \mathrm{~m}^{2}$ without a roof opening, the ventilation factor can be calculated as [37],

$$
w_{f}=O^{-1 / 2} \cdot A_{f} / A_{t}
$$

where $O$ is the opening factor defined as $O=A_{v} \sqrt{h_{e q}} / A_{t}$.

Finally it should be verified that the equivalent time $t_{e, d}$ is less than the design value of the standard fire resistance of the members and this method is not applicable to composite steel and concrete or timber construction.

It can be seen that both the CIB and Eurocode formulas are dependent on fire load density, opening area, floor area and total enclosure area, and the difference is that Eurocode formula also considers ceiling height. There is no published data as to the derivation process, but it was mentioned in Reference [65] that it came from an empirical analysis of calculated steel temperatures based on simulated fire curves.

There are disputes about the validity of those equivalent models. Law [62] stated that none of the above formulas gave satisfactory results after applying those models to fire test data with deep well-insulated compartments; they did not differentiate between a short hot fire and a longer cooler fire. Jones [45] conducted a series of room fire tests on light-frame assemblies and then examined the equivalent area concept based on the obtained test results. He stated that the equivalent area concept provides a good prediction of the failure 
time for assemblies that are subjected to fire curves less severe than the standard curve, e.g., fires with moderate growth, low peak temperature, and long duration. However, failure time prediction for systems exposed to rapid growth fires with greater severity than the standard curves is poor.

The applicability of the above time-equivalence methods relies on the type of constructions. Thomas et.al [65] checked the performance of the Eurocode formula by comparing its results with time equivalent method based on member temperatures calculated by numerical heat transfer models. Regardless of the accuracy of these numerical results, he found that the Eurocode formula showed scattered prediction for concrete and steel members, and especially light timber-frame members. In part the scattered result from how those methods are proposed. As mentioned earlier, the assessment of equivalent exposure in the CIB and Eurocode methods is mainly empirically based and compares the maximum temperature of a protected steel member achieved with that same temperature achieved in the standard test. Although this may hold for structural members sensitive to critical temperature, it is unlikely valid for construction components such as timber members and drywalls whose failures are not sensitive to maximum temperature.

\subsubsection{Equivalent energy concept}

\subsection{The normalized heat load method}

Another approach to correlate real world fires with standard fires is the Normalized Heat Load concept proposed by Harmathy and Mehaffey [66-69]. They argued that heat transfer into compartment boundaries was mainly radiative energy, and a simple integral of temperature curves could not represent the overall effect of fire gases on the boundaries. The normalized heat load concept was thus proposed, which focused on heat absorbed by 
the building element per unit surface area in compartment fires, and then used the amount of heat absorption to compare the destructive potential of real world fires and the standard fire. The normalized heat load was defined as follows [67],

$$
H=\frac{1}{\sqrt{k \rho c}} \int_{0}^{\tau} q \cdot d t
$$

where, $\sqrt{k \rho c}$ is the thermal inertia of the compartment inner surface boundaries, $k$ $(\mathrm{W} / \mathrm{m} \cdot \mathrm{K}), \rho\left(\mathrm{kg} / \mathrm{m}^{3}\right), c(\mathrm{~J} / \mathrm{kg} \cdot \mathrm{K})$ are thermal conductivity, density and specific heat. $q$ is heat flux (per unit area) absorbed by the enclosure boundaries and $\tau$ is the duration of the fire.

Harmathy and Mehaffey [67] designed a procedure to calculate the "potential of destruction scale", which indicate the equivalent time duration of building elements exposed to a standard test when the elements were subjected to real and arbitrary compartment fires. To get the equivalent time of exposure, the normalized heat load $H$ in the real compartment fire should be first calculated, and then find the time when the normalized heat load in the standard fire is equal to the calculated $H$ in the real fire. The obtained time $\tau$ is the equivalent time of fire exposure.

For real compartment fires with cellulosic fuels, Harmathy [70] developed an iterative procedure to obtain the normalized heat load, by considering fire severity parameters including air mass flow rate, rate of burning, average rate of evolution of energy, average fire temperature, characteristics of fuel, compartment geometry and surface material properties. Instead of the complex iterative method, Mehaffey [67] proposed a simpler semi-empirical equation to calculate the normalized heat load as shown below [67], 


$$
H=10^{6} \frac{(11.0 \delta+1.6) G}{A_{t} \sqrt{k \rho c}+935 \sqrt{\Phi G}}
$$

where, $G$ is total fuel mass, $\mathrm{kg} ; \delta(\leq 1)$ is a factor that accounts for the fact that not all the heat in a compartment fire is released inside the room, which can be estimated by [67],

$$
\delta=0.79 \sqrt{h_{c}{ }^{3} / \Phi} \text { or 1,whichever is less }
$$

$\Phi$ is related to the ventilation condition of the compartment, defined as [67],

$$
\Phi=\rho_{a} A_{v} \sqrt{g h}
$$

where $\rho_{a}$ is the density of ambient air $\left(\mathrm{kg} / \mathrm{m}^{3}\right), A_{v}$ is the opening area $\left(\mathrm{m}^{2}\right) ; h$ is the height of the ventilation opening (m). An example of a practical application using this method to rubber tyre houses can be found in reference [71].

The normalized heat load concept is based on the effect of heat flux on the surface of building elements, which is more advanced than the time equivalent models reviewed earlier, as other models were basically correlations based on limited experimental tests and related the fire severity with just the fire load and ventilation conditions. However, some limitations of the concept being discussed should also be noted. One limitation is that, as pointed out by Harmathy himself [68], the normalized heat load concept cannot be applied to load bearing building elements and exposed steel. The other point $[58,72]$ is that the normalized heat load concept was developed based on one dimensional heat flow into a semi-infinite slab with constant thermal properties, but this basis may not be right for thin sheet materials such as gypsum board. Besides the above, the theoretical basis and applicability of the method are unknown when the building elements consist of multi-layer components such as light frame construction.

Harada's time - heat flux area method [73] 
Harada et.al [73] proposed a simple formula to calculate the equivalent time of fire exposure, based on the equivalency in time - heat flux area, by assuming that the behaviour of a building element is identical if the amount heat absorbed by the surface is the same. The equivalent time of fire exposure under a design fire to the ISO 834 standard fire is as follows [73],

$$
t_{e q}=\left(\frac{\beta}{230}\right)^{\frac{3}{2}} t_{D}
$$

where, $t_{e q}$ is the time equivalence in minutes or hours; $t_{D}$ is the duration of the design fire, $\beta$ is the fire severity coefficient, $\mathrm{K} / \mathrm{s}^{1 / 6}$.

For ventilation controlled fire, $\beta$ is calculated by [73],

$$
3.0 T_{0}\left(A_{w} \sqrt{H_{w}} / A_{T} \sqrt{k \rho c}\right)^{1 / 3}
$$

For fuel surface controlled fire [73],

$$
\beta=0.022 T_{0} \frac{\dot{Q}^{\frac{2}{3}}}{\left(A_{T} \sqrt{k \rho c} A_{w} \sqrt{H_{w}}\right)^{1 / 3}} t^{1 / 6}
$$

where, $\dot{Q}$ is the heat release rate of the room fire $(\mathrm{kW}), T_{0}$ is the ambient temperature $(\mathrm{K})$, AT is the total internal area of the room $(\mathrm{m} 2), A_{W}$ and $H_{W}$ are the width and height of the opening (m). For the ISO 834 fire, $\beta=230 \mathrm{~K} / \mathrm{s}^{1 / 6}$.

The author also checked the accuracy of the formula against one dimensional numerical calculation of the heat flux history for thermally thin and thick walls, and further checked against the experimental test data as well. The results showed reasonable estimation during heating period.

Kodur's absorbed energy method [74,75]

Kodur [74,75] proposed an energy-based time equivalence method for evaluating the fire 
resistance of reinforced concrete beams under design fire scenarios, and established equivalency between standard and design fire exposures. He assumed that two fires would have the same fire severity if the same amount of energy is transferred into the beam, which involves heat transfer via convection and radiation. Knowing the area of the boundary exposed to the fire, the amount of energy transferred to the beam can be calculated as $[74,75]$,

$$
E=\eta A \int\left(4 \sigma \varepsilon T_{f}^{4}+h_{c} T_{f}\right) d t
$$

where, $A$ is the area of the boundary exposed to fire, $\mathrm{m}^{2} ; T_{c}$ is the temperature on surface of boundary, $\mathrm{K} ; \eta$ is constant defined with $\eta T_{f}=T_{f}-T_{c} ; h_{c}$ is the convective heat transfer coefficient, $\mathrm{W} / \mathrm{m}^{2} \mathrm{~K}$.

And a design fire will have the same fire severity as the standard fire if the total energy transfer under the design fire is the same as that of the standard fire.

From the above it can be found that the energy transfer is a function of the fire temperature or fire curve. But it should be noted that this energy based approach can only be applied if the compartment temperature can be assumed as uniform and convective heat transfer coefficient and emissivity are homogeneous along the surface of structure component (an emissivity $\varepsilon=0.5$ and convective heat transfer coefficient $h_{c}=25 \mathrm{~W} / \mathrm{m}^{2} \mathrm{~K}$ were used).

To verify the proposed method, he conducted analysis of four types of reinforced concrete beams under one standard fire and 17 design fires to calculate the time equivalence values, using various methods including the present method, finite element analysis, equivalent area method, Law's method, CIB method, and Eurocode method. Results showed that time equivalence values predicted by equal area method, Law's, CIB and Eurocode methods provided non-conservative results with significant variations. The time equivalence values 
predicted by this method showed less variation compared to others, and they were on the conservative side.

\subsection{Cumulative Radiative Energy Method}

Knowing the weakness of traditional time equivalent methods introduced in Section 2.3.1.1 and Section 2.3.1.2 and acknowledging that the dominant way of heat transfer in a compartment fire is radiant energy, Nyman $[30,46,47]$ proposed a new method that can predict the equivalent time of failure of building elements by using a cumulative radiative energy $E$, which is expressed as below,

$$
E=\int_{0}^{t} \dot{Q}^{\prime \prime}(t) d t=\varepsilon \sigma \int_{0}^{t} T^{4}(t) d t
$$

where, $E$ is the cumulative radiative energy received by a building element over a period of time, $\mathrm{J} / \mathrm{m}^{2} ; \dot{Q}^{\prime \prime}(\mathrm{t})$ is the radiant heat flux upon the surface of building elements at time $t$ (in seconds), $\mathrm{W} / \mathrm{m}^{2} ; \varepsilon$ is the emissivity (taken as 1 ); $\sigma$ is Stefan Boltzmann constant $\left(5.67 \times 10^{-8} \mathrm{~W} / \mathrm{m}^{2} \mathrm{~K}^{4}\right) ; T(t)$ is compartment gas temperature $(\mathrm{K})$ at time $t$.

It was stated that if the temperature history in the real compartment fire and the time of failure of a building element ( $\left.t_{\text {ISOfail }}\right)$ in a standard fire test were known, the equivalent failure time of the same element in the real fire $\left(t_{\text {fail }}\right)$ can be predicted. By using this method, Nyman compared the building assembly failure times in natural fire tests with predicted failure times. The author found that this method could conservatively predict the insulation failure times of light timber-framed assemblies, but overestimate the integrity failure times of light steel-framed assemblies when the failure was due to deformation of the steel studs. It was assumed that compartment and standard furnace fires had similar heat transfer coefficients and equal proportion of convective heat transfer to total energy transfer. This 
method is similar to the normalized heat load concept but it ignores the effects of thermal properties of building element surfaces and the construction types. For the range of application, Nyman [76] declared that this method was designed to predict the insulation failure of building elements of cavity drywall construction, and should not be applied to assess structural failure and integrity failure.

\subsubsection{Probabilistic approaches}

\subsubsection{Barrier Failure Model in FiRECAM}

The comprehensive fire risk assessment model FiRECAM was introduced earlier in Section 2.1.1. It contains a Barrier Failure submodel that was described in [77]. This Barrier Failure model is based on the time equivalence method (CIB W14, see Section 2.3.1.2) and probabilistic theory, and can eventually produce a time-independent failure probability of a building element, and thus can be further used in the Fire Spread submodel. The cumulative probability was written as shown below [77],

$$
P_{f}=1-\Phi\left(\frac{F R R-\mu}{\sigma}\right)=\frac{1}{\sqrt{2 \pi} \sigma} \int_{F R R}^{+\infty} \exp \left(-\frac{(t-\mu)^{2}}{2 o^{2}}\right) d t
$$

This barrier failure model recognizes the fact that failure of a building element may differ from what happens in real fires and transforms the deterministic nature of the timeequivalence model into a probabilistic one. However, this model inherited the weakness of the time equivalent models (CIB W14), that is, the neglect of detailed structure components of the barrier. Furthermore, the probabilistic distribution of failure time is derived from the probabilistic distribution of the fire load density, which, however, comes from statistical data and contains large uncertainties. 


\subsubsection{Barrier Response model in CESARE-Risk}

An optional Barrier Response model [21] is provided in the fire risk assessment model CESARE-Risk (see Section 2.1.3), which can predict the probability of barrier failure in case of severe fires where fire spread may occur. This model can estimate the time dependent probability of failure of wood-framed walls in standard and real fires. It incorporates a time-to-failure model into a Monte Carlo loop by a probability model.

The time-to-failure model numerically simulates the thermal and structural behavior of a light wood framed wall that is exposed to a real fire, including three submodels: fire severity, heat transfer and structural response. The fire severity submodel predicts fire gas temperature, and the heat transfer submodel uses a finite difference method to calculate the conductive heat transfer through solid materials as well as discrete radiative heat transfer through cavities. The structural submodel determines the overall flexural stiffness of wall cross-sections using composite section theory.

The probability model repeats the time-to-failure model for a required number of simulations. It generates values for input random variables at ambient conditions, including thermal properties of wood and gypsum boards (such as density), mechanical properties of timber (such as tensile strength) and structural loads (such as dead load). After the Monte Carlo analysis, the cumulative probability of failure with time for each failure mode (insulation, integrity and structure) is found by summing up the number of failures before a given time and then the sum is divided by the total number of runs. The overall cumulative probability of failure is the joint probability of the three failure modes.

This model has the following drawbacks: a) given a specific building assembly, the thermophysical properties of the assembly components should not be treated as random variables; 
b) the reactions of assembly components such as the fall-off of gypsum boards were not accounted for in this model, but those phenomena would change the construction of the assembly and pattern of heat transfer, thus affecting the failure times; c) this model needs too many input parameters and requires difficulties to find probability distribution of these parameters; d) this model can only be used for light wood frame constructions; and e) the accuracy of the time-to-failure model when real fires are modeled is not known as no validation study was found. Given these weaknesses and complexity this model is not suitable for incorporation in a comprehensive fire risk assessment model.

\subsubsection{Probability based fire resistance design}

Yaping He [78-80] proposed a risk-based probabilistic method to calculate the failure probability of fire resistance design. The design parameters of fire resistance level and fire severity are treated as random parameters. Fire severity is a measure of fire intensity in terms of equivalent time of fire exposure to the standard fire, denoted as random variable $S$. Fire resistance level means the a building element's capacity to withstand the fire attack in terms of survival time in the standard fire test, denoted as variable $R$. Failure occurs when the severity of fire exceeds the fire resistance of the building element: $S>R$.

In this study, both $S$ and $R$ were regarded as continuous random variable with probabilistic density distribution function $f(t)$ and $g(t)$, and probability function $F(t)$ and $G(t)$, and the probability of failure was,

$$
P_{f}=P(\infty)=1-\int_{0}^{\infty} f(r) G(r) d r
$$

The technique that treats fire resistance of a barrier and fire severity as two random variables is not a new concept, though. Ramachandran [81] assumed that both random 
variables $R$ and $S$ had a normal probability distribution, with means $\bar{R}$ and $\bar{S}$ and standard deviations $\sigma_{R}$ and $\sigma_{S}$. If the two random variables are independent, then the safety margin $W=R-S$ also follows a normal distribution with mean $u_{W}=\bar{R}-\bar{S}$, and standard deviation $\sigma_{W}=\sqrt{\sigma_{R}^{2}+\sigma_{S}^{2}}$. Then the ratio of mean and standard deviation of the safety margin, which is called the safety index $\beta$ by He [78], was defined as,

$$
\beta=\frac{u_{W}}{\sigma_{W}}=\frac{\bar{R}-\bar{S}}{\sqrt{\sigma_{R}^{2}+\sigma_{S}^{2}}}
$$

Further, the ratio of mean value of $\mathrm{R}$ and $\mathrm{S}$, which is called the safety factor $\lambda$ by He [78], was obtained,

$$
\lambda=\frac{\bar{R}}{S}=\frac{1+\beta r \sqrt{2-\beta^{2} r^{2}}}{1-\beta^{2} r^{2}}
$$

And $r$ is a coefficient of variation for both $R$ and $S$. when $\lambda=1$, the probability of barrier failure is 0.5 ; when $\lambda>1$, the probability of failure is less than 0.5 ; and when $\lambda<1$, the probability is greater than 0.5 .

This method is too conceptual and the determination of R and S is very hard when it is applied to specific fire scenarios, because there are too many factors affect the fire severities and the fire resistance of building assemblies.

\subsubsection{Component additive method (CAM)}

Traditionally Fire Resistance Ratings of building assemblies were obtained from standard tests. An alternative method to determine the fire resistance ratings of building elements is called the Component Additive Method (CAM). CAM is permitted as an alternative method of determining the fire resistance rating of load-bearing light wood-frame floor and roof assemblies, and load-bearing and non-load-bearing light wood-frame wall assemblies, 
as described in the National Building Code of Canada (NBCC) [82], Division B, Appendix D, Fire-Performance Ratings.

CAM was developed by the National Research Council of Canada, based on a large number of test data. It uses principles described in Harmathy's Ten Rules of Fire Endurance Rating [83], and determines the fire resistance rating by adding assigned time values of components of assembly such as gypsum board, wood studs, insulation, when the specification and arrangement of materials comply with nationally recognized standards, as listed in the NBCC.

Richardson and Batista [84] "revisited" the component additive method by using results of 22 fire endurance tests. For one thing, they argued that it should be clarified whether the time assigned to exposed membrane linings should be based on integrity criteria or insulation criteria, because deflection of structural members during tests usually results in falling of the gypsum boards in load-bearing walls. For another, it was questioned whether the contribution of rock-fibre insulation was reasonably accounted for in non-load bearing wood-frame walls and steel-frame walls.

It should be noted that CAM is a method to estimate the fire resistance rating of light frame assemblies, and it cannot be used to predict the fire resistance of building elements in arbitrary fires. Nevertheless, it shed light on the point that evaluation of barrier failure should account for the contribution of individual components of the building elements. It might not be appropriate to just look at the thermal properties of fire exposed assembly surfaces, which are adopted by the time equivalent methods.

Eurocode method for timber frame wall and floor assemblies in standard fire exposure [57] Eurocode 5 [57] divides the wall and floor assemblies into load-bearing construction, 
separating construction, and load-bearing and separating constructions. A design method is provided to analyze the separating function of the timber frame wall and floor assemblies, by taking into account the contributions of different material components and their position in the assembly. This method is given in Annex E of [57] and only applies for standard fire exposure not exceeding 60 minutes.

In the Eurocode method, the insulation time of a building construction is calculated as the sum of the contributions of the insulation layers used in the construction, which are a function of basic insulation value of each layer $i, t_{i n s, i}$ in minutes, a position coefficient $k_{p o s}$, and a joint coefficient $k_{j}$, as the equation below,

$$
t_{i n s}=\sum_{i} t_{i n s, i} k_{p o s} k_{j}
$$

The layer denotes the components of timber frame wall or floor assembly, including timber stud, panel, void cavity, cavity insulation. Panels considered include plywood, particleboard and fiberboard, wood panelling and gypsum board. The basic insulation value of layer $t_{i n s, i}$ is determined as a function of the layer thickness and/or density. The position coefficient of each layer is given based on the position of the layer, for example, on the fire exposed side or unexposed side as well as number of layers. The effects of joints are considered depending on whether the panel joint is backed with a batten, stud or joist.

Similar to the Component Additive Method (CAM), the Eurocode method described above is used to estimate the fire resistance of light frame constructions in the standard fire exposure. Both of the two methods estimate the fire resistance of the light frame constructions based on their detailed structure, i.e., contribution of each layer or component. In comparison, the Eurocode method determines the insulation value of each layer in a more sophisticated way, i.e., it considers the effects of layer type, thickness, position and 
joints, rather than a simple time assignment in the CAM. However, it is not clear about the validity and verification of those calculations. 


\section{Chapter 3 Modelling of Fire Spread in CUrisk}

Fire spread from the compartment of fire origin to other compartments in a building needs to be considered as part of the fire risk analysis calculations. It was determined either through external model or expert estimates. A fire spread model has been developed at Carleton University [8] to calculate the fire spread process in building fires. However, the fire spread model was not incorporated into CUrisk.

In this chapter, details of the Fire Spread model developed by Cheng [8] are provided and the role of this model as a submodel of CUrisk is identified and changes to CUrisk are presented. At last, a case study is given using the improved CUrisk.

Brief introduction of the existing Fire Spread model [8]

Cheng [8] developed a dynamic fire spread model which is based on the Bayesian network approach, and can predict the probability of fire spread across a building with time. This submodel actually contains both a boundary failure and a fire spread module. To enhance the performance of CUrisk, as part of this research, the fire spread model has been incorporated into CUrisk. Some details of this submodel are given in this section.

It was assumed that fire spread from the fire compartment to an adjacent compartment includes two processes: failure of the barrier between the two compartments and fire growth to a fully-developed fire in the adjacent compartment. Barrier failure refers to the situation where fire severity overcomes the fire resistance of the barrier between the two compartments, and transfers to the adjacent compartment where it ignites combustible material. The process of fire growth to a fully-developed fire means that the fire in the adjacent compartment after ignition grows to a fully-developed fire. 
The probability of fire spread from compartment B to compartment A was written as [8],

$$
\begin{gathered}
P(a \mid b)=P\left(a \mid a^{\prime}\right) P_{i g}\left(a^{\prime} \mid b\right) \\
P_{i g}\left(a^{\prime} \mid b\right)=P\left(a^{\prime} \mid b\right) P(b)
\end{gathered}
$$

If a target room has several adjacent fire compartments, heat could be transferred to this room simultaneously from all the adjacent fire compartments, which will increase the probability of ignition of the combustible materials in the target room. Assuming that compartment A has two adjacent fire compartments B and C, the probability of fire spread to compartment $\mathrm{A}$ due to fire in compartments $\mathrm{B}$ and $\mathrm{C}$ were written as,

$$
\begin{gathered}
P(a \mid b, c)=P\left(a \mid a^{\prime}\right) P_{i g}\left(a^{\prime} \mid b, c\right) \\
P_{i g}\left(a^{\prime} \mid b, c\right)=P\left(a^{\prime} \mid b\right) P(b)+P\left(a^{\prime} \mid c\right) P(c)-P\left(a^{\prime} \mid b\right) P\left(a^{\prime} \mid c\right) P(b) P(c)
\end{gathered}
$$

In the above equations, $P(a \mid b)$ is the probability of fire spread from compartment $\mathrm{B}$ to compartment $\mathrm{A} ; P\left(a \mid a^{\prime}\right)$ is the probability of fire growth from ignition to a fully-developed fire in compartment $\mathrm{A} ; P_{i g}\left(a^{\prime} \mid b\right)$ is the probability of fire ignition in compartment $\mathrm{A}$ due to heat transfer from fire compartment $\mathrm{B} ; P\left(a^{\prime} \mid b\right)$ is the probability of barrier failure indicating the probability that heat is transferred from the fire compartment $\mathrm{B}$ to the adjacent compartment $\mathrm{A}$ and ignites the combustible materials in compartment $\mathrm{A} ; P(b)$ is the probability that a fully-developed fire occur in compartment B. Others can be interpreted similarly.

It was assumed that both the probability of barrier failure and the probability of fire growth to a fully-developed fire follow the properties of a normal distribution. The cumulative probability of barrier failure was written as,

$$
p_{b f}(t)=\int_{t_{f o}}^{t} \frac{1}{\sigma_{b f} \sqrt{2 \pi}} \exp \left(-\left[\left(t-t_{f o}\right)-\mu_{b f}\right]^{2} / 2 \sigma_{b f}^{2}\right) d t \quad\left(0 \leq t-t_{f o} \leq \tau_{f d}\right) \quad \text { Equ.(3.5) }
$$


where, $t_{f o}$ is the time of flashover in the fire compartment, in minute; $\mu_{b f}$ is the mean time of failure of a barrier linking the fire compartment to an adjacent compartment, in minute; $\sigma_{b f}$ is the standard deviation time of failure; $\tau_{f d}$ is the duration of the fullydeveloped fire period in the fire compartment, in minute.

The fire resistance of a building assembly was determined based on a time equivalence method [73], and the mean and standard deviation of the fire resistance to a fully developed compartment fire for the assembly was calculated as shown below,

$$
\begin{gathered}
\mu_{b f, i}=\frac{\mu_{F R R, i}}{(\beta / 230)^{3 / 2}} \\
\sigma_{b f, i}=\frac{\sigma_{F R R, i}}{(\beta / 230)^{3 / 2}}
\end{gathered}
$$

where, $\mu_{F R R, i}$ is the mean of the duration of fire resistance to the standard ISO 834 fire for assembly $i$, which is the same as Fire Resistance Ratings of the assembly (in minute); $\sigma_{F R R, i}$ is the standard deviation of the duration of fire resistance to the standard ISO 834 fire for assembly $i$, in minute; $\mu_{b f, i}$ is the mean of the time to failure (in minute) in a fully developed compartment fire for assembly $i ; \sigma_{b f, i}$ is the standard deviation of the time to failure in a fully developed compartment fire for assembly $i$. The parameter $\beta$ is given by the equation shown below [8],

$$
\beta=3.0 T_{0}\left(\frac{A_{o} \sqrt{H_{o}}}{A_{T} \sqrt{k \rho c}}\right)^{1 / 3}
$$

and in the above equation,

$$
A_{T} \sqrt{k \rho c}=\sum_{i} A_{T, i} \sqrt{k_{i} \rho_{i} c_{i}}
$$




$$
A_{o} \sqrt{H_{o}}=\sum_{i} A_{o, i} \sqrt{H_{o, i}}
$$

where, $k_{i}$ is the thermal conductivity of boundary material $i, \mathrm{~kW} /(\mathrm{m} \cdot \mathrm{K}) ; \rho_{i}$ is the density of the boundary material $i, \mathrm{~kg} / \mathrm{m}^{3} ; c_{i}$ is the specific heat of the boundary material $i, \mathrm{~kJ} /(\mathrm{kg} \cdot \mathrm{K})$. The cumulative probability of fire growth to a fully-developed fire at time $\mathrm{t}$ can be calculated by the following equations:

- When flashover does not occur in the compartment

$$
\begin{aligned}
& P_{f d}(t)=\int_{t_{i g}}^{t} \frac{1}{\sigma_{f o} \sqrt{2 \pi}} \exp \left(-\left[\left(t-t_{i g}\right)-\mu_{f o}\right]^{2} / 2 \sigma_{f o}^{2}\right) d t \quad\left(0 \leq t-t_{i g} \leq \tau_{g r}^{\max }\right) \quad \text { Equ. (3.11) } \\
& P_{f d}(t)=0 \quad \text { Otherwise; }
\end{aligned}
$$

- When flashover occurs in the compartment

$$
\begin{aligned}
& P_{f d}(t)=\int_{t_{i g}}^{t} \frac{1}{\sigma_{f o} \sqrt{2 \pi}} \exp \left(-\left[\left(t-t_{i g}\right)-\mu_{f o}\right]^{2} / 2 \sigma_{f o}^{2}\right) d t \quad\left(0 \leq t-t_{i g} \leq \tau_{g r}+\tau_{f d}\right) \quad \text { Equ.(3.12) } \\
& P_{f d}(t)=0 \quad \text { Otherwise; }
\end{aligned}
$$

where, $t_{i g}$ is the ignition time in the compartment; $\mu_{f o}$ is the mean of the time for the fire to develop from ignition to flashover in the compartment; $\sigma_{f_{o}}$ is the standard deviation of duration for the fire to develop from ignition to flashover; $\tau_{g r}^{\max }$ is the maximum duration of fire growth phase in the compartment; $\tau_{g r}$ is the duration of fire growth phase in the compartment. The calculation of the maximum fire growth time $\tau_{\mathrm{gr}}^{\max }$, fire growth time $\tau_{\mathrm{gr}}$ and duration of fully developed fire please $\tau_{f d}$ are explained in [8].

The calculation of the mean time and standard deviation for fire to develop from ignition to flashover in the compartment is as follows, 


$$
\begin{gathered}
\mu_{f o}=\sqrt{\frac{750 A_{o} \sqrt{H_{o}}}{\mu_{\alpha}}} \\
\sigma_{f o}=\sqrt{\frac{750 A_{o} \sqrt{H_{o}}}{\mu_{\alpha}^{2}}} \sigma_{\alpha}
\end{gathered}
$$

where, $\mu_{\alpha}$ is the mean of the fire growth coefficient for a $\mathrm{t}^{2}$ fire; $\sigma_{\alpha}$ is the standard deviation of the fire growth coefficient for a $\mathrm{t}^{2}$ fire. In the calculation $\sigma_{f o}=0.15 \mu_{f o}$ was applied because reference was not available for $\sigma_{\alpha}$.

As the main objective of this research is to develop a barrier failure submodel that will provide input to the fire spread submodel, the above details are presented in this chapter to provide the reader with a general impression of the fire spread model. More details of the fire spread submodel can be found in reference [8].

\subsection{Implementation of the Fire Spread submodel in CUrisk}

\subsubsection{Input and output data}

Most of the input data of the Fire Spread submodel are common to the input data used by other submodels of CUrisk, such as simulation time, initial temperature, building geometry information and so on. There are, however, some input data unique to the Fire Spread submodel, such as fire load densities and fire resistance ratings. Although the simulation time can be the same as the main model, the simulation step size in this submodel can only be one minute or 60 seconds because this is the time unit used implicitly in the model. Therefore, an additional input file named "F15_FireSpreadUserIn.txt" was created.

The input data for the Fire Spread submodel includes the following:

- Simulation time, time step size, initial temperature; 
- Quantity of combustibles in each compartment (fire growth rates, fire load density and its standard deviation);

- Building properties (number of storeys, length, depth and height of each compartment, door and window sizes in each compartment, linking information among compartments horizontally and vertically);

- Fire resistance ratings and standard deviation of wall, floor/ceiling, door, window; and,

- Fire department action time and availability, and availability of fire sprinkler operation. The output data of the Fire Spread submodel include:

- Ignition and Flashover time in each compartment, $t_{F O}$;

- Time and probability of fire spread in each compartment $j$ as a function of time $t$, $P_{F S}(j, t)$.

\subsubsection{The position of the Fire Spread submodel in the CUrisk system model}

In CUrisk, each submodel has a specific functionality but all of them contribute to the final two decision making parameters, Fire Cost Expectation and Expected Risk to Life. In each scenario, the Building Hazardous Condition submodel collects building fire conditions produced by the Fire Growth, Smoke Movement as well as Fire Spread submodels, and then provides those data to the Fire Department Response and Action, Smoke and Fire Detection, Occupant Response and Occupant Evacuation submodels, and further the Economic Loss and Life Hazard submodels.

The Fire Spread submodel has a similar role as the Fire Growth submodel and the Smoke Movement submodel in terms of calculating building hazardous conditions. The Fire Spread submodel affects the Fire Growth submodel in a way that fire growth and development occurs in the apartments that fire spread to, and this affects the evaluation of 
fire damages. In addition, the Smoke Movement submodel and the Fire Spread submodel should also be interconnected in a way that additional smoke will be generated in multiple fire sources, which consequently impact on occupant safety.

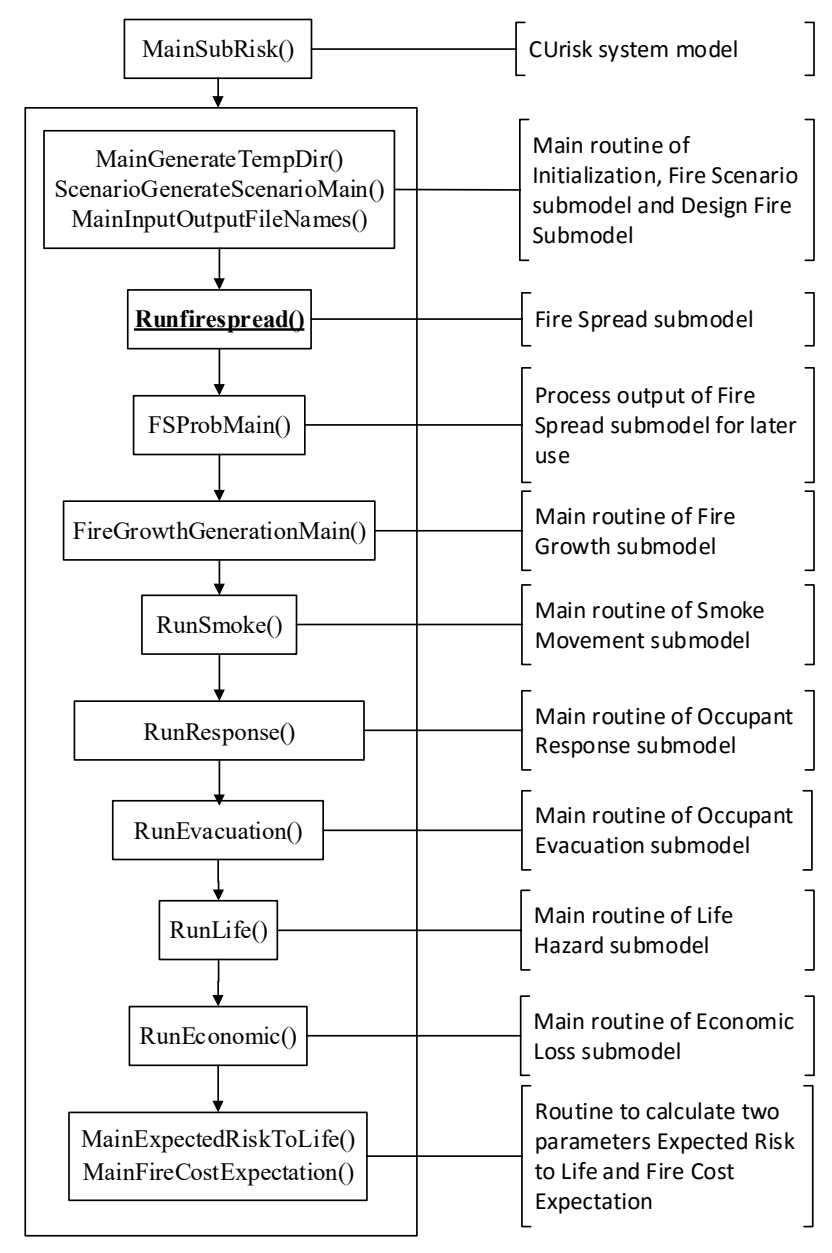

Figure 3-1 Flowchart of CUrisk system model and Position of Fire Spread submodel

As discussed above, the newly developed Fire Spread submodel is relatively independent of other CUrisk submodels. On the contrary, the Fire Growth submodel and the Smoke Movement submodel are dependent on the results of the Fire Spread submodel. As a result, it is reasonable to run the Fire Spread submodel before the Fire Growth and the Smoke Movement submodel. Figure 3-1 shows a simplified CUrisk system model structure. Names of subroutines of corresponding submodels are listed on the left column and 
explanations are on the right. The subroutines are executed from top to bottom as indicated by the arrows.

\subsubsection{Use of the fire spread data in the Life Hazard submodel}

The Life Hazard submodel [4] is used to calculate the number of occupants killed or injured in each fire scenario. This submodel takes input data from the submodels of Hazardous Conditions, Occupant Response and Evacuation, and Fire Department Response and Action, and then provides the data of number of deaths for the calculation of the final parameter of the Expected Risk to Life (ERL).

The Life Hazard submodel [4] calculates the fractional effective dose experienced by each occupant based on the hazardous conditions for each occupant as well as the information of occupant movement provided by the Occupant Response submodel and Evacuation submodel. The total probability of death, in a given compartment is calculated using the union of the individual probabilities of death from being exposed to toxic gases, hot gases, heat fluxes, and fire spread as follows:

$$
P_{O A}(t)=P_{T R}(t) \cup F I D_{T G}(t) \cup F I D_{H G}(t) \cup P_{F O}(t) \quad E q u \text {.(3.15) }
$$

where, $P_{O A}(t)$ is the overall probability of death in a given compartment; $P_{T R}(t)$ is the probability of death due to thermal radiation; $F I D_{T G}(t)$ is the probability of death due to intaking of all asphyxiant gases; $F I D_{H G}(t)$ is the probability of death due to hot gases; $P_{F O}(t)$ the probability of death due to flashover in the given compartment. The approaches used to obtain $P_{T R}(t), F I D_{T G}(t)$, and $F I D_{H G}(t)$ can be found in Reference [4].

The overall probability of the death of an occupant $m$ at a time $t$, denoted as $P_{m}(t)$, can be obtained by keeping track of the evacuation route of the occupant m. From this, 
the number of deaths for scenario $i$ at time $t$, denoted as $N_{i}(t)$, in the building can be calculated by adding up the death probability of each occupant as follows ( $P O P$ is number of occupants in the building):

$$
N_{i}(t)=\sum_{m=1}^{P O P} P_{m}(t)
$$

The approaches used to calculate the probability of death due to toxic and hot gases as well as heat flux have been described in [4]. In the Life Hazard submodel, fire spread-induced life hazards only considers the effect of flashover resulting from fire spread. The reason for this simplification is that the calculation of the detailed fire conditions such as temperature and concentrations of toxic species in a compartment after fire spread is very complicated. It is reasonable to assume that whenever flashover occurs, occupants in the compartment will be killed; i.e., the probability of death is equal to the probability of flashover in the compartment (i.e., $P_{F O}(t)$ in Equ.(3.18)). In the Life Hazard submodel, the following method [4] is used to calculate the probability of flashover caused by fire spread. At first the probability density function of flashover can be calculated using the equation below,

$$
f_{F O}(t)=\int_{t-t_{F O}}^{t}\left[\frac{2(t-\eta)}{t_{F O}^{2}}\right] f_{F S}(\eta) d \eta
$$

where, $f_{F O}(t)$ is the probability density function of the probability of flashover in the compartment; $f_{F S}(\eta)$ is the probability density function of fire spread to this compartment; $t$ is the independent variable time.

Then, the cumulative probability of flashover $P_{F O}(t)$ can be obtained by integrating the probability density function, 


$$
P_{F O}(t)=\int_{0}^{t} f_{F O}(t) d t
$$

An example of cumulative probability of flashover $P_{F O}(t)$ compared with cumulative probability of fire spread $P_{F S}(t)$ is presented in Figure 3-2. It can be seen that the cumulative probability of flashover provides smoother results than the abrupt and sudden increase of the cumulative probability of fire spread. This is more rational because probability density of death is calculated in each time step, by keeping track of the location of each occupant.

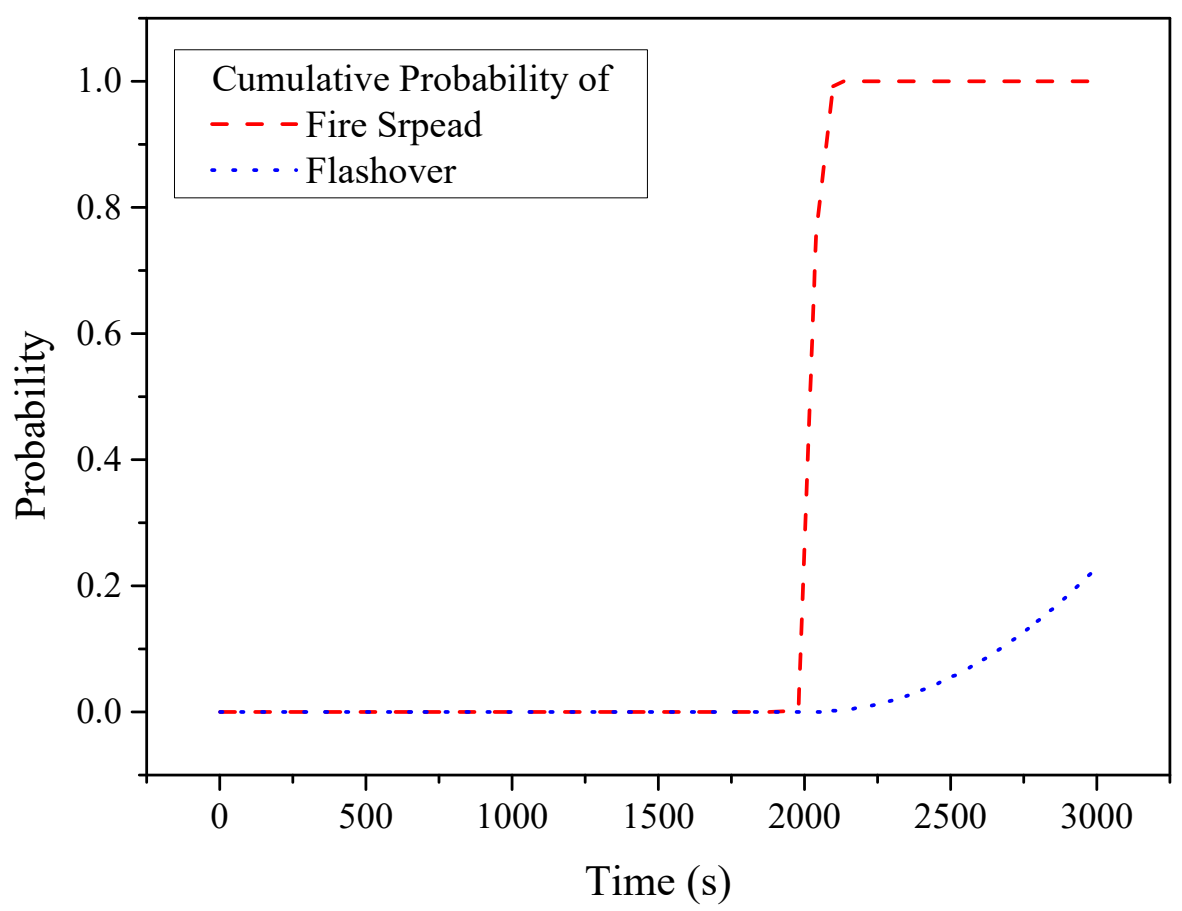

Figure 3-2 An example of the cumulative probability of fire spread and the related cumulative probability of flashover due to fire spread

In order to employ the above two equations (Equ.(3.17) and Equ.(3.18)), for each fire compartment, the flashover time $t_{F O}$ and the probability density function of fire spread $f_{F S}(t)$ which are obtained from the Fire Spread submodel are needed. As introduced in Section 3.2.1, flashover time in each compartment is an output of the Fire Spread submodel; 
and the probability density function of fire spread $f_{F S}(t)$ can be computed from the cumulative probability of fire spread $P_{F S}(t)$.

The computer code structure of Life Hazard submodel related to Fire Spread submodel is demonstrated in Figure 3-3.

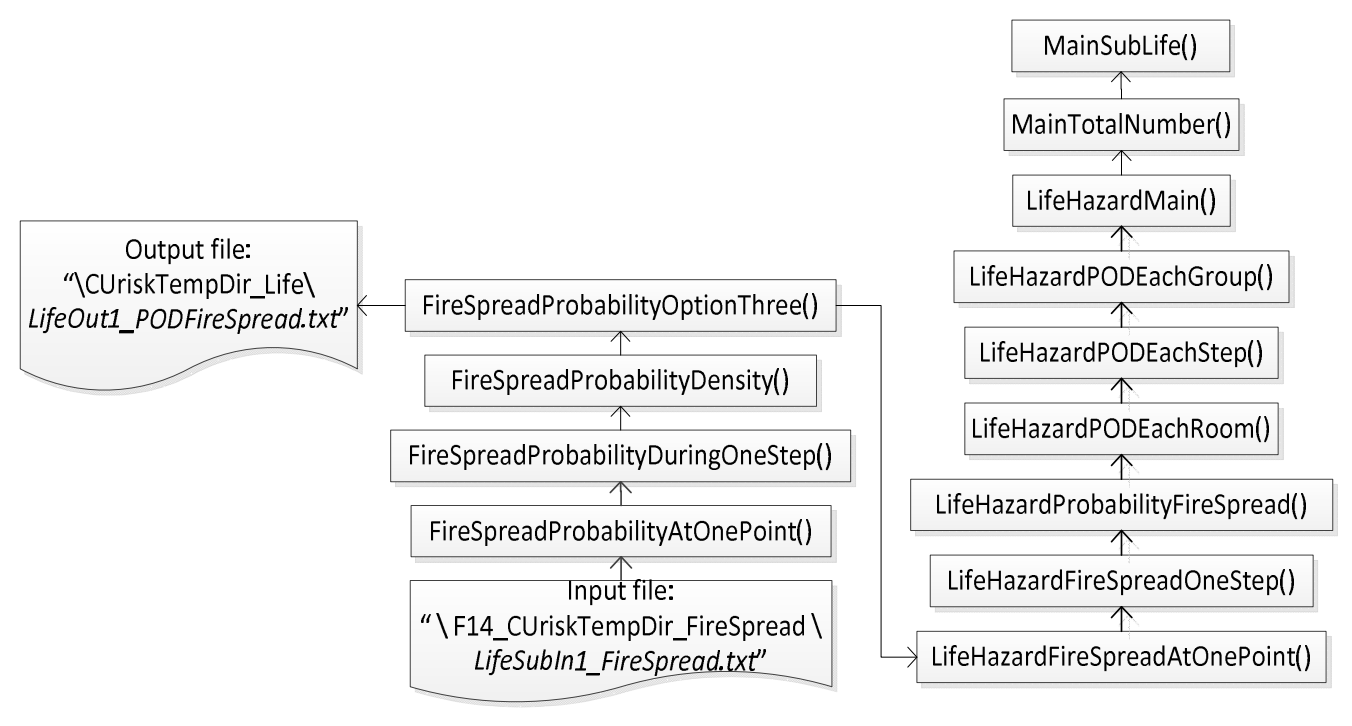

Figure 3-3 Simplified flow chart of computer module of Life Hazard submodel related to Fire Spread submodel

\subsubsection{Use of the fire spread data in the Economic Loss submodel}

The Economic Loss submodel calculates the economic loss in each fire scenario, which is used by the Fire Cost Expectation submodel. This model inputs data of fire conditions from the Hazardous Conditions submodel, data of economic values of contents, and damage criteria of contents from users to estimate the economic loss. A detailed introduction of this submodel can be found in [10].

For each fire scenario, the Economic Loss submodel is run to obtain the following data for each compartment: 
- Cost of damage to building contents due to temperature, smoke and water, (\$)

- Cost of damage to building construction (includes building components, basic building construction and passive fire protection), (\$)

- Cost of damage to fire protection systems due to temperature, smoke and water, $(\$)$

- Amount of downtime (days)

The Economic Loss submodel calculates fire losses based on the predicted fire conditions such as room temperature, smoke production and water amount (from fire suppression). A simple method to account for the effect of fire spread on damages is given in [10] as shown below,

$\operatorname{TFS}(j)=\operatorname{DamageSS}(j) \times\left[1-P_{F S}(j)\right]+\operatorname{DamageFS}(j) \times\left[P_{F S}(j)\right]$

where, $T F S(j)$, total cost of damage, estimate of damage or amount of downtime for compartment $j$ taking into account smoke spread and fire spread; DamageSS(j), estimate of damage or the amount of downtime for compartment $j$ taking into account only smoke spread; DamageFS(j), estimate of damage or the amount of downtime if there is a fire in compartment $j ; P_{F S}(j)$, cumulative probability of fire spreading in compartment $j$ up to the end time of simulation.

In Equ.(3.19), DamageSS(j) is calculated based on the output of the Smoke Movement submodel which generates the level of smoke spread throughout the building due to the fire in the room of fire origin, ignoring the effect of fire spread. The other parameter DamageFS $(j)$ is based on the effect of fire spread in the fire compartments, and economic loss in each compartment are calculated based on the data from the Fire Growth submodel. 


\subsubsection{Effects of Fire Department action and sprinkler operation on outputs}

In CUrisk, fire suppression may occur in three ways, only due to Fire Department action, only due to sprinkler operations or due to both of the above. The effect of fire suppression on the fire is considered in the Smoke Movement submodel. The Fire Spread submodel considers the effect of fire suppression as discussed in the following sections.

\section{When only the Fire Department action is available}

At the time when the Fire Department action starts, the cumulative fire spread probability in each compartment stops increasing but remains at the value reached by that time. This is expressed in the equation below,

$$
P_{F S}(j, t)=P\left(j, t_{F D a c t i o n}\right) \quad \text { when } t \geq t_{\text {FDaction }} \quad \text { Equ.(3.20) }
$$

where, $P_{F S}(j, t)$ is the cumulative probability of fire spread in compartment $j$ at time $t$; $t_{F D a c t i o n}$ is Fire Department action time.

The reason for this is that the Life Hazard submodel calculates the probability of death due to fire spread based on the stepwise integration of the fire spread probability density, as introduced in Section 3.2.3, and in this way the probability density function of fire spread will be continuous, and after the Fire Department action, the probability density of fire spread becomes 0. In the Economic Loss submodel, as discussed in Section 3.2.4, this method also provides the highest cumulative probability $\left(P_{F S}(j)\right.$ in Equ.(3.22)) of fire spread right before the start of Fire Department action.

\section{When only the Fire Sprinkler operation is available}

When sprinklers are available in compartment $j$ and functioned properly, the probability of fire spread becomes 0 , and this change takes effect in the Fire Spread submodel output file, as shown by the equation below, 
$P_{F S}(j, t)=0 \quad$ when sprinklers operate in compartment $j$;

Equ.(3.21)

In the Life Hazard submodel, the probability of death due to fire spread becomes 0 , which is reasonable because when sprinklers operate and function effectively no occupant is expected to be injured from direct contact with fire.

In the Economic Loss submodel, when sprinklers operate properly, the fire will be contained in the compartment of fire origin. Therefore, it can be assumed that fire damage in compartment $j$ due to fire spread, DamageFS(j), is equal to fire damage due to smoke spread, DamageSS(j). Therefore, based on Equ.(3.19), when Fire Sprinkler operated the total fire damage in compartment $j, T F S(j)$, becomes,

$$
\operatorname{TFS}(j)=\operatorname{DamageSS}(j) \times\left[1-P_{F S}(j)\right]+\operatorname{DamageSS}(j) \times\left[P_{F S}(j)\right]=\operatorname{DamageSS}(j)
$$

The above approach is employed by modifying the computer codes of the Economic Loss submodel, i.e., when sprinkler is available in the fire scenario, Equ.(3.22) is applied. In this way $T F S(j)$ will be equal to DamageSS(j).

\section{When both the Fire Department action and Fire Sprinkler operation are available}

When both the Fire Department action and Fire Sprinklers are available and operate properly, the effect is the same as when only Fire Sprinklers are available.

\subsection{Case study of a six-storey building using the improved CUrisk}

In this section, a case study of fire risk analysis is presented on a six-storey residential building. Three fire protection design options are created based on the availability of fire sprinklers or fire alarms, and each design option contains a number of pre-defined fire scenarios. In particular, five different Fire-Resistance-Rating (in minutes) combination options of building assemblies (walls, floors, doors and windows) are designed with the 
purpose of verifying the performance of the Fire Spread submodel and to explore the contribution of fire spread to the ERL and FCE. Furthermore, a fire risk comparison of the three fire protection design options is given.

\subsubsection{Building description}

A simple six-storey residential building was designed to perform the fire risk analysis case study. The conceptual building view and floor layout are shown in Figure 3-4.
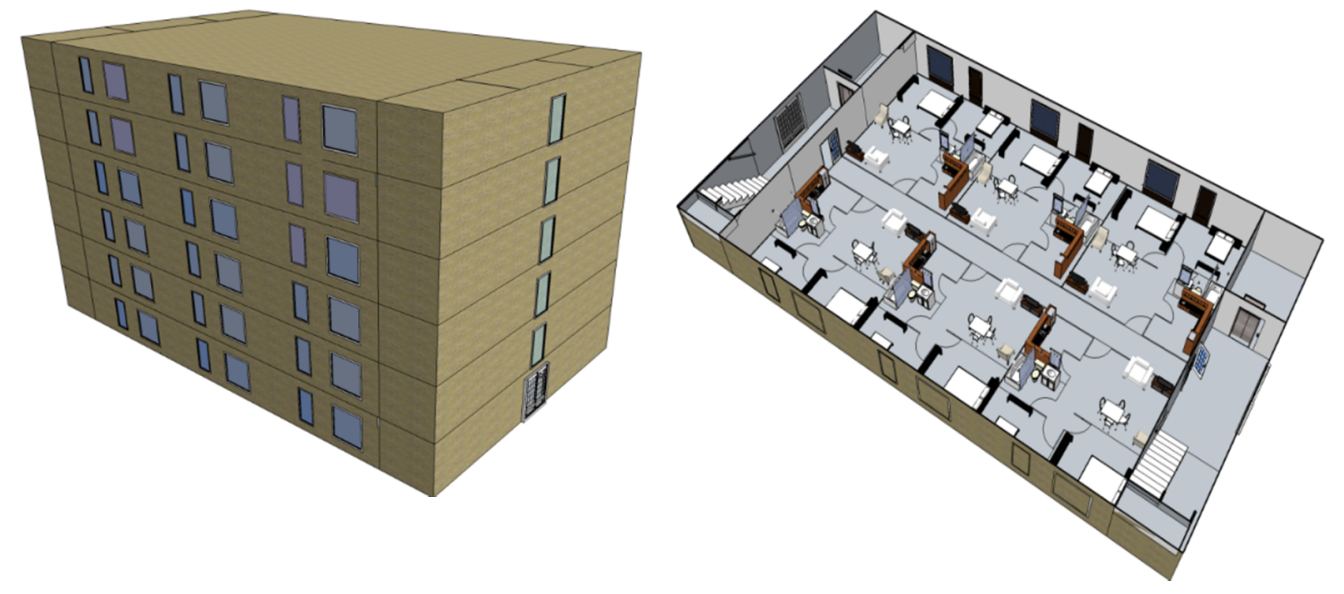

Figure 3-4 Conceptual sketch of the building and floor layout

The layout of each floor is identical and each floor of the building has 6 two-bedroom apartments $(8.0 \mathrm{~m} \times 8.0 \mathrm{~m})$, a corridor $(24.0 \mathrm{~m} \times 1.5 \mathrm{~m}), 2$ staircase shafts $(3.0 \mathrm{~m} \times 5.5 \mathrm{~m}), 2$ elevator shafts $(3.0 \mathrm{~m} \times 5.4 \mathrm{~m})$ and 2 public zones $(3.0 \mathrm{~m} \times 6.6 \mathrm{~m})$. There are only 2 main doors to the outside on each side of the first floor $(2.0 \mathrm{~m} \times 2.0 \mathrm{~m})$. The corridor on each floor is connected to each of the common areas by a door $(0.9 \mathrm{~m} \times 2.0 \mathrm{~m})$. See Figure 3-5. 


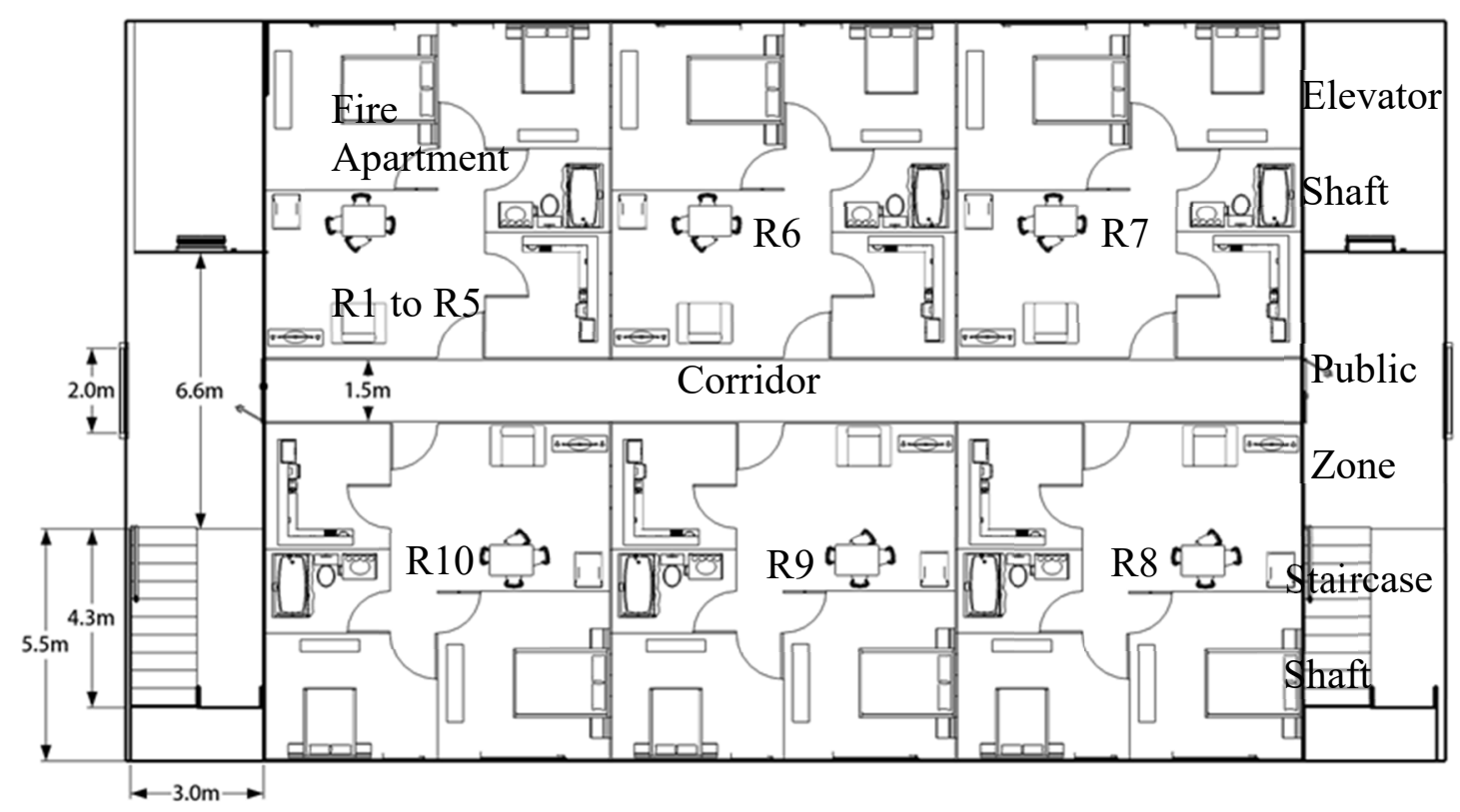

Figure 3-5 Plan of the first floor

For simplicity, all the apartments in the building are identical with 5 rooms, including a living room (R1, $5.1 \mathrm{~m} \times 4 \mathrm{~m})$, a master bedroom $(\mathrm{R} 2,4 \mathrm{~m} \times 4 \mathrm{~m})$, a small bedroom ( $\mathrm{R}$, $4 \mathrm{~m} \times 3 \mathrm{~m})$, a bathroom $(\mathrm{R} 4,2.9 \mathrm{~m} \times 2 \mathrm{~m})$ and a kitchen $(\mathrm{R} 5,2.9 \mathrm{~m} \times 3 \mathrm{~m})$, as shown in Figure 3-6. Each room has a door $(0.9 \mathrm{~m} \times 2.0 \mathrm{~m})$. R1 is connected with R2, R3, R4 and R5 through the doors, and R1 also has a door to the corridor. Two windows $(1.5 \mathrm{~m} \times 1.5 \mathrm{~m})$ are located on the outside wall of R2 and R3. For simplicity, on each floor only the first apartment (top left on Figure 3-5) is assumed to be the apartment of fire origin. For this reason the rooms of this apartment are considered and numbered from R1 to R5, and all other five apartments are considered as one room (R6 to R10). This approach significantly reduces the computer running time. Elevator shafts are not considered as compartments as they will be out of service in case of fire. Therefore, on each floor there are in total 15 compartments including the corridor, the staircase rooms and the common areas, and in the building there are in total 90 compartments. Non-fire origin apartments are assumed to have one window $(3.0 \mathrm{~m} \times 1.5 \mathrm{~m})$ instead of two windows, which results in a total of 7 windows per floor and 
42 windows in the building. Adding the number of doorways (60 apartment doors, 12 corridor doors and 12 staircase doors), there are in total 128 openings. Fires are assumed to start in the first apartment (Fire Apartment), in any of the five rooms and on any floor. Apartment rooms are numbered first (R1 to R60); for example, R11, R35 and R57 means living room of the first apartment on the second floor, kitchen of first apartment on fourth floor and top right apartment on sixth floor. All other compartments such as common areas, stairways are numbered from R61 to R90.

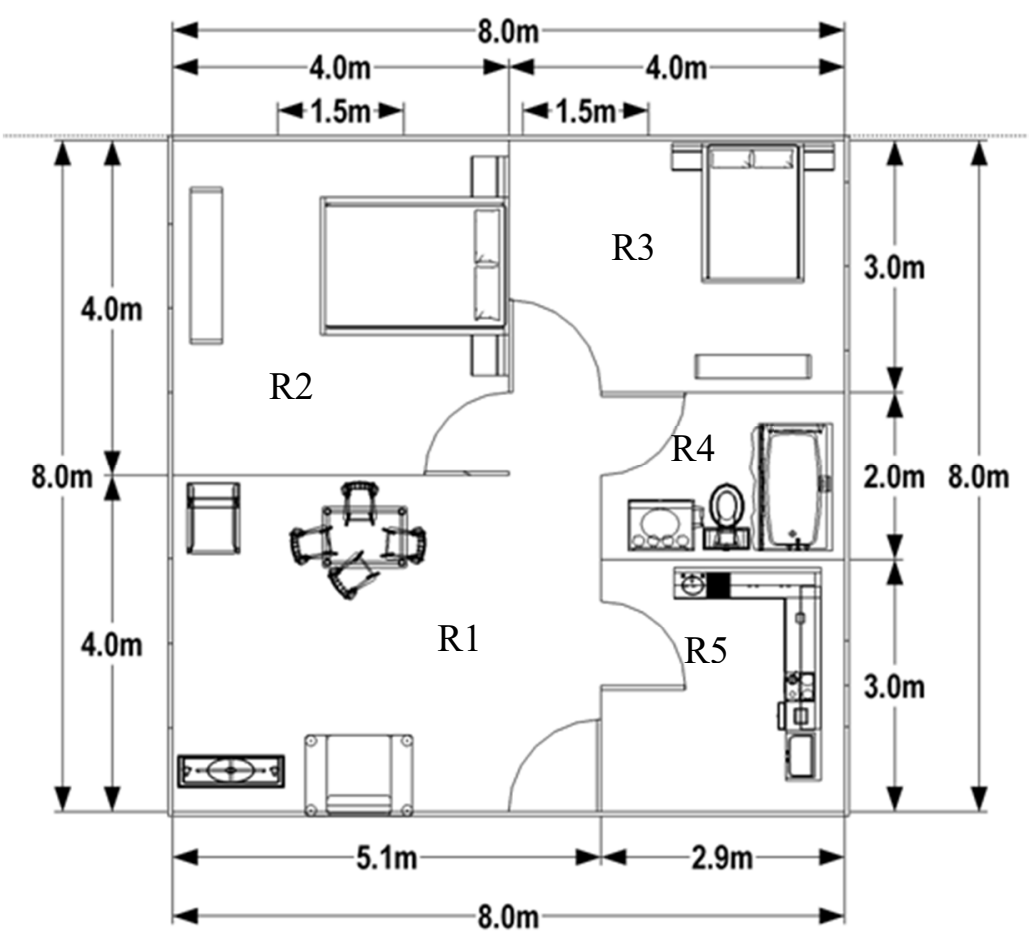

Figure 3-6 Layout of the Fire Apartment (first apartment) on the first floor

\subsubsection{Input files}

The building layout and opening data described earlier are inputs to CUrisk. Design fires are designated for the fire compartments. The t-square $\left(\dot{Q}=\alpha t^{2}\right)$ fires are used, and growth rates and maximum heat release rates for all the compartments considered are shown in 
Table 3-1, and same data are used for all other floors. The selection of design fires is based on engineering judgement and literature findings $[85,86]$. Compartments such as elevator shafts, staircase shafts, corridors and public zones are not considered to have enough fire load to support fire growth and fire spread, but smoke can spread to these areas through openings. The notional maximum heat release rate can be estimated using the fuel type and ventilation conditions, $\dot{Q}_{\max }=1518 A_{V} \sqrt{H_{V}} \quad$ [87]. The maximum values shown in the table are higher than the estimated values as the actual heat release rate of the design fires are computed by the Smoke Movement submodel.

Table 3-1 Fire growth speed and maximum heat release of different compartments

\begin{tabular}{|l|l|l|l|}
\hline Compartment & Growth rate & Value of $\alpha$ & Max HRR (MW) \\
\hline R1 & Medium & 0.0117 & 6 \\
\hline R2 & Slow & 0.00293 & 5 \\
\hline R3 & Slow & 0.00293 & 5 \\
\hline R4 & Slow & 0.00293 & 2 \\
\hline R5 & Fast & 0.0466 & 3.5 \\
\hline R6 & Medium & 0.0117 & 12 \\
\hline R7 & Medium & 0.0117 & 12 \\
\hline R8 & Medium & 0.0117 & 12 \\
\hline R9 & Medium & 0.0117 & 12 \\
\hline R10 & Medium & 0.0117 & 12 \\
\hline
\end{tabular}

The compartment boundary types are also input data. In this case study, only two types are used. One is gypsum board and the other one is concrete. Only the compartment boundary on the first floor is made of concrete, compartment boundaries on all other floors (ceilings and walls and floors) are gypsum boards. The boundary properties are used in the Smoke Movement submodel in order to calculate heat transfer and smoke spread. All the main doors of the apartments (doors to the corridors), building entrance door (the two doors to 
the outside on the first floor) are set to $20 \%$ open, and all the corridor doors and doors inside the apartments are set to $50 \%$ open to account for the fact that doors are not kept closed but are opened frequently during the fire as occupants use them to evacuate. In addition, all the windows are set to break at $300^{\circ} \mathrm{C}[88]$.

The Fire spread submodel can simulate fire spread from the room of fire origin to rooms on the same floor and across floors. The fire resistance ratings (FRR) of walls, ceilings/floors, doors and windows are important input data for this model. The FRRs of windows are assigned based on engineering judgement, so failure of windows could be calculated in the model. The In order to demonstrate the performance of the Fire Spread submodel, five different options are compared in this case study, see Table 3-2. Option 3 is close to the requirements in the National Building Code of Canada 2005 (NBCC 2005) [82] but not exactly the same because the purpose is to create different levels of FRR from Option 1 to option 5, in which the fire resistance rating combinations are increased sequentially.

Table 3-2 Five different Fire Resistance Rating (in minutes) options of building elements

\begin{tabular}{|l|l|l|l|l|}
\hline Options & Wall & Door & Ceiling/floor & Window \\
\hline 1 & 30 & 10 & 30 & 3 \\
\hline 2 & 45 & 20 & 45 & 3 \\
\hline 3 & 60 & 30 & 90 & 5 \\
\hline 4 & 90 & 40 & 90 & 8 \\
\hline 5 & 120 & 50 & 120 & 10 \\
\hline
\end{tabular}

Fire department, sprinklers, detectors and alarms are also considered as options in CUrisk. Fire department action time is divided into notification time, response time and setup time, which are set to be $30 \mathrm{~s}, 360 \mathrm{~s}, 120 \mathrm{~s}$, respectively. Sprinklers, detectors and alarms also activate when activation conditions are satisfied. 
Table 3-3 Input for Building Costs

\begin{tabular}{|l|l|l|l|l|l|l|l|}
\hline \multicolumn{2}{|c|}{ Economic Factors } & \multicolumn{2}{|c|}{ Building Characteristics } & \multicolumn{2}{c|}{ Basic Costs } & \multicolumn{2}{c|}{$\begin{array}{l}\text { Basic } \\
\text { Costs(continued) }\end{array}$} \\
\hline $\begin{array}{l}\text { Inflation rate } \\
\text { (\%) }\end{array}$ & 3.5 & $\begin{array}{l}\text { Building } \\
\text { component } \\
\text { calibration factor }\end{array}$ & 1 & $\begin{array}{l}\text { West wall } \\
\left(\$ / \mathrm{ft}^{2}\right)\end{array}$ & 24.88 & $\begin{array}{l}\text { Ceiling } \\
\left(\$ / \mathrm{ft}^{2}\right)\end{array}$ & 10.24 \\
\hline $\begin{array}{l}\text { Interest rate } \\
(\%)\end{array}$ & 5 & $\begin{array}{l}\text { Building life } \\
(\text { years })\end{array}$ & 50 & $\begin{array}{l}\text { East wall } \\
\left(\$ / \mathrm{ft}^{2}\right)\end{array}$ & 24.88 & $\begin{array}{l}\text { Floor } \\
\left(\$ / \mathrm{ft}^{2}\right)\end{array}$ & 10.24 \\
\hline $\begin{array}{l}\text { Downtime cost } \\
\text { (\$/day) }\end{array}$ & 1000 & $\begin{array}{l}\text { Total floor area } \\
\left(\mathrm{m}^{2}\right)\end{array}$ & 525 & $\begin{array}{l}\text { North wall } \\
\left(\$ / \mathrm{ft}^{2}\right)\end{array}$ & 24.88 & $\begin{array}{l}\text { Doors } \\
(\$ / \text { door })\end{array}$ & 165 \\
\hline $\begin{array}{l}\text { Rush } \\
\text { construction } \\
\text { factor }\end{array}$ & 1 & $\begin{array}{l}\text { Construction } \\
\text { calibration factor }\end{array}$ & 1 & $\begin{array}{l}\text { South wall } \\
\left(\$ / \mathrm{ft}^{2}\right)\end{array}$ & 24.88 & $\begin{array}{l}\text { Windows } \\
(\$ / \text { window }\end{array}$ & 1715 \\
\hline
\end{tabular}

144 occupants are distributed in the building with 4 people in each apartment $(2$ in the living room, 1 in the master bedroom and 1 in the small bedroom), and it is assumed that $50 \%$ of the occupants are male, $50 \%$ are female, $50 \%$ are children and $50 \%$ are adults.

Selected input data are showed in Table 3-3 and Table 3-4.

Table 3-4 Sensitivity of building contents to fire conditions

\begin{tabular}{|l|l|l|l|l|l|l|}
\hline $\begin{array}{l}\text { Title } \\
\text { contents }\end{array}$ & $\begin{array}{l}\text { Price } \\
\text { Value } \\
\mathbf{( \$ )}\end{array}$ & $\begin{array}{l}\text { Sensitivity } \\
\text { category for } \\
\text { temperature }\end{array}$ & $\begin{array}{l}\text { Sensitivity } \\
\text { category } \\
\text { for smoke }\end{array}$ & $\begin{array}{l}\text { Sensitivity } \\
\text { category } \\
\text { for water }\end{array}$ & $\begin{array}{l}\text { Replacement } \\
\text { time (days) }\end{array}$ & $\begin{array}{l}\text { Downtime } \\
\text { factor }\end{array}$ \\
\hline Lighting & 200 & HS & HS & LO & 10 & 0.01 \\
\hline Electronic & 4000 & HS & MO & HS & 10 & 0.01 \\
\hline $\begin{array}{l}\text { Furniture } \\
\text { (upholstered) }\end{array}$ & 7500 & HS & HS & LO & 10 & 0.01 \\
\hline $\begin{array}{l}\text { Furniture } \\
\text { (wood) }\end{array}$ & 16000 & LO & LO & LO & 10 & 0.01 \\
\hline Lighting & 1800 & LO & VS & LO & 10 & 0.01 \\
\hline Books & 600 & HS & HS & HS & 10 & 0.01 \\
\hline Clothes & 15000 & HS & LO & LO & 10 & 0.01 \\
\hline
\end{tabular}

NS: Non sensitivity; LO: Low sensitivity; MO: Moderate sensitivity; HS: High sensitivity; VS:

Very High sensitivity

To calculate the final two decision making parameters the Expected Risk to Life and the Fire Cost Expectation, the annual fire frequency, design life of the building, fire scenarios and their probabilities are required. The Ontario (a province in Canada) statistical data show that the residential fire ignition frequency is $2.61 \times 10^{-3}$ per unit per year [89], 
therefore, the annual fire frequency for the 36-apartment building can be estimated to be $9.396 \times 10^{-2}$ per year. The design life of the building is set to be 50 years. Four potential fatal fire scenarios and their probabilities are identified according to a study of Ontario Fire Statistics data [86], which shows that the probability of fire origin in the living room and hallway is $24 \%$, in the master Bedroom is $12 \%$, in the kitchen and dining area is $54 \%$, and in small bedrooms and other areas is $10 \%$.

According to the above information, fires are set in the model to start in 4 different rooms on different floors: living room (R1), master bedroom (R2), small bedroom (R3) and kitchen (R5), with probability $0.24,0.12,0.1,0.54$, respectively. As mentioned earlier, fire department, sprinklers, detectors and alarms are considered as options for the building, and their reliability should be considered because, for example, the fire department may fail to reach the fire site. In this case study, sprinklers, fire department and alarms are chosen to be the available fire protection options. It is acknowledged that sprinklers, detectors and alarms are prescribed by the code, but in this study they are treated as options in order to study their effects on the fire risk. According to statistics [90] and engineering judgment, the operational reliability of fire department action, sprinklers operation, and fire alarm operation are $0.6,0.95$, and 0.9 , respectively.

\subsubsection{Fire scenarios and design options}

The quantitative fire risk assessment is scenario based. A fire scenario is the description of a fire incident from fire ignition to decay, including key events to characterize a fire occurrence, and differentiate it from other possible fires. The Event Tree Method (ETM) is used to construct the scenario structures used for this study.

Three design options are created. For each design option the scenario structure is comprised 
of some or all of the following events: 1) selection of room of fire origin and design fire; 2) fire department arrival or non-arrival; 3) sprinkler activation and suppression; 4) and alarms and detectors activation. The resultant scenario structure for each design option is illustrated below in Figure 3-7 and Figure 3-8. These figures graphically illustrate different fire scenarios and the corresponding scenario probabilities. Note that the probability of fire occurrence on each floor is considered to be the same (1/6), thus the event trees only show scenarios structures of one floor, and the total number of scenarios is the number of scenarios in the figures multiplied by 6 . Similarly all the apartments on each floor are considered to have the same fire occurrence probability, which significantly reduces the number of fire scenarios. The code-compliant Option 3 as shown in Table 3-2 is chosen for the fire resistance ratings of the building components. The simulation time for all the scenarios is 1800 seconds, with a step size of 2 seconds. 

$\begin{array}{lllll}\begin{array}{l}\text { Each Floor } \\ (1 / 6)\end{array} & \text { Fire Room } & \begin{array}{l}\text { Alarms } \\ (0.9)\end{array} & \begin{array}{l}\text { Sprinkler } \\ (0.95)\end{array} & \begin{array}{l}\text { Fire Dept. } \\ (0.6)\end{array}\end{array}$

0.17

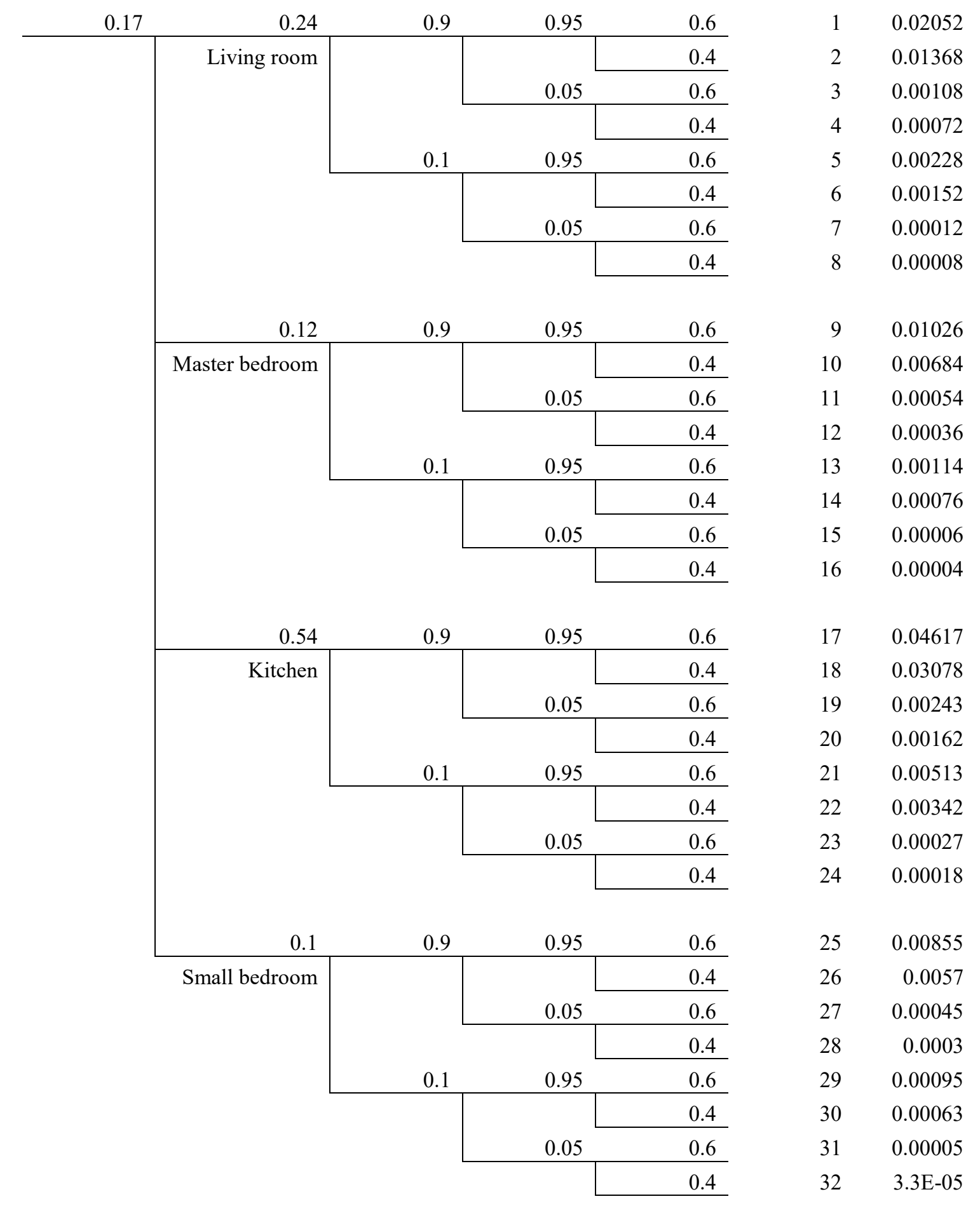

Figure 3-7 Design Option 1, sprinklers, detectors and alarms are installed in the building, and fire department is available 
(a)

\begin{tabular}{|c|c|c|c|c|c|}
\hline \multirow{2}{*}{$\begin{array}{l}\text { Each Floor } \\
(1 / 6) \\
\end{array}$} & Fire Room & \multirow{2}{*}{$\begin{array}{l}\text { Alarms } \\
(0.9) \\
\end{array}$} & \multirow{2}{*}{$\begin{array}{l}\text { Fire Dept. } \\
\begin{array}{ll}(0.6) & 0.6\end{array}\end{array}$} & \multirow{2}{*}{$\begin{array}{r}\text { Scenario \# } \\
1\end{array}$} & \multirow{2}{*}{$\begin{array}{r}\text { Probability } \\
0.0216\end{array}$} \\
\hline & 0.24 & & & & \\
\hline & $\begin{array}{r}\text { Living } \\
\text { room }\end{array}$ & & 0.4 & 2 & 0.0144 \\
\hline & & 0.1 & 0.6 & 3 & 0.0024 \\
\hline & & & 0.4 & 4 & 0.0016 \\
\hline & 0.12 & 0.9 & 0.6 & 5 & 0.0108 \\
\hline & $\begin{array}{r}\text { Master } \\
\text { bedroom }\end{array}$ & & 0.4 & 6 & 0.0072 \\
\hline & & 0.1 & 0.6 & 7 & 0.0012 \\
\hline & & & 0.4 & 8 & 0.0008 \\
\hline & 0.54 & 0.9 & 0.6 & 9 & 0.0486 \\
\hline & Kitchen & & 0.4 & 10 & 0.0324 \\
\hline & & 0.1 & 0.6 & 11 & 0.0054 \\
\hline & & & 0.4 & 12 & 0.0036 \\
\hline & 0.1 & 0.9 & 0.6 & 13 & 0.009 \\
\hline & Small & & & & \\
\hline & bedroom & & 0.4 & 14 & 0.006 \\
\hline & & 0.1 & 0.6 & 15 & 0.001 \\
\hline & & & 0.4 & 16 & 0.00067 \\
\hline
\end{tabular}

(b)

\begin{tabular}{|c|c|c|c|c|}
\hline \multirow{2}{*}{$\begin{array}{l}\text { Each Floor } \\
(1 / 6) \\
\end{array}$} & Fire Room & $\begin{array}{l}\text { Fire Dept. } \\
(0.6)\end{array}$ & Scenario \# & Probability \\
\hline & 0.24 & 0.6 & 1 & 0.024 \\
\hline & $\begin{array}{r}\text { Living } \\
\text { room }\end{array}$ & 0.4 & 2 & 0.016 \\
\hline & 0.12 & 0.6 & 3 & 0.012 \\
\hline & $\begin{array}{r}\text { Master } \\
\text { bedroom }\end{array}$ & 0.4 & 4 & 0.008 \\
\hline & 0.54 & 0.6 & 5 & 0.054 \\
\hline & Kitchen & 0.4 & 6 & 0.036 \\
\hline & 0.1 & 0.6 & 7 & 0.01 \\
\hline & $\begin{array}{r}\text { Small } \\
\text { bedroom }\end{array}$ & 0.4 & 8 & 0.0067 \\
\hline
\end{tabular}

Figure 3-8 (a) Design Option 2, detectors and alarms are installed and Fire Department is available, and (b) Design Option 3, only Fire Department is available 


\subsubsection{Results and discussion of the case study}

\subsubsection{Fire and smoke variation}

The fire conditions in rooms and the building, which are the outputs of the Smoke Movement submodel, are the basis to calculate the effects of fire. Figure 3-9, Figure 3-10 and Figure 3-11 give an illustration of the fire conditions in the compartments when fire starts in the $2^{\text {nd }}$ floor living room R11. Please note that for this case there are no fire protection measures such as sprinklers or fire department. Doors inside the fire apartment are all $50 \%$ open, thus smoke can spread from the living room to the bedrooms, bathroom and kitchen through the doors.

Figure 3-11 shows that smoke layer temperatures reach more than $900^{\circ} \mathrm{C}$ in the room of fire origin and as high as $400^{\circ} \mathrm{C}$ in other rooms of the same apartment. The heat release rate and radiation in the room of fire origin are shown in Figure 3-10. This graph shows that the heat release rate of the fire starts to decrease at around 400 seconds, which is due to low oxygen concentration in the room. And at about 900 seconds it starts to increase because the windows break $\left(300^{\circ} \mathrm{C}\right)$, and then it turns into relatively steady state. The variation of radiation, temperature and smoke layer interface height and level of CO also confirm this point, and indicates the transition from a fuel controlled fire to a ventilation controlled fire, which is limited by the opening conditions, e.g. doors and windows. Gas species concentrations and smoke layer interface heights are also the output of the Smoke Movement submodel, as shown in Figure 3-9. 


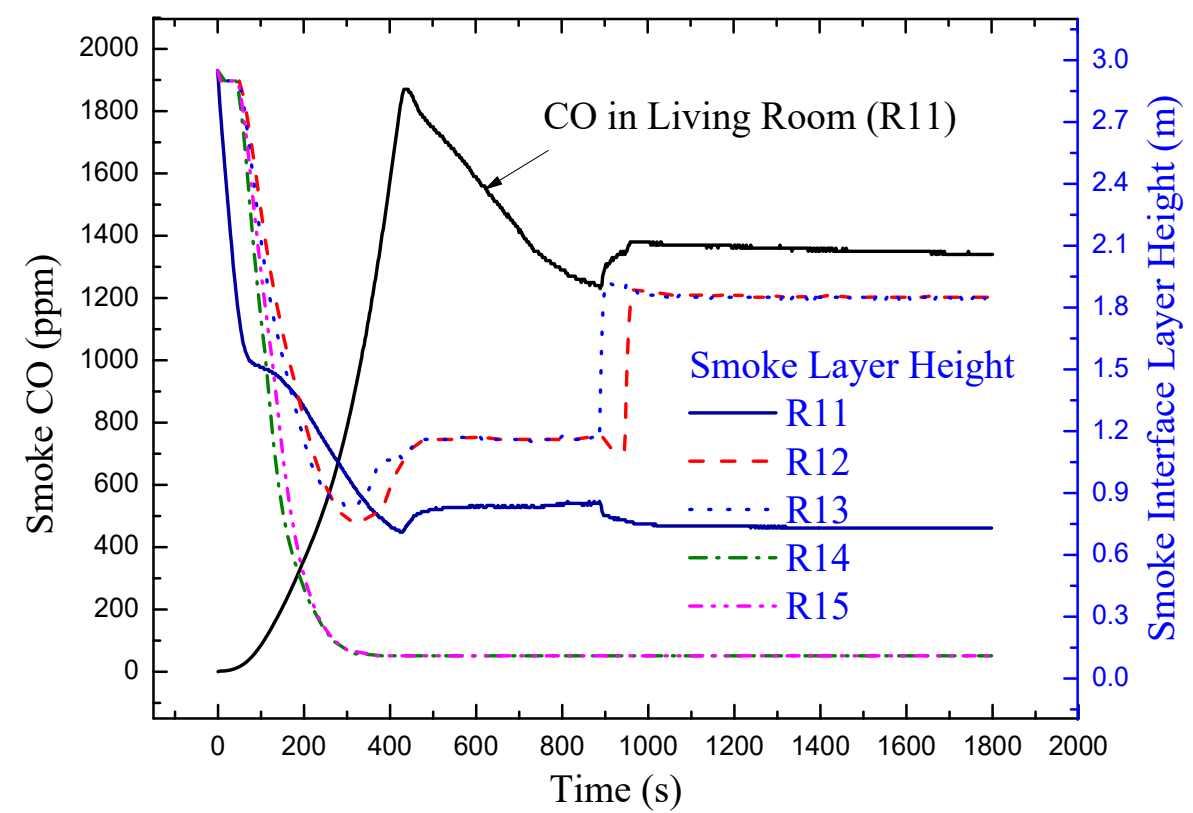

Figure 3-9 CO concentration and smoke layer heights vs. time in the apartment of fire origin, when the room of fire origin is $\mathrm{R} 11$

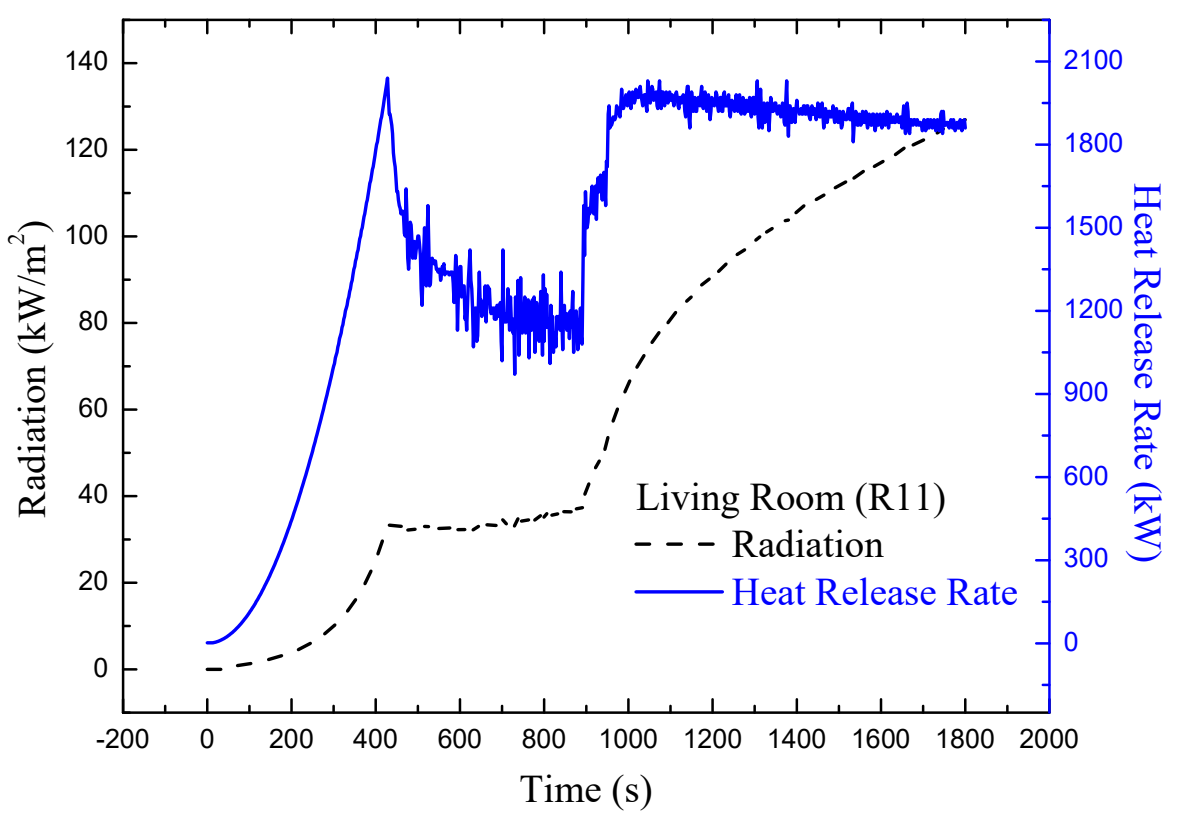

Figure 3-10 HRR and radiation vs. time in the room of fire origin R11 


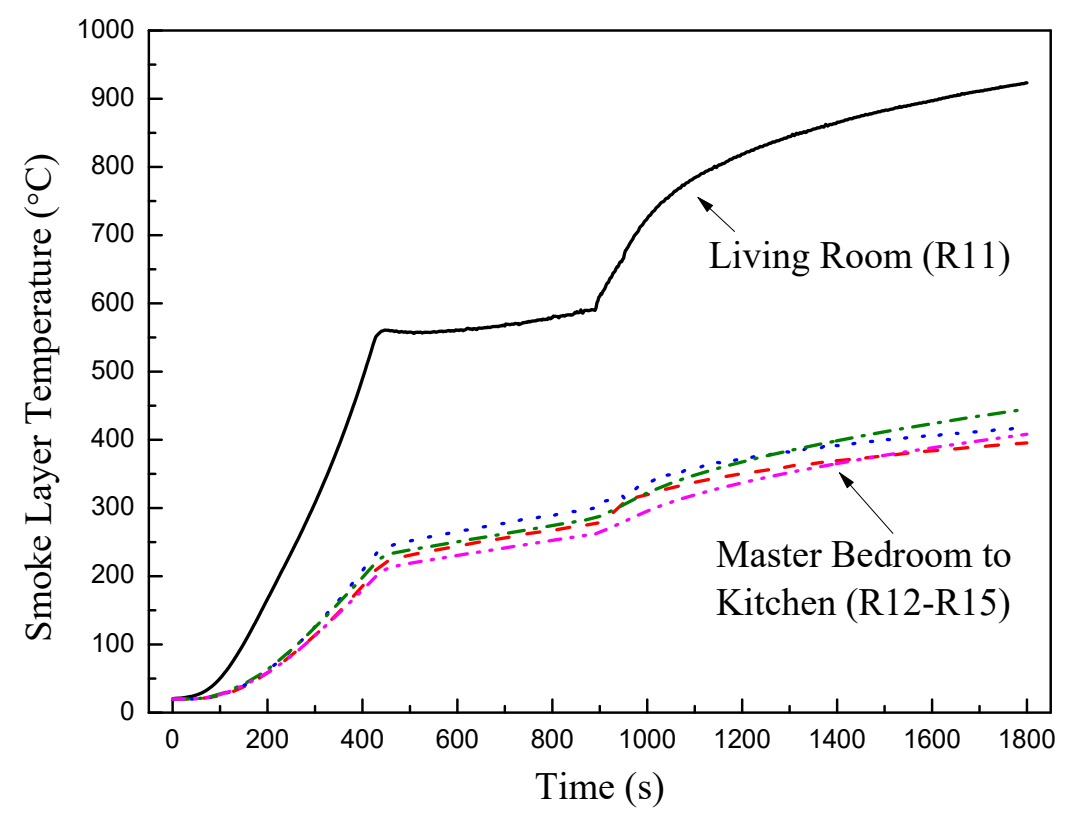

Figure 3-11 Smoke layer temperature vs. time Fire conditions in the apartment of fire origin, when the room of fire origin is R11

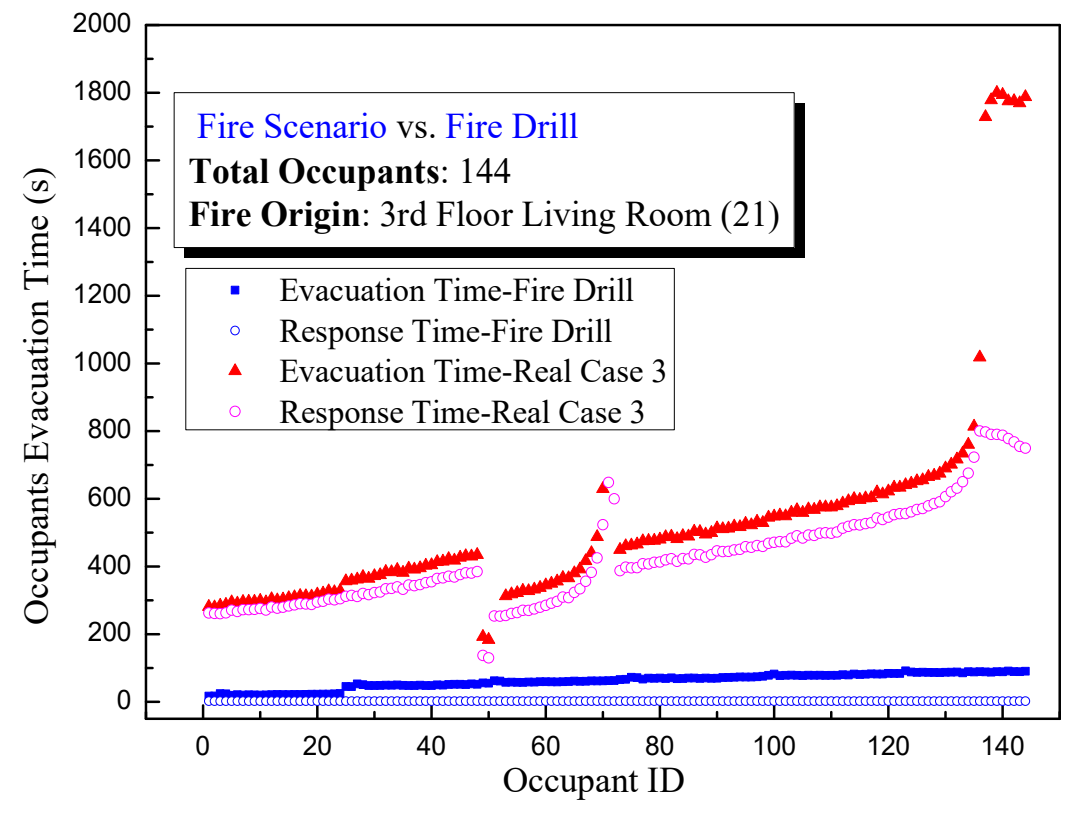

Figure 3-12 Occupant evacuation time vs. occupant ID, when the room of fire origin is R21 
Figure 3-12 shows an example of evacuation time comparing data from a fire scenario and fire drill, when fire starts in R21. Fire drill simulates evacuation drill, which represent a situation that there is no fire in the building and all occupants start to evacuate from the start of simulation with no response delay. The figure shows that the occupant evacuation time in fire scenarios are longer than the time in a fire drill mode. Some occupants fail to receive fire signals and remain trapped in their original location until the last minute. This graph demonstrates the integrated effects of occupant response behaviour and fire conditions in compartments on occupants' evacuation.

\subsubsection{Fire spread}

The Fire Spread submodel can calculate the time of flashover, and probability of barrier failure and fire spread for all the compartments during fire scenarios, based on input data such as fire growth rates, fire loads, fire resistance ratings of the building components and building layout data. Five fire resistance rating options are compared as shown in Table 3-2. The fire resistance ratings increase from Option 1 to Option 5. Figure 3-13 shows the probability of fire spread in all the compartments (considered for fire spread) at the end of the simulation time of 1800 seconds, when fire is originated at living room (R1) on the first floor. Note that there are no fire protection systems such as fire department or fire sprinklers in these fire scenarios.

The model can not only simulate fire spread on the floor of fire origin (horizontal fire spread) but also calculates fire spread across the floors (vertical fire spread). Figure 3-13 clearly shows the effect of fire resistance rating on fire spread, indicating low rating / high severity and high rating / low severity. For example, fires are contained in the fire apartment with Option 5 while they spread up to 4 floors with Option 1. Fire spread across floors is due to floor failure and external flame spread through windows, which is dominant 
for vertical fire spread.

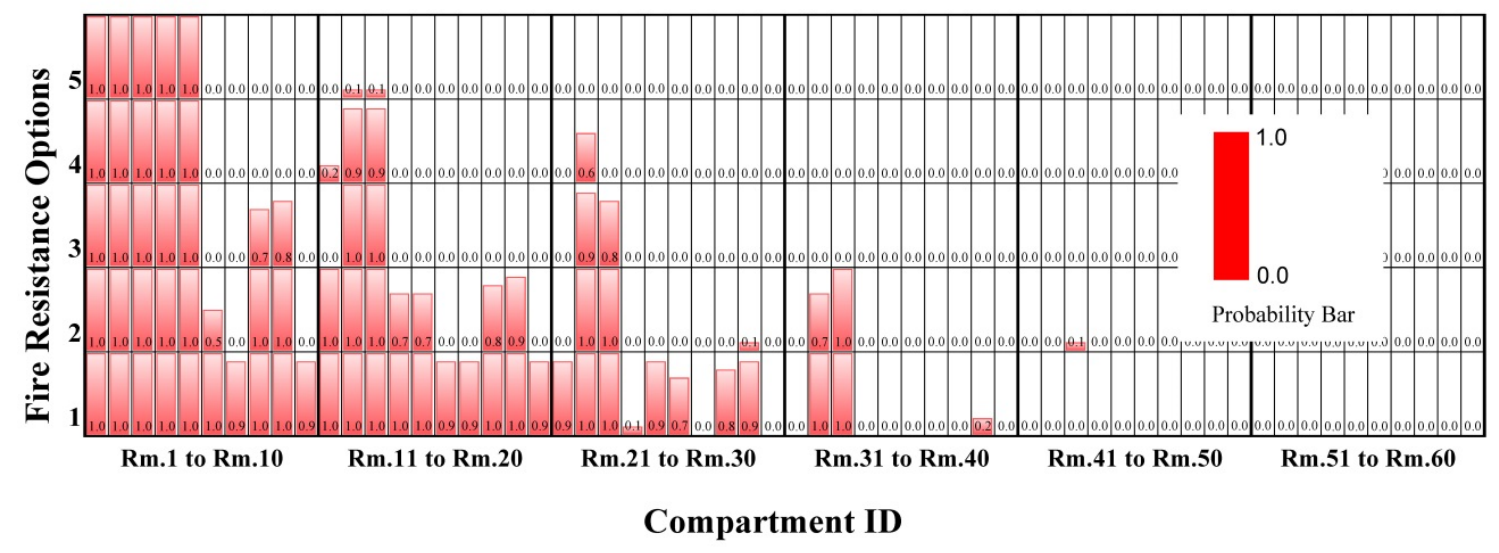

Figure 3-13 Probability of fire spread at the end of simulation time 1800 seconds with 5 different fire resistance rating options. Fire origin room, living room on the first floor (R1)

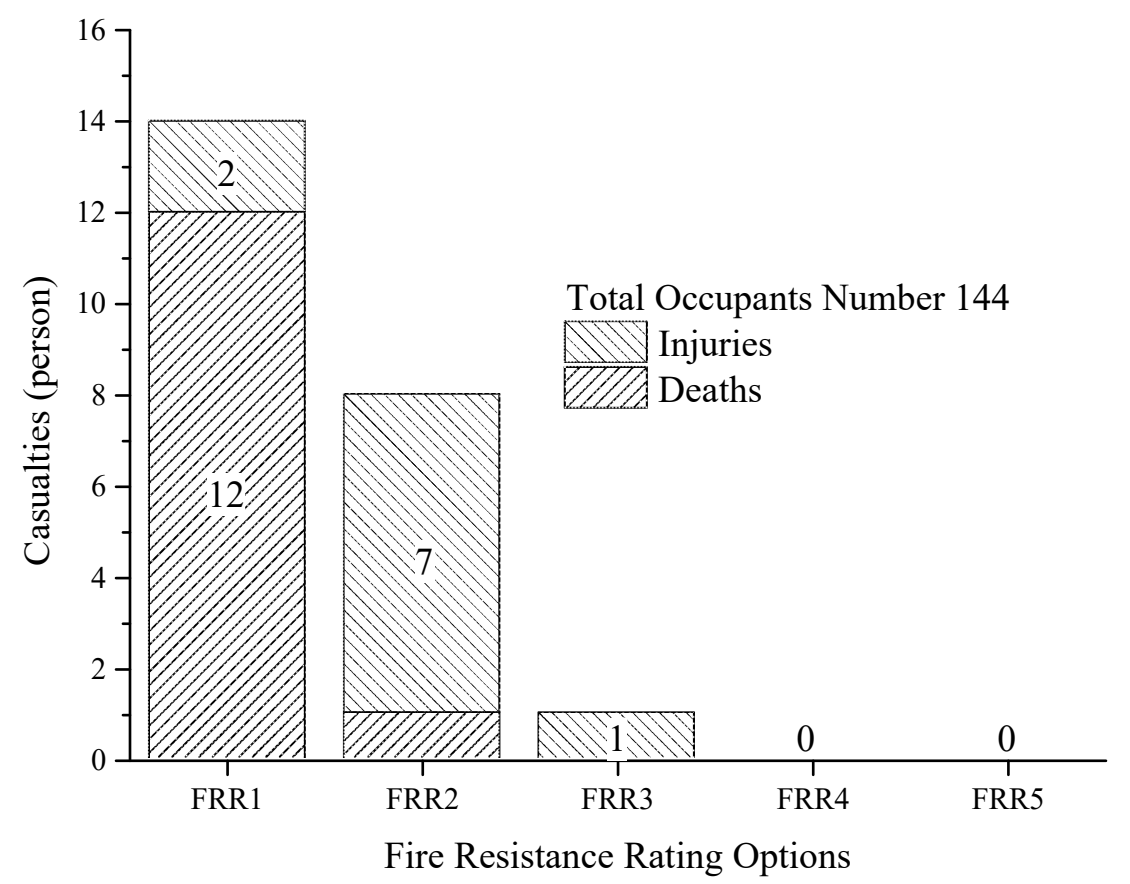

Figure 3-14 Life hazards with five different fire resistance rating options; Fire origin room: living room $(\mathbf{R} 21)$ on third floor 


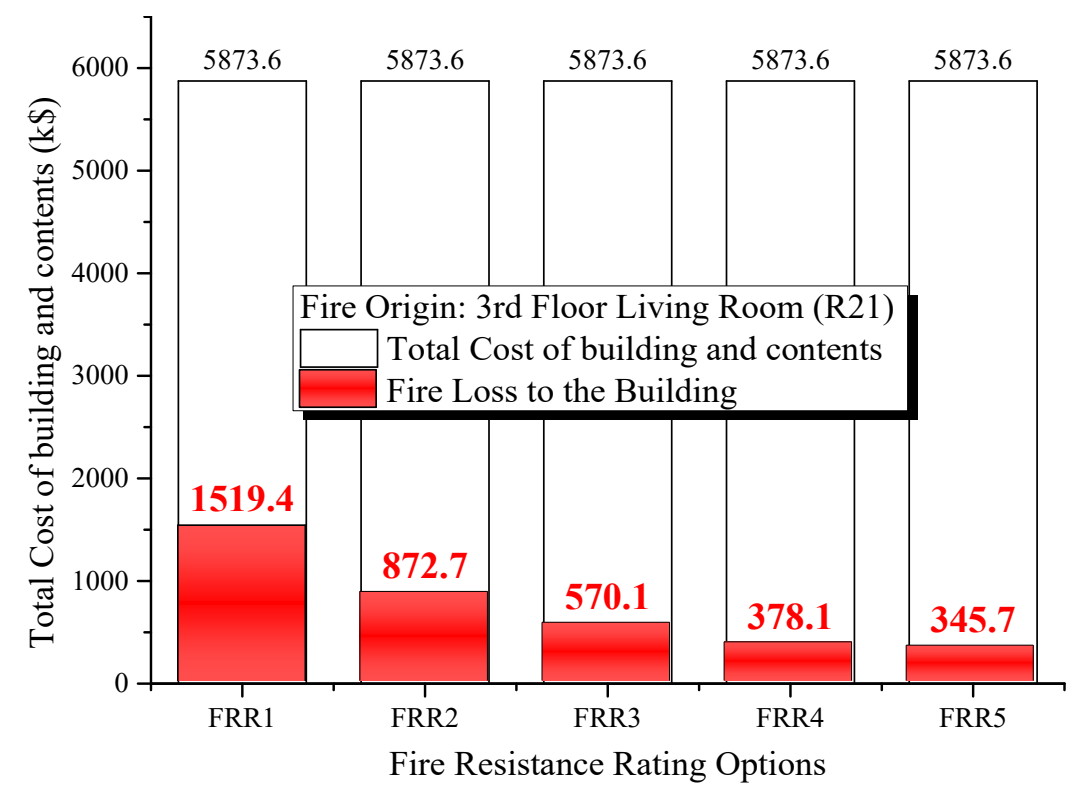

Figure 3-15 Fire losses to building contents with five different fire resistance rating options; Fire origin room: living room (R21) on third floor.

Life hazards and fire losses to building contents are also calculated to demonstrate the effects of the five different fire resistance rating options, when fire starts in the living room on the $3^{\text {rd }}$ floor (R21) in the absence of sprinklers or fire department. The number of deaths and injuries is calculated by the Life Hazard submodel which computes the probabilities of death caused by four factors, one of which is the probability of fire spread. The probability of death of each occupant is calculated separately by integrating the cumulative effects of the four factors along his/her evacuation routes. The total cost of the building is 5873.6 thousand dollars, and the total cost of damage to the entire building is the sum of damage to building construction and components, fire protection systems, passive fire protection systems and contents. The fire spread conditions significantly affect the level of damage. Figure 3-14 and Figure 3-15 shows the life and economic losses for the 5 different fire resistance rating options. Fire starts in living room (R21) on the third floor. 


\subsubsection{Fire protection options}

Figure 3-16 and Figure 3-17 demonstrate the effects of 4 different options on the smoke layer temperature and carbon monoxide concentration.

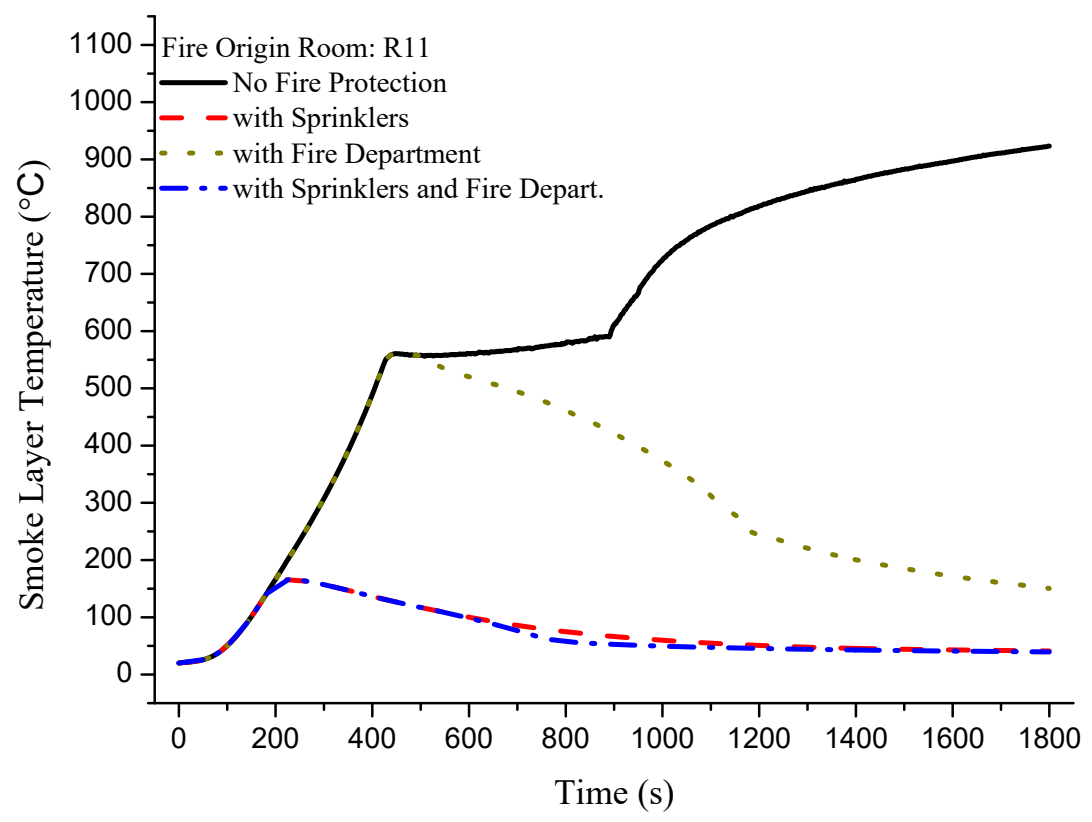

Figure 3-16 The effect of different fire protection measures on smoke temperature in fire origin room

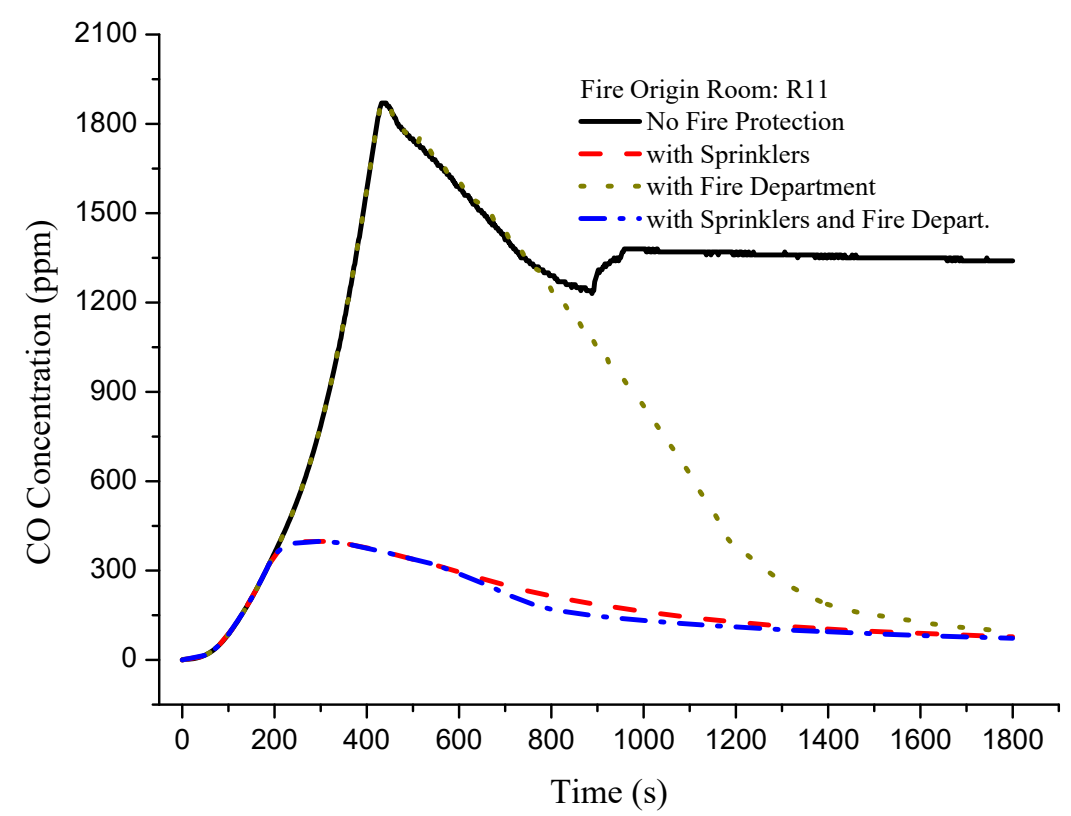

Figure 3-17 The effect of different fire protection measures on CO concentration in the room of fire origin 
Both the smoke temperature and $\mathrm{CO}$ concentration begin to drop after fire department action or sprinkler operation. Fire department action time, which includes notification time, response time and setup time, is longer than the sprinklers operation time. For this case, the sprinklers operated at about 200 seconds while the fire department started to take action after 510 seconds.

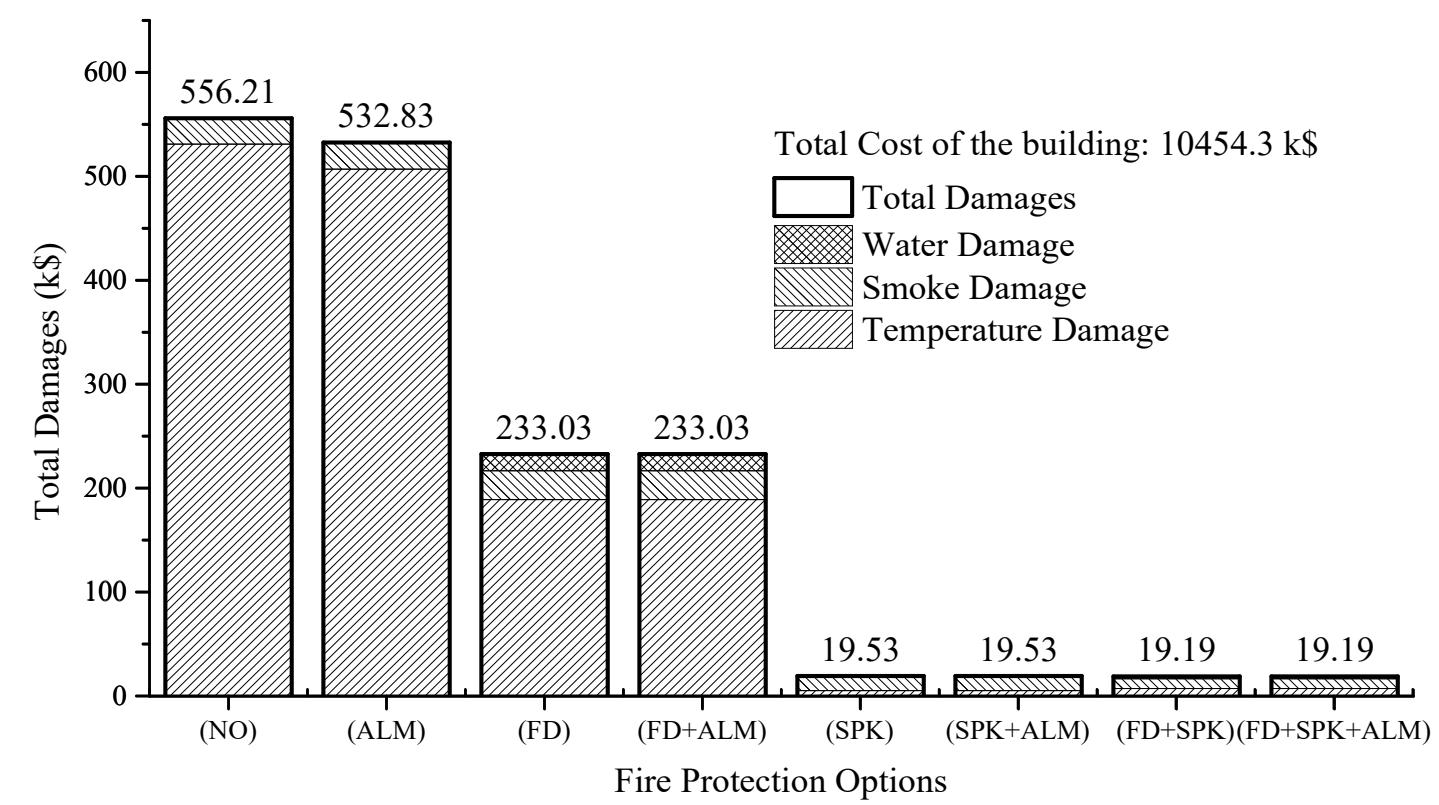

Figure 3-18 Total damages to the buiding due to 8 different fire protection options when the room of fire origin is $\mathbf{R 3 1}$ 


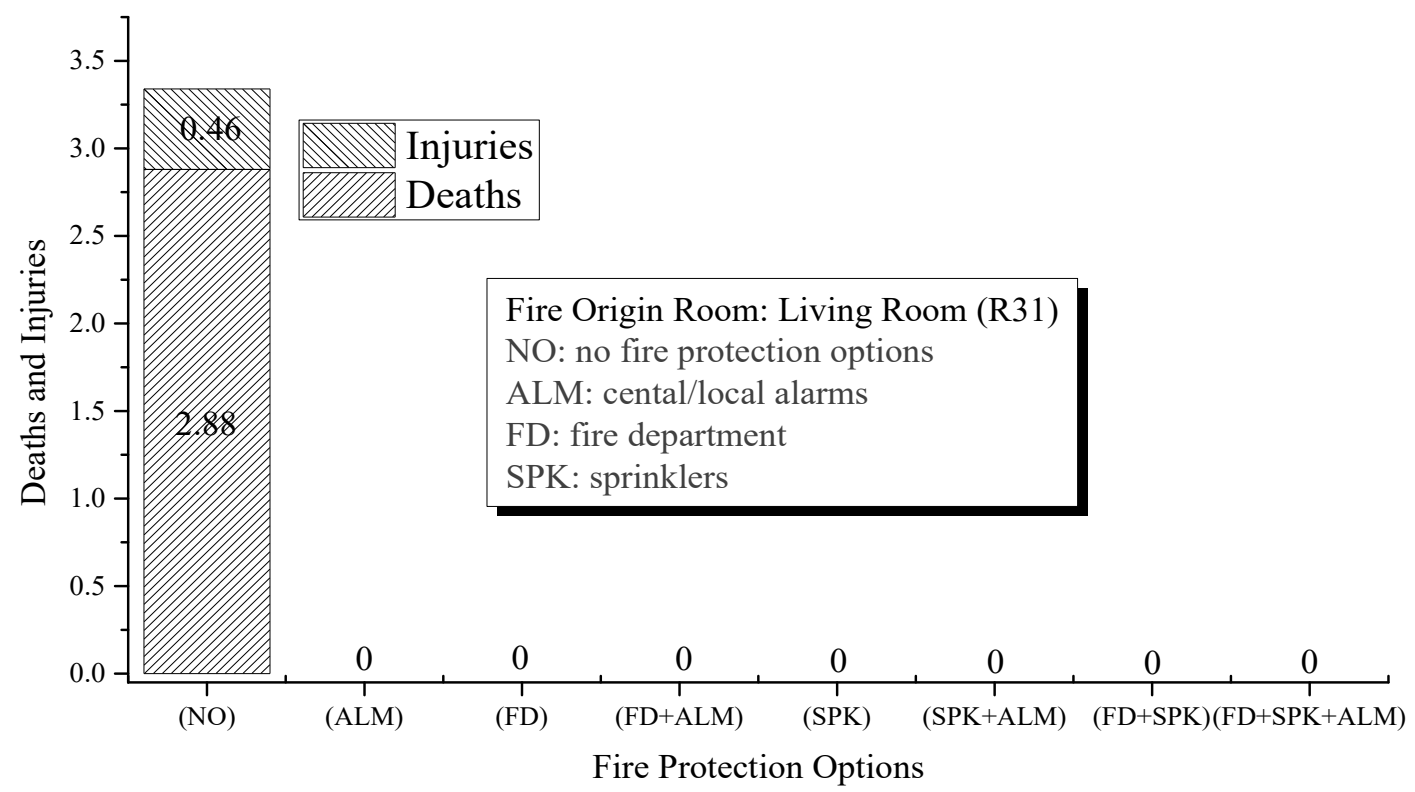

Figure 3-19 Total deaths and injuries due to 8 different fire protection options. Fire origin room: R31

In addition, fire damages and life risk are compared using eight different fire protection options. The 8 options are, 1) No systems; 2) Only alarms; 3) Only fire department; 4) Alarms and fire department; 5) Only sprinklers; 6) Sprinklers and alarms; 7) Sprinklers and fire department; 8) Fire department, sprinklers and alarms.

Figure 3-18 and Figure 3-19 show the results when the fire occurred in the 4th floor living room (R31), assuming that all fire protection measures are $100 \%$ reliable. The results show that deaths and injuries only occur when there are no fire protection systems installed. From Figure 3-18 and Figure 3-19 it can be seen that the fire department arrival time can significantly decrease the damage, such as for Option 3 and Option 4. When fire sprinklers are installed in the building, the losses can be reduced, such as for Option 5 to Option 8 .

\subsubsection{Design Options}

As mentioned in earlier sections, three design options are considered and all the scenarios 
for these options are shown in Figure 3-7 and Figure 3-8. After looping through all the scenarios, two decision making parameters the Expected Risk to Life $(E R L)$ and the Fire Cost Expectation $(F C E)$ are obtained.

The ERL, EROI (Expected Risk of Injury) and AFL (Expected Annual Fire Loss) are predicted by CUrisk for the three different options, and the results are shown in Table 3-5. From the table the fire performance of the design options can be compared, which shows that when both the sprinklers and alarms are installed (Option 1) in the building, the fire risk and damages can be reduced. Furthermore, when alarms are available, comparing Option 2 with Option 3, the ERL and EROI are lowered but the existence of alarms does not affect the level of AFL.

Table 3-5 CUrisk results for three different fire scenario design options

\begin{tabular}{|l|l|l|l|l|l|}
\hline $\begin{array}{l}\text { Design } \\
\text { option } \#\end{array}$ & Sprinklers & Alarms & ERL (per Y.P.) & EROI (per Y.P.) & AFL (k\$per Y.) \\
\hline 1 & $\mathrm{Y}$ & $\mathrm{Y}$ & $3.02 \times 10^{-7}$ & $9.63 \times 10^{-7}$ & 2.7 \\
\hline 2 & $\mathrm{~N}$ & $\mathrm{Y}$ & $6.04 \times 10^{-6}$ & $1.93 \times 10^{-5}$ & 27 \\
\hline 3 & $\mathrm{~N}$ & $\mathrm{~N}$ & $6.04 \times 10^{-5}$ & $2.40 \times 10^{-5}$ & 27 \\
\hline
\end{tabular}

Note: per Y.P. means per year per person

It is hard to find related fire statistics in terms of wood construction or hybrid multistory residential buildings, though some are in service and more are under design or construction. The fire casualty data from 2006 to 2010 were obtained from the Office of Fire Marshal in Ontario, Canada [91], as shown in Table 3-6. It is found that the results of CUrisk are close to those data and they have the same level of magnitude. Interestingly the death rate (same meaning as ERL) of Option 2 of CUrisk results is very close to the average Ontario fire death rate, but the fire injury rate (same meaning as EROI) is somewhat lower than the Ontario injury rate. Please note that the Ontario fire statistics are based on residential units, most of which are actually lower than six storeys, thus the comparison here may not be 
highly appropriate.

Table 3-6 Ontario, Canada fire statistics in recent five years

\begin{tabular}{|l|l|l|l|l|l|l|}
\hline Year & 2006 & 2007 & 2008 & 2009 & 2010 & Average \\
\hline Fire death rate $\left(\times 10^{-6}\right.$ per Y.P. $)$ & 5.9 & 6.5 & 6.5 & 5.8 & 5.3 & 6.0 \\
\hline Fire injury rate $\left(\times 10^{-6}\right.$ per Y.P. $)$ & 32.54 & 34.14 & 26.28 & 36.64 & 33.48 & 32.62 \\
\hline Ontario population ( million) & 12.2 & 12.8 & 12.9 & 13.1 & 13.2 & 12.84 \\
\hline
\end{tabular}

Note: per Y.P. means per year per person

\subsection{Summary}

In this chapter, an existing probabilistic fire spread model developed at Carleton University was introduced. In order to integrate this model into CUrisk as the Fire Spread submodel, the role and position of the Fire Spread submodel were analyzed, and the input and output data of the Fire Spread submodel were determined. Furthermore, changes in the system model were identified, the modifications of the Life Hazard submodel and Economic Loss submodel were implemented, and impacts of active fire protection systems were included. Those changes enable CUrisk to take the Fire Spared submodel into its system structure. With these modifications, CUrisk now can employ the Fire Spread submodel to predict the fire hazard conditions in a building fire, and adopt these intermediate data outputs to predict occupant safety as well as fire damage. Further, a case study of fire risk assessment is presented with the improved CUrisk. The newly integrated Fire Spread submodel demonstrated the effects of fire resistance design on fire spread hazard. The impacts of fire spread level on the building occupant safety as well as fire losses are also presented and discussed. 


\section{Chapter 4 Full-Scale Fire Tests on Combustible and Non-Combustible}

\section{Constructions}

\subsection{Introduction}

This chapter discusses six full-scale fire tests conducted at Carleton University's Fire Laboratory. These tests represent a realistic bedroom fire environment with different room construction types, i.e., Cross Laminated Timber (CLT) construction, Light Timber Frame construction and Light Steel Frame construction. The purposes of this study are to:

a) Understand the development features of realistic bedroom fires, including heat release rates and room temperature. This work will provide a database that can help to improve the prediction of fire development and evolution in the Fire Growth submodel and the Smoke Movement submodel;

b) Compare the performance of various construction types in natural fires, focusing on the failure of gypsum boards, reaction of inner structural component, and wood charring on the timber structural components. This study provides database regarding to barrier failure mechanism of diverse room structures, thus can provide reference for the development of the Barrier Failure submodel, and,

c) Investigate the fire contribution of combustible room structures, such as the CLT panels in CLT construction, and wood studs in Light Timber Frame construction. These findings will help to identify changes to CUrisk aiming to make CUrisk capable of reflecting the changes in the room fire severity based on the contribution of timber components.

\section{An introduction to Cross Laminated Timber (CLT)}

Because CLT as a relatively new engineered wood product is used as a test material in this 
study, a brief description of it is given as follows. Since the last decades interests in CLT construction have spreads from Europe to other parts of the world because of the favor of "green" buildings from the public and industries. A CLT panel consists of several layers of boards stacked crosswise and glued together on their wide faces (sometimes on the narrow faces as well) [50]. CLT products are usually fabricated with three to seven layers and even more in some cases, as shown in Figure 4-1.

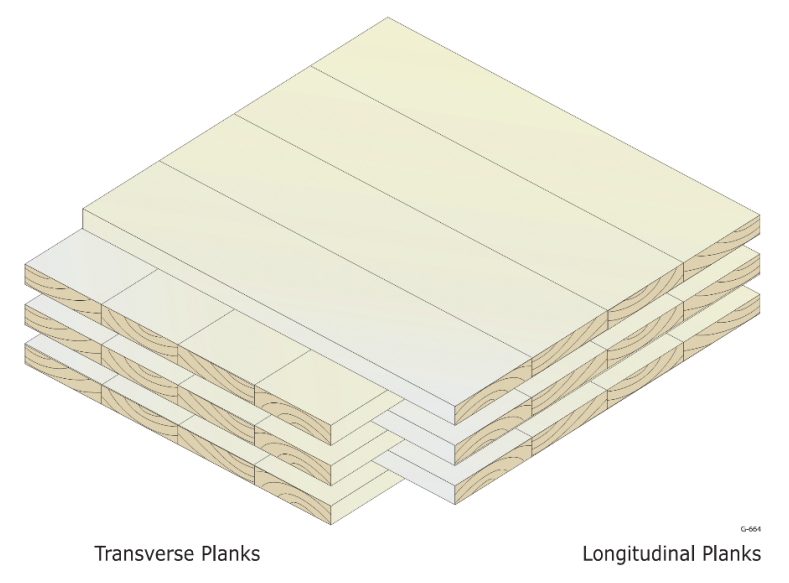

Figure 4-1 An illustration of CLT panel configuration (taken from [50])

The thickness of individual layer may be from $10 \mathrm{~mm}$ to $50 \mathrm{~mm}$ and the width from about $60 \mathrm{~mm}$ to $240 \mathrm{~mm}$, and panel sizes vary by manufacturers, typically $0.6 \mathrm{~m}, 1.2 \mathrm{~m}$, and $3 \mathrm{~m}$ in width, up to $18 \mathrm{~m}$ in length and up to $400 \mathrm{~mm}$ in thickness [50].

Because of large dimensions of CLT panels and the nature that predictable charring rate under fire, they can provide great fire resistance and maintain structural capacity under fire exposure, thus can be typically used as load-carrying building assemblies such as walls and floors [50].

\section{Previous related work at Carleton University}

Five full-scale tests were conducted at Carleton University Fire Research Laboratory in 
2012 by McGregor [92]. All the test rooms were constructed with Cross Laminated Timber (CLT) panels, protected or unprotected by gypsum boards (GB). The room size is exactly following the room size of [49], i.e., inner dimensions of the room (before installation of protective linings) were $4.5 \mathrm{~m}$ long, $3.5 \mathrm{~m}$ wide and $2.5 \mathrm{~m}$ high. The single opening was a door measuring $1.07 \mathrm{~m}$ wide and $2 \mathrm{~m}$ high. Four configurations were designed using two fuel types (propane and a real bedroom furniture set) and two lining options (protected by two layers of gypsum board and unprotected) on CLT panels. Tests 1 and 2 were repeated due to the temperature acquisition system failure in Test 1.

Table 4-1 Test configuration in McGregor's tests [92]

\begin{tabular}{|l|l|l|l|l|l|}
\hline Test \# & 1 & 2 & 3 & 4 (repeat of 2) & 5 \\
\hline Ambient Temp & $5.5^{\circ} \mathrm{C}$ & $17.5^{\circ} \mathrm{C}$ & $16^{\circ} \mathrm{C}$ & $27^{\circ} \mathrm{C}$ & $21^{\circ} \mathrm{C}$ \\
\hline Protected by 2 layers of GB & Yes & Yes & No & Yes & No \\
\hline Fuel type & Propane & Furniture & Propane & Furniture & Furniture \\
\hline
\end{tabular}

The aim of the study was to investigate the contribution of CLT construction to the development, duration and intensity of room fires.

\subsection{Test descriptions}

In this work, as a continuation of McGregor's fire tests [92] three full-scale tests were conducted on combustible constructions (CLT and light timber-frame) and noncombustible constructions (light steel-frame). This study selects six tests that used furniture as the fuel from the series of fire tests conducted at Carleton University and provides a comprehensive analysis of the test data. The test configurations are shown in Table 4-2. The fire tests includes three CLT room fires mentioned in Section 4.1.2, i.e., protected CLT room ( 2 tests) and unprotected CLT room ( 1 test), and the three tests conducted later that includes the light timber-frame construction ( 2 tests, lined by 1 layer or 2 layers of gypsum 
board on the fire exposed side) and light steel-frame construction (1 test, lined with 1 layer of gypsum board).

Table 4-2 Tests configurations

\begin{tabular}{|l|l|l|l|l|l|}
\hline Test \# & $1 \& 2$ & 3 & 4 & 5 & 6 \\
\hline Construction type & CLT & CLT & $\begin{array}{l}\text { Light timber- } \\
\text { frame }\end{array}$ & $\begin{array}{l}\text { Light timber- } \\
\text { frame }\end{array}$ & $\begin{array}{l}\text { Light steel } \\
\text { frame }\end{array}$ \\
\hline $\begin{array}{l}\text { Gypsum boards } \\
\text { lining }\end{array}$ & Double & None & Double & Single & Single \\
\hline
\end{tabular}

\subsubsection{Room construction}

The room was originally constructed with CLT panels to study CLT performance in natural fires. Test 1 to Test 3 were performed in protected or unprotected CLT rooms. For Test 4 to Test 6, light frame wall structures were attached to those CLT panels in order to maintain structural stability. Thus, all the walls were non-load bearing.

The CLT panels were produced and pre-fabricated by Nordic Engineered Wood. The CLT panels had three layers each $105 \mathrm{~mm}$ thick. The outermost layer was made from SPF 1950Fb machine stress-rated (35 x $89 \mathrm{~mm})$ lumber and the center layer was made from SP-F No 3/Stud (35 x $89 \mathrm{~mm})$ at a 90 degree offset orientation.

The test rooms were first assembled with CLT panels, including all the walls, ceiling and floor, as illustrated in Figure 4-3. The exterior size of the room measured $4.71 \mathrm{~m}$ long $\times$ 3.71m wide $\times 2.71 \mathrm{~m}$ high, see Figure $4-4$ and Figure 4-5. Deducting the thickness of the bare CLT panel, the inner size of the room before applying any linings becomes $4.5 \mathrm{~mm}$ long $\times 3.5 \mathrm{~mm}$ wide $\times 2.5$ high, exactly the same as the room size in Hakkarainen's study [49]. Instead of a window opening $(1.2 \mathrm{~m} \times 2.3 \mathrm{~m})$ in Hakkarainen's study, a doorway measuring $1.069 \mathrm{~m}$ wide and $2 \mathrm{~m}$ high was installed in the front wall as shown in Figure 4-4. 

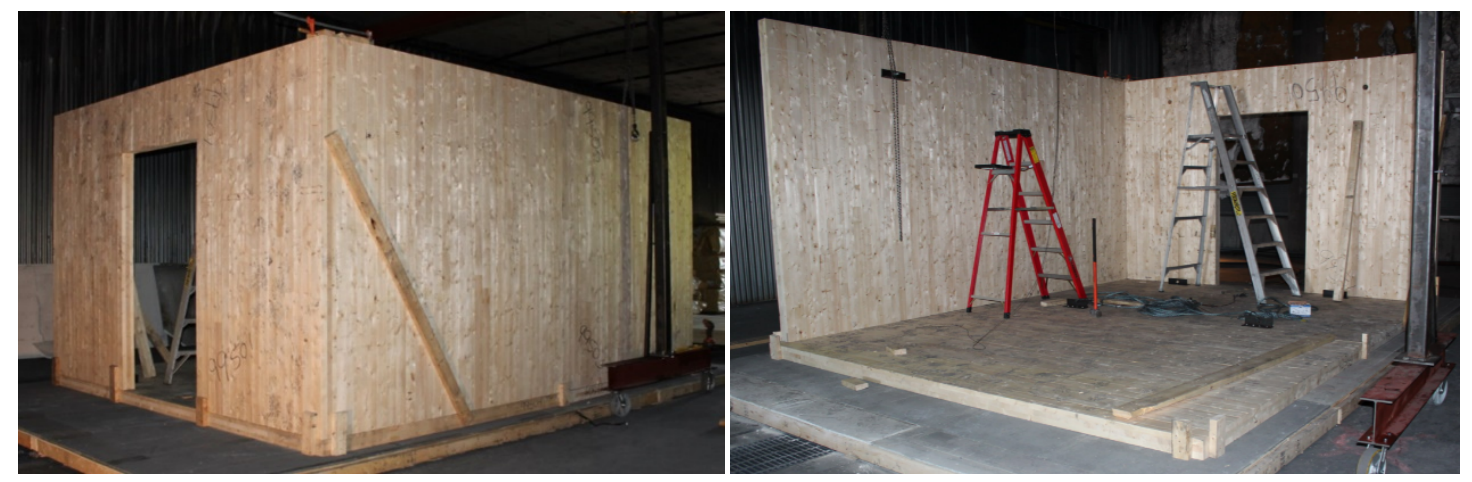

Figure 4-2 CLT room outlook

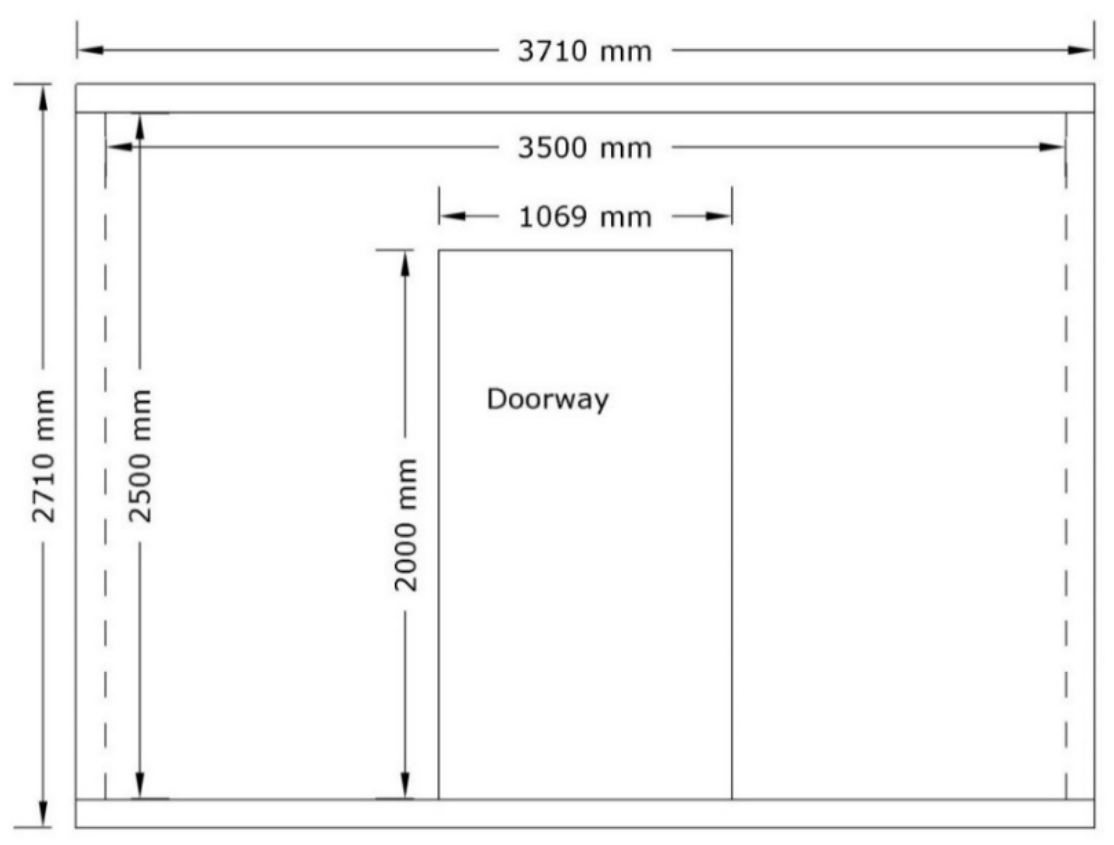

Figure 4-3 Front View of the test room 


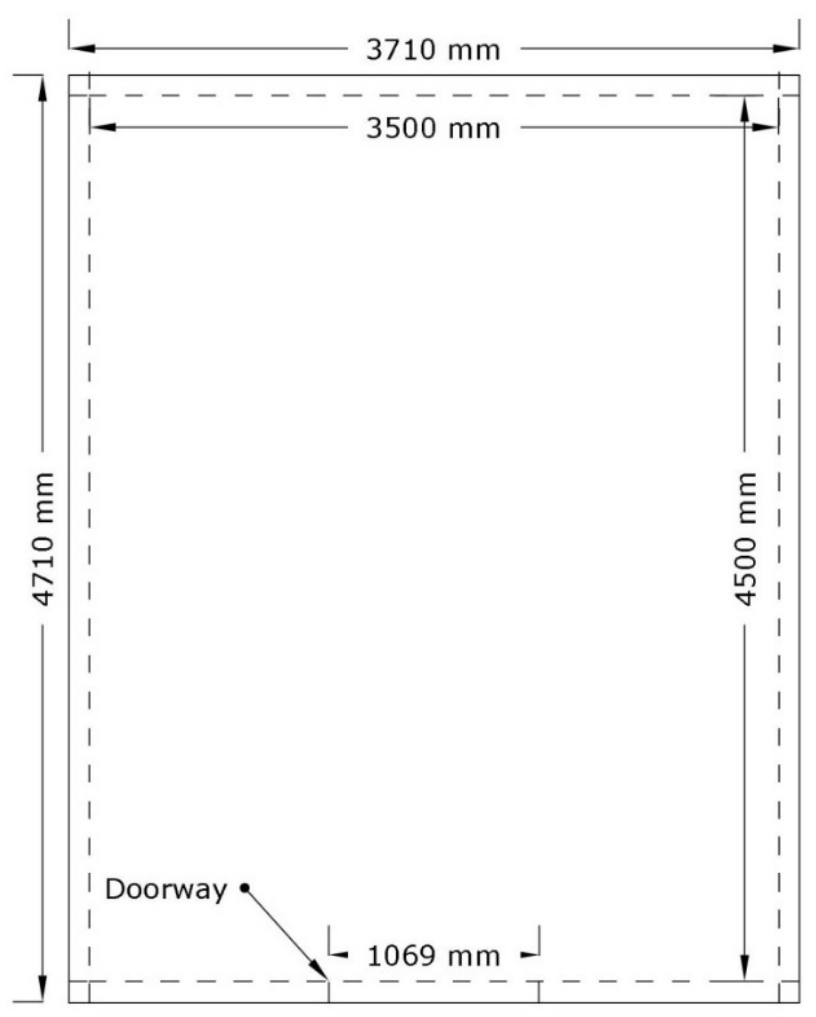

Figure 4-4 Top View of the test room

Three types of joints were used to connect the CLT panels in the room construction. Lap joints connecting panels longitudinally at the walls, ceiling and floor were secured at 300 mm intervals with $6 \mathrm{~mm} \times 100 \mathrm{~mm}$ self-tapping screws. Wall to wall corner joints were secured at $300 \mathrm{~mm}$ intervals with $8 \mathrm{~mm}$ x $180 \mathrm{~mm}$ self-tapping screws. $8 \mathrm{~mm}$ x $180 \mathrm{~mm}$ self-tapping screws were used at $300 \mathrm{~mm}$ intervals and driven in at 45 degree to form wall to floor joints.

The CLT floor panel in each room was protected with a layer of ProRoc ${ }^{\circledR}$ Type X fire rated $15.9 \mathrm{~mm}(5 / 8 \mathrm{inch})$ fire rated gypsum with a layer of Permabase ${ }^{\circledR} 12.7 \mathrm{~mm}$ cement board installed on top. A layer of $19 \mathrm{~mm}$ hardwood tongue and groove maple flooring was installed on top of the concrete board. 


\subsubsection{Test 1 to 3, CLT room tests}

Test 1 and Test 2 had exactly the same room configuration. Walls and ceiling were lined with two layers of $12.7 \mathrm{~mm}$ (1/2 inch) ProRoc ${ }^{\circledR}$ Type-C fire rated gypsum board on top of the CLT panels. The second layer of the gypsum board was installed at an offset with the first layer to make sure that no joints were aligned on both layers. In Test 3, the wall and ceiling CLT panels were totally exposed.

\subsubsection{Test 4 to Test 6 , light frame room tests}

Light-framed walls were built over the CLT panels, in order to maintain the structural stability during the fire. On the unexposed side of the light-framed walls, two layers of 12.7 mm ProRoc ${ }^{\circledR}$ Type C fire rated gypsum boards were secured on top of the CLT wall panels inside the room. In Test 4 and Test 5, the timber-frame walls and ceiling were constructed with nominal 2 by 4 (actually measuring $38.1 \mathrm{~mm}$ by $88.9 \mathrm{~mm}$ ) timber studs including vertical studs, top and bottom plates. Vertical wood studs were spaced $406 \mathrm{~mm}$ (16 inches) from stud centerlines and fastened to the gypsum boards and CLT panels. The exposed sides of the walls and ceiling were protected with one or two layers of $12.7 \mathrm{~mm}$ ProRoc ${ }^{\circledR}$ Type C fire rated gypsum boards, depending on the configuration. When two layers of gypsum boards were used, the second layer was installed at an offset. In Test 6, steel frame walls and ceilings were employed, which were constructed using $63.5 \mathrm{~mm}$ x $31.75 \mathrm{~mm}$ x $0.46 \mathrm{~mm}$ thick cold-formed steel lipped channel section studs with 4 service holes in the web on each stud. Studs were spaced $406 \mathrm{~mm}$ (16 inches) from centerlines, arranged in the horizontal tracks that were anchored to the floor and ceiling. The exposed side of the light frame was protected with one layer of $12.7 \mathrm{~mm}$ ProRoc $^{\circledR}$ Type $\mathrm{C}$ fire rated gypsum boards. All the cavities in Test 4 to 6 were insulated with $89 \mathrm{~mm}$ R-12 EcoTouch $^{\mathrm{TM}}$ PINK $^{\mathrm{TM}}$ 
FIBERGLAS $^{\circledR}$ insulation. Ceiling and floor configurations were the same as those in the first three tests.

To ensure that no additional material contributed to the fire, the door frames in all the tests were lined with two layers of precut $12.7 \mathrm{~mm}$ fire rated gypsum boards, and the external front wall was lined with one layer of $12.7 \mathrm{~mm}$ fire rated gypsum board. The gypsum boards in these positions and the front external roof were then covered with $25 \mathrm{~mm}$ fiberglass blankets. In this way, the thermocouple wires on the roof were also protected. In addition, all screw heads, joints and corners in each layer of gypsum were taped and skimmed with building compound to provide a completed seal.

A summary of wall structures is listed in Table 4-3, and a summary of room components is listed in Table 4-4.

Table 4-3 Walls and ceiling structures and thicknesses in Test 4 to Test 6

\begin{tabular}{|l|l|l|l|l|}
\hline & Test 4 & Test 5 & Test 6 & Ceiling/roof \\
\hline $\begin{array}{l}\text { Vertical } \\
\text { Cross-section }\end{array}$ & & & & \\
\hline $\begin{array}{l}\text { Structure } \\
\text { (fire } \\
\text { unexposed to } \\
\text { exposed side }\end{array}$ & $\begin{array}{l}\text { CLT panel, } \\
\text { 2 layers GBs, } \\
\text { Wood stud } \\
\text { 2 layers GBs }\end{array}$ & $\begin{array}{l}\text { CLT panel, } \\
\text { 2 layers GBs, } \\
\text { Wood stud, } \\
\text { 1 layer GB }\end{array}$ & $\begin{array}{l}\text { CLT panel, } \\
\text { 2 layers GBs, } \\
\text { Metal stud, } \\
1 \text { layer GB }\end{array}$ & $\begin{array}{l}\text { CLT panel, } \\
\text { 2 layers GBs }\end{array}$ \\
\cline { 2 - 5 } & $\begin{array}{l}\text { Wood or metal studs spaced at 16 inch, cavity filled } \\
\text { with fiberglass }\end{array}$ & 206.3 & 130.4 \\
\hline $\begin{array}{l}\text { Theoretical } \\
\text { Thickness } \\
(\mathrm{mm})\end{array}$ & 245 & 232.3 & 207 & 131 \\
\hline $\begin{array}{l}\text { Actual } \\
\text { thickness } \\
(\mathrm{mm})\end{array}$ & 250 & 233 & & \\
\hline
\end{tabular}


Table 4-4 Properties of room components

\begin{tabular}{|c|c|c|}
\hline Components & Thickness (mm) & Description \\
\hline CLT panel & 105 & $\begin{array}{l}3 \text { layers, produced and pre-fabricated by Nordic } \\
\text { Engineered Wood }\end{array}$ \\
\hline Type C GB & 12.7 (or $1 / 2$ inch) & $\begin{array}{l}\text { ProRoc } \AA \text { Type-C fire rated, Width of } 48 \text { inches } \\
(1.22 \mathrm{~m}) \text {, length } 96 \text { inches }(2.438 \mathrm{~m})\end{array}$ \\
\hline Type X GB & 15.9 (or $5 / 8$ inch) & $\begin{array}{l}\text { ProRoc } \AA \text { Type } X \text { fire rated, Width of panel } 48 \\
\text { inches }(1.22 \mathrm{~m})\end{array}$ \\
\hline Wood stud & $\begin{array}{l}88.9 \text { (by } 38.1 \text {, or } 3.5 \\
\text { inch by } 1.5 \text { inch) }\end{array}$ & $\begin{array}{l}2 \text { by } 4 \text { inch }(35 \text { studs } \times 238.6 \mathrm{~cm}+2960 \mathrm{~cm} \text { plates } \\
=113 \mathrm{~m} \text {, estimated total weight } 191 \mathrm{~kg})\end{array}$ \\
\hline Metal stud & 63.5 (by 31.75$)$ & $\begin{array}{l}\text { flange } 1 \frac{1}{4} \text { inch by Web } 2 \frac{1}{2} \text { inch and Return lip } \\
1 / 4 \text { inch, thickness } 0.46 \mathrm{~mm} \text {. }\end{array}$ \\
\hline Fiber glass & 89.0 (or 3.5 inch) & 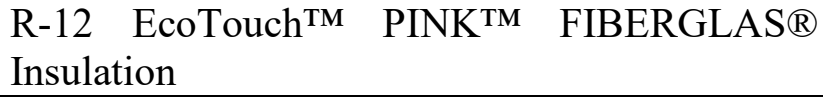 \\
\hline $\begin{array}{l}\text { Maple } \\
\text { flooring } \\
\text { Deck }\end{array}$ & 19.1 (or3/4 inch) & $\begin{array}{l}\text { a layer hardwood tongue and groove maple } \\
\text { flooring }\end{array}$ \\
\hline Cement board & 12.7 (or $1 / 2$ inch) & 1 layer of $12.7 \mathrm{~mm}$ Permabase ${ }^{\circledR}$ cement board \\
\hline
\end{tabular}

A summary of room interior sizes, doorway opening sizes for all the tests are presented in Table 4-5. For comparison, the configuration of Hakkarainen' tests [49] are also included. Due to the light framed construction inside the CLT rooms, room interior sizes in Test 4, 5 and 6 were slightly smaller than the first three tests. The doorway sizes after lining the protection materials varies slightly. The opening factors are also calculated by this equation,

$$
F_{o}=A_{v} \sqrt{H_{v}} / A_{T}
$$

where $A_{v}$ and $H_{v}$ are the area and height of the window opening, respectively, and $\mathrm{A}_{\mathrm{T}}$ is the total area of inner boundary surfaces (opening area included).

The above formula produces equivalent opening factors for all the tests, and consequently equivalent theoretical maximum heat release rates calculated by [87]

$$
\dot{Q}_{\max }=1518 A_{v} \sqrt{H_{v}}
$$


Table 4-5 Interior room sizes, doorway sizes and estimated maximum heat release rates

\begin{tabular}{|c|c|c|c|c|c|c|c|}
\hline \multirow[t]{2}{*}{ Test \# } & \multicolumn{3}{|c|}{$\begin{array}{l}\text { Room Interior } \\
\text { Size }\end{array}$} & \multicolumn{2}{|c|}{$\begin{array}{l}\text { Doorway } \\
\text { Opening Size }\end{array}$} & \multirow{2}{*}{$\begin{array}{l}\text { Opening } \\
\text { Factor }\end{array}$} & \multirow[t]{2}{*}{$\begin{array}{l}\text { Estimated Maximum } \\
\text { HRR (MW) }\end{array}$} \\
\hline & $\mathrm{W}$ & $\mathrm{D}$ & $\mathrm{H}$ & $\mathrm{W}$ & $\mathrm{H}$ & & \\
\hline 1,2 & 3.45 & 4.45 & 2.5 & 1.07 & 2 & 0.0423 & 4.594 \\
\hline 3 & 3.5 & 4.5 & 2.5 & 1.07 & 2 & 0.0423 & 4.594 \\
\hline 4 & 3.21 & 4.22 & 2.42 & 1.12 & 1.96 & 0.0487 & \multirow{3}{*}{4.665} \\
\hline 5 & 3.24 & 4.24 & 2.42 & 1.12 & 1.96 & 0.0482 & \\
\hline 6 & 3.29 & 4.29 & 2.42 & 1.12 & 1.96 & 0.0473 & \\
\hline Hakkarainen & 3.5 & 4.5 & 2.5 & 2.3 & 1.2 & 0.0423 & 4.589 \\
\hline
\end{tabular}

\subsubsection{Fuels}

All the tests used the same bedroom furniture sets, as demonstrated in Figure 4-8. In order to keep exactly the same quantity and quality of the fuel in each test, all the room furniture sets were bought directly from a store with the same brands and models. The weights of those fuel components were either taken from the product specifications or weighed at the laboratory. The heat of combustion values used were based on a survey of Canadian residential buildings conducted by Bwalya [93]. For heat of combustion of wood, Lennon [42] adopted $17 \mathrm{MJ} / \mathrm{kg}$, Hakkarainen [49] adopted $15.5 \mathrm{MJ} / \mathrm{kg}$, and Eurocode 1 [37] recommends $17.5 \mathrm{MJ} / \mathrm{kg}$. Wood flooring was also included in the fuel load because it is directly involved in the fires. However, combustible room structural components such as CLT panels and light timber-frame were not included. A list of the fuel contents is provided in Table 4-6, and the fuel distribution inside the room is shown in Figure 4-9. 


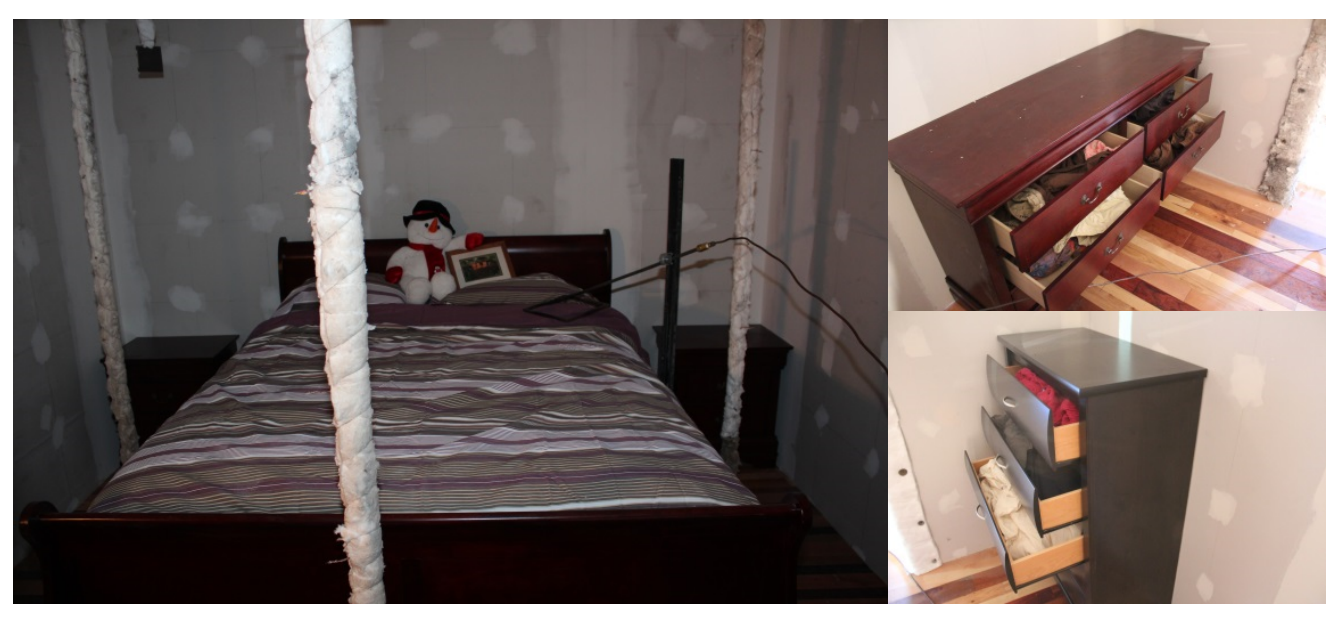

Figure 4-5 Photos of furniture set inside the test room

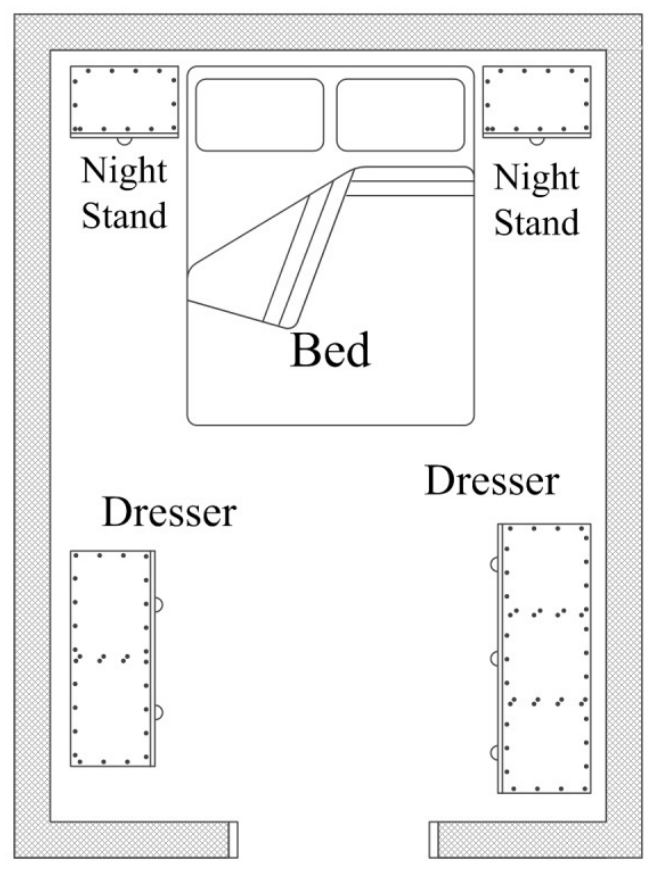

Figure 4-6 Fuel layout in the room

The minor differences among fuel loads and densities were due to slight variations of the wooden floor densities as well as floor areas. The test room size and its fuel load (ranging from 529 to $624 \mathrm{MJ} / \mathrm{m}^{2}$ ) in this study well represented a common residential primary bedroom as reported by Bwalya, et.al [93]. 
Table 4-6 List of fuels

\begin{tabular}{|c|c|c|c|c|c|c|c|}
\hline \multicolumn{2}{|l|}{ Fuel name and heat release rates } & \multicolumn{6}{|c|}{ Weight in Test \# (kg) } \\
\hline Fuel name & $\begin{array}{l}\Delta H_{c} \\
(\mathrm{MJ} / \mathrm{kg})\end{array}$ & 1 & 2 & 3 & 4 & 5 & 6 \\
\hline Headboard and footboard & 18 & \multicolumn{6}{|c|}{29.5} \\
\hline Queen bed sleigh side rail & 18 & \multicolumn{6}{|c|}{12.5} \\
\hline Mattress & 20 & \multicolumn{6}{|c|}{39.5} \\
\hline Bedspring & 20 & \multicolumn{6}{|c|}{16.2} \\
\hline Bedding (Pillows, Sheets, Duvet) & 20 & \multicolumn{6}{|c|}{6.3} \\
\hline 6 drawer dresser (taller) & 18 & \multicolumn{6}{|c|}{60} \\
\hline Dresser (shorter) & 18 & \multicolumn{6}{|c|}{46} \\
\hline Night stand $* 2$ & 18 & \multicolumn{6}{|c|}{24} \\
\hline Clothes or paper books & 20 & \multicolumn{6}{|c|}{20} \\
\hline Maple floor & 18 & 221 & 235 & 223 & 199 & 202 & 207 \\
\hline \multicolumn{2}{|l|}{ Fuel load and density } & \multicolumn{6}{|c|}{ Energy load in Test \# (kg) } \\
\hline \multicolumn{2}{|l|}{ Total fuel load (MJ) } & 8395 & 8710 & 8332 & 8318 & 8368 & 8458 \\
\hline \multicolumn{2}{|l|}{ Fuel load density $(\mathrm{MJ} / \mathrm{m} 2)$} & 533 & 553 & 529 & 614 & 609 & 601 \\
\hline
\end{tabular}

At the beginning of each test, a propane burner was placed on the top of the duvet close to a pillow. The test time commenced when the burner was ignited. After sustainable burning occurred on the bed, the propane burner was removed.

\subsubsection{Temperature measurement}

Temperature measurements were taken using thermocouples in the form of thermocouple trees (TCT), plate thermometers (PTC) and embedded thermocouples (ETC). A total of 4 TCTs were installed at 4 different positions in the room. These TCTs were constructed with steel tubes in which holes were drilled at specific heights, and then wrapped with a $12.7 \mathrm{~mm}$ fiberglass layer for protection. Unshielded type $\mathrm{K}$ thermocouple wires were inserted into the pipe with the thermocouple heads exiting through the pipe holes, as illustrated in Figure 4-10. TCTs were made like this in all the tests except Test 4, in which test TCTs were made with fire insulation boards instead of steel tubes. However, this attempt turned out to be a failure because three out of four trees were destroyed in the test. 


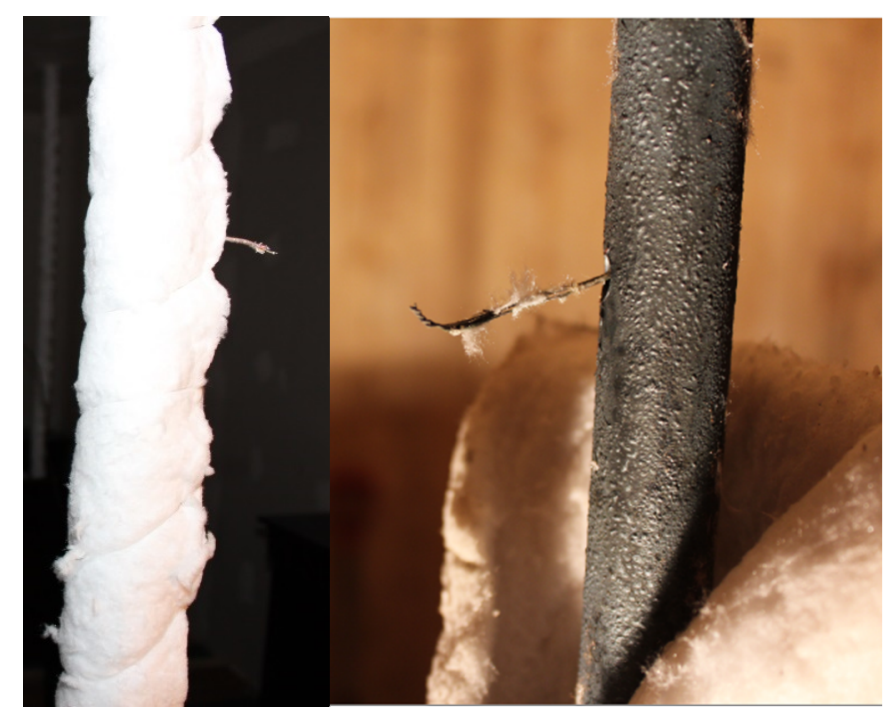

Figure 4-7 Image of segment of thermocouple trees (left: steel tube after protection; right: steel tube with drilled holes)

TCT positions for Test 1 to 3 are demonstrated in Figure 4-11, denoted as TCT1a, TCT2a, TCT3a and TCT4a. TCTs in Test 4 to 6 included 8 thermocouples on each tree, at heights $0.3,0.6,0.9,1.2,1.5,1.8,2.1$ and $2.4 \mathrm{~m}$, and the 4 TCTs were located at the back corner, center and front corner of the room and the doorway. TCT positions for Test 4 to 6 are also demonstrated in Figure 4-11, denoted as TCT1b, TCT2b, ТCT3b and TCT4b.

Plate thermometers (PTC) were used in all the tests and positioned at different positions. A plate thermometer [94] has a large surface area which is more sensitive to radiative heating than a standard thermocouple which has a small surface area and is more sensitive to local convective heat transfer. The plate thermometer represents a reading of the adiabatic surface temperature of the plate which may differ from the surrounding gases significantly. In Test 1 to 3 , only one PTC was employed at $1.5 \mathrm{~m}$ height shown as PTCa in Figure 4-11. In Test 4 to 6, three PTCs were located at back corner, center and front corner of the room, $0.5 \mathrm{~m}$ below the ceiling as shown in Figure 4-11, and denoted as PTC1b, PTC2b and PTC3b. 


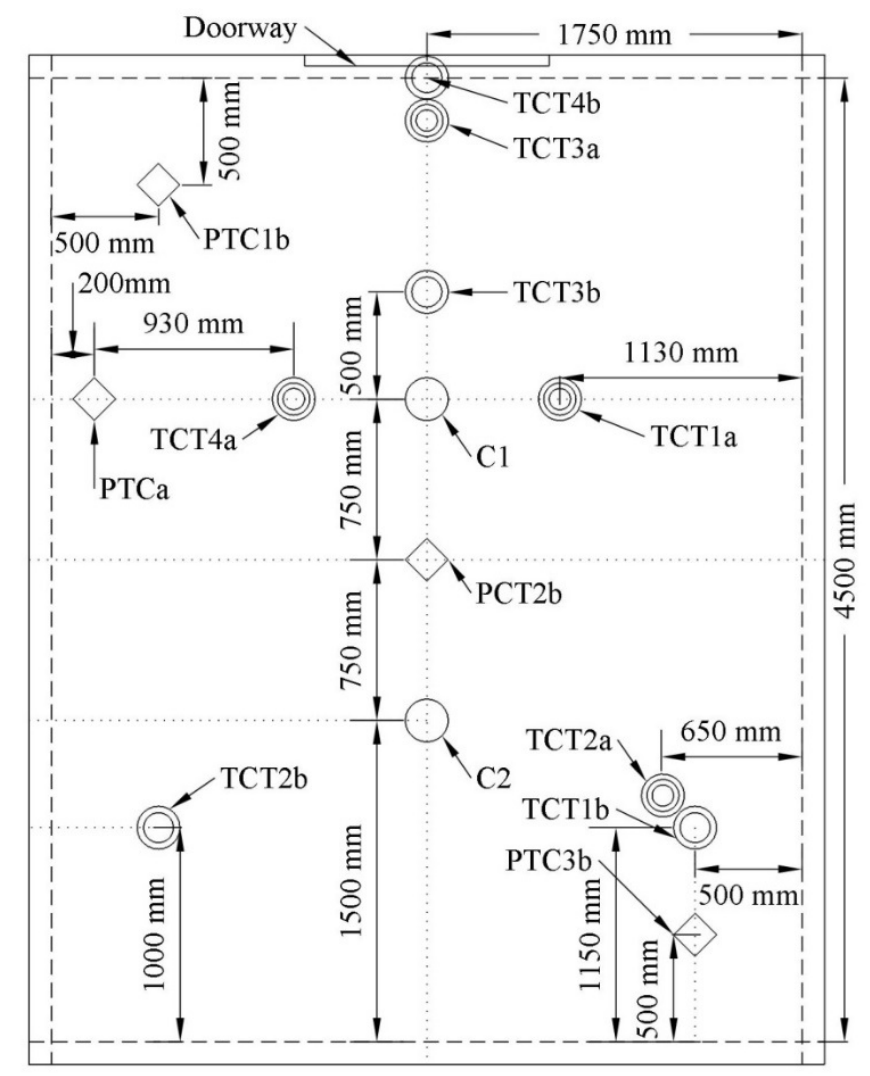

Figure 4-8 Locations of TCTs, PTCs and ceiling ETCs in all the tests

Embedded thermocouples (ETC) were distributed inside the walls and ceiling to measure temperatures at specific depths. Those thermocouples were OMEGA ${ }^{\circledR}$ Heavy Duty Transition Joint Probes (model TJ36-CAXL-116U-12): Type K sheathed thermocouple with $1 / 16$ inch $(1.5875 \mathrm{~mm})$ sheath diameter and 12 inches $(304.8 \mathrm{~mm})$ sheath length. 2.5 mm pilot holes were drilled from external wall surface to those desired depth points using a hand-held driller, and then thermocouples were inserted into those holes. To maintain the stability of ETCs, extension of ETC wires were fixed onto the walls using staples.

8 groups of ETCs were installed in the walls and ceilings in Tests 1 to 3 , and in Tests 4 to 6 the number was 11. Each group of ETCs was located at a specific position on the wall (W1 to W6 in Tests 1 to 3 , and W1 to W9 in Tests 4 to 6)) or ceiling (C1, C2 for all the tests). The position of two groups of ceiling ETCs were same in all the tests, and denoted 
as $\mathrm{C} 1$ and $\mathrm{C} 2$ as shown in Figure 4-11.

In Tests 1 to 3, 6 groups of ETCs (W1 to W6) were located in the right side wall (when looking in the room through the door), and 2 groups of ETCs ( $\mathrm{C} 1$ and $\mathrm{C} 2)$ were located on the ceiling; positions are shown in Figure 4-12. Each group including C1 and C2 contained 6 thermocouples and their respective depths measured from the fire exposed side are shown in Table 4-7.

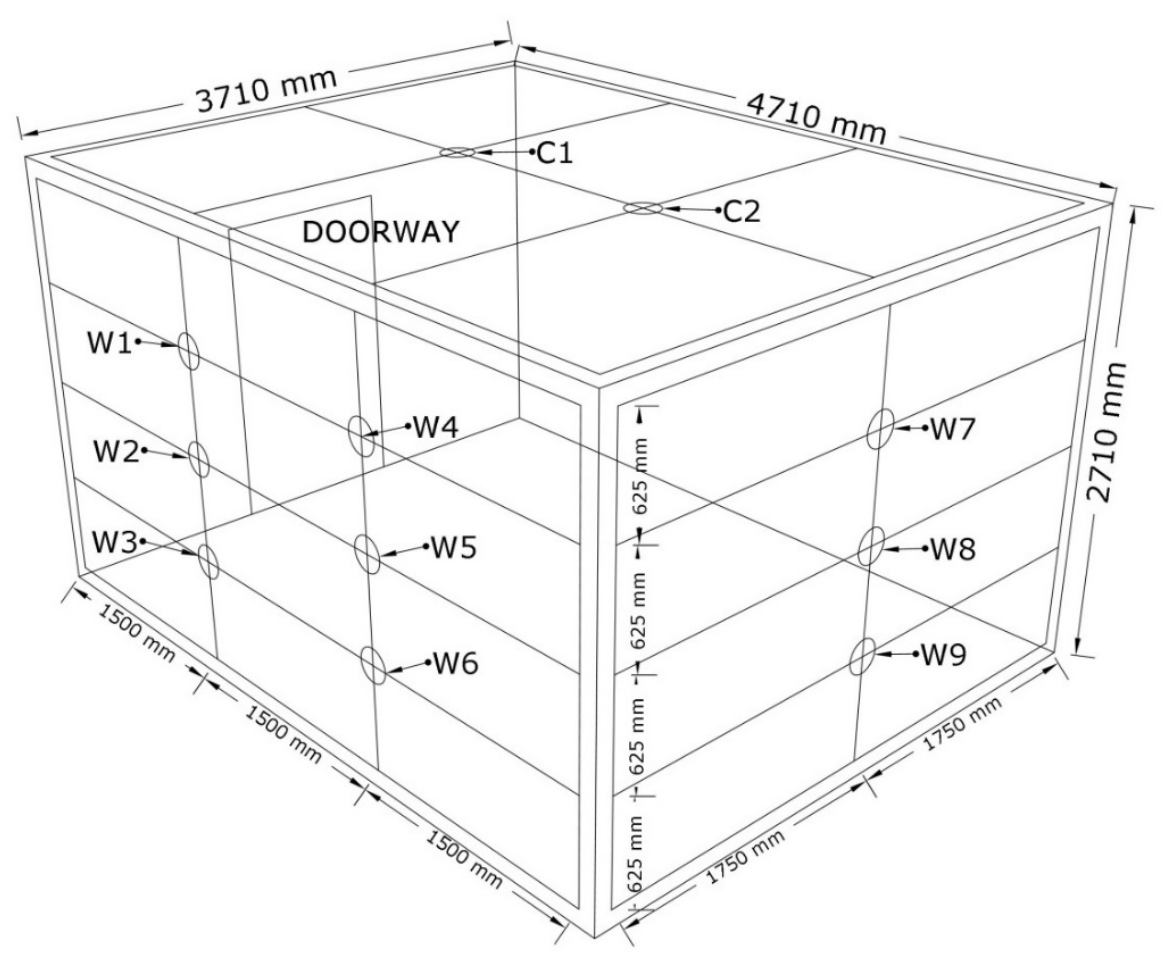

Figure 4-9 Wall thermocouple groups locations in Test 1 to 3

In Tests 4 to 6, 9 groups of wall ETCs were located at right side wall (W1 to W6) and the back wall (W7 to W9). The positions of W1 to W6 were similar to that in Tests 1 to Test 3 but slightly shifted to the nearest wood studs, because ETC groups had to be positioned into the studs and adjacent cavity. Likewise, the positions of W7 to W9 were located vertically along the center stud in the back wall, following the same height interval. Each group contained 10 thermocouples located at different wall depths, and the depths are listed 
in Table 4-7. To help to understand how thermocouples in each ETC group were arranged in Tests 4 to 6 , thermocouple locations inside the wall were dotted in Figure 4-13, and a photo of a group of ETCs on the wall is shown in Figure 4-14. Unlike Tests 1 to 3, there were two thermocouples in $\mathrm{C} 1$ and $\mathrm{C} 2$, respectively. One was at the interface of the two gypsum boards and the other was at the interface of the gypsum board and the CLT panel.

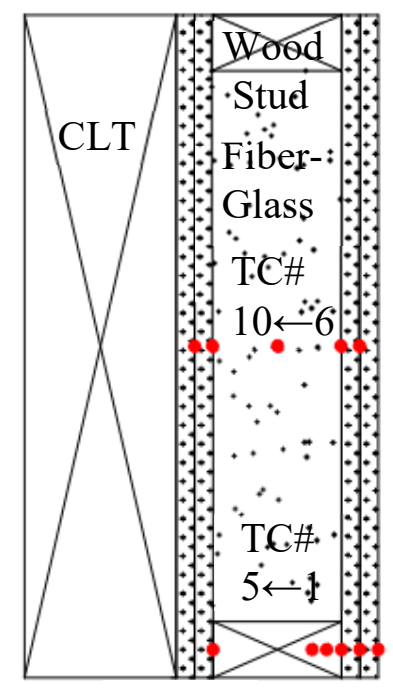

Test 4

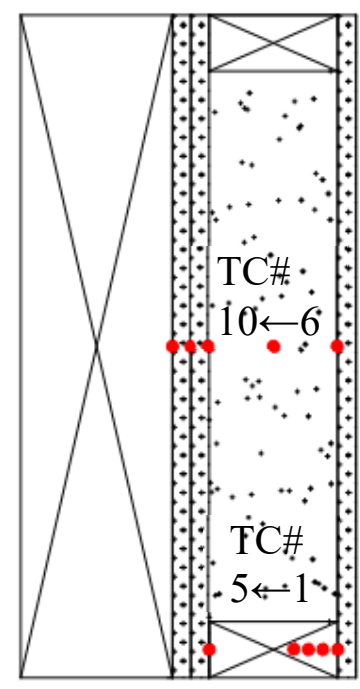

Test 5

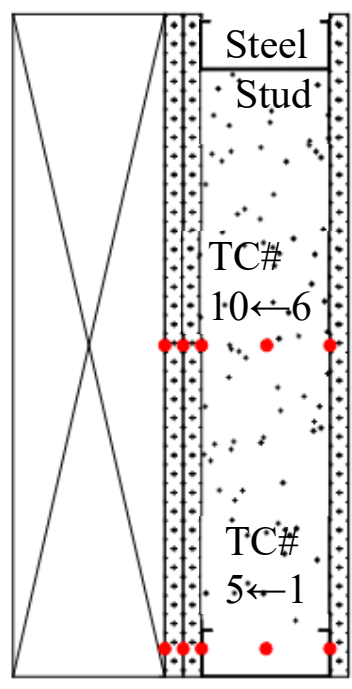

Test 6

Figure 4-10 Thermocouple depths in each ETC group in Test 4 to Test 6, an illustration

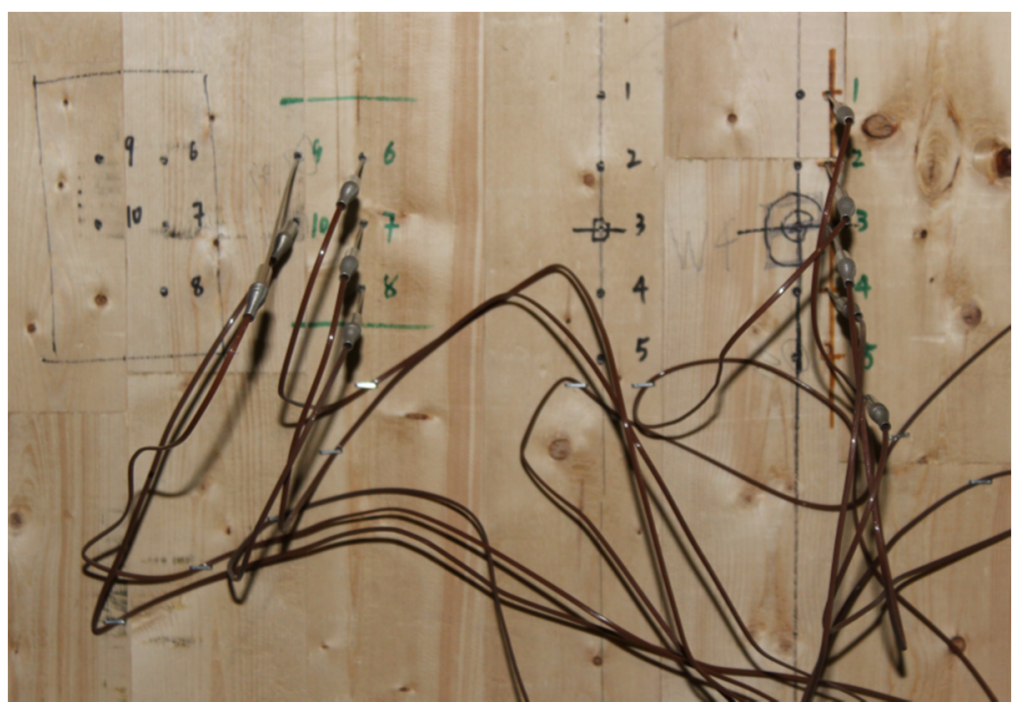

Figure 4-11 An illustration of one group of ETC on the external wall surface 
Table 4-7 ETC positions from fire exposed side to outside, number denotes mm into wood studs

\begin{tabular}{|l|c|c|l|l|l|}
\hline TC \# & Test 1,2 & Test 3 & Test 4 & Test 5 & Test 6 \\
\hline 1 & Gyp/Gyp* & 3 & Gyp/Gyp & Gyp/Stud & Gyp/Stud \\
\hline 2 & Gyp/CLT & 6 & Gyp/Stud & 10 & Mid-Stud \\
\hline 3 & $6^{* *}$ & 9 & 10 & 20 & Stud/Gyp \\
\hline 4 & 12 & 12 & 20 & 30 & Gyp/Gyp \\
\hline 5 & 18 & 18 & Stud/Gyp & Stud/Gyp & Gyp/CLT \\
\hline 6 & 24 & 24 & Gyp/Gyp & Gyp/Fbgs & Gyp/Fbgs \\
\hline 7 & - & - & Gyp/Fbgs & Mid-Fbgs & Mid-Fbgs \\
\hline 8 & - & - & Mid-Fbgs & Fbgs/Gyp & Fbgs/Gyp \\
\hline 9 & - & - & Fbgs/Gyp & Gyp/Gyp & Gyp/Gyp \\
\hline 10 & - & - & Gyp/Gyp & Gyp/CLT & Gyp/CLT \\
\hline
\end{tabular}

*The component 1/component 2 means the interface between component 1 and component 2 , from the fire exposed side to unexposed side.

**The number denotes depth into CLT (Tests 1 to 3 ) or wood studs (Tests 4 to 6), in mm.

\subsubsection{Heat release rate measurement}

The heat release rate (HRR) measurement system was located at the Carleton University fire lab, and this system was originally built to measure the HRRs in tunnel fires [95] as demonstrated in Figure 4-15. The tunnel measures $37.5 \mathrm{~m}$ long by $10.0 \mathrm{~m}$ wide by $5.6 \mathrm{~m}$ high. There is a ceiling opening at the left side of the tunnel that is connected to the mechanical exhaust system on top of the tunnel. The mechanical exhaust system is located above the tunnel, and consists of a number of interconnected chambers and three fans each of which is capable of exhausting $44 \mathrm{~m}^{3} / \mathrm{s}$ of gas. Thermocouples, gas analyzers and pressure transducers are installed inside the mechanical exhaust system. All smoke generated from the room fires could directly enter the mechanical exhaust system on top of the tunnel and real-time heat release rates could be obtained. 


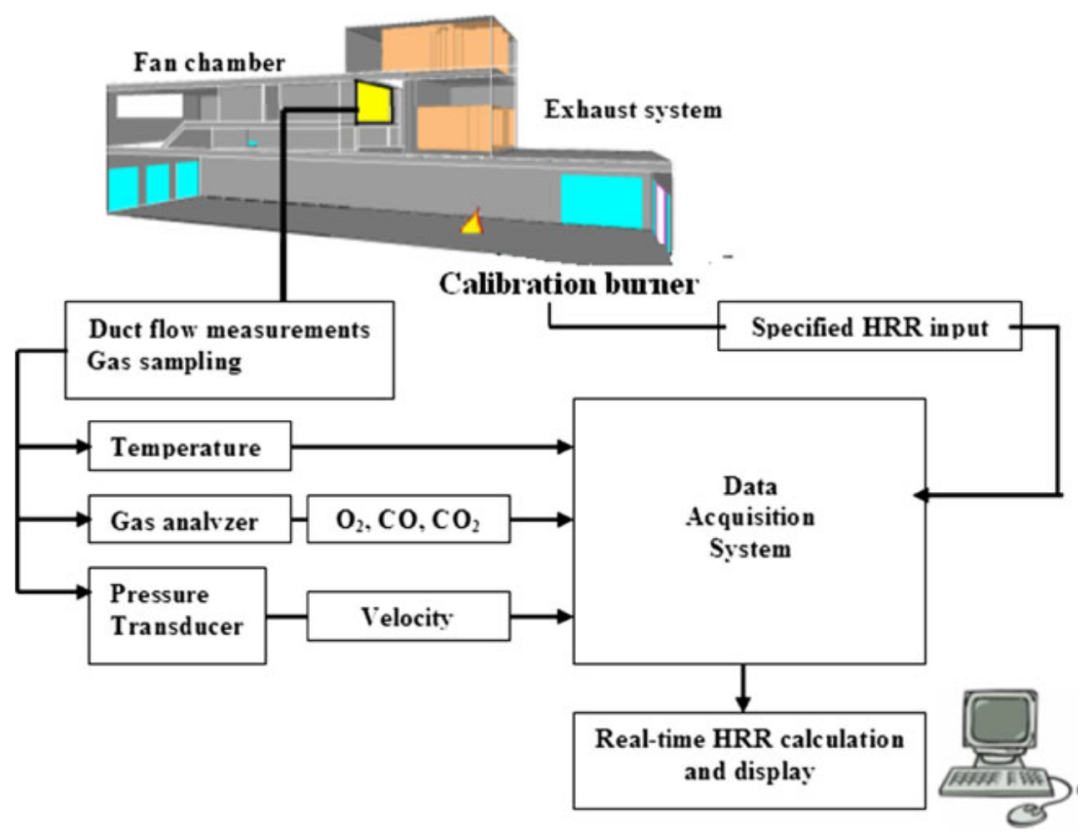

Figure 4-12 Mechanism of HRR measurement system (taken from [95])

A delay time of measurement exists due to the travel time of the smoke from the room to the chamber. Ko [96] measured these delays at 35 and 10 seconds for fan speeds between $25 \%$ and $100 \%$ respectively and also specified an additional 45 second delay time resulting from the gas analysis system. During the tests, $50 \%$ of capacity of the mechanical exhaust system was used before flashover and after that the fan speed was manually increased to $75 \%$. A calibration factor (or adjustment factor) of 0.83 was used for all the tests.

\subsubsection{Video and photos}

Video recordings during the tests were taken by two video cameras. One of the cameras was located in front of the doorway and recorded the burning behavior and wall reactions inside the room; and the other one was facing the side wall and viewed the flames issuing from the door. In addition, a digital camera was also used to take photos.

\subsubsection{Data acquisition system}

Heat release data was directly collected by the HRR measurement system and a text file was generated for each test. An NI CompactDAQ 8-Slot Ethernet Chassis and eight 16- 
Channel Thermocouple Input Modules were used to acquire all the temperature data. A NI LabVIEW computer program was created to monitor and save the temperature data (every second) during the fire tests, as shown in Figure 4-16, Figure 4-17, and Figure 4-18.

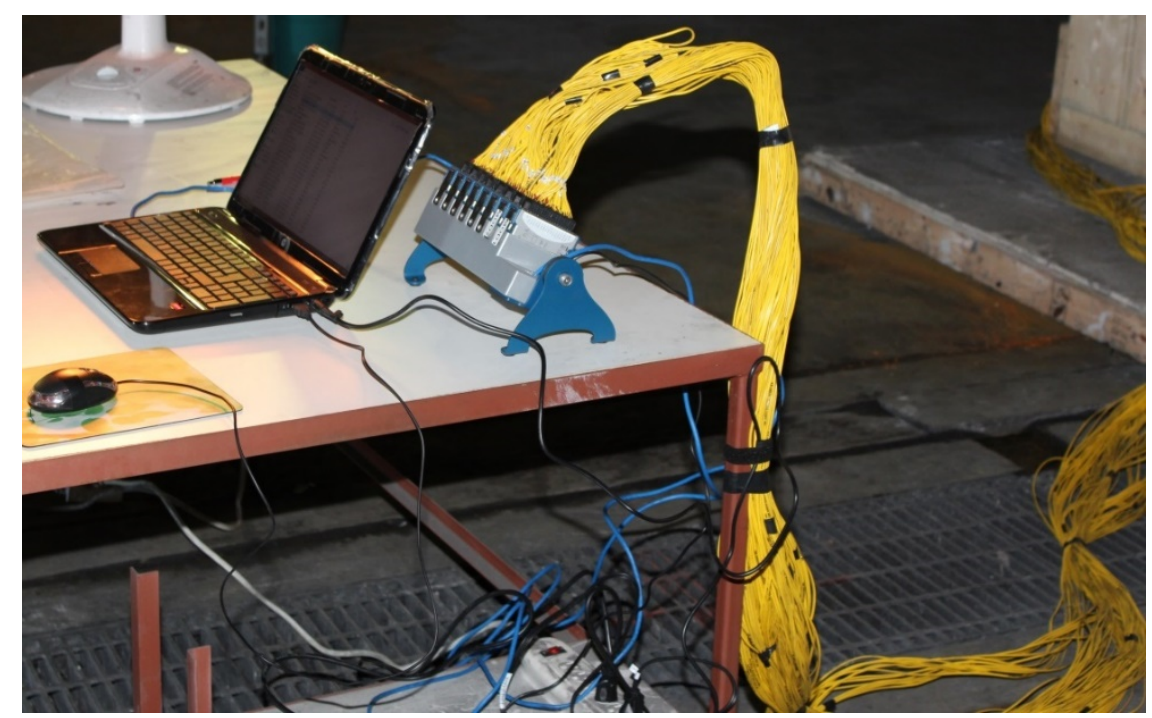

Figure 4-13 Temperature data acquisition system

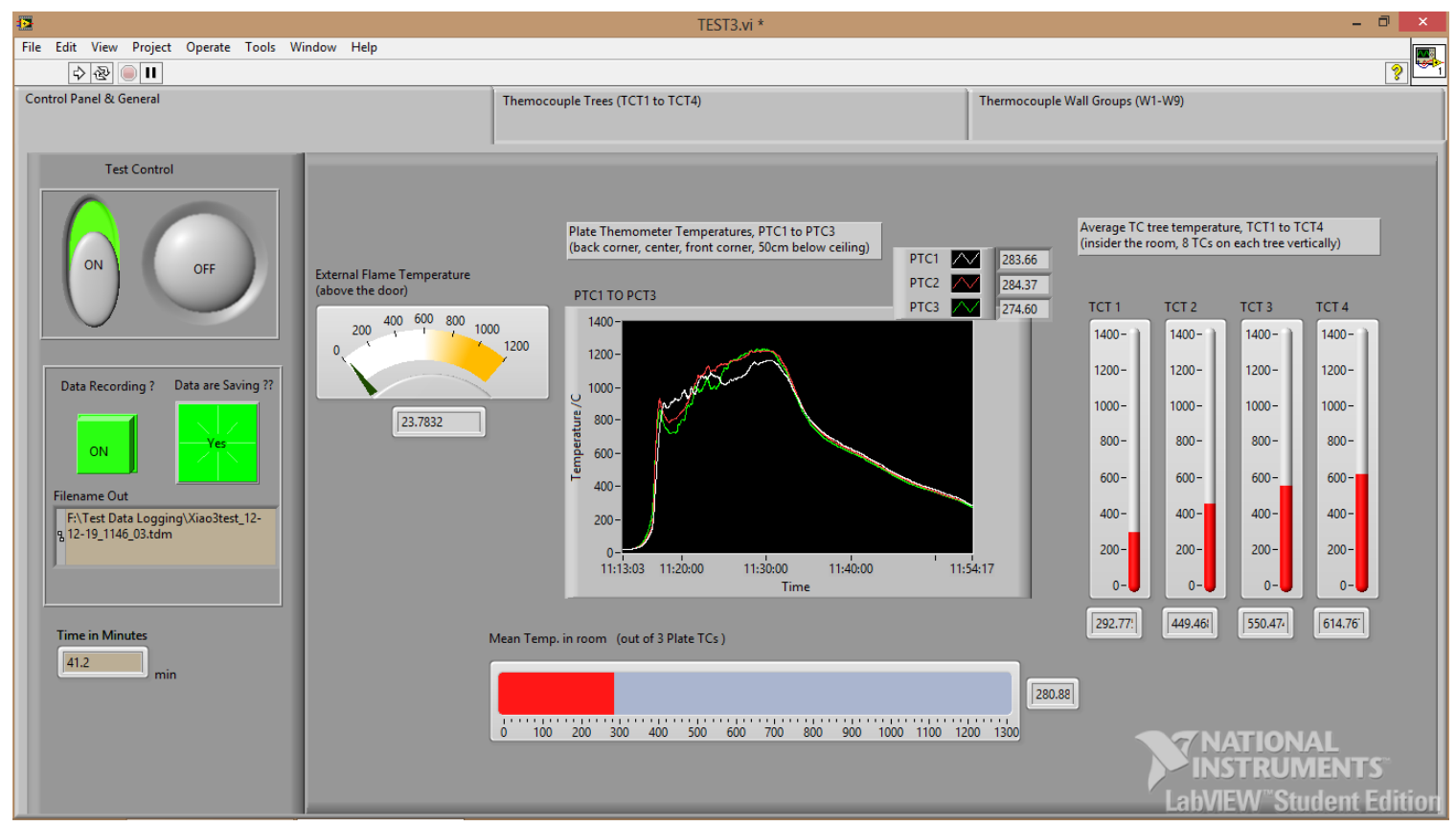

Figure 4-14 LabVIEW data acquisition program interface 1 


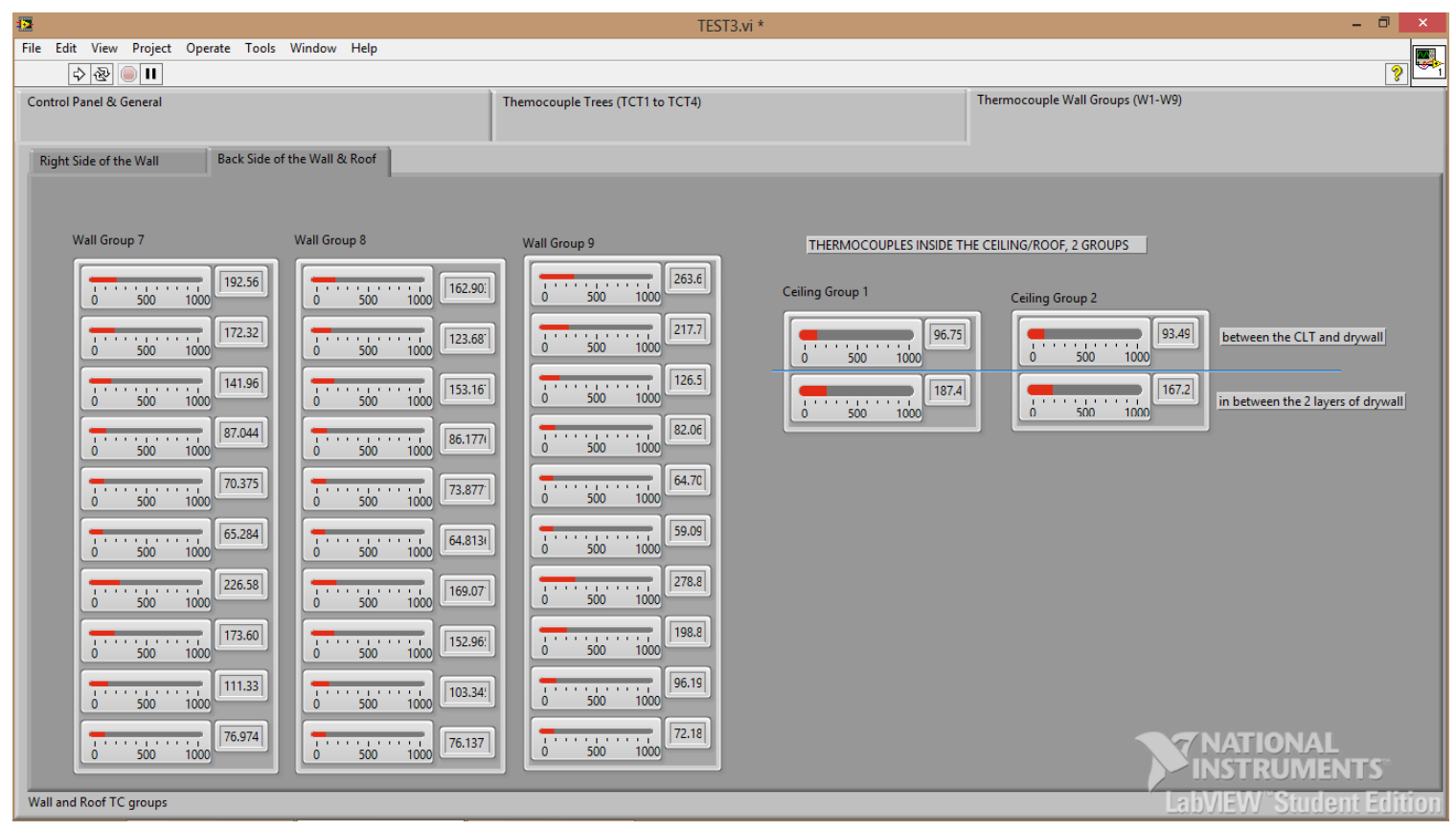

Figure 4-15 LabVIEW data acquisition program interface 2

\subsection{Test results and discussion}

\subsubsection{Total heat release rate (THRR) and room temperature}

Test 1 and Test 2 had the same room configuration, e.g., protected CLT room with 2 layers of gypsum board. Due to a system crash, temperature data in Test 1 were lost but heat release data were obtained. To simplify the analysis, mean heat release rates were used to represent this room configuration, denoted as Test $1 \& 2$. The measured heat release rate was actually a combination of in-room burning and burning outside the room, and thus is labeled total HRR. It should be noted that there is a 50 seconds time delay between the HRR measurement system and the temperature data.

Figure 4-19 depicts the THRR versus time after ignition, and Figure 4-20 shows the room temperatures measured by the plate thermometers (PTC) as well as the standard curves (ISO 834 and CAN/ULC S101). PTC temperatures in Tests 1 to 3 were measured by PTCa, 
while in Test 4 to 6 , the temperature curve is the average of the temperatures measured by PTC1b, PTC2b and PTC3b.

Except for Test 3, both the THRR and the room temperature curves follow the same trend after ignition, e.g. growth, flashover, fully developed and decay phase. The fully developed phase lasted about 15 minutes in the form of under-ventilated fire (through observation). After 25 min the fire started to decay and became a fuel control fire with external flame tips flowing out of the doorway occasionally. In comparison, the natural fire curves were shorter and hotter than the standard curves and they converged at about 30 minutes.

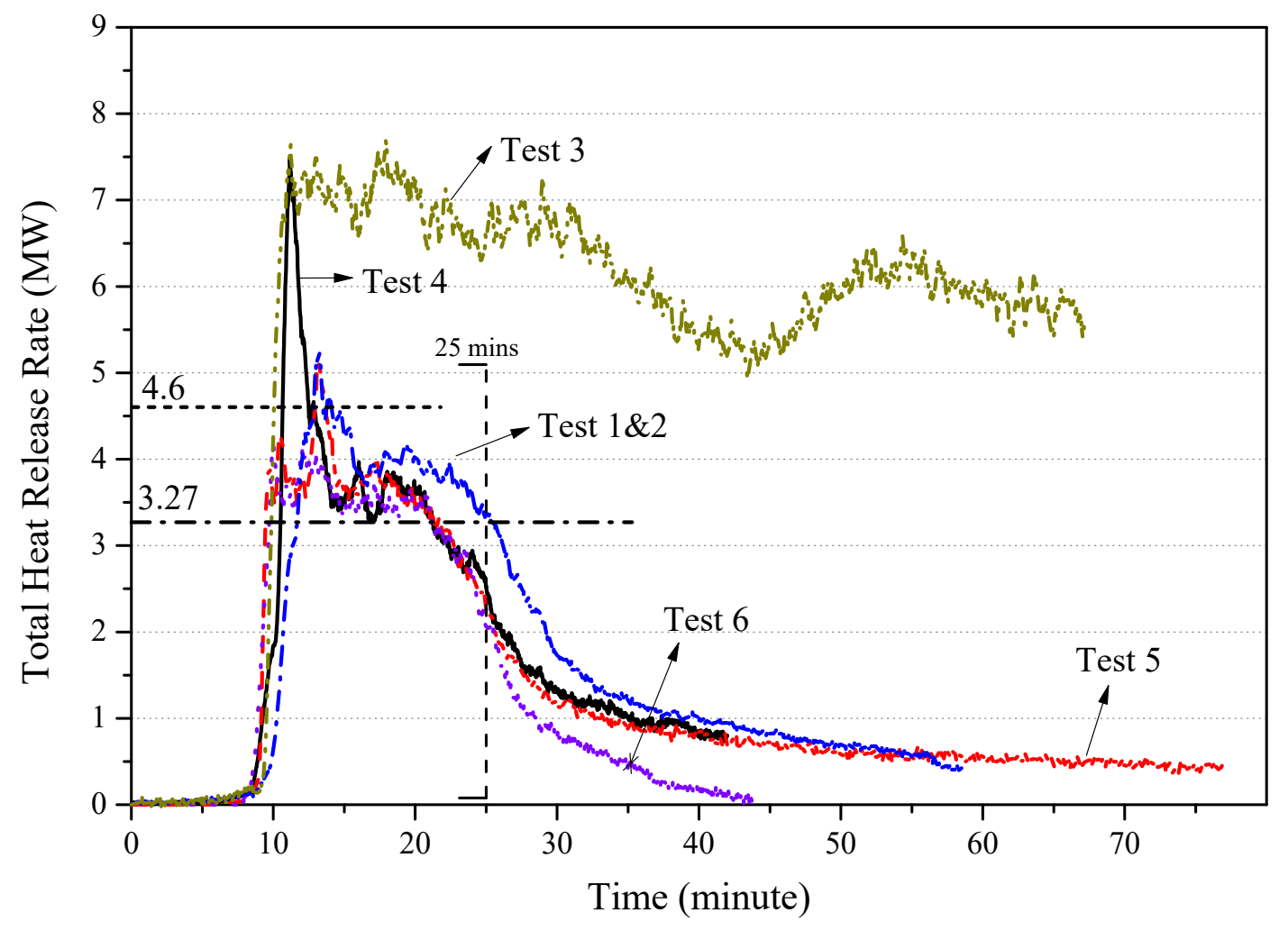

Figure 4-16 Total heat release rates of all the tests

The sharp spike following flashover in Test 4 resulted from increasing the fan speed following flashover. In order to show the heat release rates properly, the mean HRRs in the fully developed phase $\bar{Q}_{f d}$ were calculated using Equ.(4.3). The fully developed period in 
all the tests but Test 3 was defined as the period when the THRR was above $3.27 \mathrm{MW}$ (lowest peak value among all tests in fully developed periods, as indicated by $3.27 \mathrm{MW}$ in Figure 4-19). The reason for using this baseline is because visually THRR above this line can well represent the fully developed period. In Equ.(4.3), $t_{1}$ and $t_{2}$ are the times of the start and the end of the fully developed stage, respectively. In Test 3, the fully developed period was chosen from 13 to 21 minutes after fire ignition. The time period in Test 3 falls into those in other tests and relatively shorter, thus it makes sure that in this period both furniture sets and CLT panels were heavily involved in the fire, given that it is hard to identify the time boundary when furniture in Test 3 was burned out (see Figure 4-19). Table 4-8 lists the starting and ending times, durations, energy releases and mean THRRs during this period.

$$
\bar{Q}_{f d}=\frac{\int_{t_{1}}^{t_{2}} \dot{Q} d t}{t_{2}-t_{1}}
$$

Table 4-8 Summary of fuel loads and maximum THRRs and average THRRs in the fully developed

$$
\text { phase }
$$

\begin{tabular}{|l|l|l|l|l|l|}
\hline & Test $1 \& 2$ & Test 3 & Test 4 & Test 5 & Test 6 \\
\hline Total Fuel Load $(\mathrm{MJ})$ & 8552 & 8332 & 8318 & 8368.4 & 8458.4 \\
\hline Fuel Load density $\left(\mathrm{MJ} / \mathrm{m}^{2}\right)$ & 557.3 & 529 & 613.75 & 609.16 & 600.9 \\
\hline Peak THRR $(\mathrm{MW})$ & 5.24 & 7.69 & 7.49 & 5.14 & 4.15 \\
\hline Test duration $(\mathrm{min})$ & $66.6 \& 58.5$ & 63 & 42.5 & 74 & 42.5 \\
\hline$t_{1}, t_{2}($ minute $)$ & $11.7,25.3$ & 13,21 & $10.5,21.2$ & $9.45,21.2$ & $9.7,21.2$ \\
\hline$\left(t_{2}-t_{1}\right)($ minute) & 13.6 & 8 & 10.7 & 11.7 & 11.5 \\
\hline Energy release $Q(\mathrm{MJ})$ & 3256 & & 2634 & 2682 & 2478 \\
\hline Mean THRR, $\bar{Q}_{f d}(\mathrm{MW})$ & 3.995 & 7.11 & 4.103 & 3.81 & 3.607 \\
\hline
\end{tabular}

Figure 4-19 shows clearly that there is some variation of the HRR curves that depends on the type of room construction. The most obvious difference is the THRR of Test 3, which was almost double the mean THRR in other tests. The HRR for this test was over $5 \mathrm{MW}$ throughout the test. This is due to the burning of the exposed CLT panels which had a 
surface area of $53.6 \mathrm{~m}^{2}$. The faster decay phase in Test 6 after about 25 minutes as it can be seen in Figure 4-19 and Figure 4-20 is due to the early fall off of the gypsum boards which covered the floor area and quenched the fire leaving some fuels unburned.

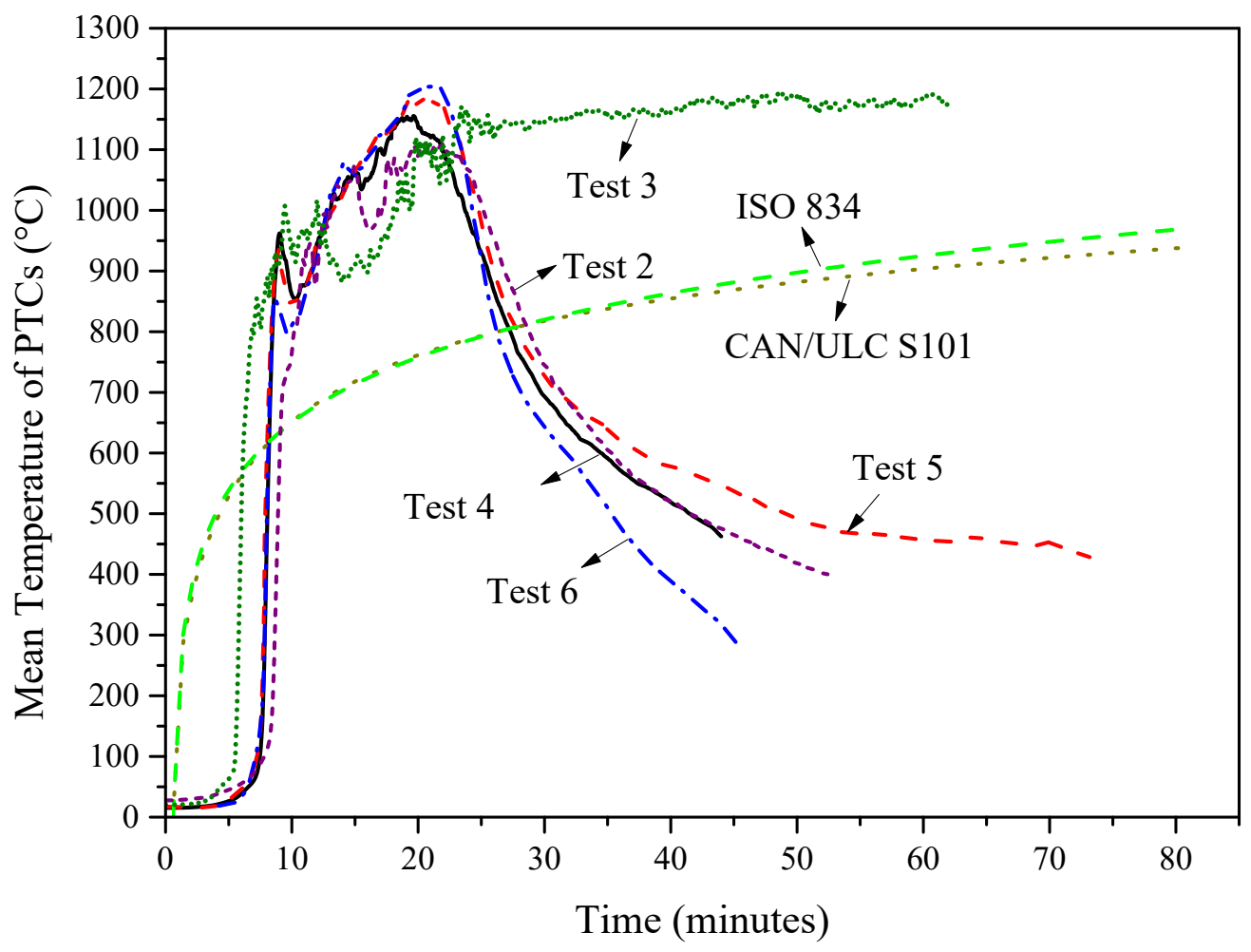

Figure 4-17 Room temperature measured by PTCs as well as standard curves

Although the mean THRR of Test 3 was almost twice the mean THRRs of the other tests, room temperatures were about $100^{\circ} \mathrm{C}$ lower during the fully developed period. In the absence of the decay phase, the temperature in Test 3 continued to rise and reach $1191^{\circ} \mathrm{C}$ (see Figure 4-20). The initial lower temperatures were due to the extremely high fuel-air ratio in the room and consequently poor burning conditions resulted from the pyrolysis gases released from both the furniture and the CLT wall panels. Unburnt pyrolysis gases flew out of the doorway resulting in extensive external flaming and extremely high THRR 
as shown in Figure 4-19.

A similar phenomenon was found in a study by Hakkarainen [49]. She conducted four tests with the same room size as our tests, and two of the tests had the same room configuration as Test $1 \& 2$ and Test 3. Room temperatures are shown in Figure 4-21. When fire occur in the unprotected CLT room (Figure 4-21(a)), the temperature was about $700^{\circ} \mathrm{C}$ during the first 40 minutes, while in the protected room test (Figure 4-21(b)) the maximum temperature reached almost $1200^{\circ} \mathrm{C}$.

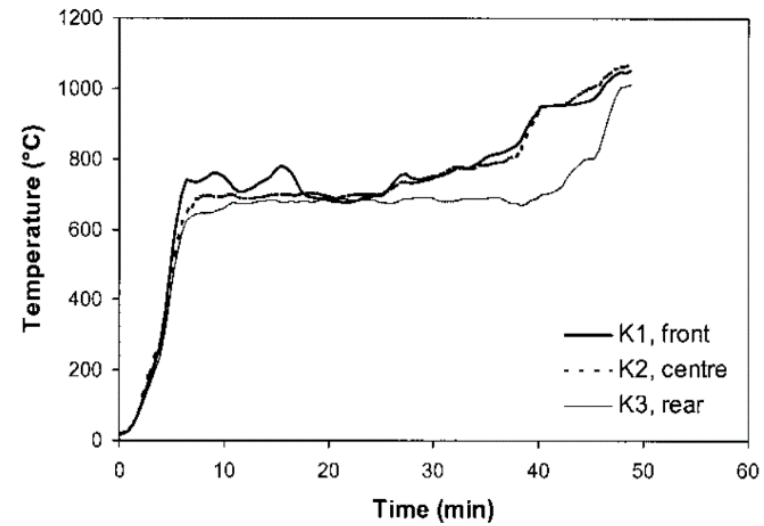

(a)

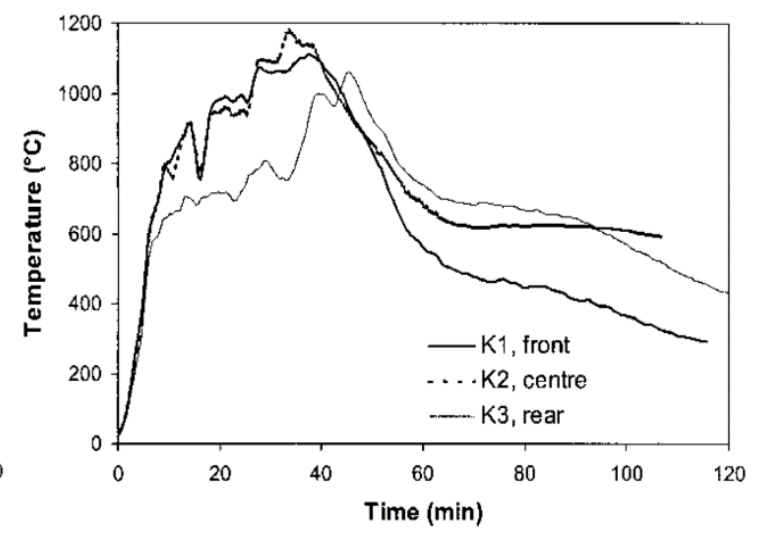

(b)

Figure 4-18 Room temperature in Hakkarainen's tests (reproduced from [49]) ; (a) unprotected CLT room, same as Test 3; (b) protected by 2 layers of gypsum boards, same as Test 1 and Test 2 in this study. Curves were average of thermocouple trees located at front corner, center and rear corner.

\subsubsection{Fire resistance and charring rates}

\subsubsection{Behaviour of gypsum board}

It is important to know the behaviour of gypsum board when subjected to realistic fires. Especially of interest is the fall-off time of gypsum board, which is a parameter with strong uncertainty. The fall-off time is affected by many factors such as the severity of the fire, 
type of board, type of fastener used and also the quality of construction. This study allowed us to compare the fall-off times of gypsum board when subjected to the same test conditions for different construction types. A summary of gypsum board fall-off times is shown in Table 4-9, which includes recorded time events when small pieces or chunks peeled off from the walls or ceiling. The times in the table were taken from available videos (DV) and photos (DC) as well as manual recordings.

Table 4-9 Events related to the fall-off of the exposed layer of gypsum board, time in minutes

\begin{tabular}{|l|l|l|l|l|l|l|}
\hline Events & Test 1 & Test 2 & Test 3 & Test 4 & Test 5 & Test 6 \\
\hline $\begin{array}{l}\text { Flashover time } \\
\text { visual } \\
\text { observation) }\end{array}$ & 6.5 & 8.6 & 5.3 & 6.2 & 5.7 & 8.0 \\
\hline $\begin{array}{l}\text { Fall-off of } \\
\text { ceiling drywall }\end{array}$ & $37.2(\mathrm{~s})$ & $39.5(\mathrm{~s})$ & - & $\begin{array}{l}35.0(\mathrm{~s}), \\
39.7(\mathrm{~s})\end{array}$ & $\begin{array}{l}44.0(\mathrm{~s}), 46.0 \\
(\mathrm{~s}), 50.0(\mathrm{~s})\end{array}$ & $\begin{array}{l}23.5(\mathrm{~s}), 24.5(\mathrm{~s}), \\
32.7(1 / 2), 41.7(\mathrm{all})\end{array}$ \\
\hline $\begin{array}{l}\text { Fall-off of } \\
\text { back wall } \\
\text { drywall }\end{array}$ & $>53.0$ & $>53.5$ & - & $33.7(\mathrm{~s})$ & $73.0(\mathrm{~s})$ & $\begin{array}{l}23.7(1 / 2), 25.4(3 / 4), \\
37.7(\mathrm{all})\end{array}$ \\
\hline $\begin{array}{l}\text { Fall-off of } \\
\text { right wall } \\
\text { drywall }\end{array}$ & $>53.0$ & $>53.5$ & - & $>42.5$ & $\begin{array}{l}60.0(\mathrm{~s}), \\
67.0(\mathrm{~m})\end{array}$ & $31.7(\mathrm{~m})$ \\
\hline $\begin{array}{l}\text { Fall-off of left } \\
\text { wall drywall }\end{array}$ & $>53.0$ & $>53.5$ & - & $>42.5$ & $\begin{array}{l}67.0(1 / 3), \\
71.0(\mathrm{~m})\end{array}$ & $24.7(\mathrm{all})$ \\
\hline Test duration & 53.0 & 53.5 & 63.0 & 42.5 & 74.0 & 46.7 \\
\hline
\end{tabular}

*texts in the parenthesis means size of drywall parts, s: small; m: major; fraction is part area relative to wall area; all: the whole wall or ceiling

From the tests it can be concluded that when lined with two layers of gypsum board (Test 1,2 and 4) the wall assemblies were able to withstand the fire exposure without significant damage to the gypsum board, which remained in good shape throughout the tests except that small pieces fell off the back wall in Test 4. In contrast, ceiling drywall was directly subjected to flame impingement which caused earlier local damage.

The behaviour of gypsum board for the tests with a single layer of gypsum board protection depended on the type of construction. In Test 5, exposed gypsum board on the walls remained in place until after 60 minutes. On the contrary, in Test 6 gypsum boards on the left wall totally collapsed before 25 minutes, and drywall on other walls fell-off shortly 
after. Cracks in the gypsum boards were believed to occur earlier but it was hard to identify due to the high intensity of the fire and smoke inside the room. It was observed that buckling of the light steel frame was the reason for quick collapse of the gypsum board in Test 6.

\subsubsection{Temperature profiles inside the walls}

Wall temperatures behind the second layer of gypsum board in Test 2 and Test 4 are shown in Figure 4-22 and Figure 4-23, and temperatures behind the single layer of gypsum board protection in Test 5 and Test 6 are depicted in Figure 4-24 and Figure 4-25. Note that for light frame construction only the top three ETC groups (W1, W4 and W7) are shown and temperatures at the gypsum board and stud (Gyp/Stud) interface and the gypsum board and fiberglass (Gyp/FbGls) interface are presented.

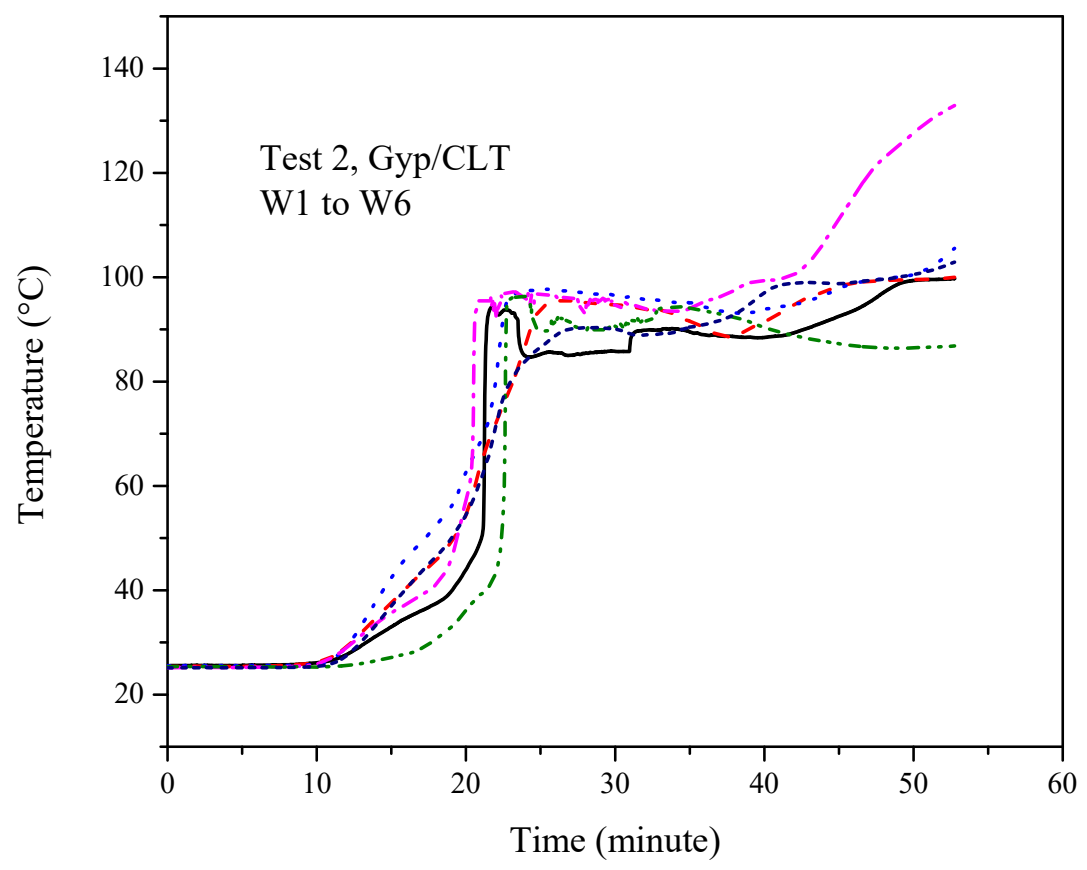

Figure 4-19 Wall temperatures behind the $2^{\text {nd }}$ layer of gypsum board in Test 2 


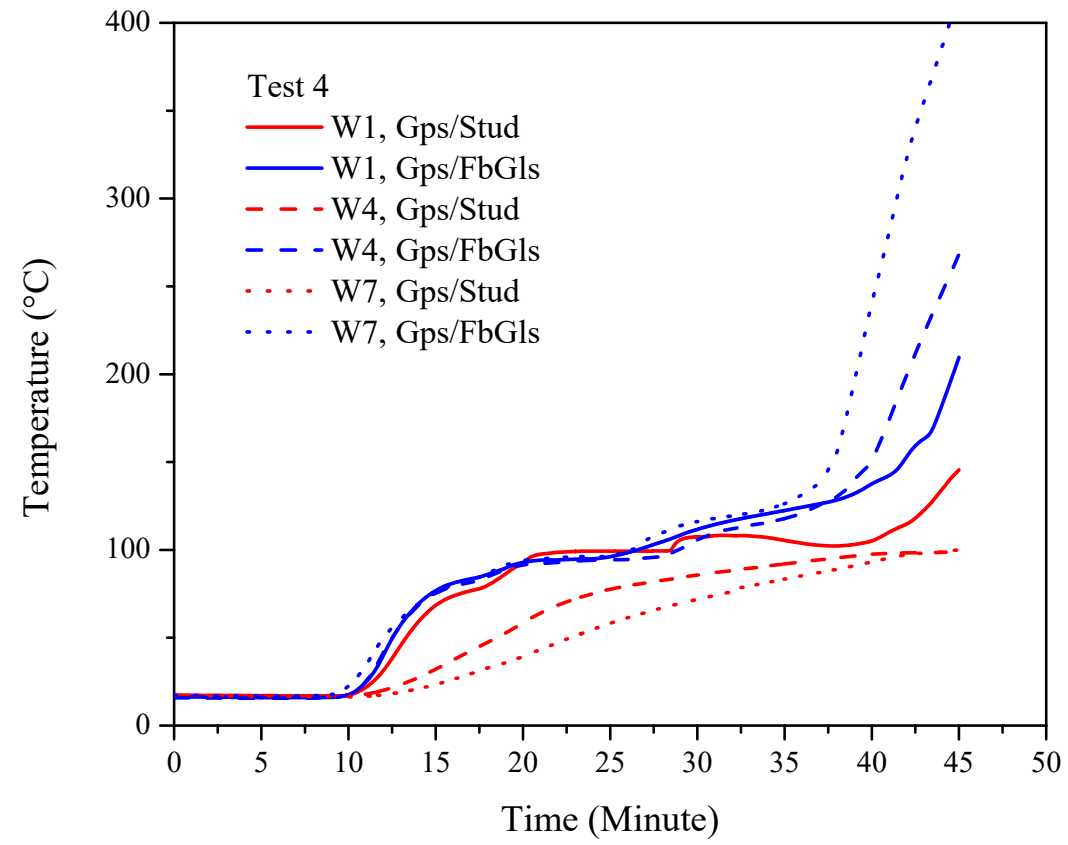

Figure 4-20 Wall temperatures behind the $2^{\text {nd }}$ layer of gypsum board in Test 4

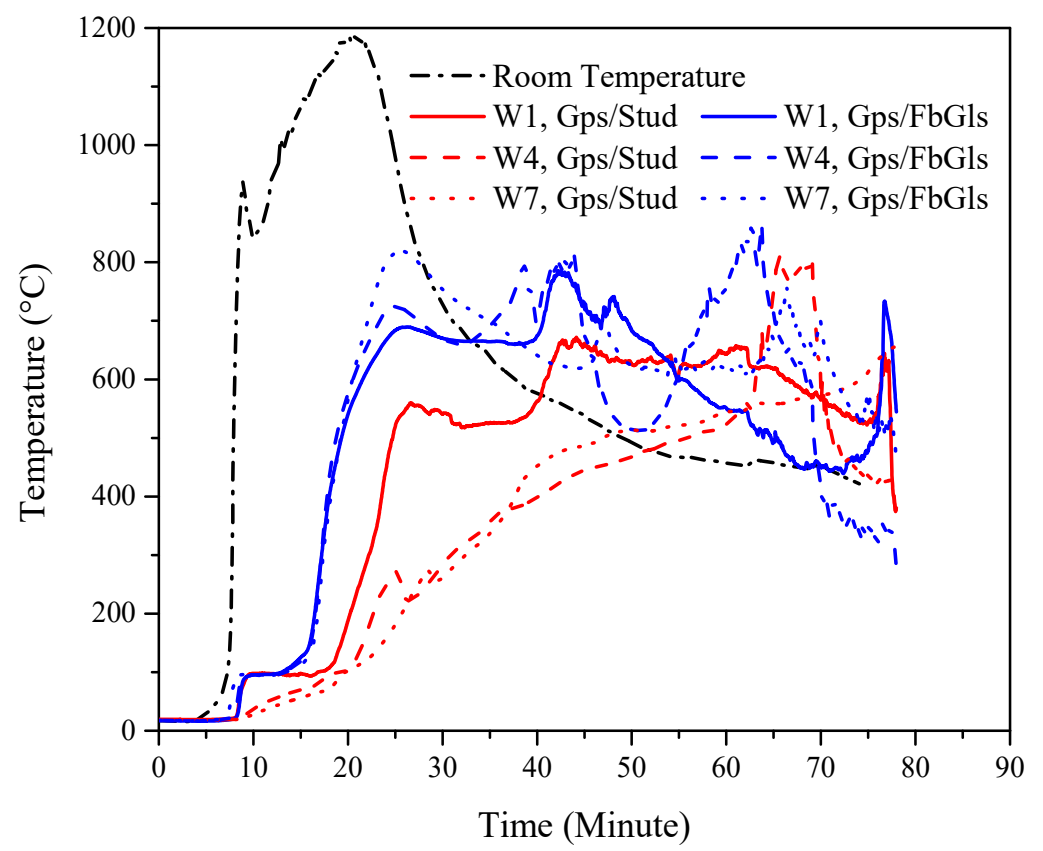

Figure 4-21 Wall temperatures behind the gypsum board in Test 5 


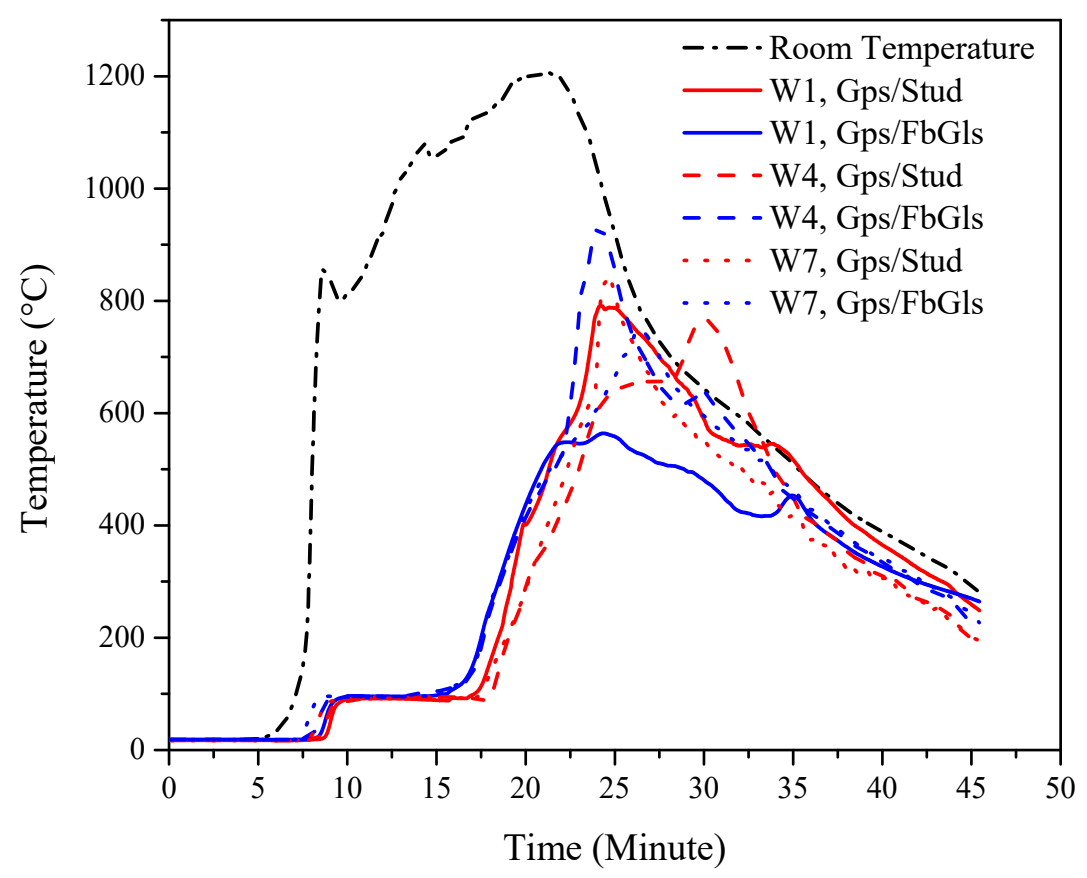

Figure 4-22 Wall temperatures behind the gypsum board in Test 6

From the temperature profiles in Figure 4-22 and Figure 4-23 it can be concluded that two layers of gypsum board protected the walls successfully. In Test 2, the temperature at the gypsum board and CLT panel interface (Gyp/CLT) reached an average of $100^{\circ} \mathrm{C}$ by the end of test (53.5 minutes). Compared with Test 2 , in Test 4 wall temperature behind the $2^{\text {nd }}$ layer of gypsum board was pretty much comparable. In both of the two tests the temperature began to rise after 10 minutes and reached the dehydration temperature of $80^{\circ} \mathrm{C}$ [58] at about 20 minutes. Later on the temperature remained at around $100^{\circ} \mathrm{C}$ until the end of the test. However, the differences between the two tests are noticeable. In Test 4 the gypsum/fiberglass (Gyp/FbGls) interface temperature went through a faster rise after 35 minutes, and at position $\mathrm{W} 7$ it reached as high as $400^{\circ} \mathrm{C}$. The faster temperature rise at the cavity side in Test 4 was due to heat penetration via drywall joints. Figure 4-26 shows the laminated wall structure in Test 4 after the fire. This image clearly demonstrated the 
consequences of heat and smoke penetration into cavity. The surface of the fiberglass was contaminated with soot but the fiberglass did not even shrink and the back surface was unaffected (pink). Also some soot accumulation was found on the wood stud surface at the drywall joint but no charring occurred. Overall, the gypsum boards performed better on the CLT panels than on the timber-frame assemblies mainly due to the tight contact between gypsum boards and CLT panels.
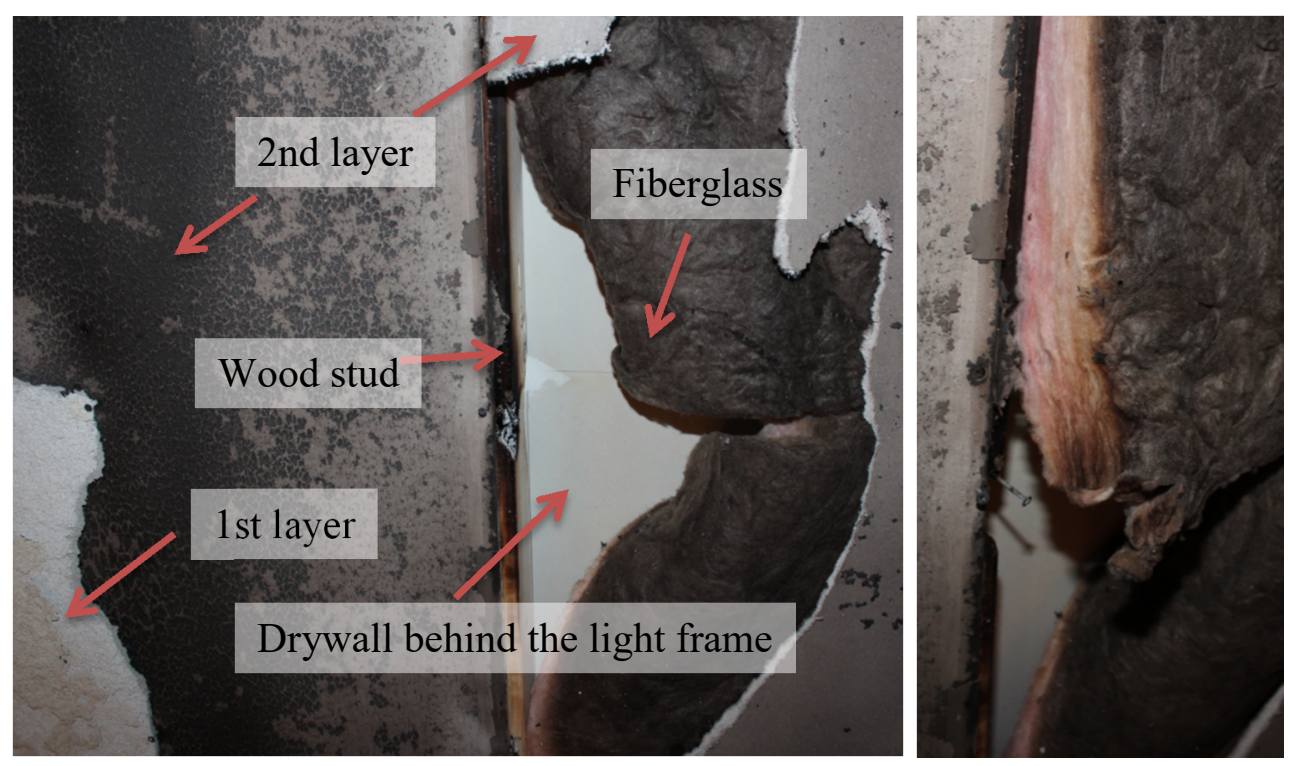

Figure 4-23 Illustration of heat penetration and soot accumulation in Test 4

Test 5 and Test 6 which had a single layer protection had notable differences as shown in Figure 4-24 and Figure 4-25. In both tests the gypsum boards entered into dehydration at around 8 minutes at a steady temperature of $95^{\circ} \mathrm{C}$, which lasted around 8 minutes. After the calcination process of the gypsum boards, both of them went through a quick temperature rise, however, temperatures under the drywall demonstrated very different features.

In Test 5, the temperature at the gypsum/fiberglass (Gps/FbGls) interface is much higher 
than that at gypsum/stud (Gps/Stud) interface. This was due to heat penetration through the gypsum board joints at the wood stud, which resulted in higher temperatures on the cavity side. Heat transfer to the gypsum/stud (Gyp/Stud) interface at studs without joints was mainly through heat conduction, and thus the temperature was lower at those positions. In addition to heat penetration from the room to the wall cavity in Test 5 , heat generation due to the burning of the wood studs led to a higher temperature in the cavity than in the room, as shown in Figure 4-27(a). Consequently, after about 27 minutes the measured temperature under the drywall fluctuated between $450^{\circ} \mathrm{C}$ to $800^{\circ} \mathrm{C}$ and finally exceeded the room temperature. The contribution of the wood studs to the fire also increased the room temperature in Test 5 and resulted in slower decay as shown in Figure 4-20.

Test 6, which is categorized as non-combustible construction, had very different results. One difference with Test 5 is that temperatures under the drywall were relatively uniform throughout the test. Unlike wood studs, steel studs were hollow with service holes and with high conductivity. Therefore, heat transferred into the wall, either through conduction or convection, could be easily transmitted through the studs and the cavity. As it is shown in Figure 4-25 the temperature of the cavity became the same as the room temperature at 25 minutes, which indicates that the gypsum board had lost its function. Observations during the test clearly identified that deformation of the steel studs lead to comprehensive damage of the drywall and caused direct exposure of the light frame structure to the room fire conditions. As shown in Table 4-9, collapse of the drywall occurred in Test 6 in about 23 minutes after ignition. Figure 4-27(b) shows the buckling of the steel studs during the test. 


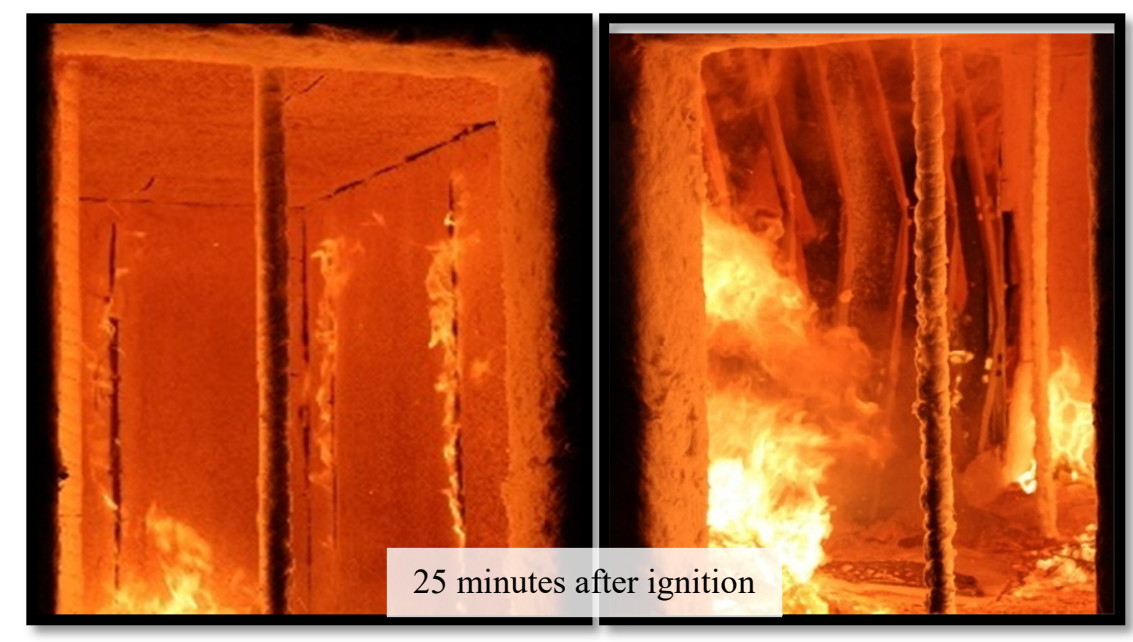

(a)

(b)

Figure 4-24 (a): An illustration of internal burning of wood studs under gypsum boards in Test 5 and (b): steel studs buckling in Test 6

As shown above, light-frame timber and light-frame steel constructions behaved very differently under the same real fire conditions. Falling of the gypsum board in Test 5 occurred after 60 minutes following ignition, while in Test 6 the majority of wall gypsum boards collapsed shortly after 23 minutes. It could be stated that light steel-frame construction tends to fail upon integrity criteria while light timber-frame construction fails due to insulation failure. This conclusion is consistent with Feng et.al's [97] observation that steel stud specimens with service holes (just as in Test 6) were predominantly governed by local buckling at lower temperatures $\left(\leq 400^{\circ} \mathrm{C}\right)$ and changed to distortional buckling mode at higher temperatures $\left(\geq 550^{\circ} \mathrm{C}\right)$, and Jones' [45] work that most of the drywall fell off at about 20 minutes as a result of steel studs buckling.

\subsubsection{Charring rates}

Charring rates were calculated based on thermocouple measurements embedded in the wood structures (see Table 4-7). The progress of the char front was indicated by the $300^{\circ} \mathrm{C}$ 
isotherm. Charring was not mentioned in Tests $1,2,4$ and 6 , so only the charring rates in Test 3 and Test 5 were analyzed and are discussed in the following text.

McGregor [92] conducted Test 3 and recorded the time when ETCs at different depths reached $300^{\circ} \mathrm{C}$. He plotted depth versus the time of onset of charring as demonstrated in Figure 4-28. The overall average charring rate was $0.85 \mathrm{~mm} / \mathrm{min}$ based on a charring depth of $24 \mathrm{~mm}$ in the test duration of 40 minutes. The most extreme charring occurred on the ceiling where the most severe exposure conditions and highest temperatures were expected. The charring rate computed over a 60 minute burning time was found to be $1 \mathrm{~mm} / \mathrm{min}$. The reason for this higher value is due to delamination of the CLT layers.

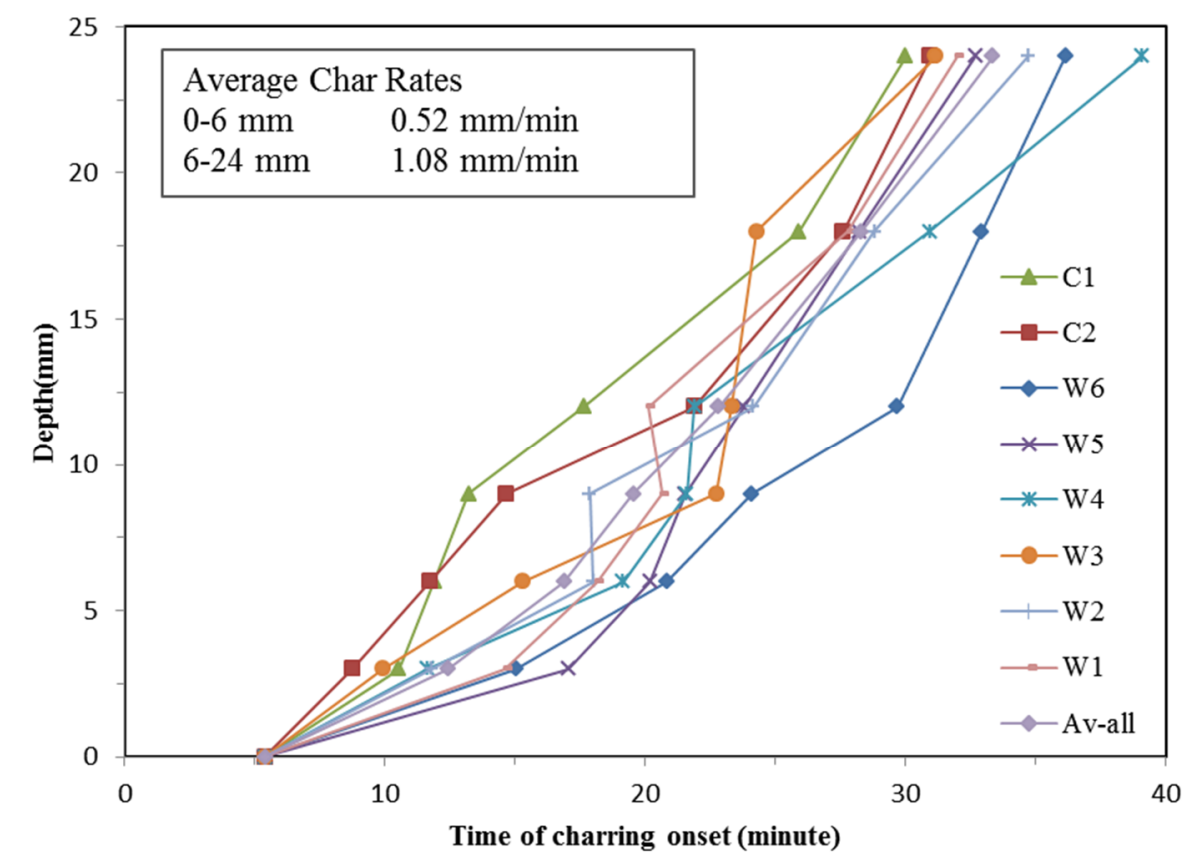

Figure 4-25 Times onset times at different ETC depth in Test 3 (adapted from [92])

The overall average of $0.85 \mathrm{~mm} / \mathrm{min}$ is much higher than what is designated in Eurocode 5 [57]. The charring depth of $24 \mathrm{~mm}$ was still in the first layer of the 3-ply CLT panel (35mm depth for each layer). The charring rate is also higher than the charring rate $(0.65$ $\mathrm{mm} / \mathrm{min}$ or slightly less) given by Frangi et.al [52] for the charring of the first layer of CLT 
panels subjected to the ISO 834 fire curve. This difference may be due to the higher temperature and strong thermal radiation of the real fire used in this study. When it comes to multi-layer charring, Frangi [52] observed an increased charring rate after the charred layer has fallen off, showing that multi-layer charring rates were always higher than that of the first layer. A similar result was found in Test 3, which indicated a higher overall charring rate of $1 \mathrm{~mm} / \mathrm{min}$. The higher charring rate was mainly due to delamination of the first layer. Another full-scale fire test performed by Hakkarainen [49] using unprotected heavy laminated timber presented an initial charring rate of $0.8 \mathrm{~mm} / \mathrm{min}$ and an overall charring rate ranging from 0.5 to $0.7 \mathrm{~mm} / \mathrm{min}$ in a 50 minutes fire exposure. No information on delamination of layers was mentioned.

In Test 5, charring took place in the wood studs behind the gypsum boards. The charring onset times at various wall ETC depths are presented in Figure 4-29. Wood stud charring and burning during and after Test 5 is illustrated in Figure 4-30. Even though the gypsum boards stayed on the walls for an hour and longer, the onset of charring in the wood studs was first measured as early as 22.2 minutes after ignition (see Figure 4-29). This, however, may not be the earliest charring time on the wood studs, as wood studs located at gypsum board joints were most vulnerable to heat attack, but no ETCs were arranged at these locations. Charring of wood studs took place behind the gypsum boards, and burning of wood studs occurred even before the gypsum boards fell-off. Charring rates averaged among adjacent ETC depths at all wall positions are listed in Table 4-10. Some odd charring rates appear in Table 4-10, including an extremely high value of 8.96 and two values less than 0 . This indicates that some ETCs were not exactly at the right depths. Two such points are marked in Figure 4-29 as solid symbols. Most probably some 
thermocouples were not along the centerline of the stud and the charring front from the cavity side reached those positions earlier than from the interface between the stud and the board. Those charring rates are marked in Table 4-10. By removing all three extreme values, the average charring rate based on a $30 \mathrm{~mm}$ charring depth is calculated to be 1.22 $\mathrm{mm} /$ minute. The mean charring rates at each $10 \mathrm{~mm}$ interval are also shown in Table 4-10. The calculated charring rates may not be precise enough due to possible errors of ETC positions.

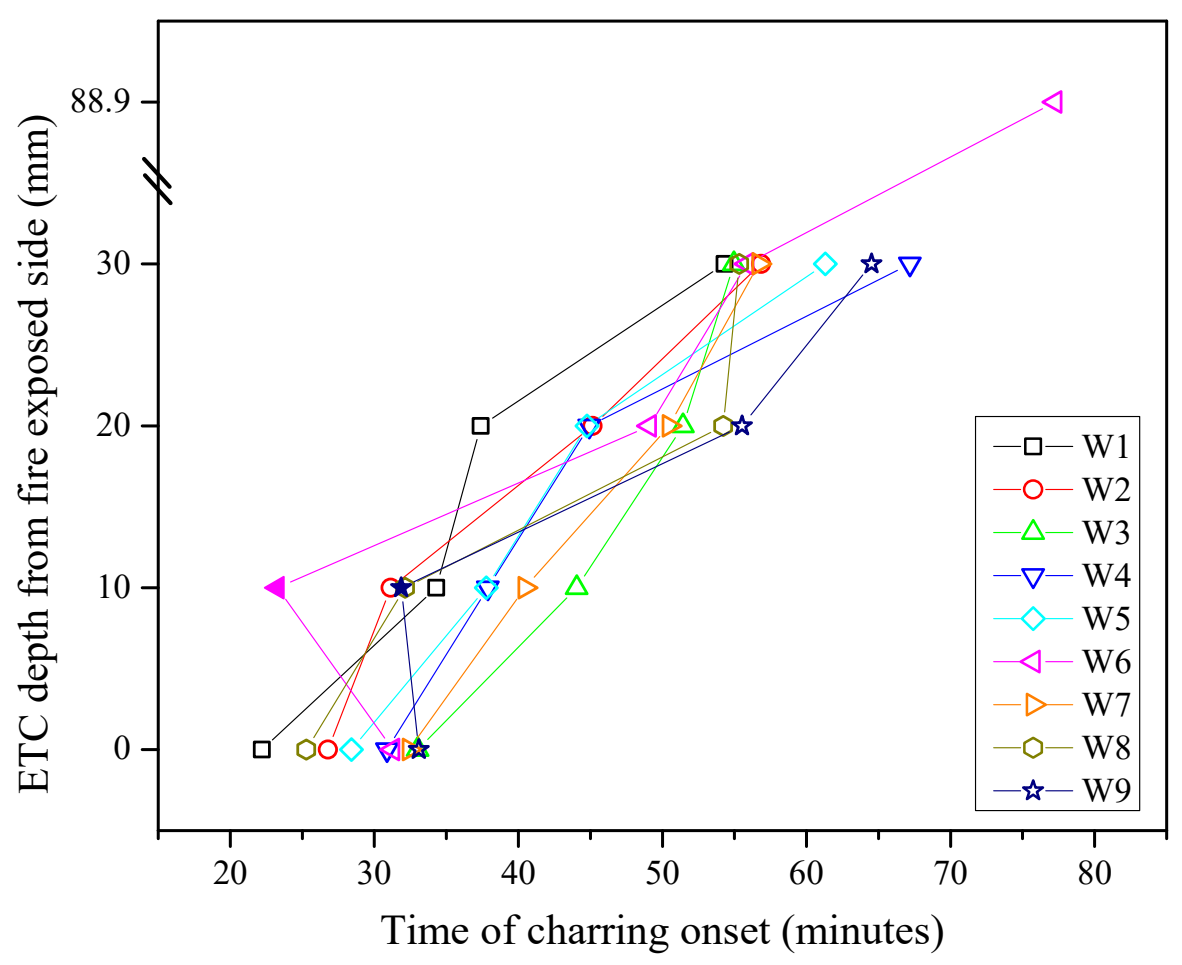

Figure 4-26 Times onset times at different ETC depth in Test 5 


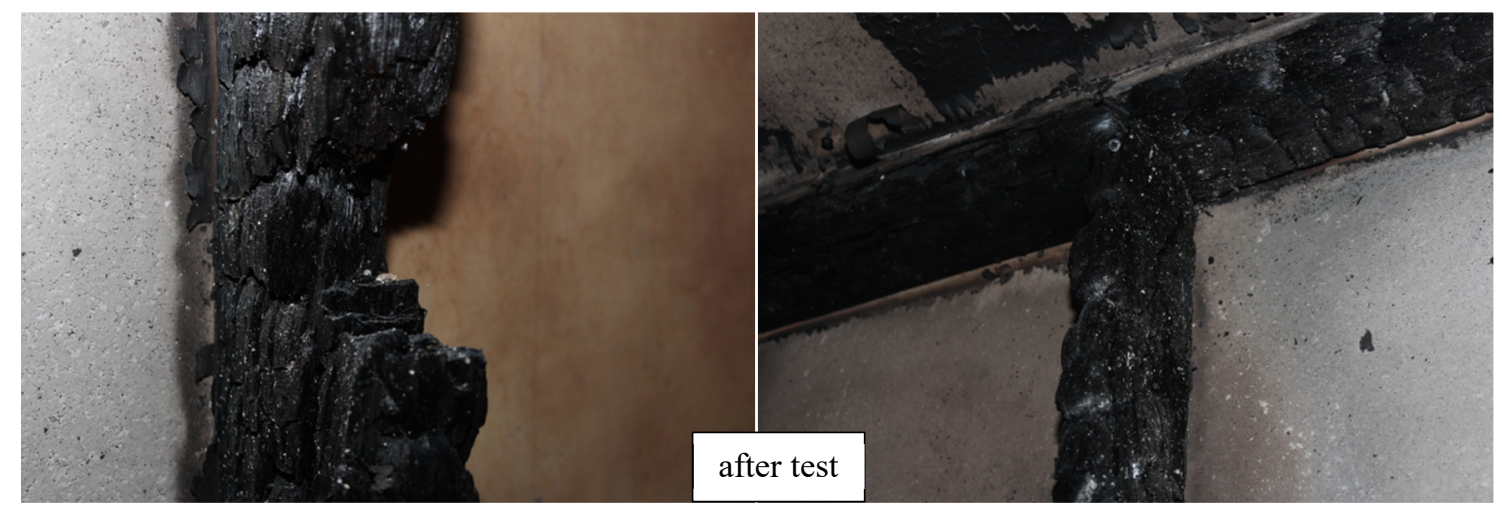

Figure 4-27 Char of wood studs after Test 5

Table 4-10 Charring rates averaged over $10 \mathrm{~mm}$ depth in Test $5(\mathrm{~mm} / \mathrm{min})$

\begin{tabular}{|c|c|c|c|}
\hline ETC Group & $0-10 \mathrm{~mm}$ & $10-20 \mathrm{~mm}$ & $20-30 \mathrm{~mm}$ \\
\hline W1 & 0.83 & 3.24 & 0.59 \\
\hline W2 & 2.30 & 0.71 & 0.85 \\
\hline W3 & 0.91 & 1.35 & 2.83 \\
\hline W4 & 1.43 & 1.42 & 0.45 \\
\hline W5 & 1.07 & 1.43 & 0.60 \\
\hline W6 & $\mathbf{- 1 . 2 5 *}$ & 0.39 & 1.48 \\
\hline W7 & 1.24 & 1.00 & 1.61 \\
\hline W8 & 1.46 & 0.45 & $\mathbf{8 . 9 6}$ \\
\hline W9 & $\mathbf{- 8 . 1 1 ^ { * }}$ & 0.42 & 1.11 \\
\hline Mean & 1.32 & 1.16 & 1.19 \\
\hline
\end{tabular}

*Values that are removed from calculating mean values

The charring rates in Test 5 are significantly higher than $0.65 \mathrm{~mm} / \mathrm{min}$ recommended in Eurocode 5 [57], which is the design charring rates applying to the standard fire exposure. In the case of one layer gypsum board protection, Eurocode 5 uses a factor to reduce the charring rate before gypsum board failure, and after protection fall off it is proposed a charring rate with a value twice the normal value (e.g. $1.3 \mathrm{~mm} / \mathrm{min}$ ), also applying to the standard fire exposure. It can be seen that this "double charring rate" occurred on wood studs in Test 5 even with the gypsum board attached. As in Test 5, wood burning already 
occurred inside the cavity before the gypsum board fell-off, thus, a higher charring rate could be possible especially in such a severe fire. Nyman [30] performed three full-scale fire tests with fires more severe than the standard fire exposure, and the charring rates of the wood stud obtained in two of the tests reached as high as $1.07 \mathrm{~mm} / \mathrm{min}$. All these findings indicate that the standard rate of charring of $0.65 \mathrm{~mm} / \mathrm{min}$ used in fire safety design could be insufficient for fires of severity greater than the standard fire.

\subsubsection{Contributions of combustible room structure}

\subsubsection{Calculation methods}

Measuring the total heat release rate (THRR) of the fires makes it possible to examine the contribution of the timber structure to the room fire. This analysis focuses on the fully developed time periods of room fires, because this period possesses the highest fire severity and risk. At first, a global fuel combustion efficiency was obtained, based on which the fuel burning rate can be estimated; and then the mass flow rates via the doorway were calculated using the temperature profile inside the room. After this, a global equivalence ratio, maximum in-room heat release rate and external heat release were computed.

\section{Total energy release and global combustion efficiency}

Total energy release can be calculated by integrating the measured HRR over time after all fuels were consumed, and then a global fuel combustion efficiency $(\varphi)$ can be estimated by inspecting the ratio of total energy release $Q$ and total fuel loads $L$ (see Table 4-6) as follows,

$$
\varphi=Q / \mathrm{L}
$$

It was observed after the tests that all the movable fuels and hardwood floor were consumed by the fire and only ashes existed on the floor. Typically between 0.43 and 1.82 percent of 
the mass of burned wood (dry basis and at $350^{\circ} \mathrm{C}$ ) results in ash, and the higher the temperature, the lower yields of ash [98]. For this reason the mass of ash was ignored and it is assumed that all the fuel was burned away.

The total energy release $Q$ can be obtained by finding the area under the THRR-time curve until the THRR decreases to a small value. In Tests 1 and 2 , the average THRR reduced to as low as $0.4 \mathrm{MW}$ at the end of the tests (about 58 minutes). The total energy release until the end of Test 5 at 58.5 minutes was 5783 MJ. In Test 4, the HRR data were extrapolated from 42 minutes to 56 minutes due to the relatively high THRR value $(0.8 \mathrm{MW})$ at the end of the test. Energy release up to 56 minutes was 5049.4 MJ. In Test 5, the contribution of wood studs is ignored due to the relative small fuel surface areas. The total energy release in Test 5 up to 60 minutes was calculated to be 5206 MJ. In Test 6 , the early and quick collapse of gypsum boards covered large area of unburned fuel, and it is not clear how much fuel was burned by the end of the test, therefore it was not possible to calculate the global combustion efficiency based on the available energy release.

In Test 3, because the unprotected CLT room structure contributed to the fire, the fuel burning rate contained contributions from two parts, from the furniture set and the CLT panels. At 40 minutes it was observed that almost all the movable fuels were consumed by the fire and the first layer of 3-ply CLT panels started to delaminate. Hence, the duration of 40 minutes was chosen to calculate the total energy release, which was $12052.5 \mathrm{MJ}$. The fire load contributed by the CLT panels is based on the charring rate obtained from the tests. It was found earlier that the average charring rate from flashover ( 5 minutes) to 40 minutes was about $0.85 \mathrm{~mm} / \mathrm{min}$. Wood releases energy in two ways: the combustion of volatiles produced during gasification; and the smouldering combustion of the remaining 
charcoal. Smoldering combustion requires oxygen to be present at the char location whereas the volatiles produced from gasification can burn remotely. Low levels of oxygen would thus promote a buildup of the char layer. Based on this it is assumed that CLT panels only produce volatiles for combustion while char remained on the wood. Knowing that the yield of volatiles is about $80 \%$ of the total wood mass [99], the fuel load of CLT panels involved in the fire up to 40 minutes can be estimated using Equ.(4.5). The calculated total energy release and global combustion efficiencies are listed in Table 4-11.

$$
L=L_{\text {existing }}+L_{C L T}=L_{\text {existing }}+\mu A_{C L T} \frac{\beta_{c h}\left(t-t_{f o}\right)}{1000} \rho_{w} H_{c}
$$

Where, $L_{\text {existing }}$ is the existing fire load ( $8332 \mathrm{MJ}$, see Table 4-6); $\mu$ is yield rate of volatiles from the CLT panel (0.8); $A_{C L T}$ is the total area of exposed CLT panels $\left(55.75 \mathrm{~m}^{2}\right) ; \beta_{c h}$ is the charring rate $(0.85 \mathrm{~mm} / \mathrm{min}) ; t$ is time duration (40 minutes), $t_{f o}$ means flashover time (5 minutes); and $\rho_{w}$ is the density of wood (515 $\mathrm{kg} / \mathrm{m}^{3}$ according to [100]), $H_{c}$ is the heat of combustion of wood (18 MJ/kg). Thus total fuel load in Test 3 is $20632 \mathrm{MJ}$.

Table 4-11 Total energy release and global combustion efficiency

\begin{tabular}{|l|l|l|l|l|}
\hline & Test 1\&2 & Test 3 & Test 4 & Test 5 \\
\hline Total Fuel Load, $L(\mathrm{MJ})$ & 8552 & 20632 & 8318 & 8368.4 \\
\hline Total Energy released, $Q(\mathrm{MJ})$ & 5783 & 12052 & 5049.4 & 5206 \\
\hline Time duration (minute) & 58.5 & $40^{*}$ & 56 & 60 \\
\hline Global combustion efficiency, $\varphi$ & 0.676 & 0.584 & 0.607 & 0.622 \\
\hline
\end{tabular}

\section{Calculation of mass flow rates through doorway}

Based on Janssens and Tran' method [101] accepted widely [102-104], the mass flow rate at the doorway can be computed using the equations below,

$$
\dot{m}_{\text {out }}=\left(C M_{U L} P b / R\right) \int_{h_{n}}^{h_{t}}\left[\left(1 / T_{\text {door }}\right) \int_{h_{n}}^{y}\left(1 / T_{\text {out }}-1 / T_{\text {in }}\right) d y\right]^{0.5} d y \quad \text { Equ. (4.6) }
$$




$$
\begin{array}{ccc}
\dot{m}_{\text {air }}=\left(C M_{U L} P b / R\right) \int_{h_{b}}^{h_{n}}\left[\left(1 / T_{\text {door }}\right) \int_{y}^{h_{n}}\left(1 / T_{\text {out }}-1 / T_{\text {in }}\right) d y\right]^{0.5} d y & \text { Equ. (4.7) } \\
\dot{m}_{\text {out }}=\dot{m}_{\text {air }}+\dot{m}_{b} & \text { Equ. (4.8) }
\end{array}
$$

where, $\dot{m}_{\text {out }}, \dot{m}_{\text {air }}$ are smoke outflow rate and air entrainment rate through the compartment doorway $(\mathrm{kg} / \mathrm{s})$, respectively; $C$ is flow coefficient, the best option now available is to use $\mathrm{C}=0.68$ and expect $\pm 10 \%$ percent errors in flow calculations $[105] ; h_{b}, h_{t}, h_{n}$ are the heights of the sill, soffit and neutral plane in the doorway plane respectively (m); $T_{\text {in }}, T_{\text {out }}, T_{\text {door }}$ are temperatures inside the room, ambient and at the doorway $(\mathrm{K}) ; b$ is the width of the compartment doorway $(\mathrm{m}) ; P$ is the pressure $(\mathrm{Pa}) ; R$ is the universal gas constant; $M_{U L}$ is the average molecular weight of flowing gas, it is accurate enough to neglect the effect of the change of molecular weight from that of air $(28.95 \mathrm{~kg} / \mathrm{mol})$ [106].

The fuel burning rate $\dot{m}_{b}$ in Equ.(4.8) can be estimated based on the global combustion efficiency $(\varphi)$ (see Table 4-11), heat of combustion of fuel and HRR, as shown in Equ.(4.9). Among the fuels present in the room, wood accounts for $82 \%$ of the total fuel load, and heats of combustion of other fuels are very close to that of wood, hence it is reasonable to apply the heat of combustion of wood $(18 \mathrm{~kJ} / \mathrm{g})$ as the global heat of combustion $H_{c}$. In this way, an effective heat of combustion $H_{c, \text { eff }}(\mathrm{KJ} / \mathrm{g})$ can be obtained as $\varphi H_{c}$. The average $\operatorname{HRR}\left(\bar{Q}_{f d}\right)$ during the fully developed period was obtained earlier and shown in Table 4-8. The fuel burning rate therefore can be estimated using,

$$
\dot{m}_{b}=\bar{Q}_{f d} / H_{c, e f f}=\bar{Q}_{f d} /\left(\alpha H_{c}\right)
$$

Temperature profiles inside the room and at the doorway during the fully developed period can be obtained from the readings of the thermocouple trees. In Test 2 and Test 3, TCT4a 
and TCT3a were employed to represent room and doorway temperature profiles, respectively. In Test 5, TCT3b and TCT4b were used to represent room temperature and the doorway temperature distribution, respectively. Temperatures during the fully developed phase were averaged. The results are listed in Table 4-12.

Table 4-12 Average temperature profiles during the fully developed phase

\begin{tabular}{|c|c|c|}
\hline \multicolumn{3}{|c|}{ From 11 to 15 minutes on TCT3b and TCT4b in Test 2} \\
\hline Heights (cm) & TCT3a $\left({ }^{\circ} \mathrm{C}\right)$ & TCT4a $\left({ }^{\circ} \mathrm{C}\right)$ \\
\hline 40 & 654 & 930 \\
\hline 80 & 811 & 1001 \\
\hline 120 & 907 & 1034 \\
\hline 160 & 954 & 1047 \\
\hline 200 & 920 & 1036 \\
\hline Outside & 27 & 27 \\
\hline \multicolumn{3}{|c|}{ From 13 to 21 minutes on TCT3a and TCT4a in Test 3} \\
\hline Heights (cm) & TCT3a $\left({ }^{\circ} \mathrm{C}\right)$ & TCT4a $\left({ }^{\circ} \mathrm{C}\right)$ \\
\hline 40 & 781 & 849 \\
\hline 80 & 898 & 859 \\
\hline 120 & 967 & 902 \\
\hline 160 & 998 & 939 \\
\hline 200 & 974 & 1004 \\
\hline Outside & 21 & 21 \\
\hline \multicolumn{3}{|c|}{ From 12 to 20 minutes on TCT $3 \mathrm{~b}$ and TCT $4 \mathrm{~b}$ in Test 5} \\
\hline Heights $(\mathrm{cm})$ & TCT3b $\left({ }^{\circ} \mathrm{C}\right)$ & TCT4b $\left({ }^{\circ} \mathrm{C}\right)$ \\
\hline 30 & 854 & 498 \\
\hline 60 & 938 & 622 \\
\hline 90 & 996 & 903 \\
\hline 120 & 1052 & 1009 \\
\hline 150 & 1056 & 1058 \\
\hline 180 & 1075 & 1043 \\
\hline Ambient & -10 & -10 \\
\hline
\end{tabular}

The calculation of the air entrainment mass flow rates was done by dividing the doorway height into 200 segments, each of which measures $0.001 \mathrm{~m}$, and the temperature at each segment was determined by linear interpolation. The precision of the neutral plane height was within $0.01 \mathrm{~m}$. The height of the neutral plane and mass flow rate was computed using a dichotomy iterative process based on the mass conservation as written in Equ.(4.8).

The mass flow rates in Test 4 could not be computed because the temperature data during the fully developed period were lost due to a system malfunction. 


\section{Global equivalence ratio}

After getting all the parameters, the global equivalence ratio can be calculated using Equ.(4.10). The global equivalence ratio represents the fuel-to-air mass ratio in the fire compartment normalized by the stoichiometric fuel-to-air ratio [107]. The stoichiometric fuel-to-air ratio of wood (spruce) is 0.258 [107]. The global equivalence ratio is a measure of the room air depletion conditions; it is ventilation controlled fire if $\Phi>1$, and well ventilated fire if $\Phi<1$. Unlike the definition of total THRR and total energy release, the global equivalence ratio only represents the overall burning conditions inside the fire room.

$$
\Phi=\frac{\dot{m}_{b}}{\dot{m}_{\text {air }}} /\left(\frac{\dot{m}_{b}}{\dot{m}_{\text {air }}}\right)_{s t o i}
$$

\section{Maximum heat release rate inside the room}

It is assumed that all the oxygen in the incoming air was completely consumed by combustion in the room. Actually this is a very approximate assumption. A related study [108] shows that oxygen concentration approaches zero in an under-ventilated $(\Phi>1)$ fire, especially in a high temperature environment, though a very limited yet unknown amount of oxygen might leave the room with the combustion products and burn outside [107]. The maximum possible heat release rate in the room can be calculated by Equ.(4.11), by assuming that all the doorway entrained air is burned inside the room.

$$
\dot{Q}_{\mathrm{max}, a i r}=\dot{m}_{a i r} Y_{o x} \Delta H_{c, o x}
$$

where, $\dot{m}_{\text {air }}$ is the air entrainment rate; $Y_{o x}$ is the mass fraction of oxygen in air $(0.23) ; \Delta H_{c, o x}$ is the heat of combustion of fuel per unit mass of oxygen consumed $(13.1 \mathrm{~kJ} / \mathrm{g})$.

\section{Heat release rate outside the room}

The heat release rate outside the room can be calculated by subtracting the maximum heat 
release rate inside the room $\left(\dot{Q}_{\text {max,air }}\right)$ from the total HRR $\left(\bar{Q}_{f d}\right)$ measured by the tunnel system, as shown in Equ.(4.12).

$$
\dot{Q}_{\text {ext }}=\bar{Q}_{f d}-\dot{Q}_{\text {max }, \text { air }}
$$

The external heat release rate calculated by the above equation may be slightly underestimated based on the fact that some of the outflowing smoke may contain the air from inside the room. Thus, it might be more appropriate to calculate additional air consumption by external burning. The additional air used for the external combustion can be estimated as follows,

$$
\dot{m}_{\text {air }, a d d}=\left(\bar{Q}_{f d}-\dot{Q}_{\text {max,air }}\right) /\left(Y_{o x} \cdot \Delta H_{c, o x}\right)
$$

\subsubsection{Calculation results and discussion}

Table 4-13 Summary of combustion conditions during fully developed phase in selected tests

\begin{tabular}{|l|l|l|l|}
\hline & Test $1 \& 2$ & Test 3 & Test 5 \\
\hline Mean total HRR, $\bar{Q}_{f d}(\mathrm{MW})$ & 3.995 & 7.11 & 3.81 \\
\hline Global combustion efficiency, $\varphi$ & $67.6 \%$ & $58.4 \%$ & $62.2 \%$ \\
\hline Fuel burning rate, $\dot{m}_{b}(\mathrm{~kg} / \mathrm{s})$ & 0.328 & 0.676 & 0.34 \\
\hline Doorway Air entrainment rate, $\dot{m}_{a}(\mathrm{~kg} / \mathrm{s})$ & 1.076 & 0.856 & 1.18 \\
\hline Smoke outflow rate, $\dot{m}_{g}(\mathrm{~kg} / \mathrm{s})$ & 1.404 & 1.532 & 1.52 \\
\hline Neutral plane height, $h_{n}(\mathrm{~m})$ & 0.87 & 0.78 & 0.84 \\
\hline Global equivalence ratio inside the room $(\Phi)$ & 1.18 & 3.056 & 1.14 \\
\hline Maximum in-room HRR, $\dot{Q}_{\text {max }, \text { air }}(\mathrm{MW})$ & 3.24 & 2.58 & 3.55 \\
\hline Heat release rate outside the room, $\dot{Q}_{\text {ext }}(\mathrm{MW})$ & 0.775 & 4.53 & 0.26 \\
\hline Additional air consumption via external flame $\dot{m}_{\text {air }, \text { add }}(\mathrm{kg} / \mathrm{s})$ & 0.25 & 1.50 & 0.086 \\
\hline
\end{tabular}

A summary of calculated parameters during the fully-developed period in Test 1 to Test 5 are listed in Table 4-13, including total HRR, global combustion efficiency, fuel burning rate, doorway air entrainment rate, neutral plane height, global equivalence ratio, maximum 
in-room HRR, external heat release rate and additional air consumption outside the room. Results suggest that the contribution to the fire of a fully unprotected combustible room structure can be significant. The contribution can be directly seen by comparing the total HRR in Test 3 with other tests. As shown in Table 4-13, the mean total HRR in Test 3 is $78 \%$ higher than that of Test 1 and 2 and $86.6 \%$ higher than that of Test 5 . Further, with the contribution of CLT panels, the fuel burning rate was almost double those in Test $1 \& 2$ and Test 5 .

An important observation from the tests is that the total HRR or energy release is not strictly an indicator of the severity of room fires as this value includes the heat released outside the fire compartment. Although Test 3 had a much higher heat release, the in-room burning conditions were much poorer with lower upper layer temperature (see Figure 4-20). Test 3 resulted in a lower room air inflow rate, of about $19 \%$ and $26 \%$ less than those in Test $1 \& 2$ and Test 5 , respectively. In addition, the global equivalence ratios in Test 3, which were calculated by considering the CLT wall panels as part of the fuel package, was much higher than the other tests, indicating an extremely under-ventilated condition.

Comparing the difference between measured total HRR and maximum HRR based on air entrainment from the doorway, it can be found that the contribution of the CLT in Test 3 is totally in the form of external heat release. As shown in Table 4-13, Test 2 and Test 5 in which there was no contribution from the room boundaries the external heat release rate are very low as most of the pyrolysis products were consumed inside the room. In contrast, when the CLT wall panels contributed to the room fire as additional fuel, the external heat release was $75 \%$ higher than the interior heat release rate.

The prediction of the maximum HRR using the ventilation factor (air entrainment rate 0.5 
$A_{v} \sqrt{H_{v}}$ or heat release rate $1518 A_{v} \sqrt{H_{v}} \mathrm{~kW}$ [87]) may misrepresent the real combustion conditions. For instance, the calculated maximum HRR 4.6 MW based on the opening condition greatly overestimates the maximum in-room HRR as shown in Table 4-13, and is even higher than the mean total HRR (excluding Test 3). This is due to the assumptions made in developing these formulae one of which is that the smoke outflow and air inflow rate through the doorway are equal. This assumption is true only when the fuel mass flow rate is very small when compared to the air inflow rate. The other assumption is that the temperature is uniform across the hot layer with a value of $800^{\circ} \mathrm{C}$. In cases where the fuel mass flow rates are significant (i.e., heavily under-ventilated conditions) and the smoke layer temperatures are high (more than $1000^{\circ} \mathrm{C}$ ), the prediction would be misleading.

Calculations of the contribution to the fire of a wood structure were also reported by Hakkarainen [49]. Two of the tests conducted were similar to Test 3 and Test $1 \& 2$ of the current study, except that the wood structure was built with Heavy Laminated Timber instead of CLT. The fuels were wood cribs weighing in total $680 \mathrm{~kg}$ and particle board 230 $\mathrm{kg}$, which is about $34 \%$ higher than the fuel load of the current study. Fire contributions of the wood structure were examined using energy balance calculations. It was found that the external to internal heat release ratio was $15 \%$ for the protected room and $50 \%$ for the unprotected room.

McGregor [92] adopted a simple way to estimate the contribution of the CLT panel structure to the fire, through comparing the heat release rates of Test 3 with other tests where no contribution occurred. The hypothesis is that when a CLT structure contributes to the fire, the contribution can be accounted for by additional heat release, as demonstrated in Figure 4-31. The average HRR of Test 1 and 2 was used as the baseline because there is 
no CLT structure contribution in those two tests. The black curve indicates the HRR contribution which was obtained by subtracting mean HRR of Test $1 \& 2$ from that of Test 3. However, this curve may underestimate the contribution because the furniture fuel package in Test 3 may endure lower combustion efficiency than that in other tests.

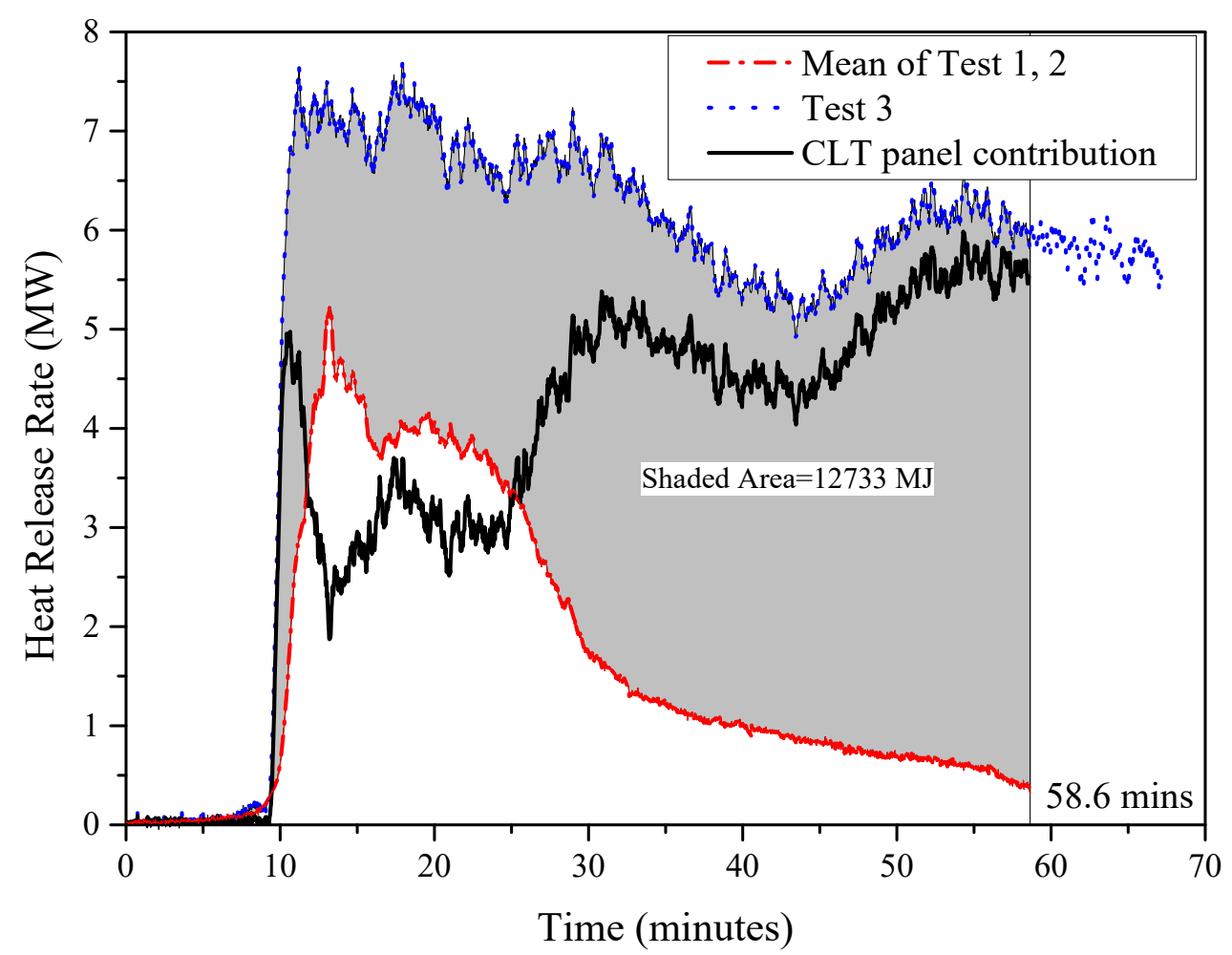

Figure 4-28 Rough estimation of CLT panels contribution in Test 3 [92]

Finally it should be noted that even though careful calculations were done in the present study to provide accurate results, the calculation approaches do involve some approximations and simplifications. 


\subsection{Summary}

Test results of six full-scale room fire tests were presented. The HRR and temperature curves in all the tests except the unprotected CLT room fire test (Test 3) generally followed the same trend after ignition, e.g. growth, flashover, fully developed and decay. The fully developed phase lasted about 15 minutes in the under-ventilated fire conditions. In contrast, with the fire contribution of the CLT panels in Test 3 , the fire experienced earlier flashover and went through continuous burning after the movable fuel load was consumed. Compared with other tests, Test 3 produced more than $80 \%$ higher HRR and slightly lower room temperatures during the fully developed phase. After careful calculation it was also discovered that the heat release in Test 3 mainly occurred in the form of external burning, and the air entrainment in the external flame $(1.51 \mathrm{~kg} / \mathrm{s})$ was $75 \%$ higher than that through the doorway $(0.856 \mathrm{~kg} / \mathrm{s})$. Other tests had slightly under-ventilated burning conditions and most of the fuels were consumed inside the room.

When walls and ceilings were lined with two layers of gypsum boards, either in CLT construction or light timber-frame construction, the combustible CLT panels or wood studs did not get exposed to the fire. The temperature profiles inside the wall suggested that the protection effect of gypsum boards were better in CLT walls than in light frame walls, mainly due to a tighter joint between the CLT panel and the gypsum boards, which effectively avoided heat penetration.

When a single layer of type $\mathrm{C}$ gypsum board was applied on the fire exposed side, significant differences appeared between the behaviour of light-frame timber (Test 5) and light-frame steel construction (Test 6). Falling of the gypsum board in Test 5 occurred after 60 minutes following ignition, while in Test 6 the majority of the wall gypsum boards 
collapsed shortly after 23 minutes following ignition, exposing the light frame to the room fire. Even though the gypsum board stayed on the wall for an hour or longer in Test 5, the onset of charring in the wood studs was first measured as early as 22.2 minutes after ignition. Combustion of wood studs took place under the gypsum boards before they fell off. The average charring rate was $1.22 \mathrm{~mm} / \mathrm{min}$ based on a $30 \mathrm{~mm}$ charring depth, which is significantly higher than the $0.65 \mathrm{~mm} / \mathrm{min}$ recommended in Eurocode 5 for standard fire exposure. Higher charring rates of the CLT wall panels in Test 3 were also observed. The average charring rate based on a $24 \mathrm{~mm}$ charring depth in about 40 minutes was 0.85 $\mathrm{mm} / \mathrm{min}$, and the overall charring rate was $1 \mathrm{~mm} / \mathrm{min}$ in a 60 minutes time period.

These findings suggest that the fire performance of building elements in a real fire might be different from what is obtained in a standard test, to put it another way, the barrier failure time of a building assembly in an arbitrary fire might be earlier or later than its fire resistance rating. Hence it is important to account for the real fire performance when performing an engineered fire safety design. It is infeasible to test a building assembly in fires of various severities but computer models can do so. With the intention, the test findings in this chapter will be used to develop and verify a barrier failure model presented in Chapter 5. 


\section{Chapter 5 Development of the Barrier Failure Submodel for CUrisk}

\subsection{Objective and scope of the proposed Barrier Failure submodel}

Currently CUrisk lacks a versatile barrier failure submodel to predict failure times of different building assemblies. The objective of this chapter is to present a Barrier Failure model for CUrisk. This model is capable of predicting the fire behaviour of various types of building elements, including (but not limited to) light steel/timber frame (LSF, LTF), concrete, Cross-Laminated Timber (CLT) and doors. The proposed model can be incorporated in the CUrisk system model and function with the other submodels, especially the Fire Spread submodel. The scope of functionality of the model include:

- The Barrier Failure submodel in CUrisk is expected to be simple and computingfriendly, and have the same level of accuracy or sophistication as other submodels of CUrisk. Thus, two- or three-dimensional numerical models are not considered as they are too computing-intensive, especially when Monte Carlo approach is adopted in the model to do repeated runs;

- The proposed Barrier Failure submodel should be capable of distinguishing the impact of different construction types on the failure behaviour;

- The proposed Barrier Failure submodel should be able to calculate the effect of fire severity on the barrier failure. In other words, it should be able to predict the failure of barriers for any given fire severity (such as fire curve). As is known, in real arbitrary fires building elements might behave differently than in the standard fire.

The basic requirements of building structures during fire exposure should satisfy two functions: one is the load-bearing function, and the other one is the separating function [57]. The load-bearing function should be maintained if the mechanical resistance of the 
structure in case of fire is required, whereas fire compartmentation is required if the separating function should be maintained. The load bearing function prevents building structural collapse but its failure may not be the exclusive cause of fire spread. In this matter, it is known that the separating function of the building structure is essential and directly related to the occurrence of fire spread. The initiation of fire spread is due to the failure of fire compartmentation, which process usually occurs long before structural collapse. Regarding fire spread, fire separations are more important than structural members. It is common to see that after a fire the building structure remains whereas everything else inside the building is destroyed.

Therefore, the scope of barrier in this study refers to the barriers serving the fire separations / compartmentations, named hereafter the fire separating barrier. The failure of loadbearing structural members is not considered for the reasons stated earlier. The fire separating barriers refer to the elements forming the boundaries of fire compartments, including doors, windows, walls, and ceilings/floors.

\subsection{The framework of the barrier failure model - Component Subtractive Method}

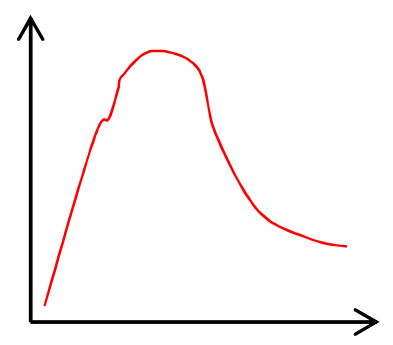

Room fire temperature in Smoke Movement submodel

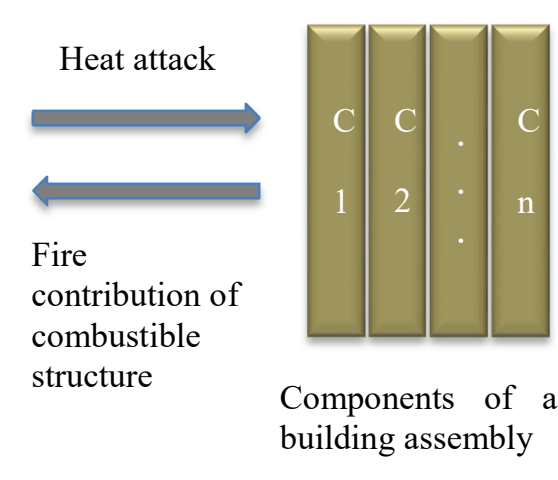

Figure 5-1 Illustration of the Component Subtractive Method 
The approach used in the proposed barrier failure model is called the Component Subtractive Method. Being the opposite of the Component Additive Method [82], the Component Subtractive Method determines the failure of a building assembly based on the failure characteristics of its components. An illustration of the Component Subtractive Method is shown in Figure 5-1.

As the proposed model will be incorporated into CUrisk, the barrier failure model inputs the fire curve generated by the Smoke Movement submodel of CUrisk. A one dimensional finite difference heat transfer model is created to predict the heat transfer process in various building assemblies. In a case where timber members in the building assembly are involved in the room fire, the contribution of them is accounted for by adding the additional fuel to the fire load, which increases the fire severity. The failure times of components are determined based on designated failure criteria. Finally the time of failure or probability of failure of a building assembly is determined.

\subsubsection{Definition of the components}

A component is a major part of a given building assembly. For example, a light timberframe wall assembly contains the components of gypsum boards, wood studs and insulation. For some of the known construction types, the components are listed as follows:

- Components in light-frame construction

○ Gypsum boards

- Wood or steel studs

- Insulation (fiberglass or rock fiber), or air in the void cavity

- Components in mass timber construction

○ Gypsum boards 
- CLT (Cross-Laminated-Timber) panel

- LSL (Laminated Strand Lumber) panel

- Door constructed with various materials

\subsubsection{Determination of the assembly failure}

The failure time of a building assembly depends on the failure of its components. The failure of an assembly usually starts from the failure of the fire-exposed component and progresses to the unexposed components, and is affected by the room fire severity $\left(T_{\text {room }}\right)$, relationships and properties of all the components $\left(c_{1}, c_{2}, c_{3}, \ldots\right)$, as described by the formula below,

$$
t_{\text {fail }}=\operatorname{func}\left(T_{\text {room }}, c_{1}, c_{2}, c_{3}, \ldots\right)
$$

The fire-exposed component is directly subjected to the room fire environment. The adjacent component is partially protected by the fire-exposed component, and subjected to a reduced fire severity from the room fire, but may be exposed to the room fire after the failure of the fire-exposed component. This process continues until the failure of the unexposed component.

Various methods may be adopted to determine the failure of components. The timeequivalent methods may be used to find the failure time of the components of the building assembly. However, as was found in the literature survey, the existing time-equivalent approaches only consider the properties of the fire-exposed components but overlook the complete structure of the whole building assembly. In addition, temperature criteria may be used to account for the thermal or mechanical reaction of the components. For example, charring of timber members commences when the temperature reaches $300^{\circ} \mathrm{C}$. Besides, structural reaction of materials may lead to integrity failure of the components, which may 
alternatively take a longer time to reach insulation failure. For instance, buckling of steel studs in light steel-frame wall assembly could lead to quick and comprehensive collapse of gypsum boards and thus cause very early failure of the whole wall assembly.

In case where the building assembly has combustible members, such as wood studs and CLT panels, these components may burn and therefore increase the room fire severity. Those fire contributions can be accounted for by adding the fuel load of combustible structural members to the fuel load in the fire room. For wood structural members, burning rates can be determined based on the charring rates and exposed surface areas.

\subsubsection{Input of the model}

- Room temperature-time profile. Since the barrier failure model is used in CUrisk, the temperature output of the Smoke Movement submodel and the Fire Growth submodel are used.

- Components of the fire separating barrier. Types of components of a barrier, such as number of layers of gypsum board, insulation type, and thermo-physical properties of each component.

\subsubsection{Output of the model}

- Time of barrier failure, and/or,

- Probability of barrier failure as a function of time.

\subsection{The deterministic heat transfer and component response model}

In order to get the temperature profile inside a building assembly, the one-dimensional finite difference method is adopted to calculate the heat transfer process. It is assumed that material properties are uniform in each component. For example, when heat transfers 
through a gypsum-protected CLT panel it is assumed that temperatures are uniform at the same depths across the panel.

For one dimensional unsteady heat conduction, the governing differential equation is,

$$
\rho c \frac{\partial T}{\partial t}=\frac{\partial}{\partial x}\left(k \frac{\partial T}{\partial x}\right)+S
$$

No heat generation is considered in the heat transfer process. Thus, by removing the source term $\mathrm{S}$ in the above equation we get the new differential equation,

$$
\rho c \frac{\partial T}{\partial t}=\frac{\partial}{\partial x}\left(k \frac{\partial T}{\partial x}\right)
$$

There are many ways of deriving discretization equations, and the method introduced in [109] is used.

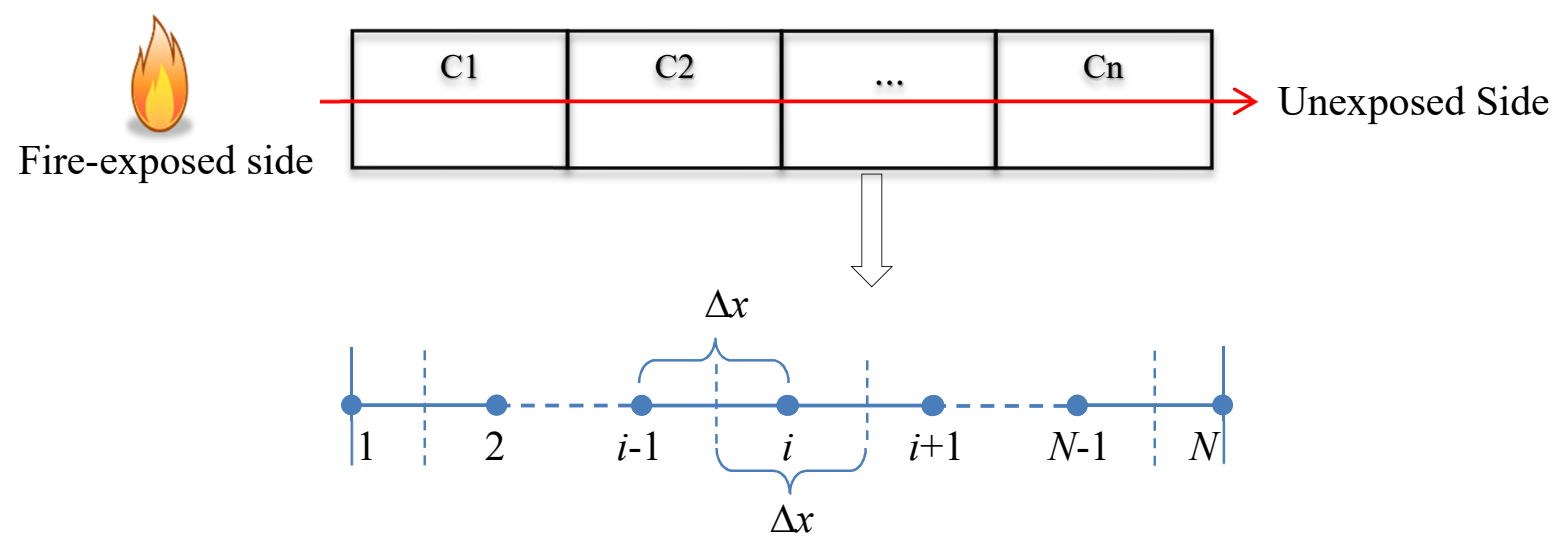

Figure 5-2 Heat transfer across components and grid spacing

The uniform grid is applied to all components but node spacing may not be same in different components depending on the grid numbers specified for each component. With the uniform gird, the grid space and width of control volumes are the same, denoted as $\Delta x$. For internal node $i$ of a layer at time step $m$, the finite difference equation (FDE) can be written as, 


$$
k_{i, l} \frac{T_{i-1}^{m}-T_{i}^{m}}{\Delta x}-k_{i, r} \frac{T_{i}^{m}-T_{i+1}^{m}}{\Delta x}=\rho_{i} c_{i} \Delta x \frac{T_{i}^{m+1}-T_{i}^{m}}{\Delta t}
$$

Where, $T_{i}^{m}$ means the temperature in node $i$ at time step $\mathrm{m}, \mathrm{K} ; \rho_{i}$ is the density at control volume $i, \mathrm{~kg} / \mathrm{m}^{3} ; C_{i}$ is the specific heat at control volume $i, \mathrm{~J} / \mathrm{kg} \cdot \mathrm{K} ; \Delta x$ is the width of the control volume, $\mathrm{m} ; k_{i, l}$ and $k_{l, r}$ are the interface conductivity $(\mathrm{W} / \mathrm{m} \cdot \mathrm{K})$ at the left and right face of the control volume $i$, respectively.

The thermal conductivity $k$ varies with temperature and therefore with depth position. Patankar [110] suggested a method to determine the interface conductivity as below,

$$
k_{i, l}=\left(\frac{1-f_{i}}{k_{i-1}}+\frac{f_{i}}{k_{i}}\right)^{-1} \text { and } k_{i, r}=\left(\frac{1-f_{i+1}}{k_{i}}+\frac{f_{i+1}}{k_{i+1}}\right)^{-1}
$$

where, $f_{i}=\frac{\Delta x_{i}}{\Delta x_{i-1}+\Delta x_{i}}$, and $f_{i+1}=\frac{\Delta x_{i+1}}{\Delta x_{i}+\Delta x_{i+1}}$.

With the uniform grid,

$$
k_{i, l}=\frac{2 k_{i-1} k_{i}}{k_{i-1}+k_{i}}, \text { and } k_{i, r}=\frac{2 k_{i} k_{i+1}}{k_{i}+k_{i+1}}
$$

In the same component or layer, it is assumed that the conductivity in the adjacent nodes are the same considering that their temperatures are close, i.e., $k_{i-1}=k_{i}=k_{i+1}$, and the interface conductivity is assumed to be equal to the conductivity in the node $i$. Therefore, in Equ.(5.4), $k_{i, l}=k_{i, r}=k_{i}$. Writing the FDE Equ.(5.4) to its implicit form gives,

$$
k_{i} \frac{T_{i-1}^{m+1}-T_{i}^{m+1}}{\Delta x}-k_{i} \frac{T_{i}^{m+1}-T_{i+1}^{m+1}}{\Delta x}=\rho_{i} c_{i} \Delta x \frac{T_{i}^{m+1}-T_{i}^{m}}{\Delta t}
$$

In order to solve the discretization equations by the Thomas Algorithm (or Tri-Diagonal- 
Matrix Algorithm) [110], the above equations are expressed in the following form,

$$
a_{i} T_{i}^{m+1}=\mathrm{b}_{i} T_{i+1}^{m+1}+c_{i} T_{i-1}^{m+1}+d_{i}
$$

Let

$$
\mathrm{Fo}_{i}=\frac{k_{i} \Delta t}{\rho_{i} c_{i} \Delta x^{2}}
$$

Those factors can be derived,

$$
\begin{array}{cc}
a_{i}=1+2 F O_{i} & \text { Equ.(5.10) } \\
b_{i}=F O_{i} & \text { Equ.(5.11) } \\
c_{i}=F O_{i} & \text { Equ.(5.12) } \\
d_{i}=T_{i, m} & \text { Equ.(5.13) }
\end{array}
$$

\subsubsection{Boundary conditions at the fire-exposed nodes}

When a building assembly is subjected to the fire, it is assumed that one face of the assembly is directly exposed (fire-exposed side), and the other face is unexposed (unexposed side). In a realistic fire scenario initiated in a fire compartment, all the inner compartment interior faces are exposed to the fire. The fire-exposed side is subjected to heat attack in the form of both heat convection and heat radiation. Convective and radiative heat transfer through the fire-exposed boundary can be calculated using the room temperature data. The configuration factor for the radiative heat transfer to the assembly surface is assumed to be unity to simplify the calculation, and this treatment is acceptable because it would produce conservative results. 
Fire-exposed side h, $\varepsilon$

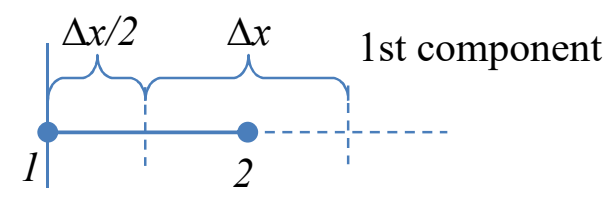

Control volume of node 1,2

\section{Figure 5-3 Boundary condition at the fire-exposed surface}

On the fire-exposed boundary node the heat transfer FDE in its implicit form is,

$$
h_{f}\left(T_{f}^{m+1}-T_{1}^{m+1}\right)+\epsilon \sigma\left[\left(T_{f}^{m+1}\right)^{4}-\left(T_{1}^{m+1}\right)^{4}\right]-k \frac{T_{1}^{m+1}-T_{2}^{m+1}}{\Delta x}=\rho c \frac{\Delta x}{2} \frac{T_{1}^{m+1}-T_{1}^{m}}{\Delta t}
$$

Equ.(5.14)

where $h_{f}, \epsilon$, and $\sigma$ are the convective heat transfer coefficient, emissivity, and the StefanBoltzmann constant, respectively.

Following the form of Equ.(5.8), we can get,

$$
\begin{gathered}
a_{1}=1+2 F o_{1}\left\{\frac{\Delta x}{k_{1}}\left[h_{f}+\epsilon \sigma\left(T_{1}^{m+1}\right)^{3}\right]+1\right\} \\
b_{1}=2 F O_{1} \\
c_{1}=0 \\
d_{1}=T_{1}^{\mathrm{m}}+2 F o_{1} \frac{\Delta x}{k_{1}} T_{f}^{m+1}\left[h_{f}+\epsilon \sigma\left(T_{f}^{m+1}\right)^{3}\right]
\end{gathered}
$$

The term, $T_{1, m+1}^{3}$ in the coefficient $a_{1}$ represents the temperature at the fire-exposed node in one time step into the future. To avoid the complexity, an approximation is made for this term. The surface temperature at the next time step can be estimated by taking the average of the fire temperature at the next time step and the surface temperature at the current time step. The same treatment was also adopted in [111]. This gives a coefficient for $a_{1}$ of: 


$$
a_{1}=1+2 \mathrm{Fo}_{1}\left[\frac{\Delta x}{k_{1}}\left(h_{f}+\epsilon \sigma\left[\frac{T_{f, m+1}+T_{1, m}}{2}\right]^{3}\right)+1\right]
$$

However, the underlying assumption on the above treatment is that the exposed surface material has a low thermal inertia and the surface temperature can reach the fire temperature quickly. In the case of a material with high thermal inertia, the next step surface node temperature can be assumed to be equal to the temperature in the current time step, i.e., the following form of $a_{1}$ should be used,

$$
a_{1}=1+2 \mathrm{Fo}_{1}\left[\frac{\Delta x}{k_{1}}\left(h_{f}+\epsilon \sigma T_{1, m}^{3}\right)+1\right]
$$

\subsubsection{Boundary conditions on the unexposed nodes}

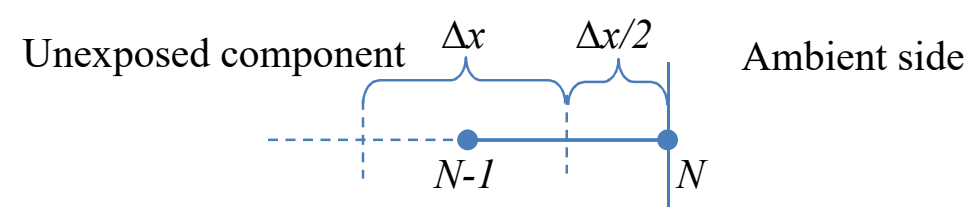

Control volume of node $N-1, N$

Figure 5-4 Boundary condition at the unexposed surface

On the unexposed surface of a building assembly, the heat loss from the component surface to the ambient environment is through heat convection, the effect of radiation is ignored due to its insignificance at low temperatures. On the unexposed boundary node the heat transfer FDE in its implicit form is,

$$
k \frac{T_{N-1}^{m+1}-T_{N}^{m+1}}{\Delta x}-h_{\infty}\left(T_{N}^{m+1}-T_{\infty}^{m+1}\right)=\rho c \frac{\Delta x}{2} \frac{T_{N}^{m+1}-T_{N}^{m}}{\Delta t}
$$

where, $h_{\infty}$ is the convective heat transfer coefficient at the ambient surface, $\mathrm{W} / \mathrm{m}^{2} \cdot \mathrm{K}$. Following the form of Equ.(5.8), we can get, 


$$
\begin{gathered}
a_{N}=1+2 \mathrm{Fo}_{N}\left[\frac{\Delta x}{k_{N}} h_{\infty}+1\right] \\
b_{N}=0 \\
c_{N}=2 F O_{N} \\
d_{N}=T_{N}^{m}+2 F O_{N} \frac{\Delta x}{k_{N}} T_{\infty}^{m+1} h_{\infty}
\end{gathered}
$$

\subsubsection{Boundary conditions at the joint of two different components}

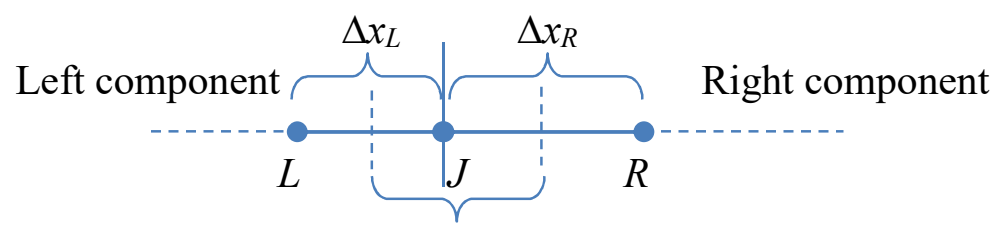

Control volume of node $J$

Figure 5-5 Boundary condition at the joint of two components

Although the grids are uniformly spaced in each layer, the grid spacing in a different layer might be different. In the case where heat transfers through the interface of two different components, it is supposed that the last node of the left component is overlapped with the first node of the right component (as node $J$ in Figure 5-5). And therefore the control volume of node $J$ contains half volume (with properties $T_{J}, \rho_{J, \text { left }}, c_{J, \text { left }}$ and $\Delta x_{L} / 2$ ) from left component and the other half from the right component (with properties $T_{J}, \rho_{J, \text { right }}$, $c_{J, \text { right }}$ and $\left.\Delta x_{R} / 2\right)$. It is still assumed that the temperature prevails the whole control volume. The heat conduction FDE in its implicit form is, $k_{l} \frac{T_{L}^{m+1}-T_{J}^{m+1}}{\Delta x_{L}}-k_{r} \frac{T_{J}^{m+1}-T_{R}^{m+1}}{\Delta x_{R}}=\left(\rho_{J, \text { left }} c_{J, \text { left }} \frac{\Delta x_{L}}{2}+\rho_{J, \text { right }} c_{J, r i g h t} \frac{\Delta x_{R}}{2}\right) \frac{T_{J}^{m+1}-T_{J}^{m}}{\Delta t}$

Equ.(5.26) 
Where, $k_{l}$ and $k_{r}$ are interface conductivities on the left face and right face of grid $\mathrm{J}$, respectively; $\rho_{J, \text { left }}$ and $\rho_{J, \text {,ight }}$ are the densities in the left half of grid $\mathrm{J}$ and right half of grid J, respectively; $c_{J, \text { right }}$ and $c_{J, \text { left }}$ are the specific heats of the left half and right half of grid J, respectively.

Following the form of Equ.(5.8), we can get,

$$
\begin{gathered}
a_{J}=\left[\frac{k_{l}}{\Delta x_{L}}+\frac{k_{r}}{\Delta x_{R}}+\frac{\rho_{J, \text { left }} c_{J, \text { left }} \Delta x_{L}+\rho_{J, r i g h t} c_{J, r i g h t} \Delta x_{R}}{2 \Delta t}\right] \\
b_{J}=\frac{k_{r}}{\Delta x_{R}} \\
c_{J}=\frac{k_{l}}{\Delta x_{L}} \\
d_{J}=\frac{\rho_{J, l e f t} c_{J, l e f t} \Delta x_{L}+\rho_{J, r i g h t} c_{J, r i g h t} \Delta x_{R}}{2 \Delta t} T_{J}^{m}
\end{gathered}
$$

In case of the joint of void cavity and the other material, taking the void cavity in the lightframe construction for example, the equivalent thermal conductivity in in Equ.(5.31) should be used as the properties of air, on the side of the cavity in the joint as shown in Figure 5-5. This part is further discussed in the following section.

\subsubsection{Heat transfer through the void cavity}

In case when the component is void and enclosed by different materials, taking the void cavity in the light-frame construction for example, the heat transfer through the void cavity is by natural convection and radiation. Heat conduction through the void cavity is not considered due to the fact that the air thermal conductivity is very low (about 0.03 $\left.\mathrm{W} / \mathrm{m}^{2} . \mathrm{K}\right)$. Like the grid distribution in the solid components, uniformly spaced grids are 
also placed into the depth of void cavity supposing that each control volume is filled with air. Furthermore, the convective heat transfer through the void cavity can be accounted for by substituting conductive heat transfer with convective heat transfer. Technically, the term $k_{i} / \Delta x$ in Equ.(5.7) should be replaced with convective heat transfer coefficient $h$, and therefore, the term $k_{i}$ in the $F o_{i}$ should be replaced with equivalent heat conductivity,

$$
k_{i, e q u}=h_{i} \Delta x_{i}
$$

Radiative heat transfer inside the void cavity is of great importance to model the thermal behavior of the whole assembly [112]. The radiative heat flux depends on the temperature of the two solid surfaces surrounding the void cavity. Radiative heat flux is calculated by assuming two infinite length parallel plates, as the equation below ([113], Equ 13.59),

$$
\begin{gathered}
\dot{q}_{r a d}^{\prime \prime}=\frac{\sigma\left(T_{l s}^{4}-T_{r s}^{4}\right)}{\frac{1}{\varepsilon_{l s}}+\frac{1}{\varepsilon_{r s}}-1} \\
\varepsilon_{c}=\frac{1}{\frac{1}{\varepsilon_{l s}}+\frac{1}{\varepsilon_{r s}}-1}
\end{gathered}
$$

Where, $\dot{q}_{\text {rad }}^{\prime \prime}$ is radiative heat flux $\left(\mathrm{W} / \mathrm{m}^{2}\right)$ through the void cavity from one solid surface to the other; $T_{l s}$ and $T_{r s}$ are left and right surface temperatures $(\mathrm{K})$, respectively; $\varepsilon_{l s}$ and $\varepsilon_{r s}$ are the emissivity of the left and right surface, respectively. For simplicity, the emissivity in the cavity is defined as $\varepsilon_{c}$, see Equ.(5.33). 


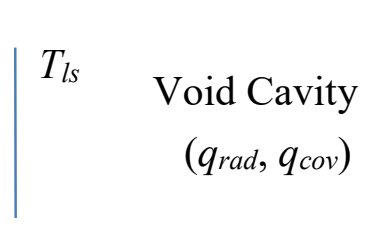

Left solid surface

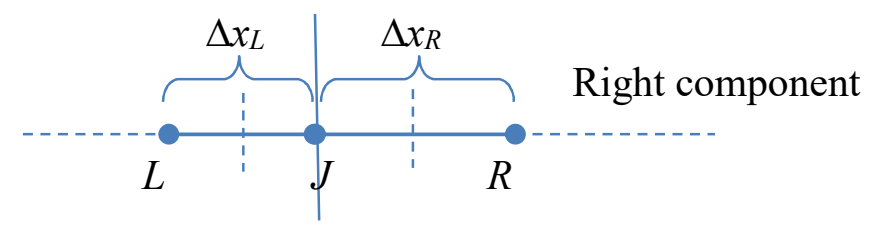

Right solid surface, $T_{r s}=T_{J}$

Figure 5-6 An demonstration of heat transfer at the interface of void cavity and right solid surface

At the interface of void cavity and right solid surface (as shown in Figure 5-6), the heat conduction FDE in its implicit form is shown in the following equation,

$$
\varepsilon_{c} \sigma\left[\left(T_{l s}^{m+1}\right)^{4}-\left(T_{J}^{m+1}\right)^{4}\right]+h_{c}\left(T_{L}^{m+1}-T_{J}^{m+1}\right)-k_{r} \frac{T_{J}^{m+1}-T_{R}^{m+1}}{\Delta x_{R}}=\left(\rho_{J, l e f} c_{J, l e f t} \frac{\Delta x_{L}}{2}+\rho_{J, r i g h t} c_{J, r i g h t} \frac{\Delta x_{R}}{2}\right) \frac{T_{J}^{m+1}-T_{J}^{m}}{\Delta t}
$$

Equ.(5.34)

where, $\varepsilon_{c}$ is the emissivity in the cavity, see Equ.(5.33); $T_{l s}$ is the temperature on the left surface of void cavity; $h_{c}$ is the convective heat transfer coefficient in the void cavity; $k_{r}$ is the interface conductivity at the right face of grid $J ; \rho_{J \text {,left }}$ and $\rho_{J, \text { right }}$ are the densities in the left half of grid $J$ and right half of grid $J$, respectively; $c_{J, r i g h t}$ and $c_{J, l e f t}$ are the specific heats of the left half and right half of grid $J$, respectively.

Following the form of the Equ.(5.8), we can get,

$$
\begin{gathered}
a_{J}=\varepsilon_{c} \sigma\left(T_{J}^{m+1}\right)^{3}+h_{c}+\frac{k_{r}}{\Delta x_{R}}+\frac{\rho_{J, l e f t} c_{J, l e f t} \Delta x_{L}+\rho_{J, r i g h t} c_{J, r i g h t} \Delta x_{R}}{2 \Delta t} \\
b_{J}=\frac{k_{r}}{\Delta x_{R}} \\
c_{J}=h_{c} \\
d_{J}=\varepsilon_{c} \sigma\left(T_{l s}^{m+1}\right)^{4}+\frac{\rho_{J, l e f t} c_{J, l e f t} \Delta x_{L}+\rho_{J, r i g h t} c_{J, r i g h t} \Delta x_{R}}{2 \Delta t} T_{J}^{m}
\end{gathered}
$$


To avoid complexity, the next-time-step temperature on the left cavity surface $T_{l s}$ as well as the temperature on the right surface $T_{J}$ are assumed to be equal to the value in the current time step. Thus, the factors $a_{J}$ and $d_{J}$ can be rewritten as shown below,

$$
\begin{gathered}
a_{J}=\varepsilon_{c} \sigma\left(T_{J}^{m}\right)^{3}+h_{c}+\frac{k_{r}}{\Delta x_{R}}+\frac{\rho_{J, l e f t} c_{J, l e f t} \Delta x_{L}+\rho_{J, r i g h t} c_{J, r i g h t} \Delta x_{R}}{2 \Delta t} \\
d_{J}=\varepsilon_{c} \sigma\left(T_{l s}^{m}\right)^{4}+\frac{\rho_{J, l e f t} c_{J, l e f t} \Delta x_{L}+\rho_{J, r i g h t} c_{J, r i g h t} \Delta x_{R}}{2 \Delta t} T_{J}^{m}
\end{gathered}
$$

\subsubsection{Emissivity and convective heat transfer coefficient}

For the emissivity of the fire, values of $\varepsilon=0.8$ and 0.9 are widely used $[6,111,112,114$ 117] in the literature, whereas for the emissivity of gypsum board, values close to the above are also used [112,114,115,117-119]. In the current model, the emissivity of fire and gypsum board (inside void cavity) is taken as $\varepsilon=0.8$. For the convective heat transfer coefficient on the fire exposed surface, unexposed surface, and in the void cavity, a value of $\mathrm{h}=10 \mathrm{~W} / \mathrm{m}^{2} \cdot \mathrm{K}$ is widely used $[6,112,116,119]$ and this value is applied in the current model as well.

\subsubsection{Thermo-physical properties and behaviour of components}

In order to correctly model the heat transfer in a building assembly, the thermo-physical property data of various building components should be known. Those properties include thermal conductivity, density, specific heat capacity, and so on. Knowing these properties at elevated temperatures is critical not only in obtaining the temperatures, but also in assessing the structural behaviour inside these assemblies. In the following, the thermophysical properties of common assembly components are introduced.

Although in the literature some data for material properties are available, it is found that this information is scarce and often inconsistent, in part due to the different manufacturing 
processes. For many years the National Research Council of Canada (NRCC) has been investigating the thermal properties of various building component materials for the development of a 2-D numerical heat transfer and structural performance model [6]. Comprehensive thermal property data of many materials have been collected through literature reviews and material tests $[41,58,120-122]$. For the most part, the materials used in the above studies represent the Canadian and North American standards and interests. Therefore, material properties available in the above literature were adopted in the current model.

Most materials used in building construction are not stable when their internal temperature rises, and they might undergo physicochemical changes, accompanied by transformation in their microstructure and properties. In this regard, the temperature-dependent thermophysical properties of most building materials are irreversible, in other words, materials might not be able to retain the original properties when their internal temperature rises to a certain level. Among the materials discussed below, only air and rock fiber can keep their thermo-physical properties at all temperatures in a fire environment, and all others would not be able to maintain their properties at high temperature. When materials properties have available experimental measurements, the thermo-physical properties as a function of temperature are fitted segment by segment using polynomial (linear, quadratic or cubic) equations, depending on the complexity of the curve segments.

\subsubsection{Gypsum board properties}

Gypsum board is a panel product consisting of a non-combustible core with paperlaminated surfaces. It is commonly used as a component in wall and ceiling assemblies. Gypsum is a common name of calcium sulphate dehydrate, which is a crystalline mineral 
that contains chemically bonded water and a small amount of free water [58]. When gypsum boards are exposed to a room fire and subjected to elevated temperature, the first process gypsum boards go through is called calcination that is the removal of chemically bonded water. This includes two dehydration processes occurring at different temperatures [58]. The first dehydration starts at about $80^{\circ} \mathrm{C}$ and finishes at about $120^{\circ} \mathrm{C}$, and about $75 \%$ of the water of crystallization is driven off. The second dehydration reaction occurs when calcium sulphate hemihydrate is converted to calcium sulphate anhydrite. Sultan [41] reported that the remaining dehydration occurs at approximately $600^{\circ} \mathrm{C}$, but there is disagreement on this temperature.

After dehydration, shrinkage and cracking continues at higher temperatures [45]. Shrinkage is a mechanical characteristic of gypsum boards and has a significant influence on heat transmission. Cracking appears as a random formation of fine cracks across the surface of the lining. Following shrinkage and cracking, thin layers of gypsum fall off because of chemical and physical changes in the material. This process is called ablation. Sultan [41] observed that this behavior of the exposed gypsum plaster lining occurs once the unexposed face reaches temperatures of about $600^{\circ} \mathrm{C}$, based on his study on Type $\mathrm{X}$ gypsum boards.

For the thermal conductivity of gypsum boards, Aguanno [111] slightly modified the data obtained from NRCC $[120,122]$ on Canadian Type X gypsum board, and stated that the conductivity data "match most closely with the scattered values found in the published literature". The same data are used in the current model, as shown in Figure 5-7. For the specific heat of gypsum board, as Thomas [123] reviewed, published curves are generally compatible with each other but there are disagreements on the temperature of the second 
dehydration of gypsum board. The specific heat of gypsum boards of various types are also provided in NRCC publications [120,122]. However, the specific heat spikes resulting from the second dehydration of gypsum board were not shown on the curve. The specific heat variation with temperature for the Canadian Type X gypsum board in an earlier NRCC publication [41] is adopted as shown in Figure 5-8, in which a second dehydration of gypsum board occurred between $600^{\circ} \mathrm{C}$ and $800^{\circ} \mathrm{C}$. Similar specific heat-temperature curve was in the other publications [116]. The density reduction factor of gypsum board (type X) is also taken from NRCC publication [120], as shown in Figure 5-9.

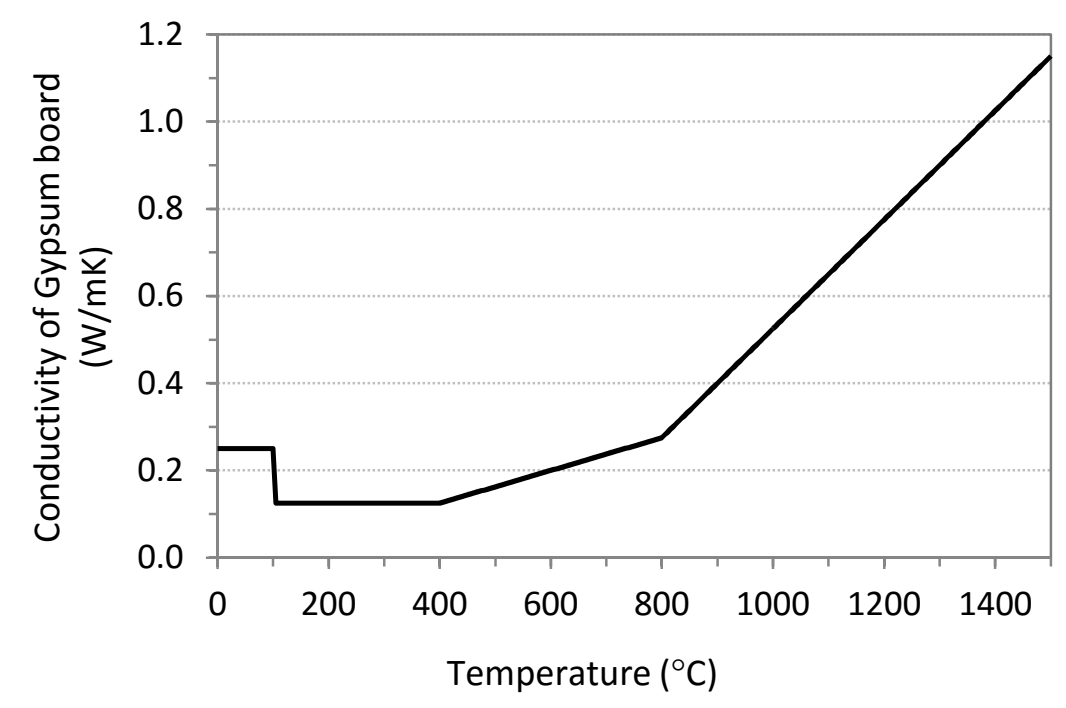

Figure 5-7 Thermal conductivity of Type $X$ gypsum board with temperature (reproduced from $[111,120,122])$ 


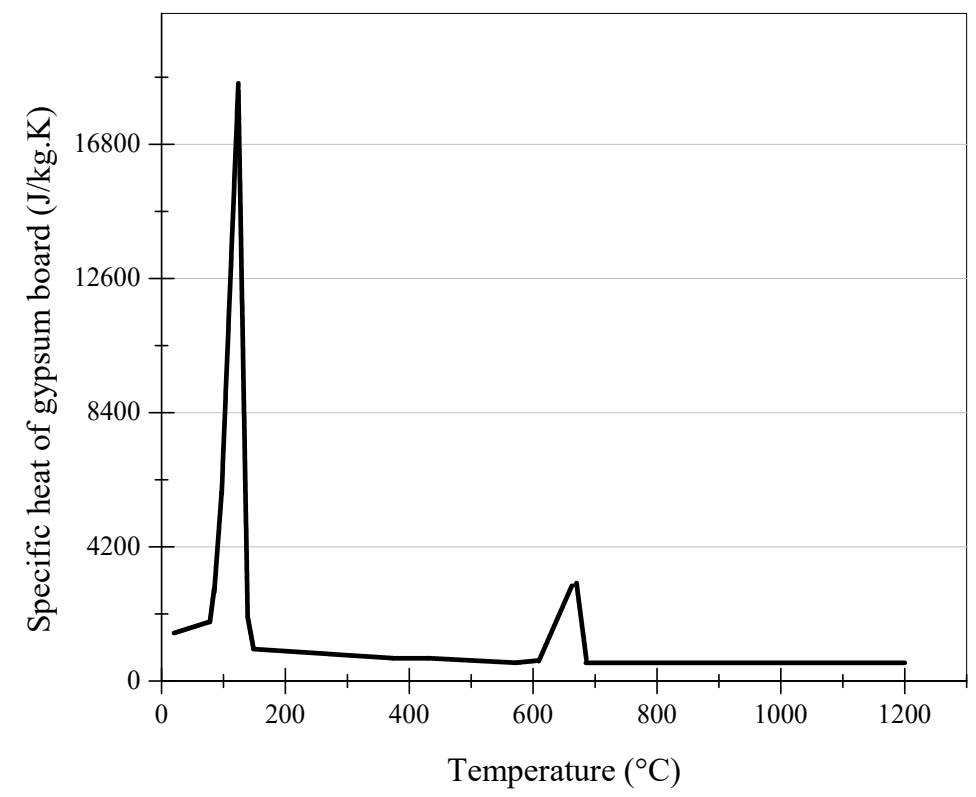

Figure 5-8 Specific heat of Type X gypsum board with temperature (reproduced from [41])

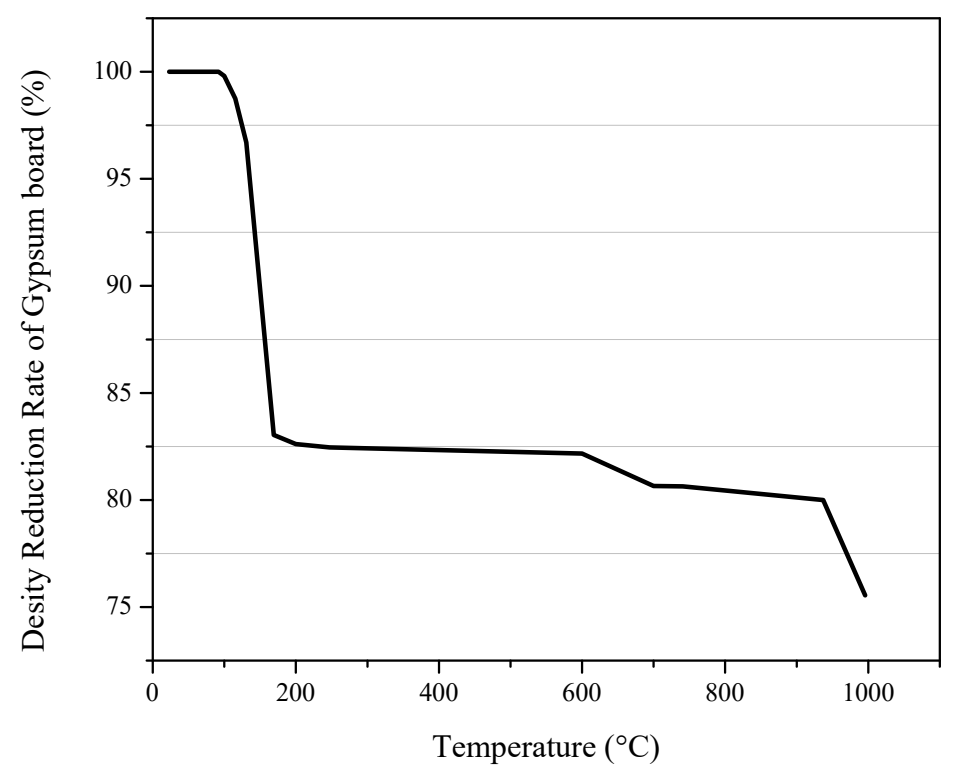

Figure 5-9 Density reduction rate of Type $X$ gypsum board with temperature (reproduced from

[120]) 


\subsubsection{Failure temperature criteria of gypsum boards}

Gypsum boards are commonly used in building assembly constructions as very important fire-resistant components. The prediction of gypsum board behavior in fires is, therefore, essential to understand the performance of building assemblies. Limited number of studies have dealt with the failure criteria of gypsum boards. The failure judgement can be based on either time period or temperature, both of which lack of theoretical background though supported by experimental test data. In Eurocode 5 Part 1-2 [57], gypsum board insulation time or failure time in the standard fire exposure is calculated based on the thickness of the board and number of layers, for given types of gypsum boards of European manufacture. The derivation process of the method is not found in the document but it is supposed to be derived empirically.

Sultan [124] proposed temperature criteria to predict the gypsum board fall-off and failure time. The temperature criteria is based on the sudden temperature rise on the back side of the fire exposed gypsum board, through analysis of 80 full-scale fire resistance tests conducted at NRCC in accordance with the Canadian standards. The 80 floor assemblies consisting of solid wood, wood I-joists, steel C-joists and wood trusses subjected to the ULC-S101/ASTM E119 standard fire exposure. The gypsum board failure temperature criteria are shown in Table 5-1. The values found in this table are taken at the back face of each gypsum board. Sultan noted that the temperatures found in the table are intended for use with $12.7 \mathrm{~mm}$ thick, Type $\mathrm{X}$ gypsum boards, and temperatures may be higher for thicker gypsum boards. 
Table 5-1 Type X Gypsum board fall-off or failure temperature criteria (taken from [124])

\begin{tabular}{|c|c|c|c|c|}
\hline \multicolumn{2}{|c|}{ Assembly Characteristics } & \multicolumn{3}{|c|}{ Failure temperature \pm Standard Deviation $\left({ }^{\circ} \mathrm{C}\right)$} \\
\hline Insulation & $\begin{array}{c}\text { Screw Spacing } \\
(\mathrm{mm})\end{array}$ & \multirow{2}{*}{$\begin{array}{c}\text { Single layer } \\
\text { assembly }\end{array}$} & \multicolumn{2}{|c|}{ Double Layer Assembly } \\
\cline { 4 - 5 } & 406 & $460 \pm 20$ & $620 \pm 50$ & $430 \pm 90$ \\
\hline No insulation & 610 & Face layer & Base layer \\
& 406 & $680 \pm 50$ & $510 \pm 50$ & $330 \pm 40$ \\
\hline Insulation & 610 & N/A & $640 \pm 40$ & $620 \pm 40$ \\
against gypsum & & & & $480 \pm 40$ \\
board layers & 406 & $670 \pm 40$ & N/A & N/A \\
\hline $\begin{array}{c}\text { Sprayed-on } \\
\text { insulation }\end{array}$ & 610 & N/A & $600 \pm 40$ & $380 \pm 30$ \\
\hline
\end{tabular}

Gypsum boards failure or fall-off criteria are rarely found in the literature. The above research findings are the most comprehensive so far and comply with Canadian standards. It should be noted that data in Table 5-1 are obtained from floor tests, but it is generally considered to be conservative to be used in non-load-bearing walls, because the ceiling drywall is usually subjected to higher fire severity than walls, and also because of the loadbearing condition of floor assemblies from where those data are obtained. Another point is that the gypsum board failure and fall-off may not always happen at the same time. Gypsum board fall-off time relies on observations, but the gypsum board failure suggested by temperature change can be trusted in most cases and should be treated as the failure criteria. With this in mind, the gypsum board failure temperature criteria listed in Table 5-1 are adopted in the barrier failure model to determine the failure of gypsum board layers.

\subsubsection{Void cavity (air) properties}

The air material properties at elevated temperatures are based on the thermo-physical property data provided in reference [125], and the density and specific heat of air are presented in Figure 5-10 and Figure 5-11, respectively. Linear interpolation is applied for thermo-physical property data in every two temperature intervals. The thermo-physical 
properties of air are assumed to be reversible and no chemical reaction occurs at high temperatures. This is in contrary to the thermo-physical properties of materials such as gypsum board or wood, for which chemical reactions inside those materials at certain temperatures would change their thermal properties, and make them unable to retain the properties when temperature decreases.

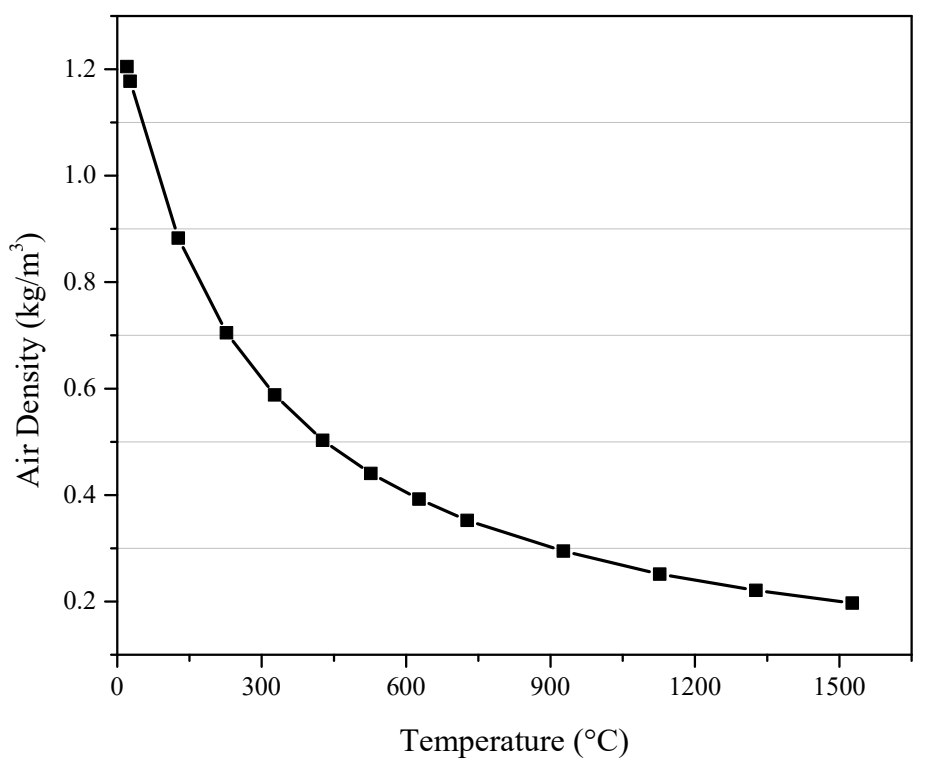

Figure 5-10 Density of air as a function of temperature (reproduced from [125]) 


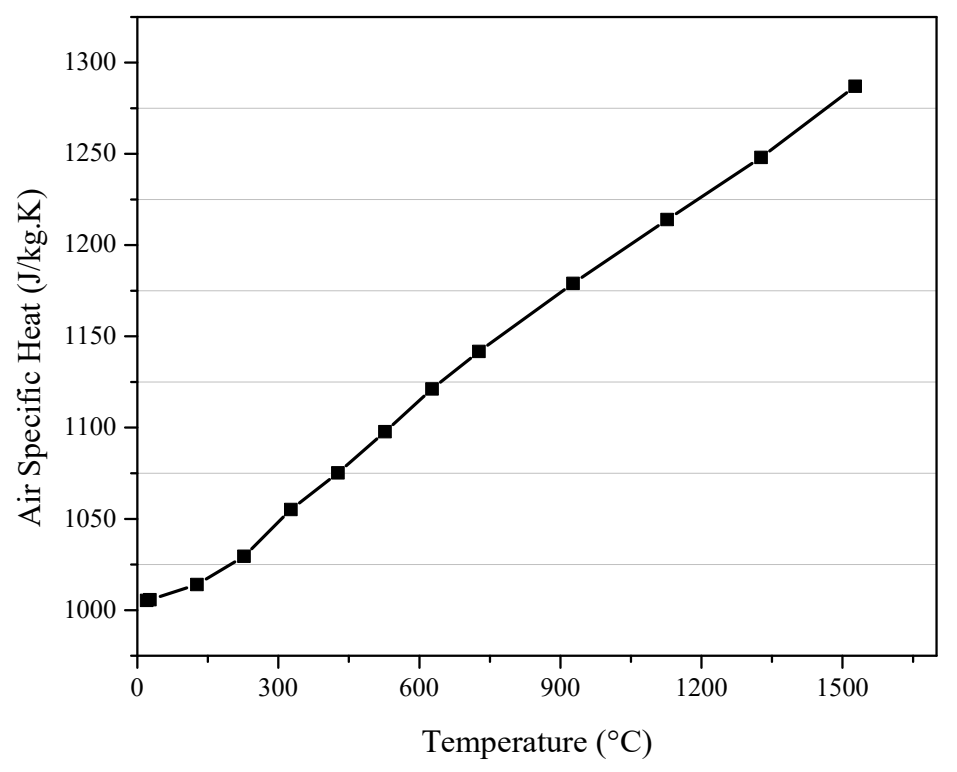

Figure 5-11 Specific Heat of air as a function of temperature (reproduced from [125])

\subsubsection{Insulation properties}

The thermal properties of insulations obtained in NRCC tests [120,122] are adopted in the current numerical model. At this stage material properties of all the insulation types in the market are impossible to collect. At least the above products represent the Canadian or North American standards. Thermal properties of each type of insulation obtained in $[120,122]$ are adopted in the current model. The temperature-dependent thermo-physical properties (thermal conductivity, specific heat and density) of two types of insulation, rock fiber and glass fiber, are presented from Figure 5-12 to Figure 5-14. 


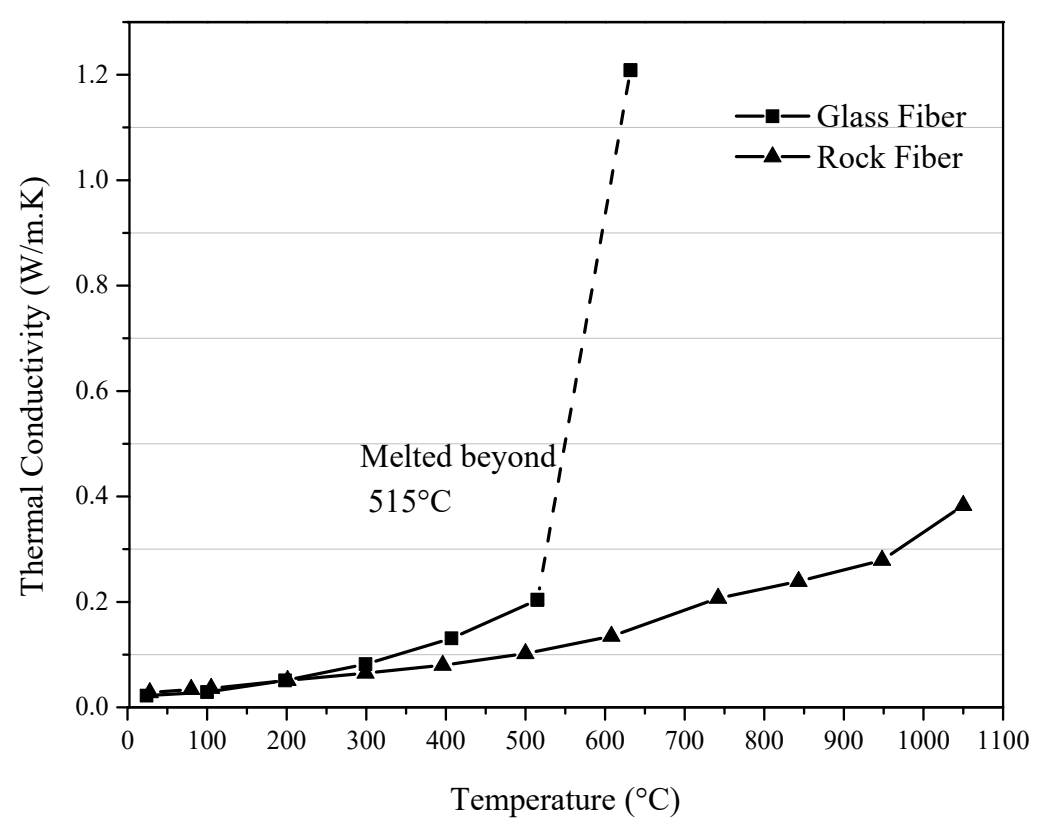

Figure 5-12 Thermal conductivity of rock and glass fiber as a function of temperature (reproduced from [120])

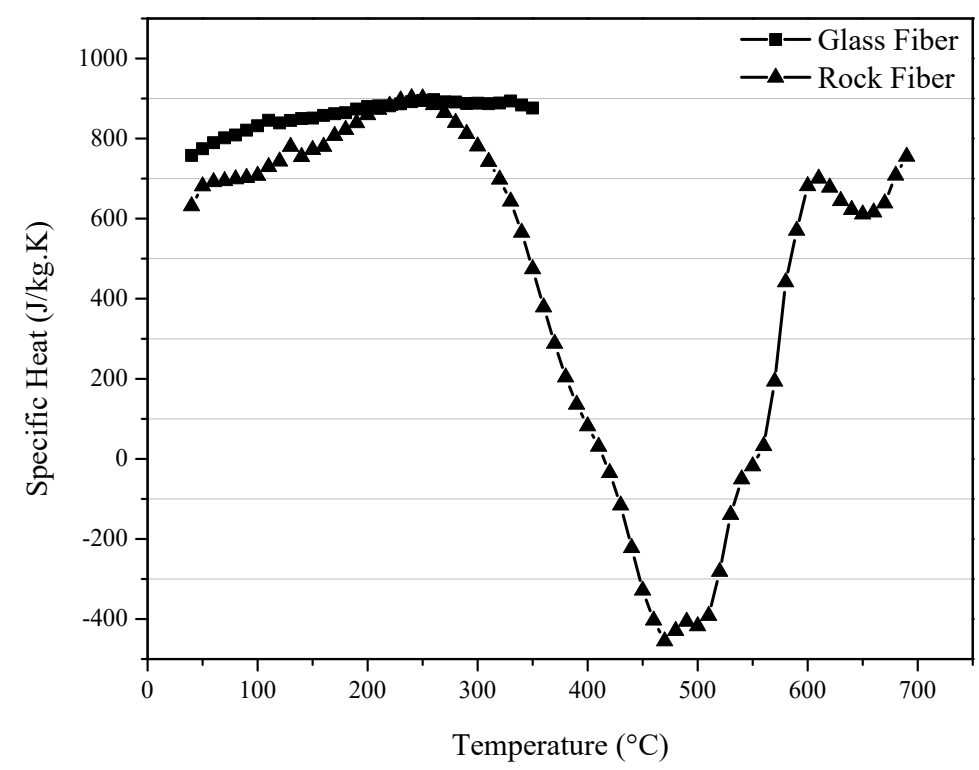

Figure 5-13 Specific heat of rock and glass fiber as a function of temperature (reproduced from [120]) 


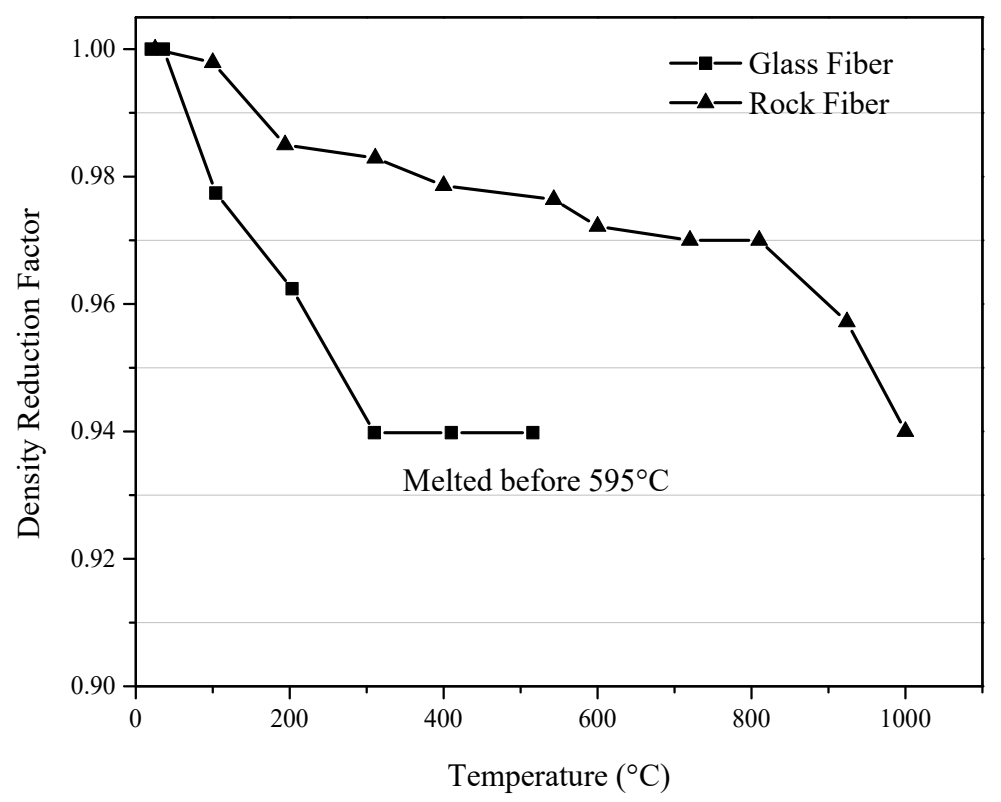

Figure 5-14 Density reduction factor of rock and glass fiber as a function of temperature (reproduced from [120])

For the glass fiber, it was found in $[120,122]$ that it melted in the temperature range from $500^{\circ} \mathrm{C}$ to $600^{\circ} \mathrm{C}$, followed by significant volume reduction. The specific heat of glass fiber was obtained for temperatures up to $350^{\circ} \mathrm{C}$ due to early termination of the measurements, as shown in Figure 5-13. For this model it is assumed that glass fiber insulation shrinks into negligible volume when the mid-cavity temperature (half cavity depth) reaches $500^{\circ} \mathrm{C}$. Two situations are considered in modeling the behaviour of glass fiber insulation in light frame construction. One is when the gypsum boards are present. After the glass fiber reaches its melting temperature, the cavity turns into void/empty and thermo-physical properties of air are applied in the model instead of glass fiber properties. The other situation is when gypsum boards fail before the glass fiber melts. Although glass fiber cannot withstand direct fire exposure, from the observation of Test 6 (light steel-frame wall assembly protected with 1 layer gypsum board, please refer to Chapter 4) it was found that 
glass fiber insulation did not disappear immediately but lasted for quite a while as a fire barrier. Therefore, in this case it is still assumed that the glass fiber insulation continues to function as a layer of component until the above-mentioned criterion is satisfied. And after that it will disappear and the unexposed gypsum board will be subjected to the direct exposure.

Unlike glass fiber, rock fiber does not melt or disappear even up to a very high temperature. As shown in Figure 5-14, the density of rock fiber did not change too much (6\%) after the temperature increased to $1000^{\circ} \mathrm{C}$. In the light frame construction, it acts as an additional fire barrier after the fire exposed gypsum boards fall off [121]. Therefore, in the numerical model it is supposed that rock fiber insulation stays in place even after the fire-exposed gypsum boards fall off.

\subsubsection{Wood properties}

In the development of the one-dimensional numerical model, wood thermo-physical properties and material behaviors are needed, including thermal conductivity, density, and specific heat as well as charring temperature. The effect of moisture contents is not considered.

When wood is heated it goes through a thermal degradation process. Wood decomposes at certain temperatures, releases combustible species and finally is converted into char. The charring process has been studied broadly and generally considered to begin when wood temperature reaches $300^{\circ} \mathrm{C}$. In the current model, wood in a control volume becomes char when the temperature of that node reaches $300^{\circ} \mathrm{C}$.

Aguanno [111] performed a literature survey of wood thermal property data for his modelling of heat transfer, and he finally adopted values taken from Buchanan [126]. 
However, in the same reference Buchanan stated that the thermal conductivity of wood at temperatures above $500^{\circ} \mathrm{C}$ is too low because cracks in the charcoal increase heat transfer due to radiation and convection (the increased heat transfer due to shrinkage cracks of char above $500^{\circ} \mathrm{C}$ and the consumption of the char layer at about $1000^{\circ} \mathrm{C}$ ). Eurocode 5 Part 12 [57] (Annex C) recognized the above issue and provided thermal conductivity values for soft woods, as shown in Figure 5-15. The specific heat and density reduction rate of wood with temperature are also obtained from [57] (Annex C), as shown in Figure 5-16 and Figure 5-17, respectively. Both of them agree very well with Marc's reference [111,127].

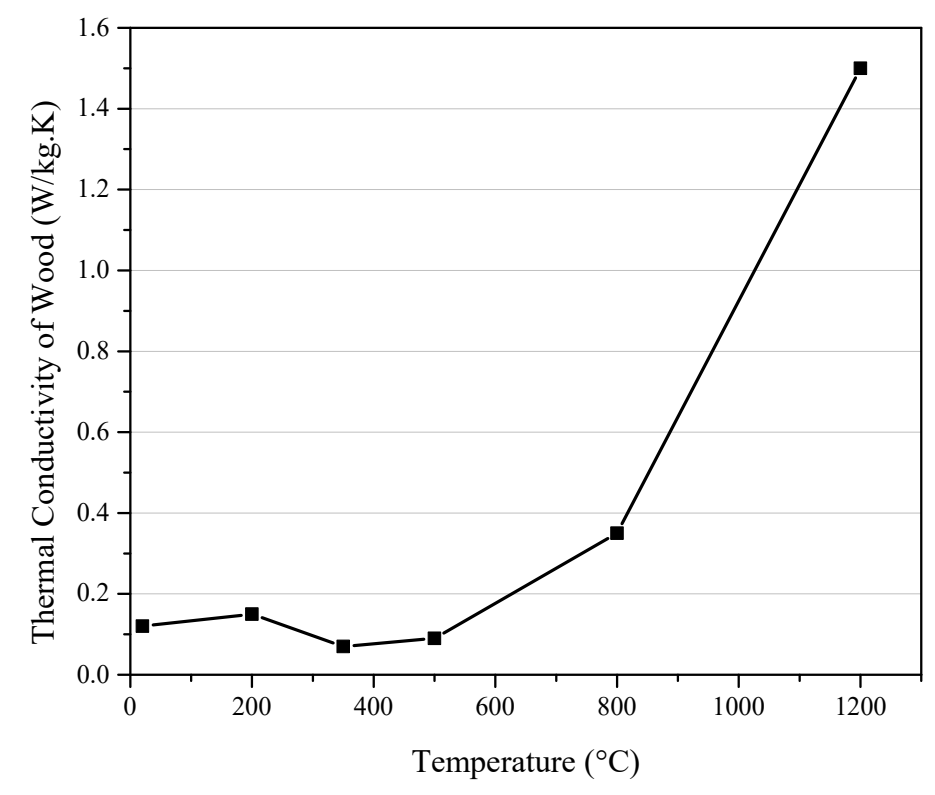

Figure 5-15 Thermal conductivity of wood with temperature (reproduced from [57]) 


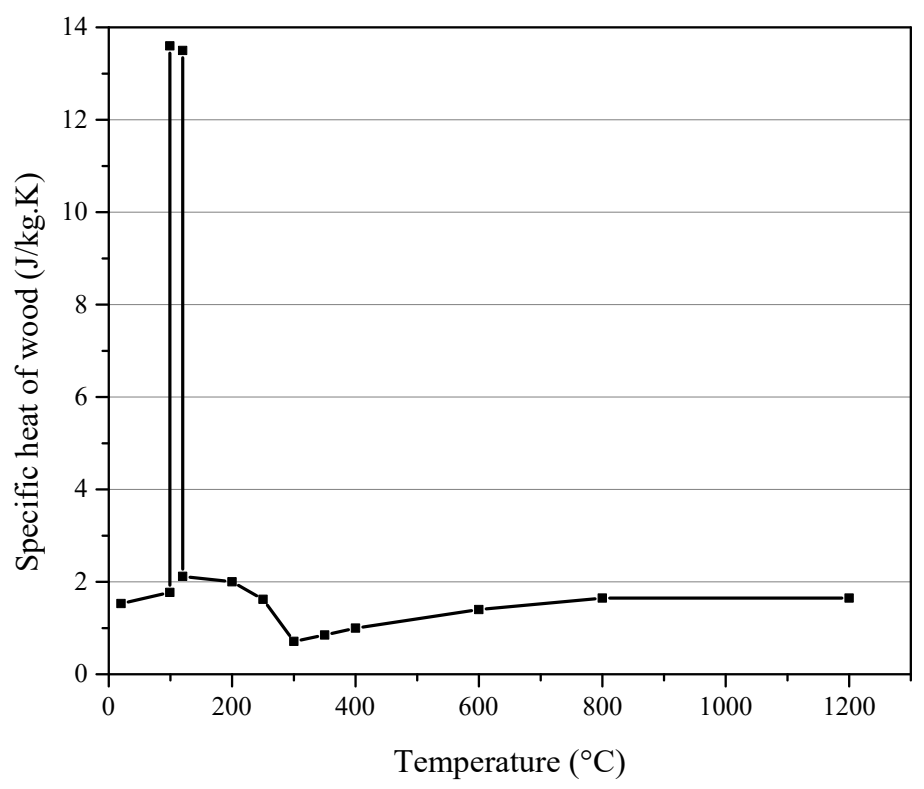

Figure 5-16 Specific heat of wood with temperature (reproduced from [57])

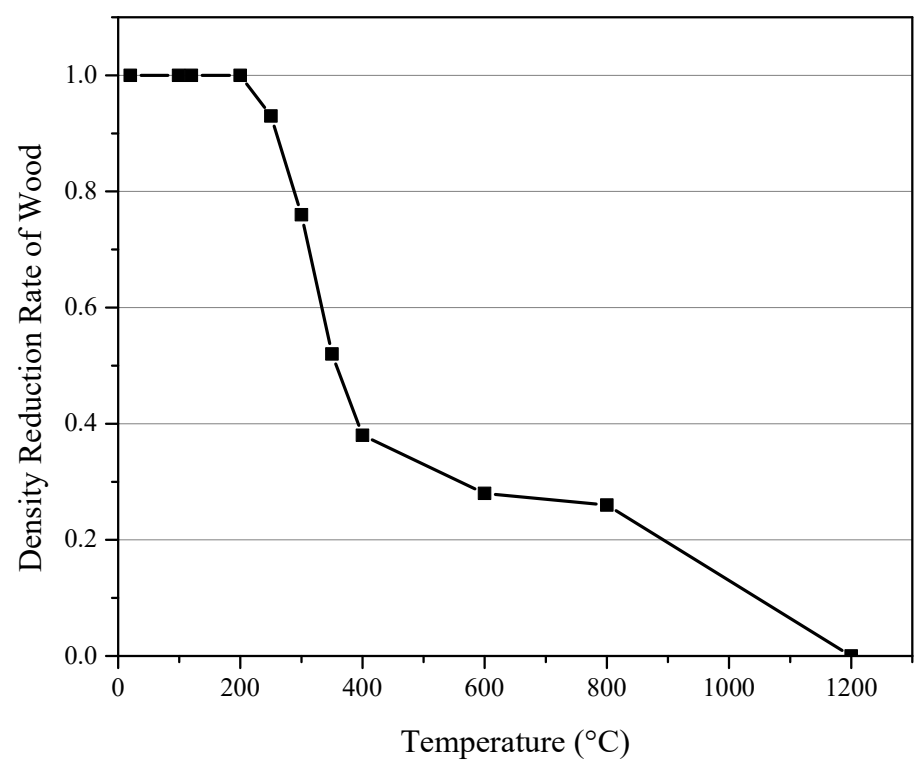

Figure 5-17 Density reduction factor of wood with temperature (reproduced from [57])

\subsubsection{Charring of wood components}

Timber components inside the building assembly might get involved in the room fire if 
conditions apply. Examples of timber components include wood studs in Light TimberFrame construction, CLT panels and wooden doors. Charring of timber component begins when the wood node closest to the fire side reaches $300^{\circ} \mathrm{C}$. And the charring rates are calculated based on the progress of $300^{\circ} \mathrm{C}$ char-line with time. This assumption is valid for most softwoods and hardwoods [57].

One drawback of the current numerical heat transfer solution is that it cannot support selfsustained charring of wood. The advance of char front would stop at a certain time after the room temperature enters the decay phase, because the temperatures of wood nodes do not increase. However, in reality the charring will continue with the drop of fire intensity or even after the room fire dies out. To solve this problem, the design charring rate stated in Eurocode 5 [57] is assigned from the time point when charring could not continue in the numerical calculation. The design charring rates are shown in Table 2-3. In this case when wood members are exposed to the fire only on one side such as for a heavy timber panel, the one dimensional charring rate of $0.65 \mathrm{~mm} / \mathrm{min}$ is applied, whereas more than one side is exposed to the fire, a notional charring rate of $0.8 \mathrm{~mm} / \mathrm{min}$ is applied.

\subsubsection{Behaviour of steel studs in the light frame assemblies}

Light-gauge steel studs usually have very high thermal conductivities (46-65 W/m.K) relative to other materials in the building assembly, so heat can be quickly transferred into the steel studs. In this perspective, the accurate determination of thermo-physical properties of steel, such as specific heat and thermal conductivity, are of little importance for the thermal modelling of LSF walls exposed to the fire, because of the extremely small volume and high heat transfer rate of steel. Although steel studs may function as a thermal bridge their buckling behaviour would make them lose contact to the back layer of linings. In 
other words, steel framing plays a minor role in the heat transfer through the assembly [128].

When exposed to more severe fire exposures than the standard fire test, many fire tests of small and large scale $[30,45,46]$ showed that non-load bearing light steel-frame (LSF) gypsum board wall assemblies fail the integrity criteria, showing early and excessive deflections of steel studs which results in gypsum board damage. In addition, the structural failure is also the dominant mode of failure in the load-bearing LSF assemblies [114].

The critical temperature of steel is often used as a bench mark for determining the failure of steel members in fire. North American standards (ASTM E119) assume a critical or failure temperature of $538^{\circ} \mathrm{C}$ for structural steel members [129]. The critical temperature of light-gauge steel is much lower than other types of steel. Gerlich [114] argued that the failure of load-bearing LSF systems is expected before the changing temperature $650^{\circ} \mathrm{C}$ of the crystalline structure of carbon steels typically used in construction. In his study he suggested that in predicting the performance of load-bearing LSF walls the steel temperature should be limited to $400^{\circ} \mathrm{C}$ on the fire side, noting that it is conservative for most applications. Eurocode 3 [130] limits the critical temperature to an even lower value $350^{\circ} \mathrm{C}$. In the current model, it is assumed that the steel studs at temperature $400^{\circ} \mathrm{C}$ undergo deformations that will result in the failure of the fire-exposed gypsum boards. Technically, this will happen when the temperature of the node at the gypsum board and cavity interface reaches $400^{\circ} \mathrm{C}$.

\subsubsection{Behaviour of wood studs in the light frame assemblies}

In load-bearing timber walls it is essential to retain sufficient cross-sectional area of residual stud to carry the load. In contrast, in non-load-bearing walls, the studs only need 
to hold the lining material in place for the duration of the fire, so they may be completely burnt away by the end of the test [126].

Unlike steel studs, which may go through deflection during the fire, the wood studs usually show less deformations in fire. However, the charring of wood studs reduces the size of their cross-sections and generates heat. The heat generation due to charring of wood studs is negligible because of the relatively small total charring area compared to the room enclosure area. One thing that should be taken care of, nevertheless, is the loss of holding power of wood studs to the fire-exposed gypsum boards. The holding power can be interpreted based on the charring depth of wood studs.

After some research of engineering practices, it is found that

- When working with $12.7 \mathrm{~mm}(1 / 2 ")$ drywall, $31.75 \mathrm{~mm}(1-1 / 4 ")$ or $34.9 \mathrm{~mm}(1-$ 3/8") nails are often used

- When working with $15.9 \mathrm{~mm}(5 / 8 ")$ drywall, $34.9 \mathrm{~mm}(1-3 / 8 ")$ or $41.3 \mathrm{~mm}(1-5 / 8 ")$ nails are often used

After a simple calculation, it is found that the drywall screws/nails are about $19 \mathrm{~mm}$ deep into the wood studs. Therefore, it is assumed that the drywall screw will not be able to hold the gypsum board in place when the charring depth reach more than $19 \mathrm{~mm}(3 / 4 ")$ (a smaller value can be used for conservative results) and the fire exposed gypsum boards fall-off. After that the cavity gets exposed to the fire in the room.

\subsection{The probabilistic barrier failure model}

The barrier failure of a building assembly is a consequence caused by a variety of factors. Heat attack and transfer into the assembly is the direct reason for failure, while the changes of physical properties and the resulting mechanical behavior of assembly components play 
more important roles in the failure process. Traditional heat transfer models mostly deal with the heat (some may consider mass) transfer in a specific building assembly or component. For load-bearing assemblies, failure can be determined by examining the load and resistance capacities. However, for non-load-bearing assemblies, it is more difficult to judge the failure. Apparently the barrier failure process involves more than heat transfer into the assembly, and physical and mechanical material behaviours may vastly change the pattern of heat transfer and affect the failure time. To better handle the uncertainties inherent in the barrier failure process, mechanical behaviors of building components should be treated as stochastic and interpreted probabilistically. Taking the fall-off time of gypsum board as an example, the simplest way is to specify a temperature criterion, but more appropriately, a probabilistic distribution of failure temperature should be given to account for its stochastic nature.

Given the thermo-physical properties of assembly components (such as gypsum board and insulation), the failure time of the whole building assembly is the combined effect of heat attack and, for most part, mechanical behavior of the components. Factors that affect the failure time of the building assembly are listed as follows,

- Light Timber Frame Assembly

- The failure temperature criterion of fire-exposed gypsum board

- The failure temperature on the unexposed gypsum surface

○ Charring depth of wood stud

$\circ$ Melting temperature of glass fiber

- Light Steel Frame Assembly

- Deflection temperature criterion of steel stud 
- The failure temperature on the unexposed gypsum surface

○ The failure temperature criterion of fire-exposed gypsum board

- Melting temperature of glass fiber

- CLT assembly

- Failure is not considered due to its high fire rating as a structural member and unlikeliness/insignificance as a fire spread path

- Charring of CLT is considered as additional fuel to the room fire

- Wooden door

○ Charring depth

- Unexposed surface temperature

\subsubsection{Probabilistic distribution of influential factors}

1) Failure temperature criterion of fire-exposed gypsum board, $T_{\text {fail,gyp, fire }}$

The mean value and standard deviation of failure temperature obtained from experimental findings are descripted in Section 5.3.6.2. Due to lack of data and to stay on the conservative side, lower temperature values (resulting from wider stud spacing or thinner gypsum board) are adopted and are intended to be applied to all the stud spacing and gypsum board thicknesses on the fire-exposed side.

It is assumed that the failure temperature of gypsum board follows a normal distribution $N(\mu, \sigma)$. The so called $3-\sigma$ rule specifies that $99.7 \%$ of a normal distribution are within three standard deviations $(\sigma)$. Therefore, the sampling space for each temperature distribution is within $3-\sigma$ on each side of the mean value. The temperature distribution of the fire-exposed gypsum boards are listed in Table 5-2. 
Table 5-2 Distribution of $T_{\text {fail,gyp, fire }}$

\begin{tabular}{|c|c|c|c|}
\hline \multirow{2}{*}{ Cavity filling } & \multirow{2}{*}{ Single layer } & \multicolumn{2}{|c|}{ Double layer } \\
\cline { 3 - 4 } & & face layer & base layer \\
\hline Void cavity & $\begin{array}{c}\mathrm{N}(460,20), \\
\text { Range: } 460 \pm 60\end{array}$ & $\mathrm{~N}(510,50)$ & $\mathrm{N}(330,40)$ \\
& Range: $510 \pm 150$ & Range: $330 \pm 120$ \\
\hline Insulation in cavity & $\begin{array}{c}\mathrm{N}(680,50) \\
\text { Range: } 680 \pm 150\end{array}$ & $\begin{array}{c}\mathrm{N}(640,40) \\
\text { Range: } 640 \pm 120\end{array}$ & $\begin{array}{c}\mathrm{N}(480,40) \\
\text { Range: } 480 \pm 120\end{array}$ \\
\hline
\end{tabular}

2) The failure temperature criterion of the unexposed component, $T_{\text {fail,assemly }}$

The judgement of the failure criterion of unexposed components is the final descriptor of barrier failure, as the failure of the last component of the assembly denotes the failure of the whole assembly. For simplicity and in light of the standard fire tests, the failure criterion of the building assembly is assumed the same as that in the standard ISO fire tests. As specified in the insulation criterion in the standard test, the failure of the whole assembly is defined as the moment when the average temperature rise exceeds $140^{\circ} \mathrm{C}$ or maximum temperature rise exceeds $180^{\circ} \mathrm{C}$ beyond the ambient temperature $\left(20^{\circ} \mathrm{C}\right.$ as default) on the unexposed surface. Based on the above, it is assumed that the probabilistic distribution of the failure temperature follows a normal distribution $N(\mu$, $\sigma)$, defined as $N(160,20)$, with a sampling range $[140,180]$. It is acknowledged that the failure criterion in the standard test might be symbolic and conservative for use in non-standard fires, but this is acceptable from an engineering perspective.

3) Deflection temperature criterion of steel stud in LSF assembly, $T_{\text {fail,steelstud }}$

In the numerical model the deflection temperature of steel studs is set as $400^{\circ} \mathrm{C}$. It is assumed that the deflection temperature of steel studs follows a normal distribution $N(400,50)$ with a sampling range $[350,650]$. The upper and lower boundaries of the above range is based on the discussion in Section 5.3.6.7. 
4) The holding power of wood studs in the LTF assembly

The holding power of wood studs to the fire-exposed gypsum boards is discussed in Section 5.3.6.8. It is found that the charring depth of wood studs is so small at the time of assembly failure (i.e., $160^{\circ} \mathrm{C}$ ) that it is unlikely to affect the stability of the fireexposed gypsum boards and the whole assembly. For example, at the time of assembly failure, the charring depth is only about $10 \mathrm{~mm}$ on the studs, leaving an uncharred depth of $79 \mathrm{~mm}$. Therefore, the effect of wood studs is not considered in the probabilistic model.

5) Melting temperature of glass fiber insulation LTF and LSF construction

As was discussed in Section 5.3.6.4, it is assumed that glass fiber insulation shrinks into negligible volume when the mid-cavity temperature reaches $500^{\circ} \mathrm{C}$.

For LTF and LSF assembly, the controlling factors and their distribution are summarized as below,

- Light Timber Frame Assembly

○ $\quad T_{\text {fail,gyp,fire }}$, see Table 5-2

○ $T_{\text {fail,assemly }}, N(160,20)$, with a sampling range $[140,180]$

- Light Steel Frame Assembly

○ $\quad T_{\text {fail,gyp, fire }}$, see Table 5-2

○ $T_{\text {fail,assemly }}, N(160,20)$, with a sampling range $[140,180]$

○ $T_{\text {fail,steelstud }}, N(400,50)$ with a sampling range $[350,650]$

\subsubsection{Sampling technique}

The most popular uncertainty analysis technique is sampling based methods (also called 
Monte Carlo method) [131,132]. Such methods involve the generation and exploration of a mapping from uncertain analysis inputs to uncertain analysis results. Among the sampling based methods, the simple random sampling approach is the simplest but it needs a large amount of samples to effectively cover the distribution range, and it becomes non-feasible to conduct uncertainty analysis when the system takes time to generate outputs. Most applications use Stratified Sampling [133] to improve the rate at which estimated quantities converge to the true quantities. The principle behind stratified sampling with a single variable is to partition the sample space into non-overlapping regions and to guarantee sampling from each region. The purpose for Stratified Sampling is to ensure that all parts of the sample space are represented, for improved (i.e. less uncertain) mean and variance estimates. The idea of fully covering the range of each parameter is further extended in the Latin Hypercube sampling (LHS) procedure [134], which is a frequently used method and many applications exist in the fire safety engineering area [135-138]. For Latin hypercube sampling, the range of all the input variables are exhaustively divided into same number of disjoint intervals of equal probability and one set of input values is selected at random from each interval. This requires that the investigated input variables should have clear and continual distributions, such as normal distribution. A detailed illustration of differences of the Random Sampling, Stratified Sampling and Latin hypercube sampling can be found in [139].

To improve efficiency, Latin Hypercube sampling (LHS) was adopted in this model. A computer program was written to facilitate the sampling process, which flows as in Figure $5-18$. 
LHS technique is adopted to generate samples for the variables ( $\left.T_{\text {fail,gyp,fire }}, T_{\text {fail,assemly }}, T_{\text {fail,steelstud }}\right) .1000$ groups of samples are generated.

Input those samples to the numerical model by keeping other inputs same, and perform Monte Carlo simulation.

1000 assembly failure times are obtained from the same number of Monte Carlo simulation. Analyze those results and find the probabilistic distribution of failure times.

Provide the cumulative failure probability as a function of time.

Figure 5-18 Flow chart illustrating the sampling process

\subsection{Validation of the Barrier Failure Model and An example calculation}

In order to verify the performance of the barrier failure model, a deterministic heat transfer and component response model is adopted to simulate the heat transfer and temperature profile in all the tested wall assemblies from Test 2 to Test 6 described in Chapter 4 . Test 1 and Test 2 were repeated tests so only Test 2 is used here. The simulated assemblies are listed in Table 5-3. 
Table 5-3 A list of simulated assemlies

\begin{tabular}{|l|l|l|}
\hline Wall Assembly & Test \# & Wall assembly description \\
\hline CLT 2GP & 2 & CLT wall panel protected with 2 layers of gypsum board \\
\hline EXPOSED CLT & 3 & unprotected CLT wall panel \\
\hline LTF GLS 2GP & 4 & $\begin{array}{l}\text { Light timber-frame protected with 2 layers of gypsum board } \\
\text { on both side and insulated with glass fiber }\end{array}$ \\
\hline LTF GLS & 5 & $\begin{array}{l}\text { Light timber-frame protected with 1 layer of gypsum board } \\
\text { on both side and insulated with glass fiber }\end{array}$ \\
\hline LSF GLS & 6 & $\begin{array}{l}\text { Light steel-frame protected with 1 layer of gypsum board on } \\
\text { both side and insulated with glass fiber }\end{array}$ \\
\hline
\end{tabular}

All the gypsum boards are $12.7 \mathrm{~mm}$ fire-rated gypsum board on both the fire-exposed side and the unexposed side. Both timber and steel studs are 2 by 4 inches with a spacing of 16 inches o.c. In the numerical model, the number of grids for each layer of gypsum board, cavity/studs and each ply of CLT panel (3-ply) were 40, 50 and 50, respectively. The measured room temperature curve for each corresponding test is adopted in the model as the input fire curve. Please refer to Figure 4-17 for the measured room fire temperature curves. The results of the model calculation are then compared with the fire test results descripted in Chapter 4, as shown in the following sections.

\subsubsection{Temperature profile comparison}

Temperature profile of the simulated assemblies at typical locations are presented from Figure 5-20 to Figure 5-19, comparing model predictions and test results. Figure 5-19 and Figure 5-20 demonstrate the temperature profile behind the $2^{\text {nd }}$ layer of the fire-exposed gypsum board in Test 2 and Test 4. In both of the two cases, the predicted temperature levels agree very well with the measured temperature data. The weakness, however, is the prediction of the temperature plateau due to the dehydration of gypsum board at about $90^{\circ} \mathrm{C}$. This is probably due to the fact that the numerical model does not consider moisture transfer inside the gypsum boards. This is not a major issue as the temperatures at this stage 
are too low to affect the assembly failure.

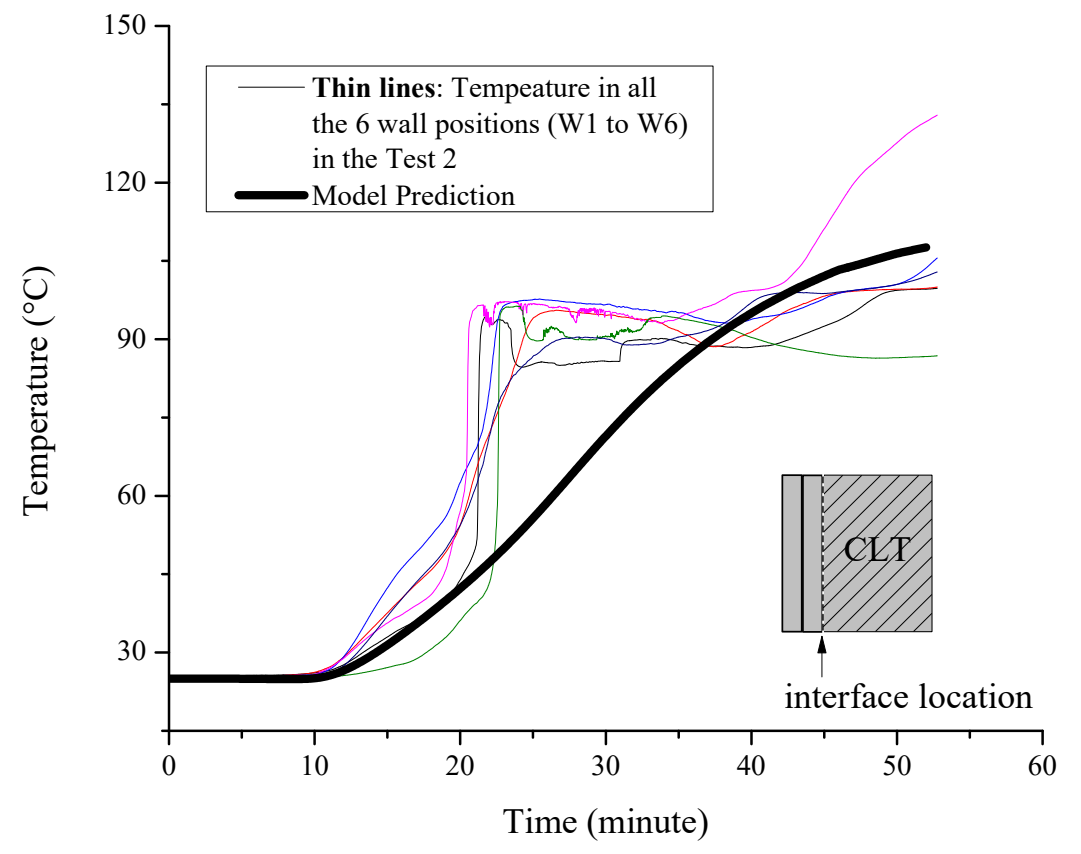

Figure 5-19 Temperature behind the 2nd layer of fire-exposed gypsum board in Test 2, a comparison of the test results and model prediction

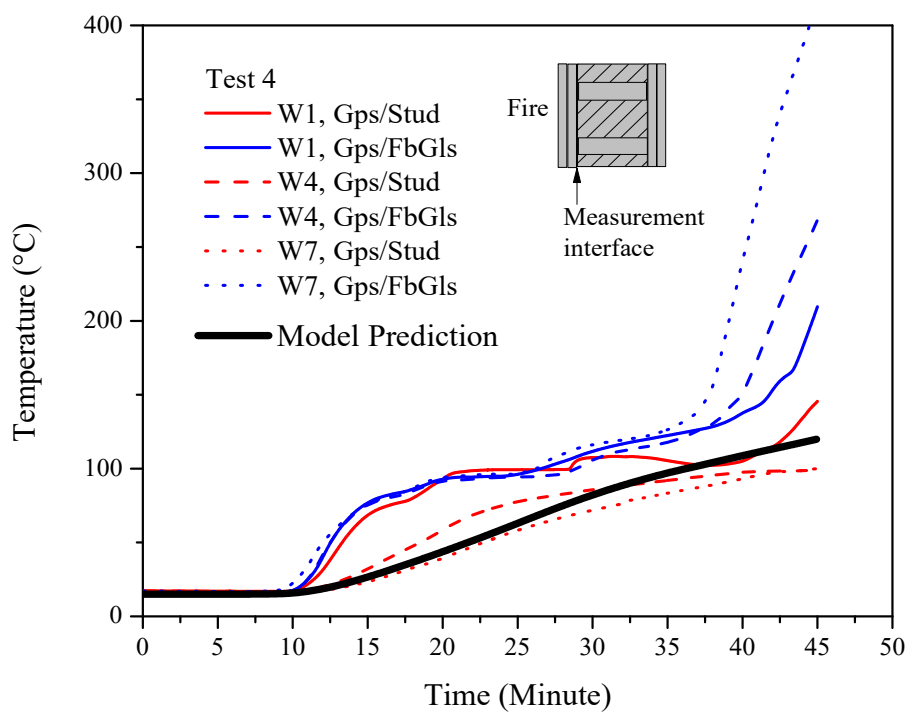

Figure 5-20 Temperature behind the $2^{\text {nd }}$ layer of fire-exposed gypsum board in Test 4, a comparison of the test results and model prediction 
Figure 5-21 demonstrates a comparison of the temperature behind the fire-exposed gypsum board in Test 5 . The calculated temperature is the interface temperature between the fireexposed gypsum board and glass fiber insulation ( $\mathrm{Gps} / \mathrm{FbGls})$, which demonstrates a slower growth period than the measured data at the same interface, and a quicker growth period than the measurements in the gypsum board/stud interface (Gps/Stud). The temperature plateau in a period from around 9 minutes to around 15 minutes indicates the dehydration period of the fire-exposed gypsum board. Furthermore, both of the calculated and measured temperature curves reach the peak almost at the same time. After the first peak, the calculated temperature begins to decrease whereas the measured temperature levels off with some fluctuations. As discussed in Section 4.3.2.2, one of the reasons contributed to the higher temperature behind the gypsum board in the fire test is the heat penetration through the gypsum board joints, which, however, is not reflected in the current model. Overall, the calculated temperature behind the fire-exposed gypsum board is on the conservative side. Nevertheless, this should not be worried because the temperature prediction at the unexposed surface of LTF GLS / Test 5 wall assembly demonstrates a much better match to the test measurements, which will be presented later in Figure 5-23.

The temperature profile behind the fire-exposed gypsum board in Test 6 is demonstrated in Figure 5-22. The model predicted a gypsum board fall-off time of 22 minutes (as shown by the thick black line segment) and after that time the calculated temperature is not shown in order to indicate the disappear of gypsum board component. The model prediction is in good agreement with the measurements in two aspects. One is that the calculated temperature curve fits nicely with the measurements. The other is that the predicted 
gypsum board fall-off time matches the findings in Test 6 , in which major collapse of gypsum boards was reported at around 25 minutes (see Table 4-9). The fall-off of gypsum boards in Test 6 can also be deduced from the temperature profiles behind the gypsum board (see Figure 5-22). The measured temperature behind the gypsum board reaches peak values at around 25 minutes, and converges to the room temperature, which indicates the failure of the fire-exposed gypsum boards.

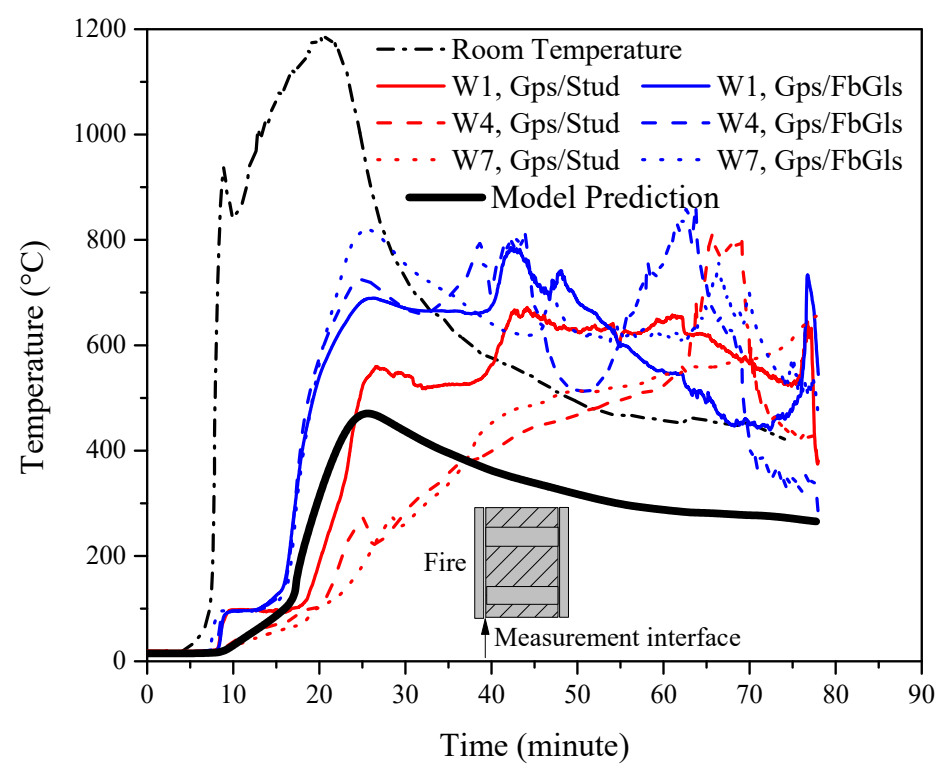

Figure 5-21 Temperature behind the $1^{\text {st }}$ layer of fire-exposed gypsum board in Test 5, a comparison of the test results and model prediction

Figure 5-23 and Figure 5-24 demonstrate the calculated temperature profiles at the unexposed surface at the LTF GLS and LSF GLS wall assemblies (simulating Test 5 and Test 6, respectively, see Table 5-3), which are compared with measurements at the same locations of the tested wall assemblies. A good match between the model predictions and test measurements is shown in both of the two wall assemblies. 


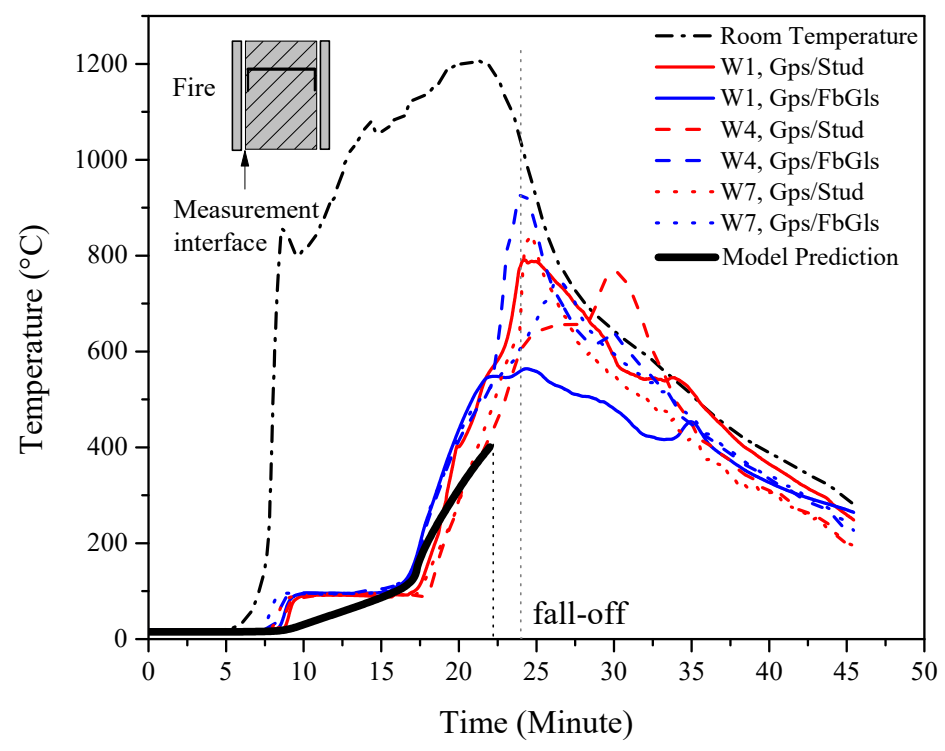

Figure 5-22 Temperature behind the $1^{\text {st }}$ layer of fire-exposed gypsum board in Test 6 , a comparison of the test results and model prediction

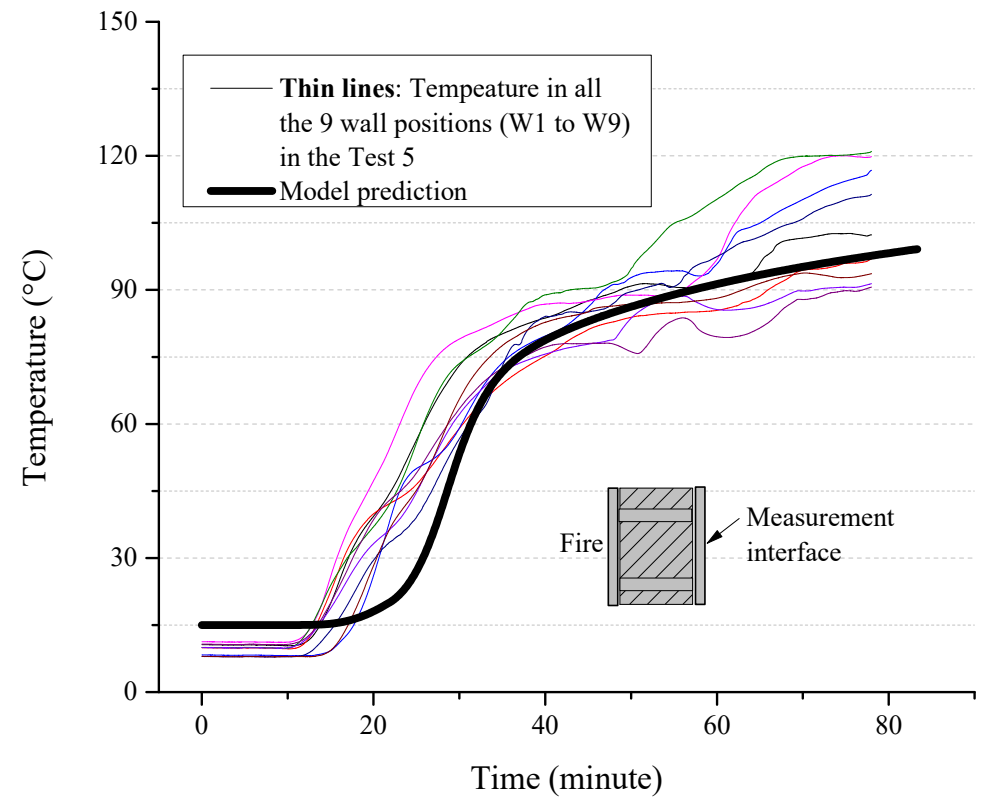

Figure 5-23 Temperature profile behind the $1^{\text {st }}$ unexposed gypsum board in Test 5 , a comparison of the test results and model prediction 


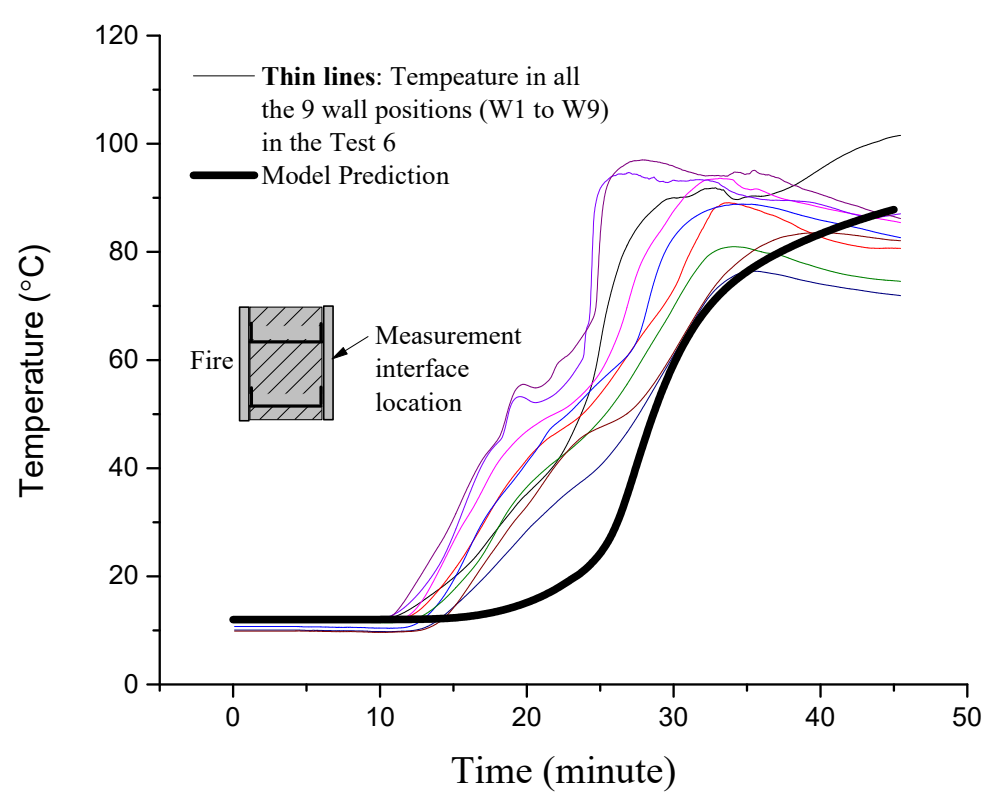

Figure 5-24 Temperature profile behind the $1^{\text {st }}$ unexposed gypsum board in Test 6 , a comparison of the test results and model prediction (input with room temperature in Test 6)

\subsubsection{Charring behaviour and contribution of timber components to the room fire}

One particular concern of mass timber construction is that the structural member itself is combustible and may become involved in the fire as part of the combustible fuel load. The results of Test 3 presented in Chapter 4 clearly demonstrated this phenomenon. A charring module has been added to the deterministic model to predict the charring rate of timber members, as presented in Section 5.3.6.6. To verify the model performance, the charring of CLT panels in the room fire Test 3 is simulated using deterministic heat transfer and component response model, and the calculated charring depth as a function of time is demonstrated in Figure 5-25. The charring begins at 8.1 minutes after the fire initiation and the accumulated charring depth reaches the delamination of the first ply of CLT panel at 41.4 minutes. The average charring rate through the first CLT ply is $1.05 \mathrm{~mm} / \mathrm{min}$, which is in a good agreement with the test measurements discussed in Section 4.3.2.3. Besides, 
the increased charring rate after the CLT ply delamination is also simulated as indicated in Figure 5-25. In summary, the comparison of charring behaviour between model prediction and test results demonstrates a good match.

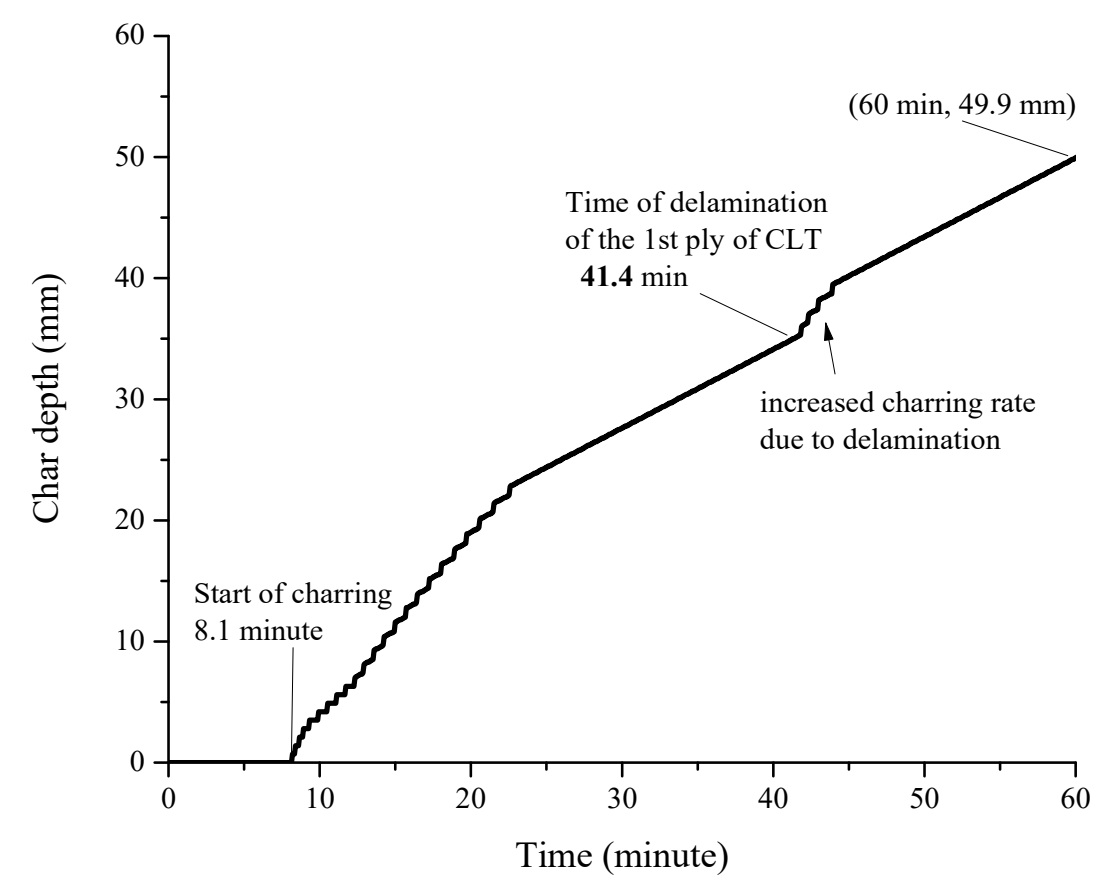

Figure 5-25 Modelling results of accumulative charring depth in Test 3

\subsubsection{Gypsum fall-off time}

Regarding the gypsum board fall-off in the LSF GLS assembly (Test 5), the model calculation results show that the fire-exposed gypsum board did not fail/fall-off during the simulation time. Although in in the later stage of Test 5 the fire-exposed gypsum board fell off in small pieces, the fall-off in big chunks occurred in the last 10 minutes mainly due to the burning of wood studs in the gypsum board joints. In this respect, the model prediction is acceptable compared with test findings.

For Test 6 , the model predicted a gypsum board fall-off time of 22 minutes as demonstrated 
in Figure 5-22. It should be noted that the failure of gypsum boards in this test was due to the buckling of steel studs which caused severe damages to the gypsum board panels. In the numerical modelling, the deflection criterion of steel studs was also reached earlier than the failure criterion of the fire-exposed gypsum board. Unlike a sudden failure of gypsum boards presumed in the modelling, the failure and fall-off of gypsum boards in the test is actually a relatively slow process occurred in a few minutes, and heats gradually pass through cracked gypsum board joints, and that is why the measured temperature behind the gypsum board reaches much higher values.

\subsubsection{Comments on the comparison between test data and model results}

Although satisfactory agreement was demonstrated between the test data and the model calculations, it should be acknowledged that conducting full-scale fire experiments is a complicated process and the test results are expected to have some variation from test to test. Some reasons for this include the quality of construction of the test facility, the accuracy of the sensor locations, especially the depth of the thermocouples embedded in the wood studs, the reliability and accuracy of the data measurement system and the stochastic nature of fire development.

The numerical model developed in this study involves many assumptions and simplifications, such as the assumption of one-dimensional heat transfer and the neglect of mass transfer. Therefore, considering the above the agreement level in this study is considered reasonable.

\subsection{An example calculation of the probability of barrier failure}

An example calculation using the Probabilistic Barrier Failure model is presented in the 
following section. The probabilities of barrier failure of six different building assemblies are calculated, which are timber or steel light-frame wall assemblies with void cavity or filled with glass fiber or rock fiber insulation. The simulated wall assemblies are listed as follows,

- LTF VOID: Light timber-frame without insulation

- LTF GLS: Light timber-frame insulated with glass fiber

- LTF ROCK: Light timber-frame insulated with rock fiber

- LSF VOID: Light steel-frame without insulation

- LSF GLS: Light steel-frame insulated with glass fiber

- LSF ROCK: Light steel-frame insulated with rock fiber

All the light-frame assemblies are constructed with one layer of $12.7 \mathrm{~mm}$ fire-rated gypsum board lined on both fire-exposed side and unexposed side. Both timber and steel studs are nominal 2 by 4 inches with spacing in $406 \mathrm{~mm}$ (16 inches) o.c.

Two fire exposures are applied, one is the standard ISO 834 fire curve, and the other one is the room temperature curve from the full-scale room fire Test 5 described in Chapter 4 , both of which are illustrated in Figure 5-26. The cumulative probability of barrier failure of the six light-frame wall assemblies under the two different fire exposures are shown in Figure 5-27 and Figure 5-28. 


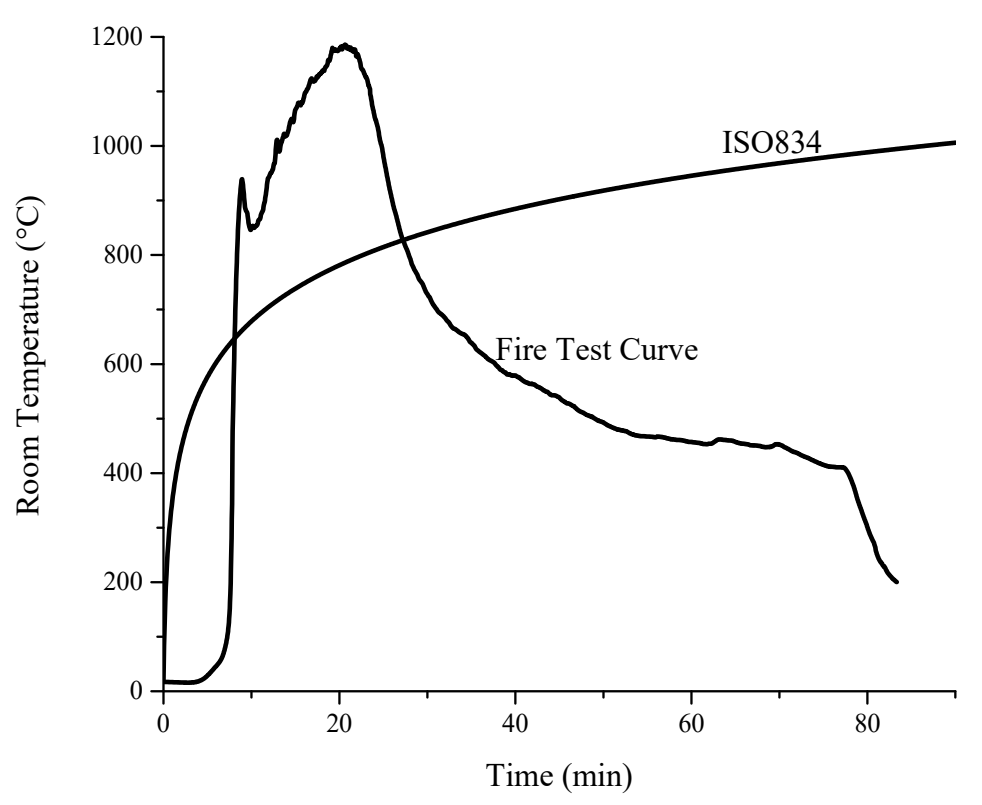

Figure 5-26 Two fire curves used in the calculation

In the standard fire exposure, the calculation results show that the six different assemblies demonstrated significantly different failure probabilities and time ranges. Figure 5-27 shows the cumulative probability of failure of the six assemblies as a function of time in a 2-hour Standard ISO 834 fire exposure. The light timber frame and light steel frame assembly without insulation (LTF VOID and LSF VOID) have the earliest failure time, at around 30 minutes after fire initiation, but the light steel frame assembly fails a bit earlier. The next assembly to fail is the light steel frame assembly with glass fiber insulation (LSF GLS), for which the probability of failure distributed in the time range beginning at about 42 minutes and ending at about 53 minutes. After that the light timber frame assembly with glass fiber insulation (LTF GLS) fails during the time range of 55 minutes to 78 minutes. The light frame assemblies with rock fiber insulation (LTF ROCK and LSF ROCK) are the last to fail. The failure of the light steel frame assembly with rock fiber insulation (LSF ROCK) happens in the time range of 75 minutes to 94 minutes. Among the six assemblies the light timber frame assembly with rock fiber insulation demonstrates the longest fire 
resistance, with a failure time ranging from 93 minutes to 114 minutes.

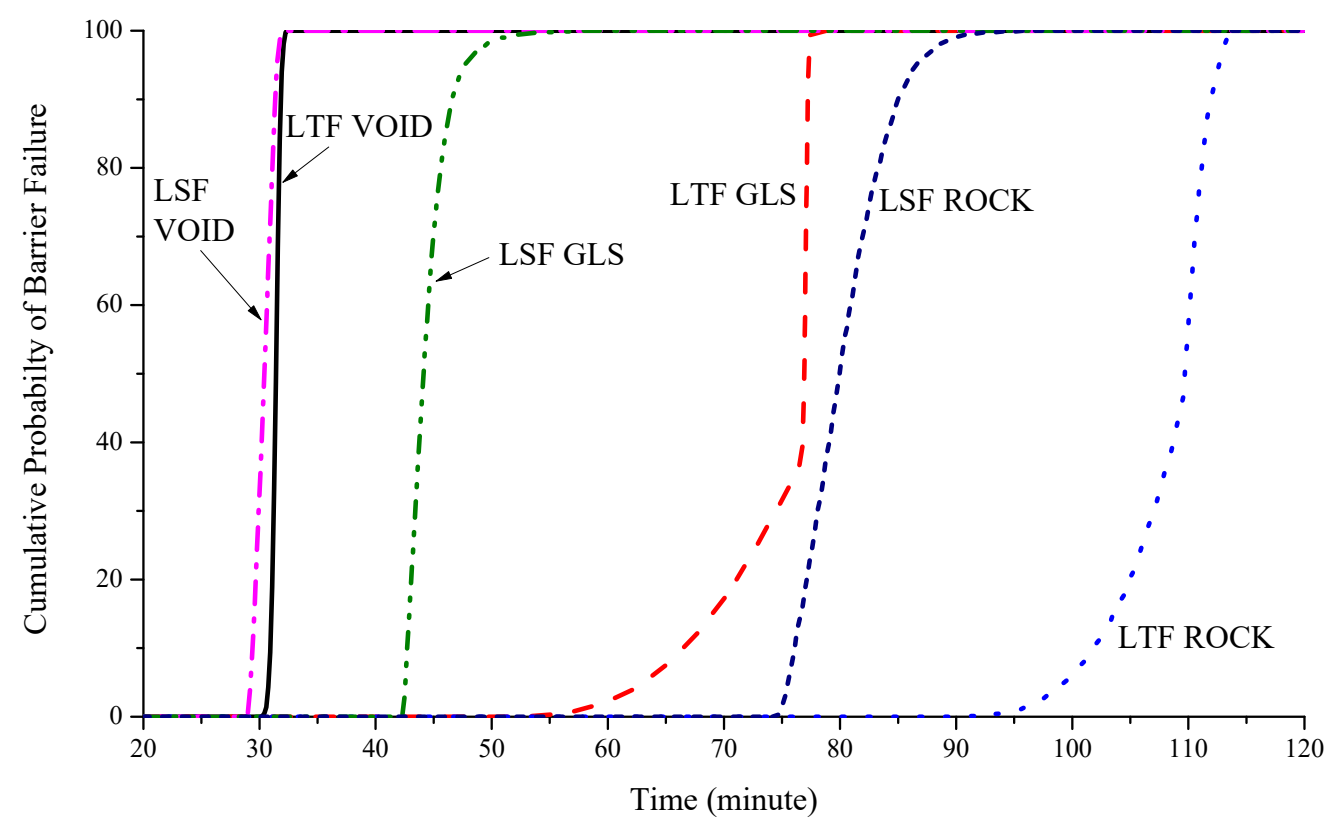

Figure 5-27 Cumulative probability of barrier failure for six light-frame walls in the ISO 834 fire

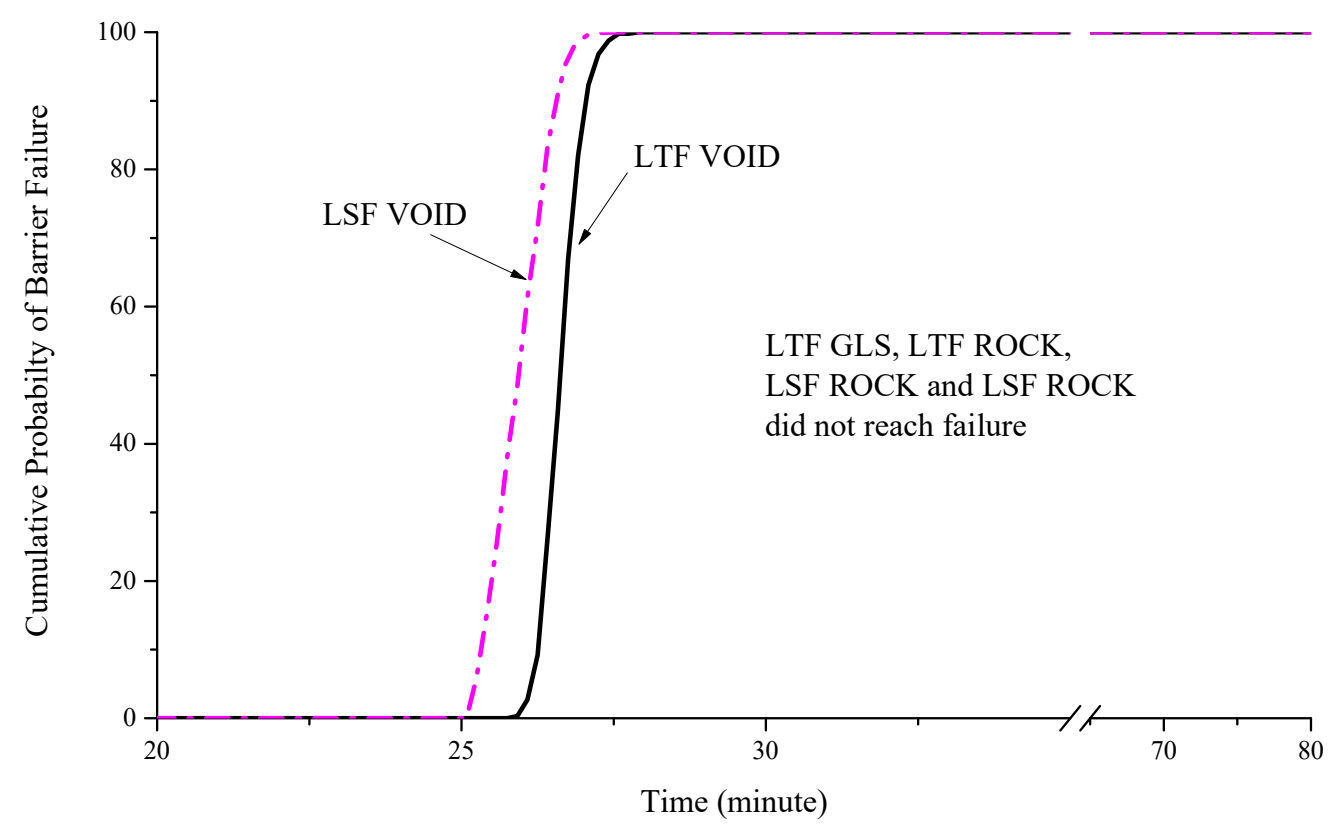

Figure 5-28 Probability of barrier failure for six light-frame walls under the fire curve of the room fire test curve 
When the six wall assemblies are subjected to the real fire exposure adopted from Test 5, the calculation results show that only two assemblies fail in the fire, i.e., the light frame assemblies without insulation (LTF VOID and LSF VOID, see Figure 5-28). The failure of both of the two assemblies occurs before 30 minutes but LSF VOID fails slightly earlier.

\subsection{Summary}

A Barrier Failure model was developed based on the concept of component subtractive method. A one-dimensional finite difference heat transfer model was created to calculate the temperature evolvement inside the barrier. Material property changes with temperature and failure of each component are considered based on the component response criteria. The heat transfer model, which is named as the deterministic heat transfer and component response model, can be used separately to simulate the temperature profile, component response as well as the charring behaviour of timber components.

Based on the deterministic heat transfer and component response model, a probabilistic barrier failure model was developed by taking into account the uncertainties of some factors that affect the assembly failure, for example, fall-off temperature criterion of the fire-exposed gypsum board(s), failure criteria of the unexposed component, deflection temperature of steel studs, and so on. The probabilistic distribution of those factors are determined and the Monte Carlo method is adopted to account for the uncertainties inherited with those factors. With this, the probability of failure as a function of fire exposure time can be generated.

The model performance is verified by comparing with the fire test results obtained in Chapter 4 . The wall assemblies tested are simulated using the deterministic heat transfer and component response model, with the same fire exposure measured in the tests. 
Temperature profiles at selected assembly locations are compared, and the model predictions agree very well with the test measurements. Besides, comparable results between the test observation and model prediction are also presented regarding the fall-off behaviour of the fire-exposed gypsum board in the light frame assembly as well as the charring behaviour in the CLT assembly. Finally, an example calculation is made using the probabilistic model. 


\section{Chapter 6 Modelling of Barrier Failure in CUrisk and a Case Study}

This chapter discusses how the Barrier Failure model presented in Chapter 5 is integrated into CUrisk as a submodel, and presents a case study performed using the improved CUrisk, with the purpose of showing the role and performance of the Barrier Failure submodel in fire risk analysis.

\subsection{Integration of the Barrier Failure Model into CUrisk}

As shown in the CUrisk model structure Figure 1-1, the Barrier Failure submodel and the Fire Spread submodel are essential elements of CUrisk, and they provide important information on the building hazardous conditions together with the Fire Growth submodel and the Smoke Movement submodel. Technically speaking, failure of building barriers is the main cause of fire spread. An introduction of the Fire Spread submodel was presented in Chapter 3 and the Barrier Failure model is described in Chapter 5.

In the Fire Spread submodel, fire spread from the room of fire origin to an adjacent room includes two processes: failure of barrier separating the two compartments and fire growth to fully developed fire in the adjacent compartment. In the barrier failure process, heat overcomes the fire resistance of the barrier between the two compartments, and transfers to the adjacent compartment, and then ignites combustible materials. And the fire in the adjacent compartment grows to a fully-developed fire. These two processes complete the fire spread process from one room to the other. Equ.(3.1) and Equ.(3.2) in Chapter 3 show the role of the two different processes in the calculation of probability of fire spread. The Fire Spread submodel has a barrier failure module as is presented in Section 0. Timeequivalence method was adopted to determine the barrier failure time under the fire exposure of a given fire severity, as shown in Equ.(3.6) in Chapter 3. 
The newly developed Barrier Failure model was incorporated in CUrisk so that it can automatically provide input to the Fire Spread submodel. To accomplish this, the barrier failure module in the Fire Spread submodel is substituted with the newly developed Barrier Failure model. However, this substitution is only limited to the data transmission, which means that the Fire Spread submodel just takes the outputs of the Barrier Failure model whereas the Barrier Failure model itself runs independently. Thus, in CUrisk the execution of the Barrier Failure submodel goes before the Fire Spread submodel.

To determine the barrier failure process of a compartment using the Barrier Failure model, the barriers of each building compartment should be specified. The barriers between two adjacent compartments and their properties are specified in the input file of the Fire Spread submodel by the users. At present the compartment barriers are limited to the walls on four sides. The failure of doors and windows (when fire spreads to the floor above) is calculated by the old barrier failure module in the Fire Spread submodel.

The Barrier Failure model runs independently and generates time-dependent failure probabilities of room barriers in the room of fire origin, and then at the time when the Fire Spread submodel runs, these outputs of the Barrier Failure model overwrite the probability of barrier failure $P\left(a^{\prime} \mid b\right)$ in Equ.(3.2) produced by the old barrier failure module of the Fire Spread submodel.

\subsection{A case study using CUrisk with the Barrier Failure submodel}

\subsubsection{Design of Case Study Building}

The upcoming National Building Code of Canada (NBCC) will allow the construction of combustible light-frame residential and office buildings up to 6 storeys. This is an increase from NBCC 2010 which had a limit of four storeys for combustible construction. A six- 
storey light-frame apartment building was created for the case study. The floor plan of the apartment building is shown in Figure 6-1. The dimensions of the compartments are shown in Figure 6-2. The total floor area is $805 \mathrm{~m}^{2}$, with a floor height of $3 \mathrm{~m}$. Each floor has ten 2-bedroom apartments ( $8 \mathrm{~m}$ by $8 \mathrm{~m}$ ) located on each floor with 5 of them on each side of a $40 \mathrm{~m}$ by $1.5 \mathrm{~m}$ corridor. At each end of the floor there is a common area, an elevator (concealed) and a stair room (fully open to the common area). The layouts of all the floors are identical except that two exits to the outside are located at the two ends of the first floor. The design of all the apartments are the same, each of which comprises of a living room, a kitchen and 2 bedrooms. However, the partitions within all the apartment are ignored, and each apartment is considered as one compartment in the CUrisk simulation. Each apartment has a door ( $2 \mathrm{~m}$ high by $0.9 \mathrm{~m}$ wide) opening to the corridor and a window measuring (1.5 $\mathrm{m}$ high by $4.5 \mathrm{~m}$ wide). A door measuring $2 \mathrm{~m}$ high by $0.9 \mathrm{~m}$ wide connects the corridors and the common areas. Two exits $(2 \mathrm{~m}$ by $2 \mathrm{~m}$ ) are located on each end of the first floor. All the doors of apartments (doors to the corridors), corridors and the building entrances are set to $10 \%$ open, and all the windows are assumed to break at $300{ }^{\circ} \mathrm{C}[88]$.

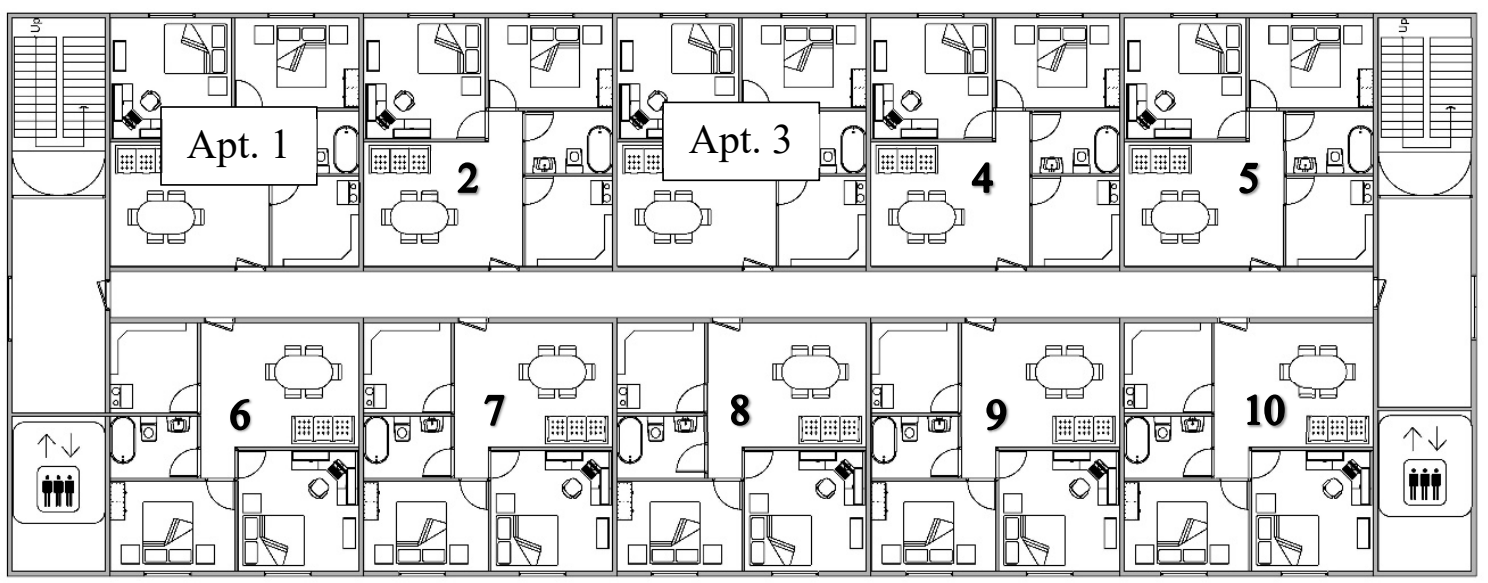

Figure 6-1 Floor plan of the first storey

It is assumed that 4 persons occupy each apartment ( 2 occupants are located in each 
bedroom) which is the design occupant load specified by the National Building Code of Canada (NBCC) 2010 [82]. The occupants are assumed to be 50\% male, 50\% female, 50\% adults and $50 \%$ children.

Active fire protection systems are installed in the building as per code requirements. Sprinklers are installed in all the apartments and corridors. Smoke alarms are installed in all the apartments, and smoke detectors are installed in all the corridors and stair rooms. The time of Fire Department action is divided into notification time, response time and setup time, which are set to be $30 \mathrm{~s}, 360 \mathrm{~s}$, and $120 \mathrm{~s}$, respectively.

Design fires in the apartments are specified based on statistical data and engineering judgement, whereas fire scenarios in other compartments such as corridors, common areas and staircases are ignored due to extremely low fire loads in those areas that could not support sustainable fires. According to Canadian statistics [140], for family dwellings the mean value of fire load density is $500 \mathrm{MJ} / \mathrm{m}^{2} .80$ th, and 90 th percentile values are 750 $\mathrm{MJ} / \mathrm{m}^{2}$, and $825 \mathrm{MJ} / \mathrm{m}^{2}$, respectively. The design fire load is usually chosen as a value between the 80th and 95th percentile [126]. In this study, a $90^{\text {th }}$ percentile of $825 \mathrm{MJ} / \mathrm{m}^{2}$ is chosen as the fire load density in each apartment. To be on the conservative side, a fast growth t-Square fire $\left(0.19 \mathrm{~kW} / \mathrm{s}^{2}\right.$ [87]) is specified for the fire growth period of the design fire, and the nominal maximum heat release rate of the design fire is set to 17.6 MW. The actual size of the fully developed fire and the time of the decay phase are calculated by the Smoke Movement submodel based on the ventilation conditions of apartment and the available fire loads.

For the Building Cost sub-model and Economic Loss sub-model, input data include the cost of building construction, the cost of active and passive fire protection systems, the cost 
of emergency systems, the cost of building contents and other general input data, such as inflation rate, interest rate, and downtime cost.

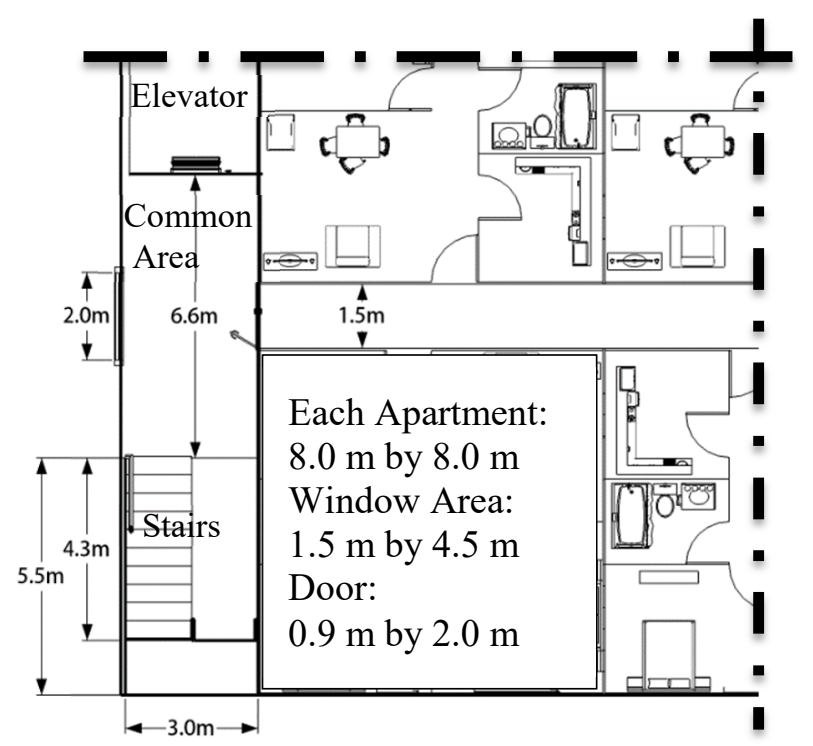

Figure 6-2 Dimensions of apartment and other spaces

The event tree method is adopted to create fire scenarios clusters. The fundamental events that affect the fire consequences include the initiating event and some intervening events. The initiating event is the start of fire. Two fire locations and their respective occurrence probabilities are created based on statistical data. The occurrence time of the fire (daytime or nighttime) is also an important factor that affects the fire consequences especially life risk, as occupants needs longer time to respond to the fire at night. The Occupant Response submodel is able to simulate the response behavior during daytime or night time. Statistical data [141] show that $20 \%$ of the fires occurred at night from $11 \mathrm{pm}$ to $7 \mathrm{am}$ when people are sleeping, and $80 \%$ occur in daytime. The intervening events include the reliability of activation of fire sprinklers, detectors and alarms, and the reliability of the Fire Department action. Sprinkler reliability is a combination of the operational probability and performance probability which is $87 \%$ based on the US statistical data [142]. Reliability of smoke 
detectors is $86 \%$ [143]. Fire department has a probability of $75 \%$ to arrive at the fire scene and begin firefighting in 8 minutes [144]. It should be noted that the reliability of detector and alarm systems is already considered in the Occupant Response submodel, thus is not included in the event tree. Using the event tree method, 16 fire scenarios are created as shown in Figure 6-3.

\begin{tabular}{|c|c|c|c|c|c|}
\hline $\begin{array}{l}\text { Occurring } \\
\text { Time }\end{array}$ & Fire Location & $\begin{array}{l}\text { Reliability of } \\
\text { Fire } \\
\text { Sprinklers }\end{array}$ & $\begin{array}{l}\text { Reliability of } \\
\text { Fire } \\
\text { Department }\end{array}$ & $\begin{array}{l}\text { Fire } \\
\text { Scenario } \\
\text { Number }\end{array}$ & $\begin{array}{l}\text { Fire } \\
\text { Scenario } \\
\text { Probability }\end{array}$ \\
\hline Day & Apartment 1 & $\mathrm{Y}$ & $\mathrm{Y}$ & & \\
\hline \multirow[t]{9}{*}{0.8} & 0.50 & 0.87 & \begin{tabular}{|ll} 
& 0.75 \\
$\mathrm{~N}$ &
\end{tabular} & 1 & 0.261 \\
\hline & & $\mathrm{N}$ & $\begin{array}{ll} & 0.25\end{array}$ & 2 & 0.087 \\
\hline & & 0.13 & \begin{tabular}{|ll} 
& 0.75 \\
$\mathrm{~N}$ & \\
\end{tabular} & 3 & 0.039 \\
\hline & & & 0.25 & 4 & 0.013 \\
\hline & Apartment 3 & $\mathrm{Y}$ & $\mathrm{Y}$ & & \\
\hline & 0.50 & 0.87 & $\begin{array}{ll} & 0.75 \\
\mathrm{~N} & \\
\end{array}$ & 5 & 0.261 \\
\hline & & $\mathrm{N}$ & $\begin{array}{c}0.25 \\
Y\end{array}$ & 6 & 0.087 \\
\hline & & 0.13 & $\begin{array}{ll} & 0.75 \\
\mathrm{~N} & \end{array}$ & 7 & 0.039 \\
\hline & & & 0.25 & 8 & 0.013 \\
\hline Night & Apartment 1 & $\mathrm{Y}$ & $\mathrm{Y}$ & & \\
\hline \multirow[t]{9}{*}{0.2} & 0.50 & 0.87 & $\begin{array}{ll} & 0.75 \\
\mathrm{~N} & \end{array}$ & 9 & 0.06525 \\
\hline & & $\mathrm{N}$ & $\begin{array}{ll} & 0.25 \\
Y & \end{array}$ & 10 & 0.02175 \\
\hline & & 0.13 & $\begin{array}{ll} & 0.75 \\
\mathrm{~N} & \\
\end{array}$ & 11 & 0.00975 \\
\hline & & & 0.25 & 12 & 0.00325 \\
\hline & Apartment 3 & $\mathrm{Y}$ & $\mathrm{Y}$ & & \\
\hline & 0.50 & 0.87 & $\begin{array}{ll} & 0.75 \\
\mathrm{~N} & \\
\end{array}$ & 13 & 0.06525 \\
\hline & & $\mathrm{N}$ & $\begin{array}{ll} & 0.25 \\
Y & \end{array}$ & 14 & 0.02175 \\
\hline & & 0.13 & $\begin{array}{ll} & 0.75 \\
\mathrm{~N} & \\
\end{array}$ & 15 & 0.00975 \\
\hline & & & 0.25 & 16 & 0.00325 \\
\hline
\end{tabular}

Figure 6-3 Event tree demonstrating the cluster of fire scenarios 
To calculate the final two decision making parameters Expected Risk to Life and Fire Cost Expectation, the annual fire frequency, design life of the building, fire scenarios and their probabilities are needed. The Ontario (a province in Canada) statistical data shows the residential fire ignition frequency to be $2.61 \times 10^{-3}$ per unit per year [28], therefore, the annual fire frequency of the 60 -apartment building can be estimated as 0.1566 per year. The design life of the building is set to be 50 years. The simulation time for all the scenarios is $3600 \mathrm{~s}$, with a time step of $2 \mathrm{~s}$ in the simulation.

\subsubsection{Design of fire barriers}

In this case study, fire barriers comprise walls, floors, doors and windows. The failure of floors, doors and windows are handled by the old barrier failure module in the Fire Spread submodel. Eighteen types of apartment wall barriers are designed and listed in Table 6-1. These walls are of light frame construction and their failure behaviour is calculated by the Barrier Failure submodel. All the wood studs or steel studs listed in Table 6-1 are nominal 2 inch by 4 inch ( $38.1 \mathrm{~mm}$ by $88.9 \mathrm{~mm}$ in engineering practice) with a spacing of $400 \mathrm{~mm}$ o.c. the cavity is either void or filled with glass fiber or rock fiber. Type X gypsum board of $1 / 2$ inch $(12.7 \mathrm{~mm})$ or $3 / 8$ inch $(15.9 \mathrm{~mm})$ are used.

To compare the impact of different wall barriers on the building fire risk, it is assumed that one type of wall barrier only exists in the building. In other words, all wall barriers in the same building are of the same type. This leads to 18 building designs constructed with 18 types of wall barriers, respectively. All other barriers (floors, doors and windows) are the same in all the 18 building designs. 
Table 6-1 List of apartment walls

\begin{tabular}{|l|l|l|l|l|}
\hline Wall \# & $\begin{array}{l}\text { Studs } \\
\text { type }\end{array}$ & Cavity filling & $\begin{array}{l}\text { Gypsum board } \\
\text { thickness }(\mathrm{mm})\end{array}$ & $\begin{array}{l}\text { Number of layers on both fire - } \\
\text { exposed side and unexposed side }\end{array}$ \\
\hline 1 & Wood & Void & 12.7 & 1 \\
\hline 2 & Wood & Glass Fiber & 12.7 & 1 \\
\hline 3 & Wood & Rock Fiber & 12.7 & 1 \\
\hline 4 & Wood & Void & 15.9 & 1 \\
\hline 5 & Wood & Glass Fiber & 15.9 & 1 \\
\hline 6 & Wood & Rock Fiber & 15.9 & 1 \\
\hline 7 & Wood & Void & 12.7 & 2 \\
\hline 8 & Wood & Glass Fiber & 12.7 & 2 \\
\hline 9 & Wood & Rock Fiber & 12.7 & 2 \\
\hline 10 & Steel & Void & 12.7 & 1 \\
\hline 11 & Steel & Glass Fiber & 12.7 & 1 \\
\hline 12 & Steel & Rock Fiber & 12.7 & 1 \\
\hline 13 & Steel & Void & 15.9 & 1 \\
\hline 14 & Steel & Glass Fiber & 15.9 & 1 \\
\hline 15 & Steel & Rock Fiber & 15.9 & 1 \\
\hline 16 & Steel & Void & 12.7 & 2 \\
\hline 17 & Steel & Glass Fiber & 12.7 & 2 \\
\hline 18 & Steel & Rock Fiber & 12.7 & 2 \\
\hline
\end{tabular}




\subsection{Results and discussion of the case study}

\subsubsection{Fire development}

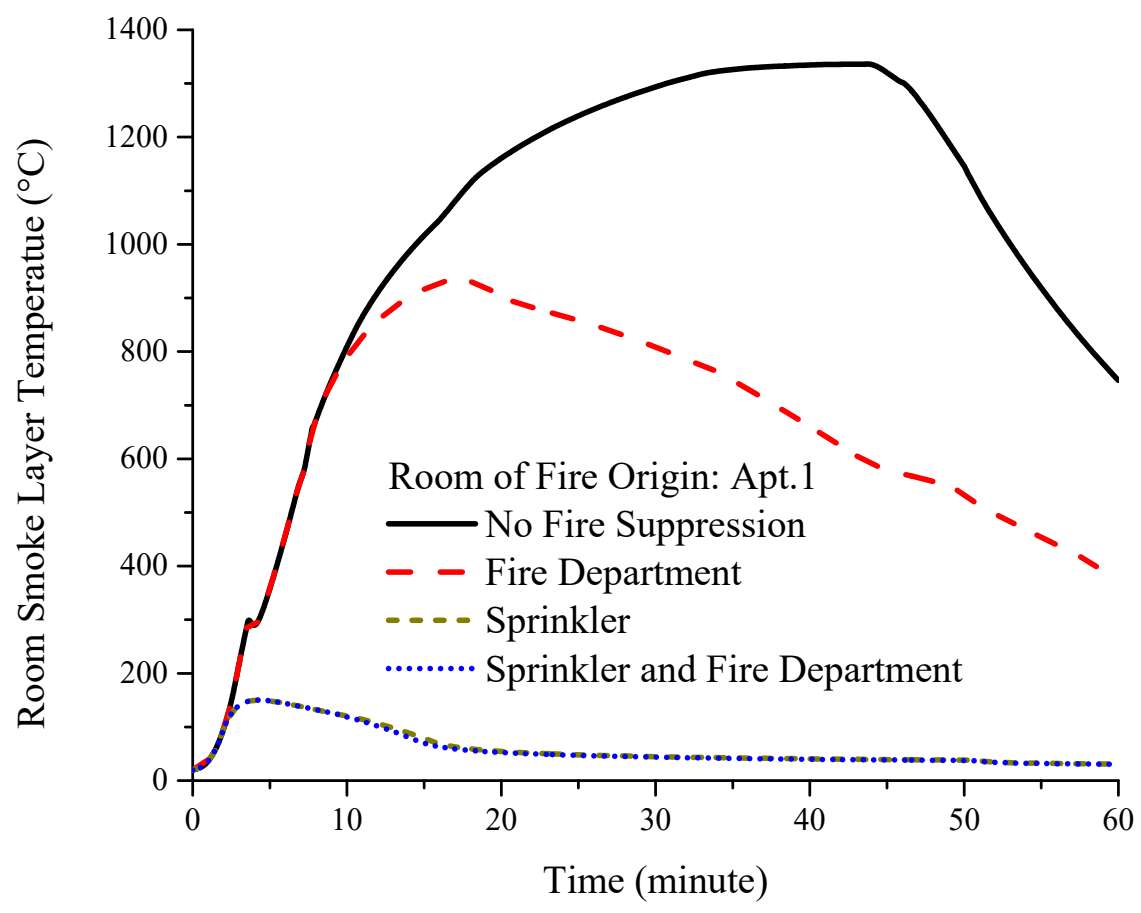

Figure 6-4 Smoke layer temperature in the apartment of fire origin Apt.1

Figure 6-4 shows the fire temperature development profile in Apartment 1 (see Figure 6-1) with or without fire suppression, computed by the Smoke Movement submodel for Scenario 1 to Scenario 4 (see Figure 6-3). The black solid curve is the fire temperature profile without any fire suppression in Scenario 4; the red dash curve shows the fire temperature with only Fire Department intervention in Scenario 3; the brown short dash curve demonstrates the impact of fire sprinkler activation and the blue dot curve shows the fire development under both the fire sprinkler and Fire Department intervention.

The fire under no suppression indicates the fire growth, fully development and decay periods, with a peak temperature of about $1300^{\circ} \mathrm{C}$. Fire department firefighting effects start at around 10 minutes and the fire begins to decay at around 17 minutes and drops to around 
$400^{\circ} \mathrm{C}$ at the end of the 60 minute simulation time. Under the intervention of the fire sprinkler (or together with the Fire Department operation), fire only reaches up to about $180^{\circ} \mathrm{C}$. The fire temperature profiles in Apartment 3 in Scenario 5 to 8 are basically the same as the results in Apartment 1. These fire temperature profiles are used in other CUrisk submodels to calculate the life risk and fire damages.

\subsubsection{Barrier failure}

The primary purpose of this case study is to show the effects of different fire barriers on the fire spread process. Even though the Barrier Failure submodel and the Fire Spread submodel are two standalone models, the outputs of the Barrier Failure submodel are directly used by the Fire Spread submodel to produce the probability of fire spread. The following graphs (Figure 6-5, Figure 6-6, and Figure 6-7) demonstrate the probability of barrier failure and fire spread for the 18 types of wall barriers.

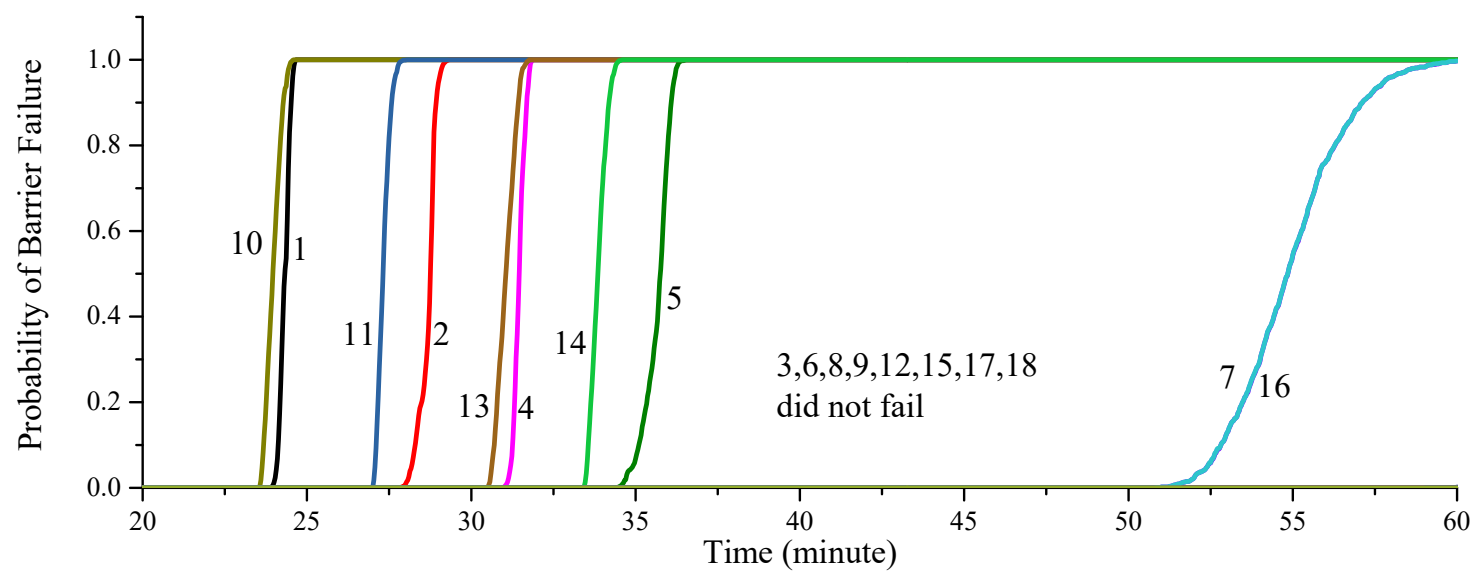

Figure 6-5 Probability of barrier failure of the 16 types of walls located in the apartment of fire origin under unsuppressed fires in Scenario 4 


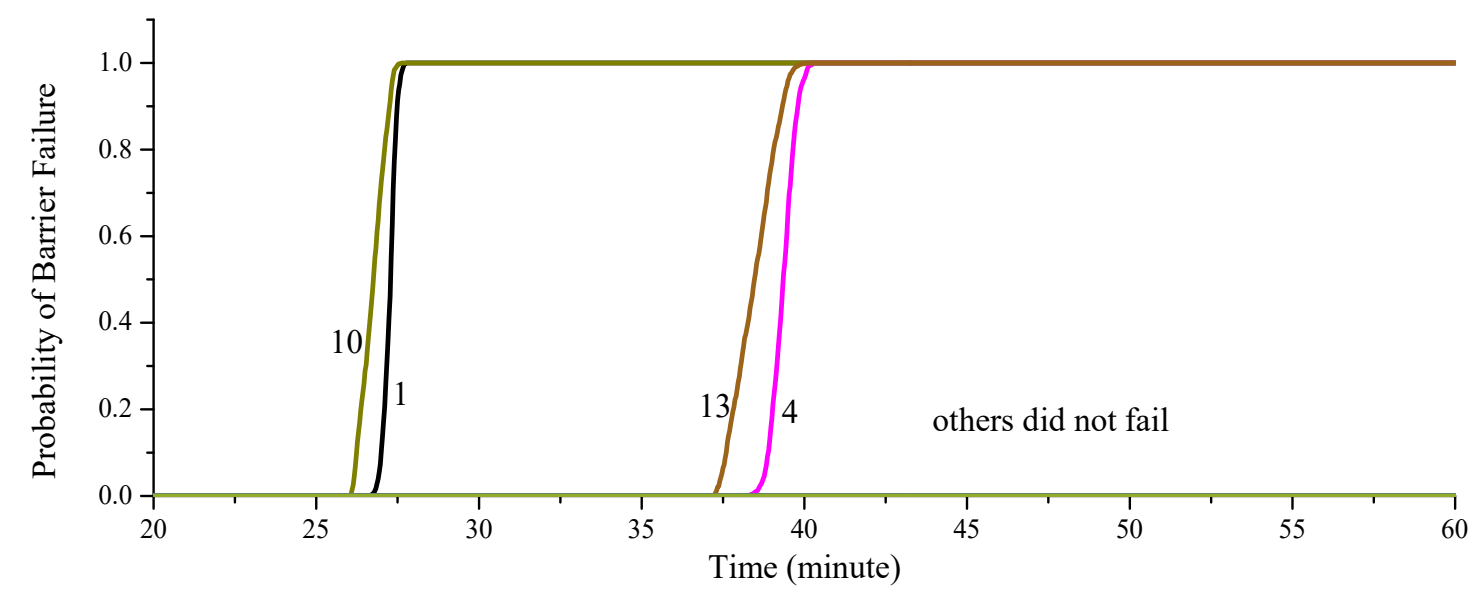

Figure 6-6 Probability of barrier failure of the 16 types of walls located in the apartment of fire origin under Fire Department intervened fires in Scenario 3

Figure 6-5 shows the probability of barrier failure of all the 18 wall barriers (see Table 6-1) under the fire in Scenario 4. These wall barriers work as boundaries of the apartment of fire origin which is Apartment 1, and thus are directly exposed to the fire with no fire suppression (see black solid curve in Figure 6-4). The 18 wall barriers demonstrate different barrier failure times ranging from 23 minutes to 60 minutes. Among them, barrier 10 (light steel frame, LSF, with one layer of $12.7 \mathrm{~mm}$ drywall on both sides and void cavity) and Barrier 1 (light timber frame, LTF with one layer of $12.7 \mathrm{~mm}$ drywall on both sides and void cavity) have the earliest failure times between 22 minutes and 25 minutes, and Barrier 10 leads to a bit earlier failure time than Barrier 1. This is followed by failure of Barrier 11 (LSF with one layer of $12.7 \mathrm{~mm}$ drywall on both side and glass fiber insulation), distributed around 24 to 25 minutes; and then Barrier 2 (LTF with one layer of $12.7 \mathrm{~mm}$ drywall on both side and glass fiber insulation), distributed between 27.5 minutes to 29.3 minutes. After that, Barrier 13 and Barrier 4 (LSF and LTF, respectively, both with one layer $15.9 \mathrm{~mm}$ drywall and void cavity) fail slightly after 30 minutes. Barrier 14 (LSF with one layer of $15.9 \mathrm{~mm}$ drywall and glass fiber insulation) fails at around 34 minutes, and 
Barrier 4 (same as barrier 14 but timber frame) fails between 34 minutes to 37 minutes. Further, Barrier 7 and Barrier 16 (LSF and LTF with two layers of $12.7 \mathrm{~mm}$ drywall on both sides and void cavity) have the same probability distribution of failure times which ranges from 51 minutes to 60 minutes. All other types of wall barriers show no sign of failure during the 60 minute simulation time, and unlikely to fail even if the simulation time is increased because the fire enters late decay phase.

Figure 6-6 displays the probability of barrier failure of all the 18 wall barriers under fire in Scenario 3, and they are directly exposed to the fire in Apt.1 under the intervention of Fire Department (see red dash curve in Figure 6-4). Compared with the early and effective fire suppression from fire sprinklers, which suppresses the fire in its early growth phase, firefighting from the Fire Department is not able to prevent the fire going into the fully developed period. Consequentially, fire is able to cause failure of four types of wall barriers, as shown in Figure 6-6. Two of them are Barrier 10 and Barrier 1, which fail at around 27 minutes. The other two are Barrier 13 and Barrier 4, which fail in tandem between 37 minutes and 40 minutes. All other types of wall barriers did not fail. 


\subsubsection{Fire spread}

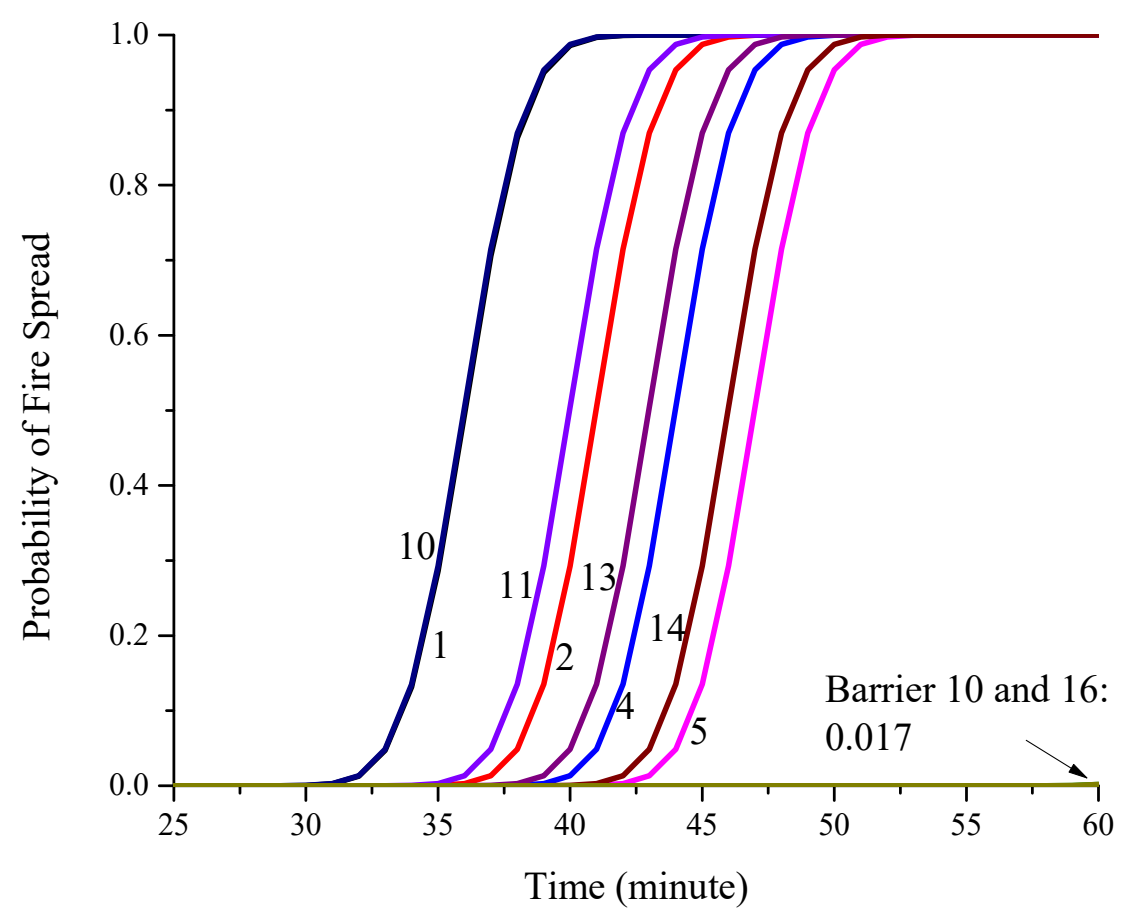

Figure 6-7 Probability of fire spread in Apartment 2 from Apartment 1, results are taken from Scenario 4 comparing 18 types of wall barriers

After the run of the Barrier Failure submodel, the Fire Spread submodel calculates the probability of fire spread in all compartments in the building. Figure 6-7 demonstrates the probability of fire spread to Apartment 2 resulting from the fire in Apartment 1 in Scenario 4. These results are a direct consequence of the barrier failure calculated by the Barrier Failure submodel as illustrated in Figure 6-5. The initiation times of the probability distribution of fire spread for the 18 wall barriers follow the same time sequence as the results of the barrier failure times, but occur at later times due to the fact that it takes time for the fire in Apartment 2 to ignite and grow to a fully developed fire. The fire may continue to grow and spread to other compartments in the building, and these fire spread outputs are further processed in other submodels to estimate the losses. 


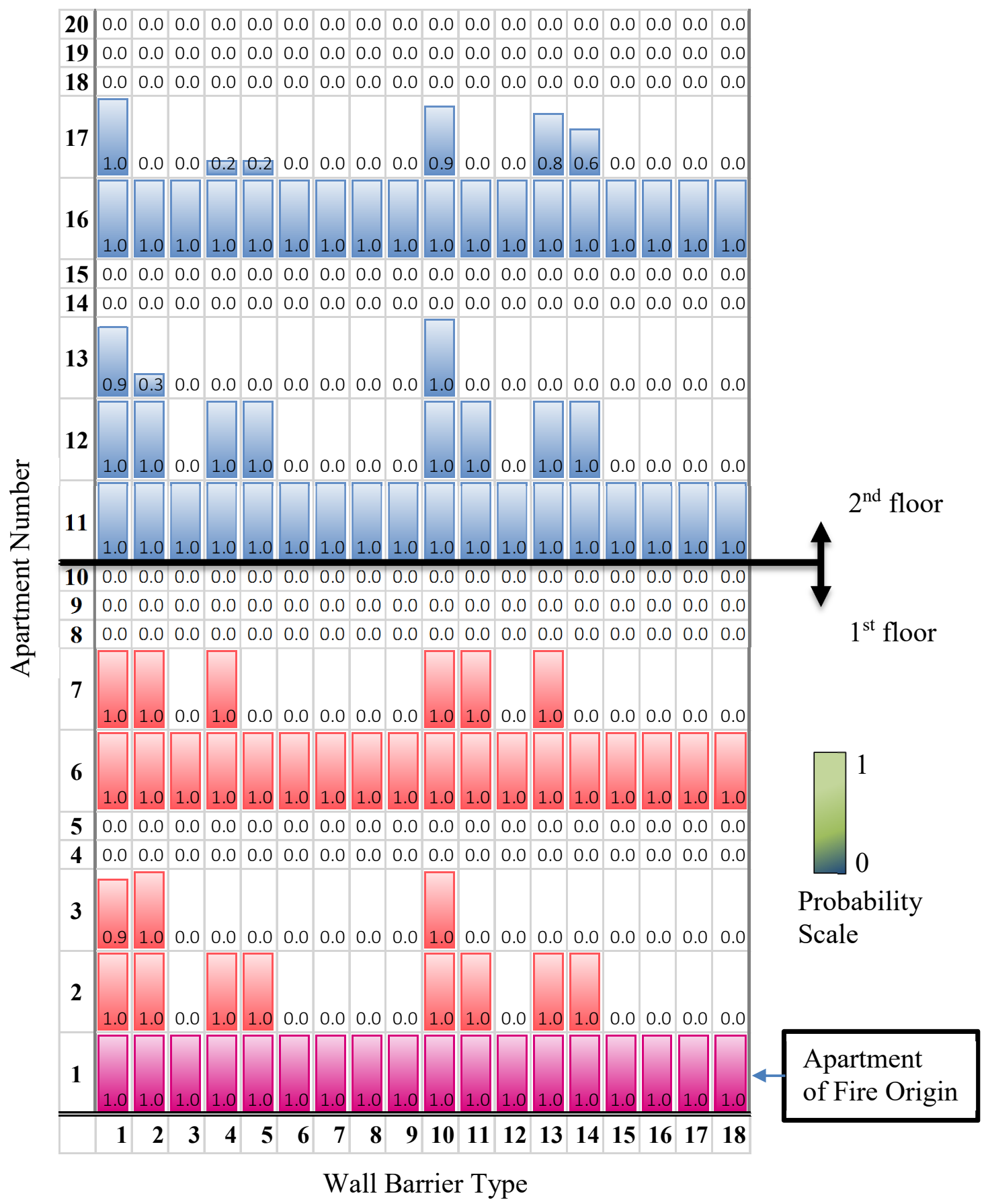

Figure 6-8 Probability of fire spread on the $1^{\text {st }}$ and $2^{\text {nd }}$ floor at 60 minutes in Scenario 4, comparing 18 types of wall barriers. Fire originated in Apartment 1 without fire suppression. 


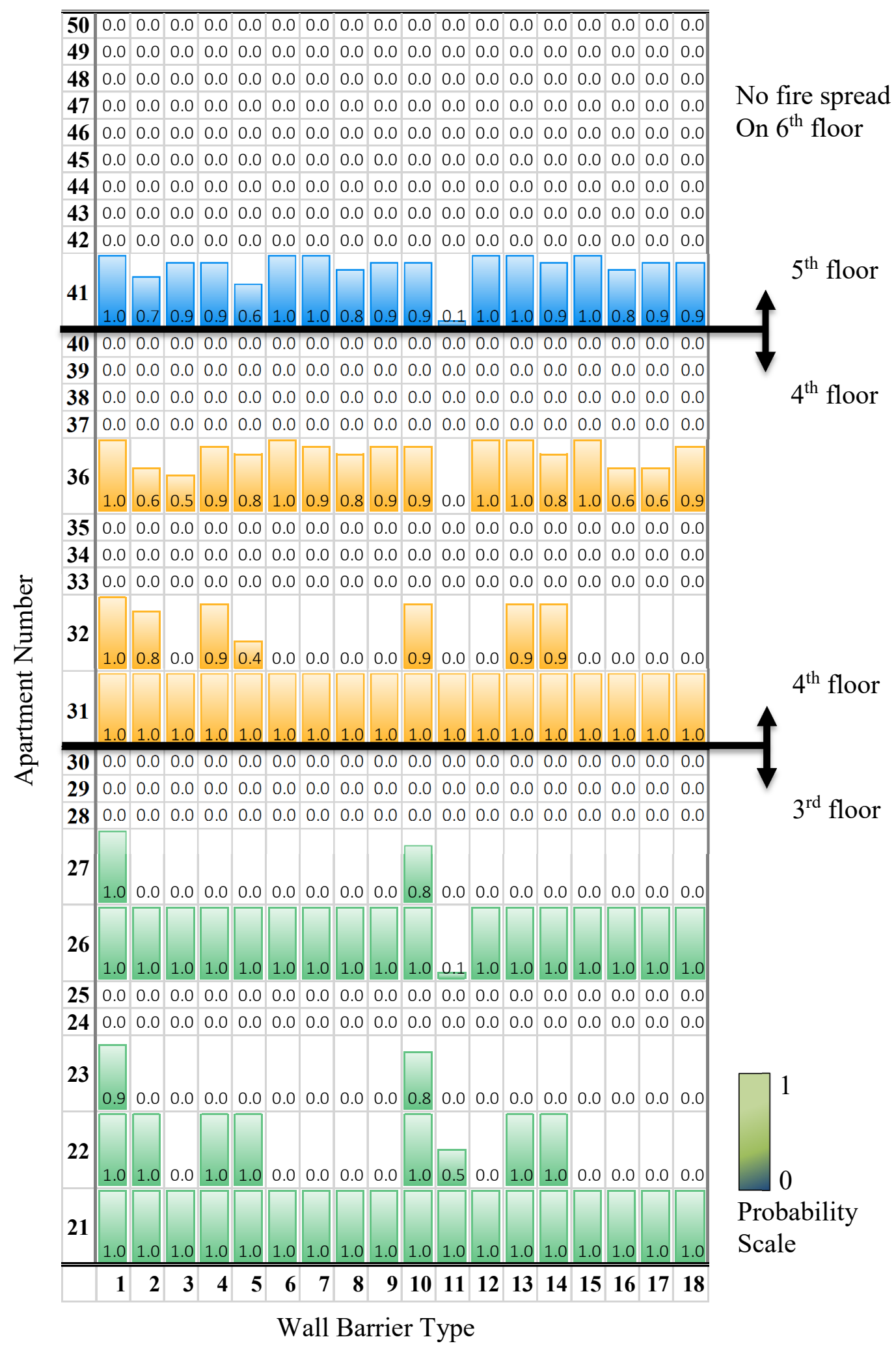

Figure 6-9 Probability of fire spread on the $3^{\text {rd }}$ to $5^{\text {th }}$ floor at 60 minutes in Scenario 4 comparing 18

types of wall barriers. Fire originated in Apartment 1 without fire suppression. 


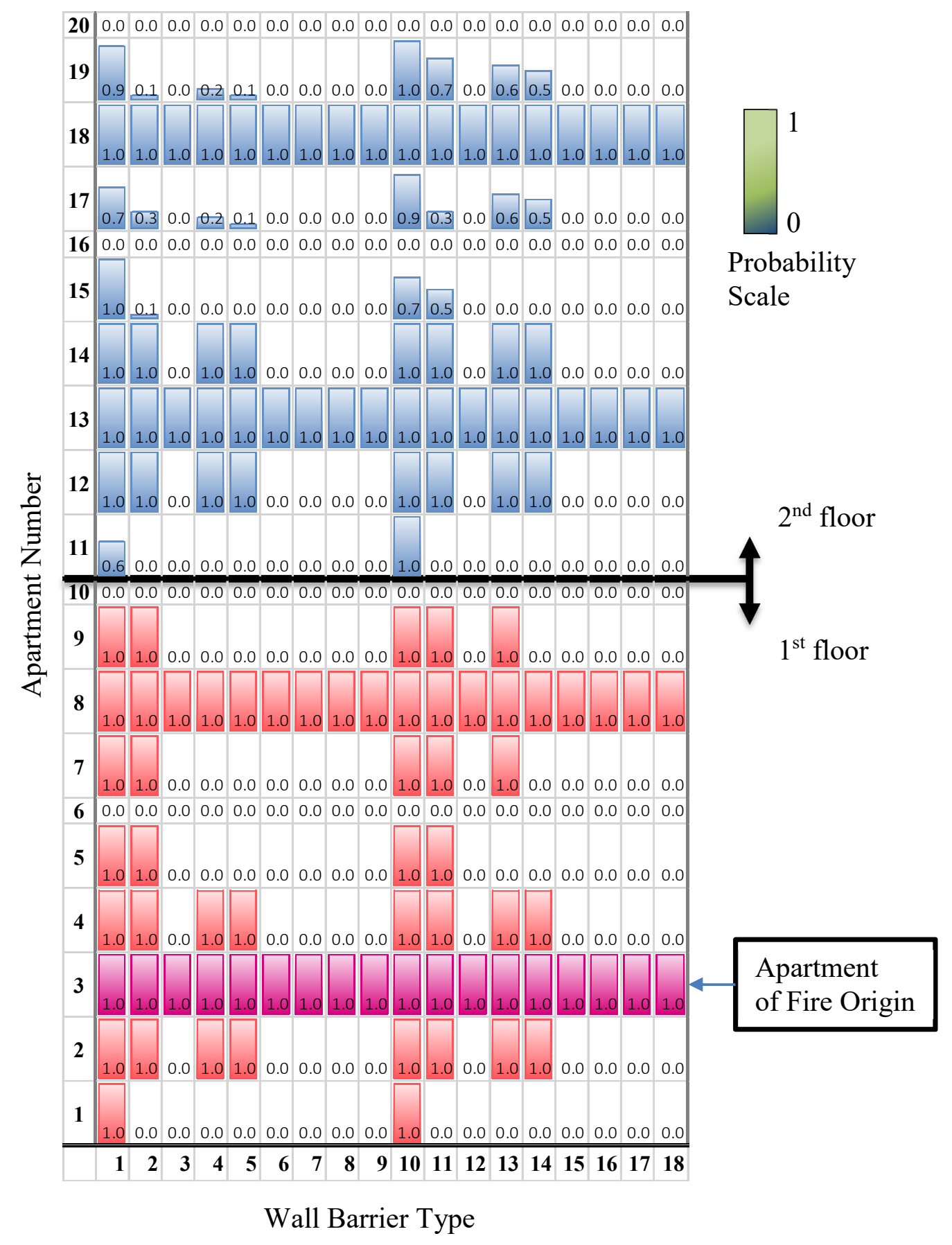

Figure 6-10 Probability of fire spread on the $1^{\text {st }}$ and $2^{\text {nd }}$ floor at 60 minutes in Scenario 8 comparing 18 types of wall barriers. Fire originated in Apartment 3 without fire suppression. 


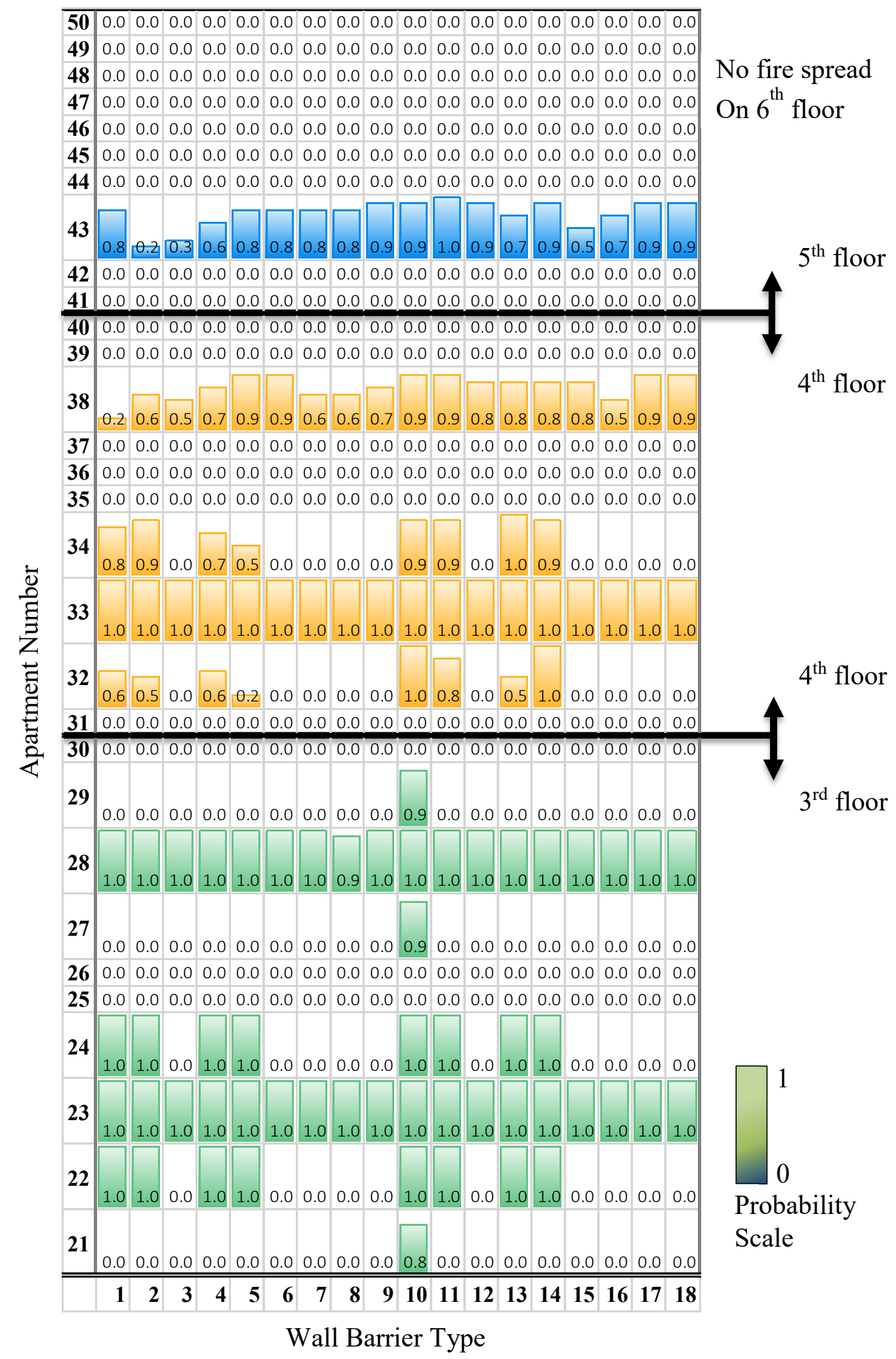

Figure 6-11 Probability of fire spread on the $3^{\text {rd }}$ to $5^{\text {th }}$ floor at 60 minutes in Scenario 8 comparing 18 types of wall barriers. Fire originated in Apartment 3 without fire suppression. 
The Fire Spread submodel is a probabilistic model based on Bayesian network approach, and can produce the time-dependent fire spread probabilities in all the compartments of a building. A fire initiated in a compartment can spread beyond the compartment of fire origin to adjacent compartments either on the same floor or floor above. Generally speaking, an uncontrolled fire could affect more building areas with a longer time duration of fire incidents. The final fire spread levels at the end of the 60 minute simulation time in the current study are mapped in Figure 6-8 to Figure 6-11. Figure 6-8 and Figure 6-9 illustrate the final probability of fire spread at 60 minutes in Fire Scenario 4 where the fire initiates in Apartment 1, whereas Figure 6-10 and Figure 6-11 show the results of Scenario 8 when Apartment 3 is the fire origin. Please note that in both scenarios no fire suppression is used.

In both fire scenarios, the fire on the first floor spreads up to the $5^{\text {th }}$ floor through external windows. Horizontally, the fire can spread to the room across the corridor by breaching the two door barriers, for example, from Apartment 1 to Apartment 6 in Scenario 4, from Apartment 3 to Apartment 8 in Scenario 8, or from Apartment 11 to 16, and so on. The above fire spread results are largely affected by the failure of windows and doors rather than wall barriers, thus the types of wall barrier have a small impact.

The wall barriers play a more important role in fire spread across adjacent apartments separated by wall barriers. Just as the failure time sequence demonstrated in Figure 6-5 and fire spread time sequence in Figure 6-7, wall Barrier 1 and Barrier 10 lead to the broadest fire spread on the floor of fire origin: three adjacent apartments (Apt.1 to Apt.3) in Scenario 4 and five adjacent apartments (Apt. 1 to Apt.5) in Scenario 8, respectively. Similar results are found on the floors above. Lower levels of adjacent fire spreads are found with Barriers 
$2,4,5,11,13$ and 14 . Other barriers generate no adjacent fire spreads.

\subsubsection{Economic loss}

The results in Figure 6-12 and Figure 6-13 are generated by the Building Cost submodel and the Economic Loss submodel. Figure 6-12 demonstrates how fire suppression options would impact the fire damages in the building design with wall barrier \#1. Fire Scenarios 1 to 8 are divided into four groups based on the availability of sprinklers or Fire Department operation, and each group includes losses resulting from two fire origins. This figure indicates that fire damages are mitigated to the minimum amount when fire sprinklers are available in the building. When only Fire Department operation is available, fire damages increase about 9 times to a value of $\$ 522 \mathrm{k}$. In both of the above two cases, damages are the same in each group since fires are prevented from spreading beyond the apartment of fire origin. In contrast, without any fire suppression in Scenario 4 and 8 , fires cause significantly higher damages than those in the other fire scenarios. Moreover, damages in Scenario 8 are higher than in Scenario 4, because the fire that originated in Apt.3 spreads to more adjacent apartments than the fire originated in Apt.1, as discussed in Section 6.3.3. 


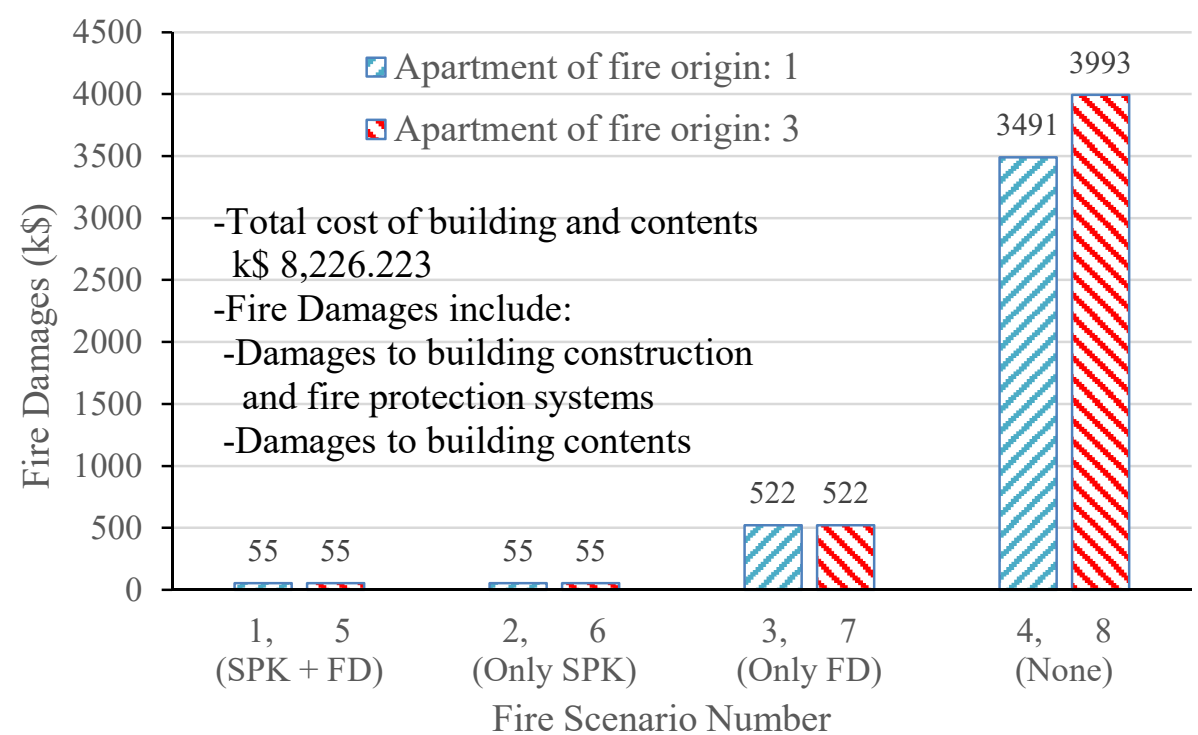

Figure 6-12 The effect of active fire protection systems on the fire losses in the building constructed with wall Barrier 1. (SPK: sprinkler, FD: Fire Department)

To demonstrate the results in a better way, the Annual Fire Loss (AFL) is compared among all the 18 building designs in Figure 6-13. AFL is a CUrisk output parameter showing the overall fire risk of economic loss, which is based on the losses of all the fire scenarios and their occurring probabilities as well as the annual fire frequency, as formulated by Equ.(1.2).

It is found from Figure 6-13 that the building wall barrier types result in different in AFLs. Among the 18 wall barriers, ten types of wall barrier designs have similar AFLs at around $\$ 26 \mathrm{k}$. This is understandable because earlier results in Figure 6-5 and Figure 6-7 indicate that these wall barriers fires fail to spread to the adjacent compartments from the apartment of fire origin. Fires in buildings constructed with the other 8 wall barriers produce different levels of ALFs, including Barrier 1 and 10 with losses around $\$ 35 \mathrm{k}$, Barrier 2 and 11 with losses around $\$ 31.5 \mathrm{k}$, Barrier 4, 5, 12 and 13 with losses from around $\$ 30 \mathrm{k}$ to $\$ 32 \mathrm{k}$.

The other finding is that wall barriers constructed with Light Steel Frame construction lead 
to slightly more AFLs than the Light Timber Frame walls under the same configuration. For example, Barrier 10 and Barrier 1 are both light frame construction protected by one layer of $12.7 \mathrm{~mm}$ gypsum board on both sides and with void cavity, except that Barrier 10 is light steel frame whereas Barrier 1 is light wood frame. The results show that the AFL of Barrier 10 is slightly higher than the AFL under Barrier 1. Similar results can be found by comparing Barrier 13 with Barrier 4, Barrier 14 with Barrier 5. AFLs of Barrier 2 and Barrier 11 are very close.

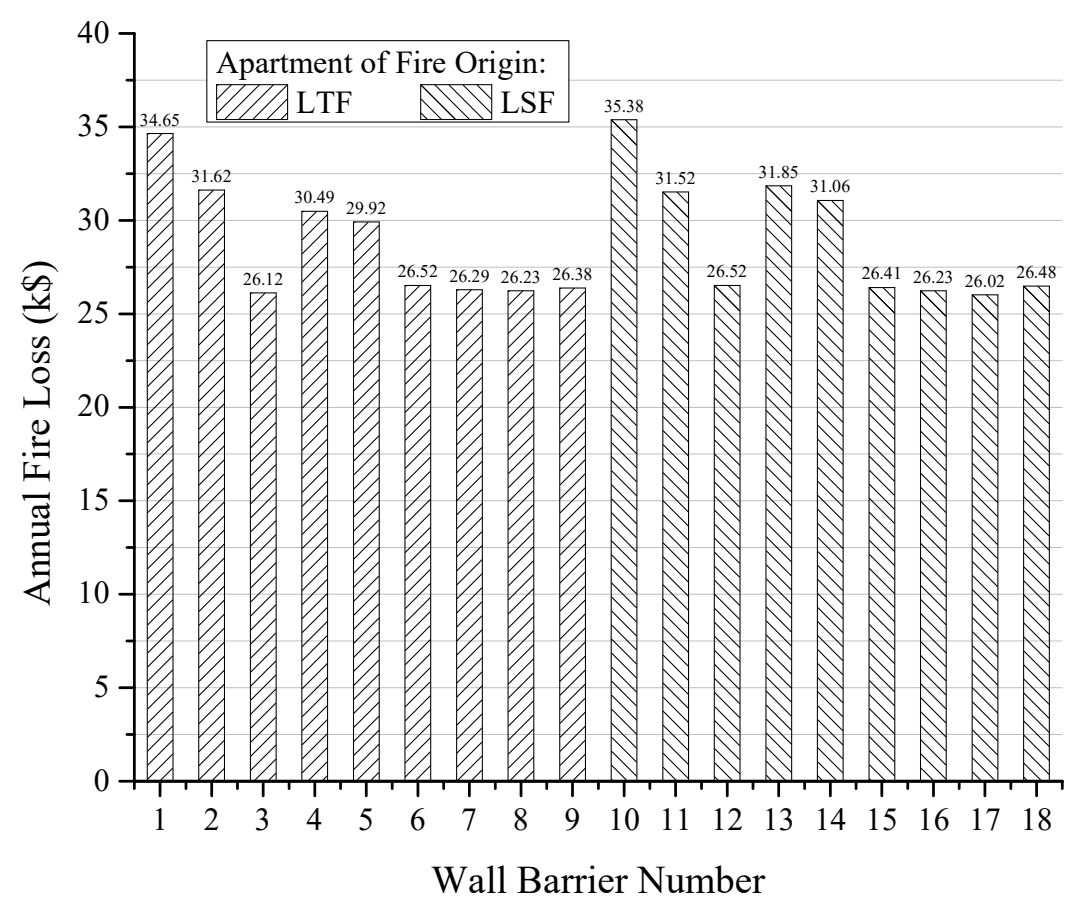

Figure 6-13 Annual Fire Loss of the 18 building wall barrier designs. (LTF: Light Timber Frame; LSF: Light Steel Frame)

\subsubsection{Life risk}

Life risk evaluations in CUrisk are calculated by the Life Hazard submodel, and are presented as number of deaths and injuries. The life risk of individual occupants is determined based on the movement path and the fire hazard conditions along the path. 
Movement path of each occupant from his/her original location to the building exit are predicted by the Occupant Evacuation submodel. Fire hazard conditions are outputs of the Smoke Movement submodel and the Fire Spread submodel. The probability of death of each occupant is a combined effect of heat (thermal radiation and hot gases), toxic gases and fire spread, see Section 3.2.3 for more explanations. It should be noted that Monte Carlo approach is adopted in the Occupant Evacuation submodel, and 2000 Monte Carlo loops are used in this case study. Correspondingly, the same number of runs are conducted for the Fire Spread submodel and the Life Hazard submodel. As a result, in the following discussion the mean value of the 2000 runs is presented.

Despite that deaths and injuries occur in some fire scenarios, results suggest that fire spread has little impact on occupant life risk in all the pre-defined fire scenarios and building designs. Deaths and injuries are mainly caused by heat and toxic gases according to outputs of Life Hazard submodel. Simulation results demonstrate that no death is attributed to fire spread for the daytime fire scenarios while only a small amount of deaths are resulted from fire spread for the night-time fire scenarios. 


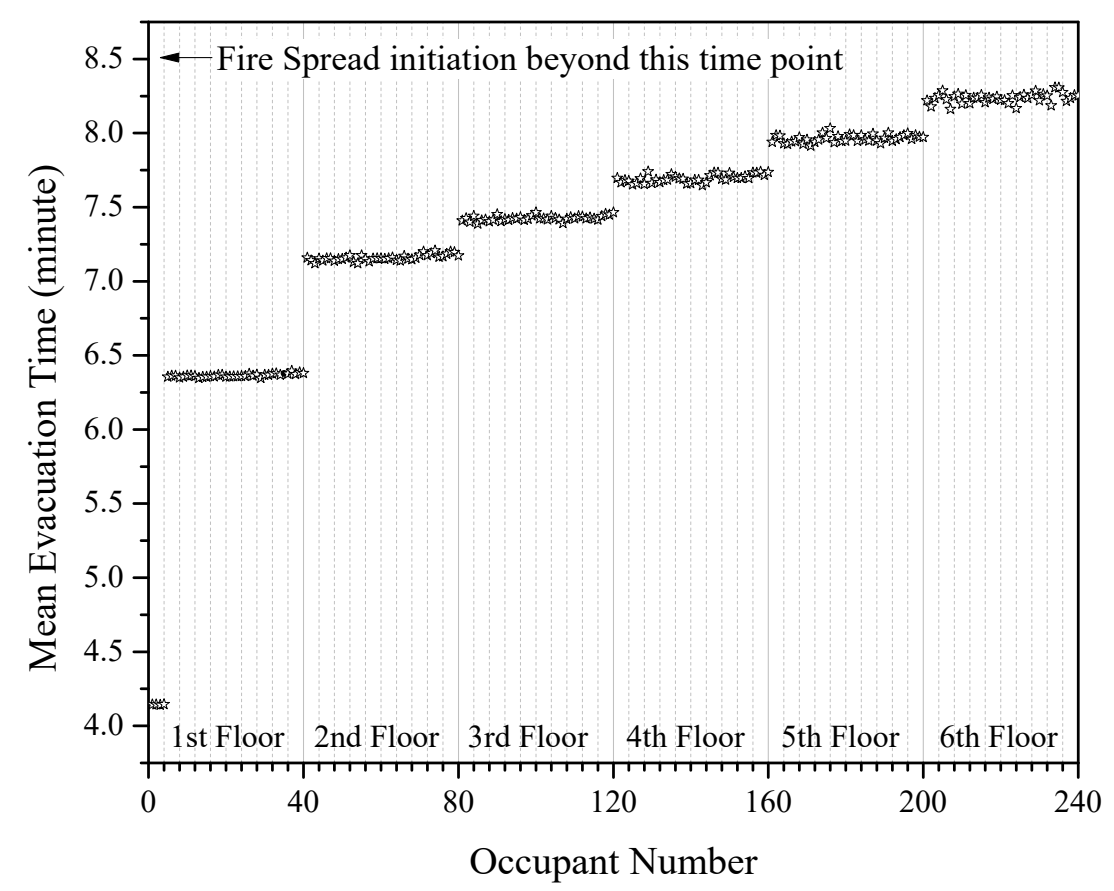

Figure 6-14 Mean evacuation time of each occupant in Scenario 4 and in the building designed with

\section{Wall Barrier 1}

In the daytime fire scenarios (Scenario 1 to 8 , see Figure 6-3), simulation results show that no death is attributed to fire spread, in other words all deaths are caused by heat and toxic gases. Figure 6-14 demonstrates why fire spread fails to threat life in the daytime fires using the results in Scenario 4 and building designed with wall Barrier 1. It shows the mean occupant evacuation times of all the occupants. The occupant number in the horizontal axis is counted from the first floor to the top floor with 40 occupants on each floor. It can be found that occupants in the apartment of fire origin (Apt.1) evacuate the building at the earliest time, around 4.2 minutes on average, before the fire reaches flashover (see bottom left corner in Figure 6-14). Apart from that, the evacuation times are basically grouped by floors, showing higher mean evacuation times in higher storeys. However, compared with occupant evacuation times, fire spread occurs much later. The first fire spread from the apartment of fire origin is Apartment 11, which occurs at around 20 minutes. Similar results 
are found in all other daytime fire scenarios and building designs.

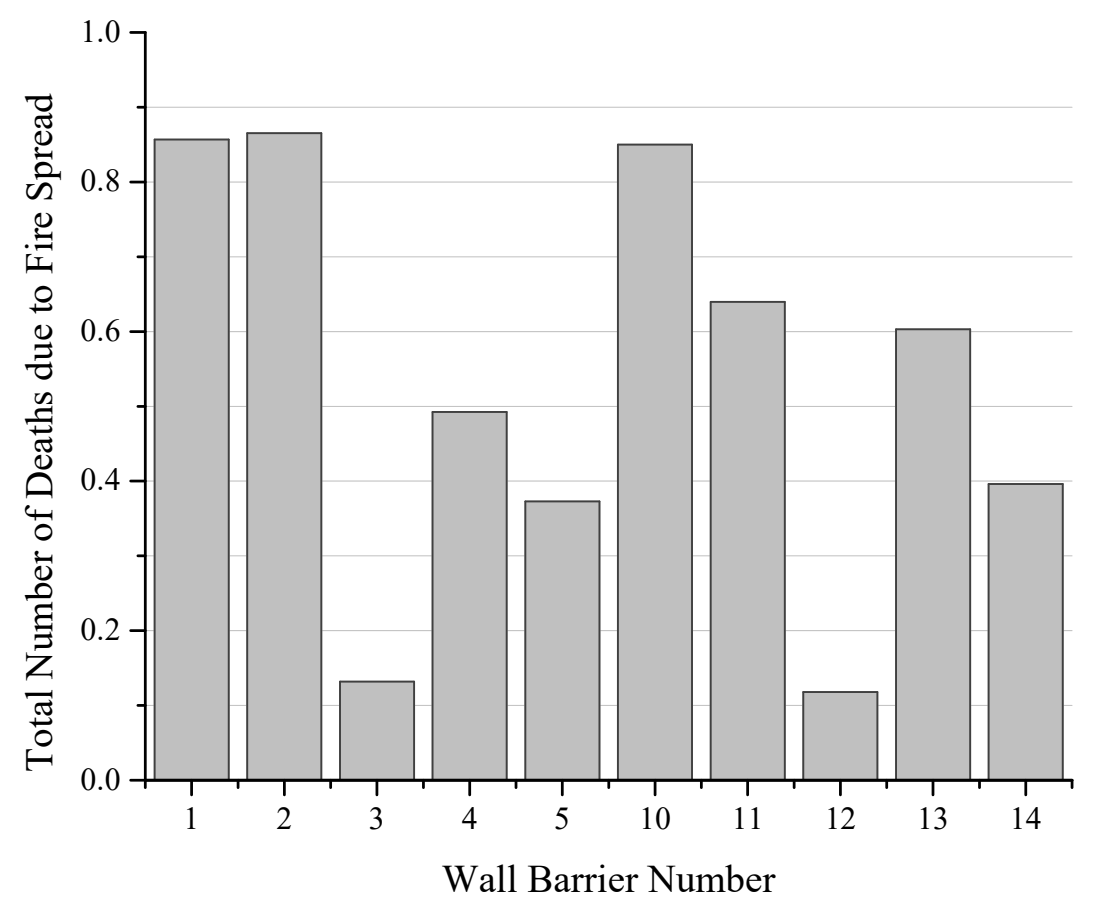

Figure 6-15 Total probability of death due to fire spread in Scenario 16, comparing 10 different types of wall barriers

During night-time fire scenarios (Scenario 9 to 16), occupants need more time to respond to the fire, thus the evacuation times are longer than in daytime fires. Unlike daytime fire scenarios, the simulation results show that some deaths resulting from fire spread. In order to show the effect of wall barrier types on the deaths due to fire spread, the death predictions of fire Scenario 16 are shown in Figure 6-15. This figure presents the total number of deaths due to fire spread when fire occurred in buildings constructed with 10 different wall barrier types. The death numbers are not integers because they are averaged from the Monte Carlo repetitions.

From the figure it can be seen that wall barrier types has an effect on the total number of deaths. The effect is similar to the effect on the Annual Fire Losses shown in Figure 6-13. The earlier the wall barrier fails, the more deaths occur. The only one exception is the 
comparison between Barrier 1 and Barrier 2 but their deaths values are very close. Light Steel Frame wall barriers lead to slightly more deaths than the Light Wood Frame counterparts. The rest of 18 wall barriers (Barrier $6,7,8,9,15,16,17,18)$ generate the same level of deaths as Barrier 3 and 12, thus they are not included in the figure. In conclusion, the Barrier Failure submodel enables CUrisk to handle the impact of barrier types on life risk and fire losses. It was shown that for the 6-storey apartment building fire spread contributes little to the life risk compared with heat and toxic gases. For instance, in Scenario 16 of the building designed with wall Barrier 1, the number of deaths due to fire spread is around 0.85 , whereas the total death number of deaths (due to heat, toxic gases and fire spread) is 4.9 .

\subsection{Summary}

At the beginning of this chapter, the role of the newly developed Barrier Failure model in the CUrisk system structure was discussed. Although this model works as a submodel in CUrisk, it has strong ties with the Fire Spread submodel. The Barrier Failure submodel provides the probability of failure of fire barriers to the Fire Spread submodel, which calculates the probability of fire spread in all the compartments of the building. The new Barrier Failure submodel is a substitution of the old barrier failure module in the Fire Spread submodel.

In addition, the chapter presented a fire risk analysis case study of a six-storey apartment building, aimed at showing the effect of wall barriers on the fire risk. The apartment building has 18 different designs of wall barriers, all of which are light frame construction but with different structures. These wall barriers had different failure times under the 
unsuppressed fires in the apartment of fire origin, and consequently lead to different times of fire spread to the adjacent compartments. The maps of fire spread in the unsuppressed fires at 60 minutes demonstrated good patterns and clearly reflected the role of fire barriers. The impact of wall barrier designs on the economic losses and deaths are also discussed. Results show that the building designed with better fire-resistive barriers could lead to lower fire damages and occupant deaths. 


\section{Chapter 7 Conclusions and Recommendations for Future Work}

\subsection{Summary and Conclusions}

CUrisk has been in development for over a decade and is one of the most comprehensive fire risk assessment models created around the world. One of the shortcomings of CUrisk was the lack of submodels to evaluate barrier failure and fire spread beyond the room of fire origin. Solving this issue was the objective of this thesis.

A probabilistic fire spread model developed at Carleton University was incorporated into the CUrisk system model, and changes to the system model and some other submodels were undertaken. In order to integrate this model into CUrisk as the Fire Spread submodel, the role and position of the Fire Spread submodel were analyzed and the input and output data of the Fire Spread submodel were determined. Furthermore, changes in the system model were identified, which include the modifications of the Life Hazard submodel and Economic Loss submodel. Those changes enabled CUrisk to take the Fire Spread submodel into its system structure. With these modifications, CUrisk can now predict the fire hazard conditions due to fire spread in a building fire, which are further used to predict life risk and fire damages. After these changes, a case study of fire risk assessment is presented with the improved CUrisk. The newly integrated Fire Spread submodel is capable of predicting the effect of Fire Resistance Ratings of fire barriers on fire spread hazard. A CUrisk case study was then conducted to study the impacts of fire resistance of building components on the building occupant safety as well as fire losses. The results showed a good pattern of fire spread across the building. In addition, different combinations of Fire Resistance Ratings of walls, floors, doors and windows demonstrated reasonable variations of fire spread inside the building. As it is not possible to conduct full scale building fire 
tests to validate the results of the Fire Spread submodel, this model can be used to compare the relative effectiveness of different fire safety strategies.

An important part of this research was the experimental fire testing. Six full-scale room fire tests were conducted in a realistic bedroom fire environment with the following construction types: Cross Laminated Timber construction, Light Timber Frame construction and Light Steel Frame construction. The tests provided information on the evolution of fire temperature and heat release, contribution of the timber assembly components to the room fire, charring behaviour of wood structural components and reaction of assembly components such as gypsum board, stud and insulation. The fully developed phase lasted about 15 minutes if room barriers were protected with gypsum boards. In contrast, when the room was constructed with exposed CLT panels the room fire experienced earlier flashover and went through a continuous burning due to the involvement of CLT panels to the room fire. After careful calculation it was found that in the above test a large portion of the heat release was produced by external burning, whereas other tests in the protected rooms experienced slightly under-ventilated burning conditions. In addition to the room fire profiles, the behaviour of the wall assembly components in the fire tests was studied. The temperature profiles at various assembly inner locations were analyzed, with special attention given to the behaviour of fire-exposed gypsum boards. When a single layer of type $\mathrm{C}$ gypsum board was applied on the fire exposed side, significant earlier gypsum board fall-off appeared in the light steel frame construction than in the light timber frame construction. Moreover, regarding the charring of timber components, the average charring rate was $1.22 \mathrm{~mm} / \mathrm{min}$ based on a $30 \mathrm{~mm}$ charring depth on the wood studs in light frame construction lined with 1 layer gypsum board. In the 
unexposed CLT room fire test, the average charring rate based on a $24 \mathrm{~mm}$ charring depth in about 40 minutes was $0.85 \mathrm{~mm} / \mathrm{min}$, and the overall charring rate was $1 \mathrm{~mm} / \mathrm{min}$ in a 60 minutes time period. These findings suggest that the barrier failure time of a building assembly in a real fire might be earlier or later than its fire resistance rating. Literature survey indicated that there are limited number of full-scale room fire tests focusing on the above issues. The test obtained in those tests were used to develop and verify a barrier failure model for use in CUrisk.

Another major part of this thesis was the development of the Barrier Failure model. The model was developed based on the concept of Component Subtractive Method. Onedimensional finite difference heat transfer model was created to calculate the temperature evolvement inside the barrier. Material property changes with temperature and failure of the component were determined based on the component response criteria. The deterministic heat transfer and component response model can calculate the temperature profile, component response and charring depth of timber components under fire. On the basis of the deterministic heat transfer and component response model, a probabilistic barrier failure model was developed by taking into account the uncertainties of some factors that affect the assembly failure, for example, fall-off temperature criterion of the fire-exposed gypsum board(s), failure criteria of the unexposed component, deflection temperature of steel studs, and so on. With this model, the probability of failure as a function of fire exposure time can be generated. The model performance was verified by comparing with the full scale fire test results obtained in Chapter 4. Temperature profiles at selected assembly locations were compared, and the model prediction agrees very well with the test measurements. Besides, comparable results between the test observation and 
model prediction were also presented regarding to the fall-off behaviour of the fire-exposed gypsum board in the light frame assembly as well as the charring behaviour in the CLT assembly. An example calculation demonstrated that the probabilistic barrier failure model is able to distinguish the impacts of fire severities and different barrier structures on the barrier failure behaviour. After the Barrier Failure submodel was integrated into CUrisk, a fire risk analysis case study on a six-storey apartment building showed that 18 different light frame wall barrier designs lead to different levels of fire spread and reasonable variations in fire damages and casualties.

\subsection{Recommendation for future work}

The following is a list of recommendations for future research work, which can be undertaken to improve the ability of CUrisk and its submodels.

\section{Improvements of the Fire Spread Submodel}

Solutions of two issues of the submodel can significantly improve its ability. The first issue of the model is that the floor plan must be same for all the storeys. This issue is not major since floor plans are the same in most buildings. The other issue is the prediction of vertical fire spread through window openings. Vertical fire spread means fire spread from a room to another room on the floor above. Right now the probability of fire spread on the vertical direction is determined based on the failure of floor/ceiling or external fire spread through windows, with the latter dominating the process. The current treatment of external flame spread is by assigning fire resistance ratings to windows, while ignoring other factors, such as the size and location of windows, the size of external flames and so on. Further work is needed on this matter. 


\section{Improvements of the Barrier Failure Submodel}

The barrier failure submodel developed in this thesis is first of its kind to account for the fire performance of different types of construction. It can not only provide the deterministic heat transfer profile along with component failure, but also calculate the probability of failure as a function of time. Although some verifications were conducted in this thesis, more should be done in the future. It would be of great value if a series of fire tests could be done using building assemblies of various construction types and subjected to various fire severities.

Another major limitation in modeling heat transfer is the lack of material property data. During this work it was found that the material thermo-physical property data are scarce and inconsistent, for materials such as insulations in the light frame construction, gypsum boards of fire-rated or non-fire rated or even with fibre enhancement. Moreover, even though building material properties can be obtained through extensive measurements, the building products, such as gypsum boards, vary in different countries and even for different manufacturers from the same country.

\section{Improvements of the Smoke Movement Submodel}

The Smoke Movement submodel is the primary submodel to predict the fire hazard conditions in CUrisk. Its outputs are directly used in evaluating occupant safety and property damages. It would be valuable if this submodel can be improved in the following issues.

The first improvement is to enable the submodel to account for the contribution of timber components in the building assembly using the charring prediction from the Barrier Failure submodel. At present it is accounted for by just specifying a fixed charring rate. 
The second improvement is to take into account the added fire and smoke generation due to fire spread. Currently the fire spread submodel and the smoke movement submodel are independent to each other. In the smoke movement submodel there is only one fire source in the building throughout the simulation. However, ideally whenever fire spread to another room additional heat release and smoke should be produced, which in turn will affect occupant safety. In other words, multiple fire sources may occur simultaneously and continuously throughout the simulation. One of the possible solutions of this issue is to add a fire source in the smoke movement submodel to the room whenever the fire spread to.

\section{Cost and damage evaluation of different construction types}

The Building Cost submodel and Economic Loss submodel greatly expand the ability of CUrisk. However, the difficulty lies in collection of building costs data and evaluation of damages of different building components, the latter is more important. It is suggested that the damages criteria of various types of construction should be investigated. For example, Heavy Timber Construction (such as Cross Laminated Timber) might be more vulnerable to water damages than concrete constructions.

\section{CUrisk User Interface}

For a comprehensive computer mode like CUrisk, creating a large amount of input files is inevitable. CUrisk itself has 14 input files in text format involving hundreds of input parameters, so an intuitive user interface would be most helpful. It is suggested that a WYSWYG (What You See is What You Get) interface is used for the input of building geometries. 


\section{References}

[1] Zhang, X., and Hadjisophocleous, G., (2012) An improved two-layer zone model applicable to both pre- and post-flashover fires, Fire Safety Journal 53: 63-71. DOI:http://dx.doi.org/10.1016/j.firesaf.2012.06.014.

[2] Zhang, X., Li, X., and Hadjisophocleous, G., (2013) A probabilistic occupant evacuation model for fire emergencies using Monte Carlo methods, Fire Safety Journal 58: 15-24. DOI:10.1016/j.firesaf.2013.01.028.

[3] Zhang, X., Li, X., and Hadjisophocleous, G., (2014) A probabilistic occupant response model for fire emergencies, Fire Safety Journal 68: 41-51.

DOI:http://dx.doi.org/10.1016/j.firesaf.2014.05.017.

[4] Hadjisophocleous, G., Fu, Z., and Li, X., "Technical Report on CUrisk - A Fire Risk Analysis Model." Department of Civil and Environmental Engineering, Carleton University Ottawa, Ontario, 2011.

[5] Fu, Z., and Hadjisophocleous, G., (2000) A two-zone fire growth and smoke movement model for multi-compartment buildings, Fire Safety Journal 34: 257-285. DOI:10.1016/S0379-7112(99)00045-4.

[6] Takeda, H., and Mehaffey, J.R., (1998) WALL2D: A model for predicting heat transfer through wood-stud walls exposed to fire, Fire and Materials 22: 133-140. DOI:10.1002/(SICI)1099-1018(1998070)22:4<133::AID-FAM642>3.0.CO;2-L.

[7] Wang, N. (2009). "Prediction of heat transfer and probability of insulation failure in wood-framed walls". Master of Applied Science. Carleton University, Ottawa, Ontario, Canada.

[8] Cheng, H., and Hadjisophocleous, G.V., (2011) Dynamic modeling of fire spread in building, Fire Safety Journal 46: 211-224. DOI:DOI:

10.1016/j.firesaf.2011.02.003.

[9] Gruchy, D. (2004). "Modelling occupant evacuation during fire emergencies in buildings". Master of Applied Science. Carleton University, Ottawa, Ontario.

[10] Esposito, D. (2004). "Economic Impact of Fires in Buildings". Master of Applied Science. Department of Civil and Environmental Engineering, Carleton University, Ottawa, Ontario.

[11] Yung, D., Hadjisophocleous, G.V., and Proulx, G., (1997) Modelling Concepts For The Risk-cost Assessment Model Firecam' And Its Application To A Canadian Government Office Building, Fire Safety Science 5: 619-630.

DOI:10.3801/IAFSS.FSS.5-619. 
[12] Takeda, H., and Yung, D., (1992) Simplified Fire Growth Models for Risk-Cost Assessment in Apartment Buildings, Journal of Fire Protection Engineering 4: 5365. DOI:10.1177/104239159200400202.

[13] Hadjisophocleous, G.V., and Yung, D., (1992) A Model for Calculating the Probabilities of Smoke Hazard From Fires in Multi-Storey Buildings, Journal of Fire Protection Engineering 4: 67-79. DOI:10.1177/104239159200400203.

[14] Bénichou, N., Kashef, A.H., Reid, I., Hadjisophocleous, G.V., Torvi, D.A., and Morinville, G., (2005) FIERAsystem: A Fire Risk Assessment Tool to Evaluate Fire Safety in Industrial Buildings and Large Spaces, Journal of Fire Protection Engineering 15: 145-172. DOI:10.1177/1042391505049437.

[15] Bénichou, N., Kashef, A., Torvi, D.A., Hadjisophocleous, G.V., and Reid, I., "FIERAsystem: A Fire Risk Assessment Model for Light Industrial Building Fire Safety Evaluation." Institute for Research in Construction, National Research Council Canada Report RR-120, Ottawa, 2002.

[16] Feng, P., Hadjisophocleous, G.V., and Torvi, D.A., "Equations and theory of the simple correlation model of FIERAsystem." Institute for Research in Construction, National Research Council Canada Report 779, Ottawa, 2000.

[17] Kashef, A., Bénichou, N., and Hadjisophocleous, G., "FIERAsystem theory report : fire spread model (FSPM)." Institute for Research in Construction, National Research Council Canada Report RR-134, Ottawa, 2003.

[18] Beck, V., and Zhao, L., "Cesare-risk: An Aid For Performance-based Fire Designsome Preliminary Results." Fire Safety Science, 2000 p.159-170.

[19] He, Y., and Beck, V., (1997) Smoke spread experiment in a multi-storey building and computer modelling, Fire Safety Journal 28: 139-164. DOI:http://dx.doi.org/10.1016/S0379-7112(96)00081-1.

[20] Longde Zhao, (1999) A New Approach for Modeling the Occupant Response To a Fire in a Building, Journal of Fire Protection Engineering 10: 28-38.

DOI:10.1177/104239159901000103.

[21] Clancy, P., (2002) Probability of Failure with Time for Wood Framed Walls in Real Fire, Journal of Fire Protection Engineering 12: 197-223.

DOI:10.1106/104239102031473.

[22] Fraser-Mitchell, J., "Risk Assessment Of Factors Related To Fire Protection In Dwellings." Fire Safety Science, 1997 p.631-642.

[23] Fraser-Mitchell, J., "An Object-oriented Simulation (crisp 11) For Fire Risk Assessment." Fire Safety Science, 1994 p.793-804. 
[24] Koo, S., Fraser-Mitchell, J., Upadhyay, R., and Welch, S., (2008) Sensor-linked fire simulation using a Monte-Carlo approach, Fire Safety Science 9: 1389-1400. DOI:10.3801/IAFSS.FSS.9-1389.

[25] Björkman, J., and Mikkola, E., (2001) Risk assessment of a timber frame building by using CRISP simulation, Fire and Materials 25: 185-192. DOI:10.1002/fam.770.

[26] Wade, C., Baker, C., Frank, K., Robbins, A., Harrison, R., Spearpoint, M., and Fleischmann, C., "B-RISK User Guide and Technical Manual." BRANZ Ltd Report BRANZ Study Report 282, Judgeford, Porirua City, New Zealand, 2013 .

[27] Baker, G., Wade, C., Spearpoint, M., and Fleischmann, C., (2013) Developing Probabilistic Design Fires for Performance-based Fire Safety Engineering, Procedia Engineering 62: 639. DOI:http://dx.doi.org/10.1016/j.proeng.2013.08.109".

[28] Frank, K. (2013). "Fire Safety System Effectiveness for a Risk-Informed Design Tool". Doctor of Philosophy. University of Canterbury, Christchurch, New Zealand.

[29] Wade, C., "BRANZFIRE Technical Reference Guide 2004." Building Research Association of New Zealand. Report BRANZ Study Report 92 (revised), udgeford, Porirua City, New Zealand, 2004.

[30] Nyman, J. F. (2002). "Equivalent Fire Resistance Ratings of Construction Elements Exposed to Realistic Fires". Master of Engineering. University of Canterbury, Christchurch, New Zealand.

[31] Babrauskas, V., and Williamson, R., (1978) The historical basis of fire resistance testing - Part II, Fire Technology 14: 304-316. DOI:10.1007/BF01998390.

[32] American Society for Testing and Materials. (2000). "ASTM E119, Standard Methods of Fire Tests of Building Construction and Materials." .

[33] Underwriters' Laboratories of Canada. (1989). "CAN/ULC-S101-M89: Standard Methods of Fire Endurance Tests of Building Construction and Materials." .

[34] International Organization for Standardisation, ISO 834, Fire Resistance Tests Elements of Building Construction, ISO, Switzerland, 1975 .

[35] British Standard, BS 476: Parts 20-24, Fire Tests on Building Materials and Structures, British Standards Institution, United Kingdom, 1987.

[36] Park, J., and Lee, J., (2004) Fire Resistance of Light-framed Wood Floors Exposed to Real and Standard Fire, Journal of Fire Sciences 22: 449-471. DOI:10.1177/0734904104042548.

[37] prEN1991-1-2, Eurocode 1: Actions on Structures, Part 1-2: Actions on 
Structures Exposed to Fire, European Committee for Standardisation, Brussels, 2002 .

[38] Manzello, S.L., Gann, R.G., Kukuck, S.R., and Lenhert, D.B., (2007) Influence of gypsum board type (X or $\mathrm{C}$ ) on real fire performance of partition assemblies, Fire and Materials 31: 425-442. DOI:10.1002/fam.940.

[39] Manzello, S.L., Gann, R.G., Kukuck, S.R., Prasad, K., and Jones, W.W., (2007) Performance of a non-load-bearing steel stud gypsum board wall assembly: Experiments and modelling, Fire and Materials 31: 297-310. DOI:10.1002/fam.939.

[40] Manzello, S.L., Gann, R.G., Kukuck, S.R., Prasad, K., and Jones, W.W., (2005) Real fire performance of partition assemblies, Fire and Materials 29: 351-366. DOI:10.1002/fam.892.

[41] Sultan, M.A., (1996) A model for predicting heat transfer through noninsulated unloaded steel-stud gypsum board wall assemblies exposed to fire, Fire Technology 32: 239-259. DOI:10.1007/BF01040217.

[42] Lennon, T., and Moore, D., (2003) The natural fire safety concept-full-scale tests at Cardington, Fire Safety Journal 38: 623-643. DOI:http://dx.doi.org/10.1016/S0379-7112(03)00028-6.

[43] Trelles, J., and Mawhinney, J.R., (2010) CFD Investigation of Large Scale Pallet Stack Fires in Tunnels Protected by Water Mist Systems, Journal of Fire Protection Engineering 20: 149-198. DOI:10.1177/1042391510367359.

[44] Hopkin, D. J., Lennon, T., El-Rimawi, J., and Silberschmidt, V. (2011). "Fullscale natural fire tests on gypsum lined structural insulated panel (SIP) and engineered floor joist assemblies." Fire Safety Journal, 46(8), 528-542.

[45] Jones, B. (2001). "Performance of Gypsum Plasterboard Assemblies Exposed to Real Building Fires". Master's Thesis. University of Canterbury, Christchurch, New Zealand.

[46] Nyman, J.F., Gerlich, H.J.T., Wade, C., and Buchanan, A.H., (2008) Predicting Fire Resistance Performance of Drywall Construction Exposed to Parametric Design Fires -- A Review, Journal of Fire Protection Engineering 18: 117-139. DOI:10.1177/1042391507080811.

[47] Barnett, C.R., (2007) A New T-equivalent Method for Fire Rated Wall Constructions using Cumulative Radiation Energy, Journal of Fire Protection Engineering 17: 113-127. DOI:10.1177/1042391506066098.

[48] Frangi, A., and Fontana, M., (2005) Fire Performance Of Timber Structures Under Natural Fire Conditions, 279-290. DOI:10.3801/IAFSS.FSS.8-279. 
[49] Hakkarainen, T., (2002) Post-Flashover Fires in Light and Heavy Timber Construction Compartments, Journal of Fire Sciences 20: 133-175.

DOI:10.1177/0734904102020002074.

[50] Gagnon, S., and Pirvu, C., CLT Handbook, cross-laminated timber, FPInnovations, Canada, 2011 .

[51] Kuilen, J.W.G.V.D., Ceccotti, A., Xia, Z., and He, M., (2011) Very Tall Wooden Buildings with Cross Laminated Timber, Procedia Engineering 14: 1621-1628. DOI:http://dx.doi.org/10.1016/j.proeng.2011.07.204.

[52] Frangi, A., Fontana, M., Hugi, E., and Jübstl, R., (2009) Experimental analysis of cross-laminated timber panels in fire, Fire Safety Journal 44: 1078-1087. DOI:10.1016/j.firesaf.2009.07.007.

[53] Frangi, A., Fontana, M., Knobloch, M., and Bochicchio, G., (2008) Fire behaviour of cross-laminated solid timber panels, 1279-1290. DOI:10.3801/IAFSS.FSS.91279 .

[54] Osborne, L., and Dagenais, C., Preliminary CLT Fire Resistance Testing Report, FPInnovation and National Research Council of Canada, Canada, 2012 .

[55] Frangi, A., Bochicchio, G., Ceccotti, A., and Lauriola, M.P., "Natural full-scale fire test on a 3 storey XLam timber building." Proceedings of 10th World Conference on Timber Engineering (WCTE), 2008 .

[56] Joyeux, D., (2002) Experimental investigation of fire door behaviour during a natural fire, Fire Safety Journal 37: 605-614. DOI:http://dx.doi.org/10.1016/S03797112(02)00003-6.

[57] EN 1995-1-2, Eurocode 5: Design of Timber Structures, Part 1-2: General Structural Fire Design, European Committee for Standardisation, Brussels, 2004.

[58] Bénichou, N., and Sultan, M. A. (2000). "Fire Resistance Performance of Lightweight Wood-Framed Assemblies." Fire Technology, 36(3), 184-219.

[59] Ingberg, S.H., (1928) Tests of the Severity of Building Fires, Quarterly Journal of the National Fire Protection Association 22: 43-61.

[60] Paulsen, O.R., and Hadvig, S., (1977) Heat transfer in fire test furnaces, Journal of Fire and Flammability 8: 423-442.

[61] Law, M., "A relationship between fire grading and building design and contents." Fire Research Station Report 877, U.K., 1971 .

[62] Law, M., "A Review of Formulae for T-Equivalent." Fire Safety Science - 
Proceedings of the Fifth International Symposium, International Association for Fire Safety Science, 1997 p.985-996.

[63] Pettersson, O., Magnusson, S.E., and Thor, J., "Fire Engineering Design of Steel Structures." Swedish Institute of Steel Construction Report Publication 50, Stockholm,Sweden, 1976.

[64] Thomas, P.H., (1986) Design guide: Structure fire safety CIB W14 Workshop report, Fire Safety Journal 10: 77-137. DOI:http://dx.doi.org/10.1016/03797112(86)90041-X.

[65] Thomas, G., Buchanan, A., and Fleischmann, C., "Structural Fire Design: The Role Of Time Equivalence." Fire Safety Science, 1997 p.607-618.

[66] Harmathy, T.Z., (1981) The fire resistance test and its relation to real-world fires, Fire and Materials 5: 112-122. DOI:10.1002/fam.810050306.

[67] Harmathy, T.Z., and Mehaffey, J.R., (1982) Normalized heat load: A key parameter in fire safety design, Fire and Materials 6: 27-31. DOI:10.1002/fam.810060108.

[68] Harmathy, T.Z., and Mehaffey, J.R., (1987) The normalized heat load concept and its use, Fire Safety Journal 12: 75-81. DOI:http://dx.doi.org/10.1016/0379$\underline{7112(87) 90017-8 .}$.

[69] Mehaffey, J.R., and Harmathy, T.Z., (1981) Assessment of fire resistance requirements, Fire Technology 17: 221-237. DOI:10.1007/BF02479572.

[70] Harmathy, T.Z., (1979) Effect of the nature of fuel on the characteristics of fully developed compartment fires, Fire and Materials 3: 49-60.

DOI:10.1002/fam.810030109.

[71] Yung, D., and Mehaffey, J.R., (1991) Fire resistance requirements for rubber-tire warehouses, Fire Technology 27: 100-112. DOI:10.1007/BF01470862.

[72] Thomas, G. C. (1996). "Fire resistance of light timber framed walls and floors". Doctor of Philosophy. University of Canterbury, Christchurch, New Zealand.

[73] Harada, K., Kogure, R., Matsuyama, K., and Wakamatsu, T., "Equivalent Fire Duration Based On Time-Heat Flux Area." Fourth Asia-Oceania Symposium on Fire Science and Technology, 2000 p.513-524.

[74] Kodur, V.K.R., Pakala, P., and Dwaikat, M.B., (2010) Energy based time equivalent approach for evaluating fire resistance of reinforced concrete beams, Fire Safety Journal 45: 211-220. DOI:http://dx.doi.org/10.1016/j.firesaf.2010.03.002. 
[75] Kodur, V.K.R., and Dwaikat, M.B., (2011) Design equation for predicting fire resistance of reinforced concrete beams, Engineering Structures 33: 602-614. DOI:http://dx.doi.org/10.1016/j.engstruct.2010.11.019.

[76] Nyman, J., and Gerlich, H.J.T., (2008) Letter To the Editor, Journal of Fire Protection Engineering 18: 75-76. DOI:10.1177/1042391507087458.

[77] Yung, D., Principles of Fire Risk Assessment in Buildings, John Wiley \& Sons, Ltd, United Kingdom, 2008.

[78] Yaping He, (2010) Linking Safety Factor and Failure Probability for Fire Safety Engineering, Journal of Fire Protection Engineering 20: 199-217.

DOI:10.1177/1042391510372726.

[79] Yaping He, and Grubits, S., (2010) A Risk-based Equivalence Approach to Fire Resistance Design for Buildings, Journal of Fire Protection Engineering 20: 5-26. DOI:10.1177/1042391509360306.

[80] He, Y., (2013) Probabilistic Fire-risk-assessment Function and Its Application in Fire Resistance Design, Procedia Engineering 62: 130. DOI:http://dx.doi.org/10.1016/j.proeng.2013.08.050".

[81] Ramachandran, G., (1991) Non-Deterministic Modelling of Fire Spread, Journal of Fire Protection Engineering 3: 37-48. DOI:10.1177/104239159100300201.

[82] The Canadian Commission on Building and Fire Codes, National Building Code of Canada 2010. National Research Council (Canada), Canada, 2010 .

[83] Harmathy, T.Z., (1965) Ten rules of fire endurance rating, Fire Technology 1: 93102. DOI:10.1007/BF02588479.

[84] Richardson, L.R., and Batista, M., (1997) Revisiting the Component Additive Method for light-frame walls protected by gypsum board, Fire and Materials 21: 107-114. DOI:10.1002/(SICI)1099-1018(199705/06)21:3<107::AIDFAM587>3.0.CO;2-6.

[85] Ocran, N. (2012). "Fire Loads and Design Fires for Mid-Rise Buildings". Master of Applied Science. Carleton Univeristy, Ottawa, Canada.

[86] Juneja, C. S. (2004). "Analysis of Ontario Fires and Reliability of Active Fire Protection Systems". Master of Applied Science. Department of Civil Engineering, Carleton University, Ottawa, Canada.

[87] Karlsson, B., and Quintiere, J.G., Enclosure Fire Dynamics, CRC Press LLC, United States of America, 2000 . 
[88] Babrauskas, V., (1998) Glass Breakage in Fires, The Fire Place (Washington Chapter IAAI Newsletter) 15-18.

[89] Gaskin, J., and Yung, D., "Canadian and USA Fire Statistics for Use in the RiskCost Assessment Model." Institute for Research in Construction, National Research Council Canada Report 637, Canada, 1993.

[90] Bukowski, R.W., Budnick, E.K., and Schemel, C.F., "Estimates of the Operational Reliability of Fire Protection Systems." Proceedings of Third International Conference on Fire Research and Engineering, Society of Fire Protection Engineers, 1999 p.87-98.

[91] Office of the Fire Marshal, Ontario Ministry of Community Safety and Correctional Services. (2014). "Fire Statistics." http://www.mcscs.jus.gov.on.ca/english/FireMarshal/MediaRelationsandResources/ FireStatistics/fire stats.html.

[92] McGregor, C. (2013). "Contribution of Cross Laminated Timber Panels to Room Fires". Master of Applied Science. Carleton University, Ottawa, Canada.

[93] Bwalya, A., Lougheed, G., Kashef, A., and Saber, H., (2011) Survey Results of Combustible Contents and Floor Areas in Canadian Multi-Family Dwellings, Fire Technology 47: 1121-1140. DOI:10.1007/s10694-009-0130-8.

[94] Wickstrom, U., (1994) The plate thermometer - a simple instrument for reaching harmonized fire resistance tests, Fire Technology 30: 195-208.

DOI:10.1007/BF01040002.

[95] Ko, Y., Michels, R., and Hadjisophocleous, G., (2011) Instrumentation Design for HRR Measurements in a Large-Scale Fire Facility, Fire Technology 47: 1047-1061. DOI:10.1007/s10694-009-0115-7.

[96] Ko, Y. J. (2011). "A Study of the Heat Release Rate of Tunnel Fires and the Interaction between Suppression and Longitudinal Air Flows in Tunnels". Ph.D Thesis. Carleton University (Canada), Canada.

[97] Feng, M., Wang, Y.C., and Davies, J.M., (2003) Structural behaviour of coldformed thin-walled short steel channel columns at elevated temperatures. Part 1: experiments, Thin-Walled Structures 41: 543-570. DOI:http://dx.doi.org/10.1016/S0263-8231(03)00002-8.

[98] Misra, M.K., Ragland, K.W., and Baker, A.J., (1993) Wood ash composition as a function of furnace temperature, Biomass and Bioenergy 4: 103-116. DOI:10.1016/0961-9534(93)90032-Y.

[99] Ragland, K.W., Aerts, D.J., and Baker, A.J., (1991) Properties of wood for 
combustion analysis, Bioresource Technology 37: 161-168.

DOI:http://dx.doi.org/10.1016/0960-8524(91)90205-X.

[100] Nordic Engineered Wood. (2013). "Nordic X-Lam Technical Data (T-S22_e)." http://nordicewp.com/literatures/T-S22 e Technical_Data.pdf.

[101] Janssens, M., and Tran, H.C., (1992) Data reduction of room tests for zone model validation, Journal of Fire Sciences 10: 528.

DOI:doi:10.1177/073490419201000604.

[102] Bryner, N.P., Johnsson, E.L., and Pitts, W.M., "Carbon Monoxide Production in Compartment Fires: Reduced-Scale Enclosure Test Facility." National Institute of Standard and Technology Report NISTIR-5568, United States, 1994 p. 218p.

[103] Dembsey, N.A., Pagni, P.J., and Williamson, R.B., (1995) Compartment fire near-field entrainment measurements, Fire Safety Journal 24: 383.

[104] McKay, C. (2002). "Carbon Monoxide Generation in a Compartment with a Doorway During a Fire". Master of Science. Virginia Polytechnic Institute and State University, Blacksburg, VA.

[105] Emmons, H. W. (2002). "Vent Flows." SFPE Handbook of Fire Protection Engineering, P. J. DiNenno, ed., National Fire Protection Association, Massachusetts, 2-32,2-41.

[106] Lattimer, B.Y., Vandsburger, U., and Roby, R.J., "Transport of carbon monoxide from a burning compartment located on the side of a hallway." Combustion Inst, 1996 p.1541-1547.

[107] Gottuk, D. T., and Lattimer, B. Y. (2002). "Effect of Combustion Conditions on Species Production." SFPE Handbook of Fire Protection Engineering, P. J.

DiNenno, ed., National Fire Protection Association, Massachusetts, 2-54,2-82.

[108] Gottuk, D.T., Roby, R.J., Peatross, M.J., and Beyler, C.L., (1992) Carbon Monoxide Production in Compartment Fires, Journal of Fire Protection Engineering 4: 133-150. DOI:10.1177/104239159200400402.

[109] Kreith, F., Manglik, R., and Bohn, M., Principles of Heat Transfer, SI Edition, Cengage Learning, 2010 .

[110] Patankar, S., Numerical Heat Transfer and Fluid Flow, Taylor \& Francis, 1980 .

[111] Aguanno, M. (2013). "Fire Resistance Tests on Cross-Laminated Timber Floor Panels: An Experimental and Numerical Analysis". Master of Applied Science. Carleton University, Ottawa, Canada. 
[112] Kontogeorgos, D., Ghazi Wakili, K., Hugi, E., and Founti, M., (2012) Heat and moisture transfer through a steel stud gypsum board assembly exposed to fire, Construction and Building Materials 26: 746-754.

DOI:http://dx.doi.org/10.1016/j.conbuildmat.2011.06.083.

[113] Thirumaleshwar, M., Fundamentals of Heat and Mass Transfer, Dorling Kindersley Pvt Ltd, 2006.

[114] Gerlich, J.T., Collier, P.C.R., and Buchanan, A.H., (1996) Design of Light Steelframed Walls for Fire Resistance, Fire and Materials 20: 79-96. DOI:10.1002/(SICI)1099-1018(199603)20:2<79::AID-FAM566>3.0.CO;2-N.

[115] Thomas, G., (2010) Modelling thermal performance of gypsum plasterboardlined light timber frame walls using SAFIR and TASEF, Fire and Materials 34: 385 406. DOI:10.1002/fam.1026.

[116] Ghazi Wakili, K., Hugi, E., Wullschleger, L., and Frank, T., (2007) Gypsum board in fire - Modeling and experimental validation, Journal of Fire Sciences 25: 267-282.

[117] Clancy, P., (2001) Advances in modelling heat transfer through wood framed walls in fire, Fire and Materials 25: 241-254. DOI:10.1002/fam.773.

[118] Rahmanian, I., and Wang, Y. C. (2012). "A combined experimental and numerical method for extracting temperature-dependent thermal conductivity of gypsum boards." Construction and Building Materials, 26(1), 707-722.

[119] Wullschleger, L., and Ghazi Wakili, K., (2008) Numerical parameter study of the thermal behaviour of a gypsum plaster board at fire temperatures, Fire and Materials 32: 103-119. DOI:10.1002/fam.956.

[120] Bénichou, N., Sultan, M.A., MacCallum, C., and Hum, J., "Thermal Properties of Wood, Gypsum and Insulation at Elevated Temperatures." Fire Risk Management Program, Institute for Research in Construction, National Research Council of Canada Report IR-710, Ottawa, Canada, 2001.

[121] Bénichou, N., Sultan, M.A., and Kodur, V.R., "Fire resistance performance of lightweight framed wall assemblies: effects of various arameters, key design considerations and numerical modelling." Fire and Materials 2003 International Conference, 2003 p.9-20.

[122] Bénichou, N., and Sultan, M.A., (2005) Thermal properties of lightweightframed construction components at elevated temperatures, Fire and Materials 29: 165-179. DOI:10.1002/fam.880.

[123] Thomas, G., (2002) Thermal properties of gypsum plasterboard at high 
temperatures, Fire and Materials 26: 37-45. DOI:10.1002/fam.786.

[124] Sultan, M.A., "Fall-off of gypsum board plasterboard in fire." Proceedings of the Fifth International Conference on Structures in Fire, 2008 p.644-655.

[125] DiNenno, P.J., Appendix B. SFPE Handbook of Fire Protection Engineering, National Fire Protection Association, Inc., Quincy, Massachusetts, USA, 2002, p. A23.

[126] Buchanan, A.H., Structural Design for Fire Safety, Wiley, West Sussex, England, 2001 .

[127] Tabaddor, M., "Thermal and Mechanical Finite Element Modeling of WoodFloor Assemblies Subjected to Furnace Exposure." Underwriters Laboratories Inc. Report Project Number: 07CA42520, File Number: NC9140, Northbrock, USA, 2008 .

[128] Alfawakhiri, F., Sultan, M., and MacKinnon, D., (1999) Fire Resistance of Loadbearing Steel-Stud Wall Protected with Gypsum Board: A Review, Fire Technology 35: 308-335. DOI:10.1023/A:1015401029995.

[129] Kodur, V. K. R., and Harmathy, T. Z. (2002). "Properties of Building Materials." SFPE Handbook of Fire Protection Engineering, P. J. DiNenno, and D. D. Drysdale, eds., the National Fire Protection Association, National Fire Protection Association, Inc., Quincy, Massachusetts, USA, 1-155.

[130] EN 1993-1-2. (2005). "Eurocode 3: Design of steel structures - Part 1-2: General rules - Structural fire design." .

[131] Helton, J.C., and Davis, F.J., (2002) Illustration of Sampling-Based Methods for Uncertainty and Sensitivity Analysis, Risk Analysis 22: 591-622.

DOI:10.1111/0272-4332.00041.

[132] Helton, J.C., Johnson, J.D., Sallaberry, C.J., and Storlie, C.B., (2006) Survey of sampling-based methods for uncertainty and sensitivity analysis, Reliability Engineering \& System Safety 91: 1175-1209. DOI:10.1016/j.ress.2005.11.017.

[133] Saltelli, A., Ratto, M., Andres, T., Campolongo, F., Cariboni, J., Gatelli, D., Saisana, M., and Tarantola, S., Global Sensitivity Analysis. The Primer, John Wiley \& Sons Ltd, England, 2008.

[134] McKay, M.D., Beckman, R.J., and Conover, W.J., (1979) A Comparison of Three Methods for Selecting Values of Input Variables in the Analysis of Output from a Computer Code, 21: 239.

[135] Kong, D., Johansson, N., van Hees, P., Lu, S., and Lo, S., (2013) A Monte Carlo 
analysis of the effect of heat release rate uncertainty on available safe egress time, Journal of Fire Protection Engineering 23: 5-29. DOI:10.1177/1042391512452676.

[136] Depeng Kong, Shouxiang Lu, Lei Feng, and Qimiao Xie, (2011) Uncertainty and sensitivity analyses of heat fire detector model based on Monte Carlo simulation, Journal of Fire Sciences 29: 317-337. DOI:10.1177/0734904110396314.

[137] Xie, Q., Lu, S., Kong, D., and Wang, J., (2012) The effect of uncertain parameters on evacuation time in commercial buildings, Journal of Fire Sciences 30: 55-67. DOI:10.1177/0734904111424258.

[138] Frank, K., Spearpoint, M., Fleischmann, C., and Wade, C., "A Comparison of Sources Uncertainty for Calculating Sprinkler Activation." 10th International Symposium on Fire Safety Science, 2011 p.1101-1114.

[139] Helton, J.C., and Davis, F.J., (2003) Latin hypercube sampling and the propagation of uncertainty in analyses of complex systems, Reliability Engineering \& System Safety 81: 23-69. DOI:10.1016/S0951-8320(03)00058-9.

[140] Bwalya, A., "An Extended Survey of Combustible Contents in Canadian Residential Living Rooms." National Research Council Canada Report Research report No. 176, Ottawa, Canada, 2004.

[141] Bukowski, R.W., Peacock, R.D., Averill, J.D., Cleary, M.J., Bryner, N.P., Walton, W.D., Reneke, P.A., and Kuligowski, E.D., "Performance of Home Smoke Alarms - Analysis of the Response of Several Available Technologies in Residential Fire Settings." National Institute of Standards and Technology Report NIST Technical Note 1455-1, Washington, DC, USA, 2008 p. 238.

[142] Hall, J.R., "U.S. Experience with Sprinklers." Fire Analysis and Research Division, National Fire Protection Association Report NFPA No. USS14, Quincy, MA, USA, 2013 .

[143] Ahrens, M., "Smoke Alarms in U.S. Home Fires." Fire Analysis and Research Division, National Fire Protection Association Report NFPA No. USS04- REV, Quincy, MA, USA, 2014.

[144] Ahrens, M., "Home Structure Fires." Fire Analysis and Research Division, National Fire Protection Association Report NFPA No. USS12G-01, Quincy, MA, USA, 2013 . 